\title{
ELASTIN \\ AS A BIOMATERIAL \\ FOR TISSUE ENGINEERING
}

Willeke Daamen 
Cover design and lay-out: Theo Hafmans \& Willeke Daamen

Elastin as a biomaterial for tissue engineering

Daamen, Wilhelmina Francisca

Thesis Radboud University Nijmegen Medical Centre, The Netherlands

ISBN-10: 9090201947

ISBN-13: 9789090201948

Printed by: Ponsen \& Looijen, Wageningen

๑ 2006 by W. Daamen 


\title{
ELASTIN \\ AS A BIOMATERIAL \\ FOR TISSUE ENGINEERING
}

\author{
Een wetenschappelijke proeve \\ op het gebied van de Medische Wetenschappen
}

\section{PROEFSCHRIFT}

ter verkrijging van de graad van doctor aan de Radboud Universiteit Nijmegen op gezag van de Rector Magnificus, prof. dr. C.W.P.M. Blom, volgens besluit van het College van Decanen in het openbaar te verdedigen op woensdag 25 januari 2006 des namiddags om 1.30 uur precies

door

Wilhelmina Francisca Daamen

geboren op 19 september 1975

te Druten 
Promotor:

Prof.dr. J.H. Veerkamp

Co-promotor:

Dr. T.H. van Kuppevelt

Manuscriptcommissie: Prof.dr. J.A. Jansen

Prof.dr. J. Schalkwijk

Prof.dr.ir. J.C.M. van Hest

Research presented in this thesis was performed under the supervision of Prof.dr. J.H. Veerkamp and Dr. T.H. van Kuppevelt at the Department of Biochemistry, Nijmegen Centre for Molecular Life Sciences, Radboud University Nijmegen Medical Centre, The Netherlands. The studies were carried out with financial support of Senter as a project of IOP Industrial Proteins (IIE 98012).

Publication of this thesis was financially supported by:

Radboud University Nijmegen Medical Centre, Netherlands Society for Matrix Biology, Daamen Administratie Dienstverlening, IMG Europe bv, Medtronic, Netherlands Society for Biomaterials and Tissue Engineering, Webecos, Arnold van Hooft Hypotheken \& Verzekeringen, Harlan Netherlands. 
If we knew what it was we were doing, it would not be called research, would it? 

Chapter 1 Elastin as a biomaterial for tissue engineering

Chapter 2 Comparison of five procedures for the purification of insoluble elastin

Chapter 3 Isolation of intact elastin fibres devoid of microfibrils

Chapter 4 Preparation and evaluation of molecularly-defined collagen-elastin-glycosaminoglycan scaffolds for tissue engineering

Chapter 5 Tissue response of defined collagen-elastin scaffolds in young and adult rats with special attention to calcification

Chapter 6 A biomaterial composed of collagen and solubilised 105 elastin enhances angiogenesis and elastic fibre formation without calcification

Chapter 7 Preparation of (elastin) biovesicles

Dankwoord

Curriculum vitae

Publications 



\section{Chapter 1}

Elastin as a biomaterial for tissue engineering

Willeke Daamen,

Jan van Hest,

Jacques Veerkamp,

Toin van Kuppevelt.

Biomaterials, invited review. 


\begin{abstract}
Biomaterials based upon elastin and elastin-derived molecules are increasingly investigated for their application in tissue engineering. This interest is fuelled by the remarkable properties of this structural protein, such as elasticity, self-assembly, longterm stability, and biological activity. Elastin can be applied in biomaterials in various forms, including insoluble elastin fibres, hydrolysed soluble elastin, recombinant tropoelastin (fragments), repeats of synthetic peptide sequences and as block copolymers of elastin, possibly in combination with other biopolymers. In this chapter, the properties of various elastin-based materials will be discussed, and their current and future applications evaluated.
\end{abstract}




\section{INTRODUCTION}

Elastin-based materials are becoming more and more popular as biomaterials for tissue engineering. This interest is established by its remarkable properties. Elastin is an extracellular matrix protein that provides elasticity to tissues and organs. Therefore, elastin is most abundant in organs where elasticity is of major importance, like in blood vessels, which stretch and relax more than a billion times during life, in elastic ligaments, in lung and in skin [1-3]. Another important property of tropoelastin, the precursor protein of elastin, and elastin-like peptides is their potential to self-assemble under physiological conditions. This is the basis of the process of coacervation, which probably leads to alignment of tropoelastin molecules previous to intermolecular crosslinking [4,5]. The resulting insoluble elastin has a half-life of 70 years in men and is one of the most stable proteins known [6]. It is furthermore not just a structural protein. The biological activity of peptides derived from insoluble elastin has long been established and there is growing evidence for its biological role $[7,8]$.

This chapter will first explain some basic aspects of elastin and elastic fibres, i.e. biochemistry, biophysics, elastic fibre morphology, elastic fibre assembly and physiological function of elastin. After that, we will discuss the use of elastin-based materials in biomaterials for tissue engineering applications. Exploitation of elastin in biomaterials is generally based on the before-mentioned characteristics. The properties of the different elastin preparations and materials prepared thereof will be reviewed and current and future applications in biomaterials will be evaluated as well.

\section{BIOCHEMISTRY OF ELASTIN}

Elastin is encoded by a single copy gene. Alternative splicing of transcripts results in various tropoelastin isoforms. The small exons of the elastin gene (up to 36) are interspersed by large introns $[9,10]$. Strong similarity exists between tropoelastins of different species, more than $70 \%$ on average. Perfect alignment is generally found in crosslinking domains and domains 33 and 36 (coding for the basic C-terminus) $[11,12]$. Some variations, however, exist among species. Bovine exons 34 and 35, for instance, are absent from the human gene, while this gene contains exon 26A coding for an unusual hydrophilic and charged domain, not described in other species. This exon is rarely expressed except in certain pathologies such as pulmonary hypertension $[13,14]$. Human elastin is synthesised as a $\sim 72 \mathrm{kDa}$ soluble precursor (tropoelastin) by a variety of cells including smooth muscle cells, endothelial cells, fibroblasts and chondrocytes [15-19]. Elastin has an uncommon amino acid composition, with about $75 \%$ hydrophobic residues (Gly, Val, Ala), and is highly insoluble due to interchain crosslinks [20]. As is the case in collagen, glycine accounts for one third of the amino acid residues and proline is present in high amounts. Most of the other amino acid 


\section{BIOPHYSICS OF ELASTIN}

A number of biophysical properties is crucial for the biomechanical/physiological role of elastin in the body. Elasticity, glass transition and coacervation will be discussed here only briefly, and the reader is referred to some excellent reviews on the subject: theories on the molecular mechanism of the elasticity of elastin $[11,29,30]$, elasticity and glass transition [31] and coacervation [32]. With regard to elasticity, it is generally accepted that the driving force for the spontaneous recoil of stretched elastin is entropic in origin [33]. For an ideal elastomer in the extended mode, all the energy is taken up by the backbone and can be recovered upon relaxation [29]. The glass transition temperature $\left(\mathrm{T}_{\mathrm{g}}\right)$ is an important characteristic of polymers. Below the $\mathrm{T}_{\mathrm{g}}$, a polymer will generally behave as a rigid/brittle material, whereas above the $\mathrm{T}_{\mathrm{g}}$ the polymer behaves as an elastomer or a viscous fluid. Elastin undergoes a glass transition in a temperature range that depends on its water content $[34,35]$. In the dehydrated state, $\mathrm{T}_{\mathrm{g}}$ is about $200^{\circ} \mathrm{C}$, at $30 \%$ hydration it is about $30^{\circ} \mathrm{C}$ [36]. A second phase transition that can occur with tropoelastin as well as with elastin-based materials is coacervation. At ambient temperature, tropoelastin is soluble in aqueous solutions. However, upon raising the temperature, the solution becomes cloudy due to self-aggregation of the molecules as a result of interactions between hydrophobic domains. Elastin-based polypeptides lacking hydrophobic domains, e.g. those based on crosslinking domains, cannot coacervate [37-39]. After centrifuging, a liquid-liquid phase separation occurs with on the bottom a highly-viscous, highly-concentrated tropoelastin or peptide fraction, and on top an aqueous solution. Temperature, protein concentration, salt concentration and $\mathrm{pH}$ all have an effect on coacervation behaviour as does the presence of other molecules like glycosaminoglycans $[5,38,40]$. Coacervation is a lower critical solution temperature (LCST) phenomenon, which means that the protein forms ordered structures upon raising temperature. The loss of entropy from the protein chain is compensated by the release of water $[40,41]$. Coacervation is a self-assembly process [42] thought to align tropoelastin molecules in vivo prior to crosslinking $[4,5,43]$.

\section{MORPHOLOGY OF ELASTIC FIBRES}

Elastin comprises up to $70 \%$ of the dry weight in elastic ligaments, about $50 \%$ in large arteries, $30 \%$ in lung, and $2-4 \%$ in skin $[20,44,45]$. In general, elastic fibres are present as rope-like structures like in ligaments, in the media of elastic arteries and in skin [1]. Fig. 3 shows light microscopical and scanning/transmission electron microscopical pictures of bovine aorta and ligament. The media is separated from the intima (lumen-side) by the lamina elastica interna, a layer that is formed by fusion of mainly longitudinally directed elastic fibres (insert in Fig. 3E). The lamina elastica is important for the resilience of blood vessels, its pores allowing exchange of nutrients/ metabolites. In ligaments, elastin fibres are generally present as parallel-oriented 
structures. In elastic cartilage, present in e.g. auricle (external ear) and epiglottis, elastic fibres are oriented into honeycomb structures [46].

\section{ELASTIC FIBRE ASSEMBLY}

Elastic fibres are essentially composed of two elements: amorphous elastin and microfibrils, which are 10-12 $\mathrm{nm}$ in diameter and primarily composed of fibrillin1 [47]. Fibre assembly is a complicated process and many different molecules are

\section{Aorta}

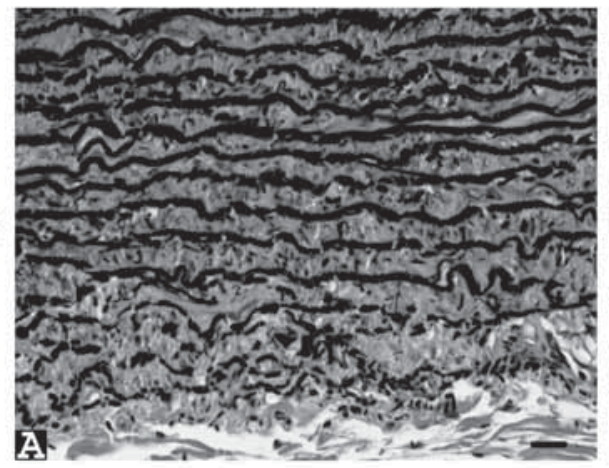

LM

TEM
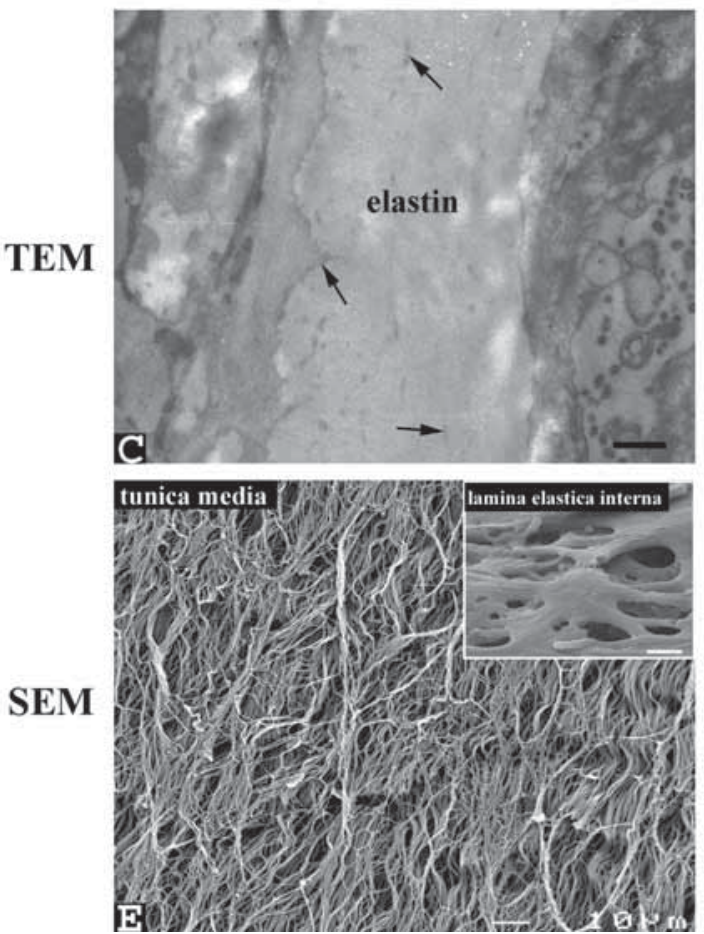

Ligament
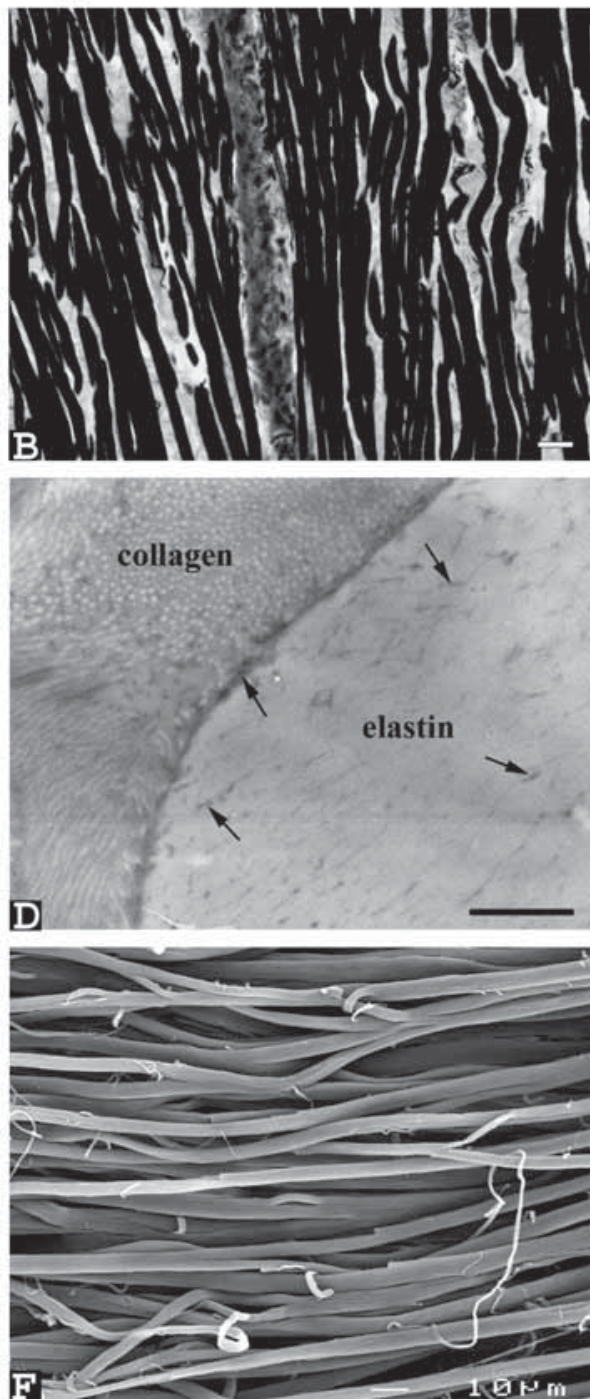

Figure 3. Light microscopical (LM) staining (Verhoeff - Van Gieson) of bovine aorta (A) and ligament (B) show elastic fibres in black and collagenous material in grey. Transmission electron micrographs (TEM) of bovine aorta (C) and ligament (D) and scanning electron micrographs (SEM) of partly purified bovine aorta (E) and ligament (F) reveal elastic fibre ultrastructure and clearly show differences in elastic fibre organisation and elastic fibre diameter between the two organs. Insert in E shows lamina elastica of aorta. Arrows indicate microfibrils. Bar represents $10 \mu \mathrm{m}$ in $A, B, E, F$, and $1 \mu \mathrm{m}$ in $C, D$. 
involved in its development. Tropoelastin is synthesised in the rough endoplasmatic reticulum and undergoes few intracellular posttranslational modifications, including release of the signal peptide and hydroxylation of some Pro residues by the enzyme prolyl hydroxylase. Intracellularly, tropoelastin is immediately bound to the $67 \mathrm{kDa}$ elastin-binding protein to prevent intracellular aggregation [48]. This chaperone is also a sub-unit of the elastin-laminin receptor (Fig. 4) which is present on many cell types, including fibroblasts, vascular smooth muscle cells, endothelial cells, chondrocytes, monocytes, lymphocytes and polymorphonuclear leukocytes [49]. The receptor is composed of two transmembrane subunits of 61 and $55 \mathrm{kDa}$ and the $67 \mathrm{kDa}$ elastin binding protein and has a binding site for elastin or laminin and for a galactoside (e.g. lactose or a glycosaminoglycan like chondroitin sulphate or dermatan sulphate) [50,51]. The elastin-binding protein only releases tropoelastin upon binding of the galactosugars of the microfibrillar component in the extracellular space. The binding for both tropoelastin and its membrane-bound $55 \mathrm{kDa}$ subunit is then dramatically reduced resulting in the release of tropoelastin from the elastin-binding protein and the release of the elastin-binding protein from the transmembrane subunit after which this is recycled $[48,52]$. Outside the cell, the microfibrillar components act as a scaffold onto which elastin is deposited, the microfibrils ultimately ending up in and around the elastic fibre. Tropoelastin molecules are crosslinked to each other involving the copper and vitamin B6-requiring enzyme lysyl oxidase, resulting in the formation of specific interchain crosslinks like (iso)desmosine [13,45,53]. Crosslinking results in mature elastin which is insoluble and extremely stable. Once microfibrils are present, fibre formation can occur without the presence of cells [54].

A

B
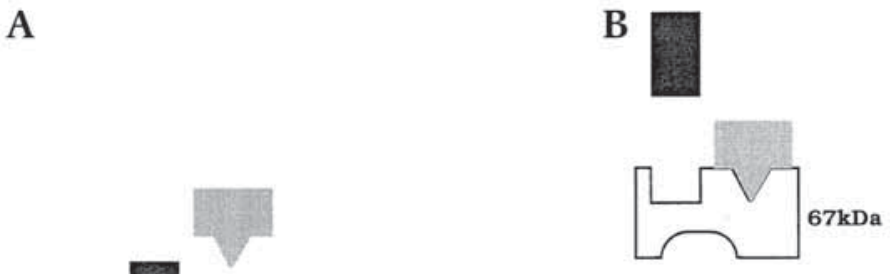

TROPOELASTIN

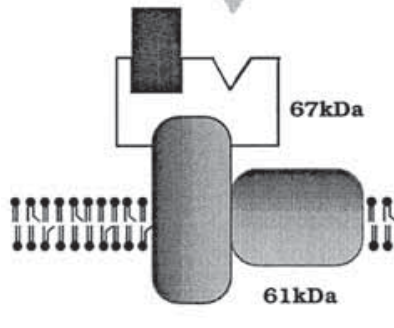

$55 \mathrm{kDa}$

Figure 4. A model for the elastin-laminin receptor which is comprised of three subunits (55, 61 and $67 \mathrm{kDa}$ ). Tropoelastin binds to the complex via the elastin-binding protein (A). Upon binding of a galactosugar, the 67 $k D a$ subunit and tropoelastin are released (B). Figure reproduced from [32] with permission. 
Next to elastin, the elastic fibre contains or is associated with a variety of molecules including fibrillins, microfibril-associated (glyco)proteins (MAGPs), latent TGF $\beta$ binding proteins, fibulins, emilins, proteoglycans and lysyl oxidases [55]. Recent research indicates that the proteins fibulin-1, fibulin-5 and lysyl oxidase-like 1 (LOXL1) are involved in elastogenesis [56-59]. Heparan sulfate, a glycosaminoglycan, also plays a role in elastic fibre formation and was found to interact with tropoelastin and to be present in human dermis elastic fibres [54,60].

\section{PHYSIOLOGICAL FUNCTION OF ELASTIN}

Not only tropoelastin is capable to interact with the elastin-laminin receptor; elastin degradation products and synthetic polypeptides are also able to bind [50,61-64]. Effects of elastin(like) molecules mediated by the receptor include elastin synthesis [7], chemotaxis [65,66], inhibition of vascular calcification [67], proliferation of fibroblasts [68], astrocytes [69], glioma cells [70], arterial smooth muscle cells [63], keratinocyte migration and differentiation [71], vasorelaxant activity [72], and regulation of matrix protease activity [73]. Other receptors may be of importance as well, e.g. integrins [74]. Tissue regeneration can thus be influenced by the presence of these molecules. Especially, induction of elastin synthesis may accelerate tissue healing since this key element in e.g. skin is difficult to restore when damaged. However, the presence of elastin (peptides) may also result in adverse effects, since an indirect role in tumour progression by upregulation of matrix metalloproteinases has been reported [75].

Mutations involving elastic fibres are important in understanding the function of elastin and the process of elastogenesis. Here, we will give some examples of elastic fibre-associated diseases and corresponding mouse models. Additional information can be found elsewhere [76-79]. Congenital supravalvular aortic stenosis (SVAS) is a pathological condition associated with a mutation in the elastin gene, resulting in left ventrical outflow obstruction and narrowing of the arterial lumen due to a failure to regulate cellular proliferation and matrix deposition of elastin [80-84]. It is caused by truncation and lack of some crosslink domains and the C-terminal region, or deficient coacervation of tropoelastin molecules [81,85]. Elastin hemizygosity is used as a mouse model for SVAS [83]. Elastin null mice die within 4 days after birth from a subendothelial accumulation of proliferating vascular smooth muscle cells that obstruct the vascular lumen $[8,86]$. SVAS can be inherited autosomal dominantly or as a part of the Williams' syndrome [87]. Another pathology linked to the elastin gene is the rare autosomal dominant disease cutis laxa [88-90] which is caused by a frameshift mutation characterised by inelastic loose-hanging skin, hernias, and emphysema due to abnormally branched and fragmented elastic fibres with reduced elastin deposition in the elastic fibres and fewer microfibrils in the dermis [91,92]. Elastin is not the only molecule to cause the autosomal dominant form of cutis laxa, since mutations 
in fibulin-5 also result in cutis laxa $[93,94]$. A mouse model for cutis laxa involving a fibulin-5 mutation exists [58,95]. Changes in other molecules found in elastic fibres may give rise to malfunctioning or abnormal structure. Marfan syndrome (MFS) is associated with mutations in the gene encoding fibrillin-1, and is an autosomal dominant disorder characterised by pleiotropic manifestations involving primarily the ocular, skeletal, and cardiovascular systems [77,96]. Clinical features involved in the cardiovasculature include aortic aneurysms, diffuse elastic fibre calcification, intimal hyperplasia, and elastolysis. Elastic fibres in the vessel wall can be fragmented and accumulated amorphous elastin is found [97]. This suggests a primary structural deficiency, but targeted mutation of the mouse fibrillin-1 gene (homozygous $\mathrm{mg} \Delta$ ) has suggested that deficiency of fibrillin-1 reduces tissue homeostasis. This results in aortic dilatation and dissection, leading to haemopericardium or haemothorax rather than malformation of the elastic fibre [98]. A homozygous mutation in the mouse fibrillin-1 gene (mgR) results in underexpression of fibrillin-1 and leads to MFS-like manifestations [99].

\section{ELASTIN AS A BIOMATERIAL}

Incorporation of elastin in biomaterials is especially significant when its elasticity or biological effects can be exploited. However, several problems may occur when using elastin as a biomaterial. One of them is calcification, a poorly-understood phenomenon in biomaterial science, and often occurring in cardiovascular prosthetic implants (e.g. bioprosthetic heart valves and aortic homografts). Besides crosslinked cellular debris, elastin and collagen may serve as nucleation sites for mineralisation, independent of cellular components [100-102]. Calcification may be genetically controlled by molecules that actively inhibit calcification and may occur passively when these inhibitors are absent [103]. Calcification can be prevented or reduced by aluminium chloride treatment [104], acyl azide crosslinking [105], ethanol/EDTA treatment [106], and presence of glycosaminoglycans [107].

Elastin can be used in biomaterials in different forms, including insoluble elastin in autografts, allografts, xenografts, decellularised extracellular matrix, and in purified elastin preparations. Insoluble elastin may also be hydrolysed to obtain soluble elastin preparations. Repeated elastin-like sequences can be produced by synthetic or recombinant means. Furthermore, recombinant tropoelastin or tropoelastin fragments can be used in biomaterials. Table 1 gives an overview of different forms of elastin and their molecular characteristics which we will now discuss with their (potential) applications. 
Table 1. Various forms of naturally occurring and (bio)synthetic elastin.

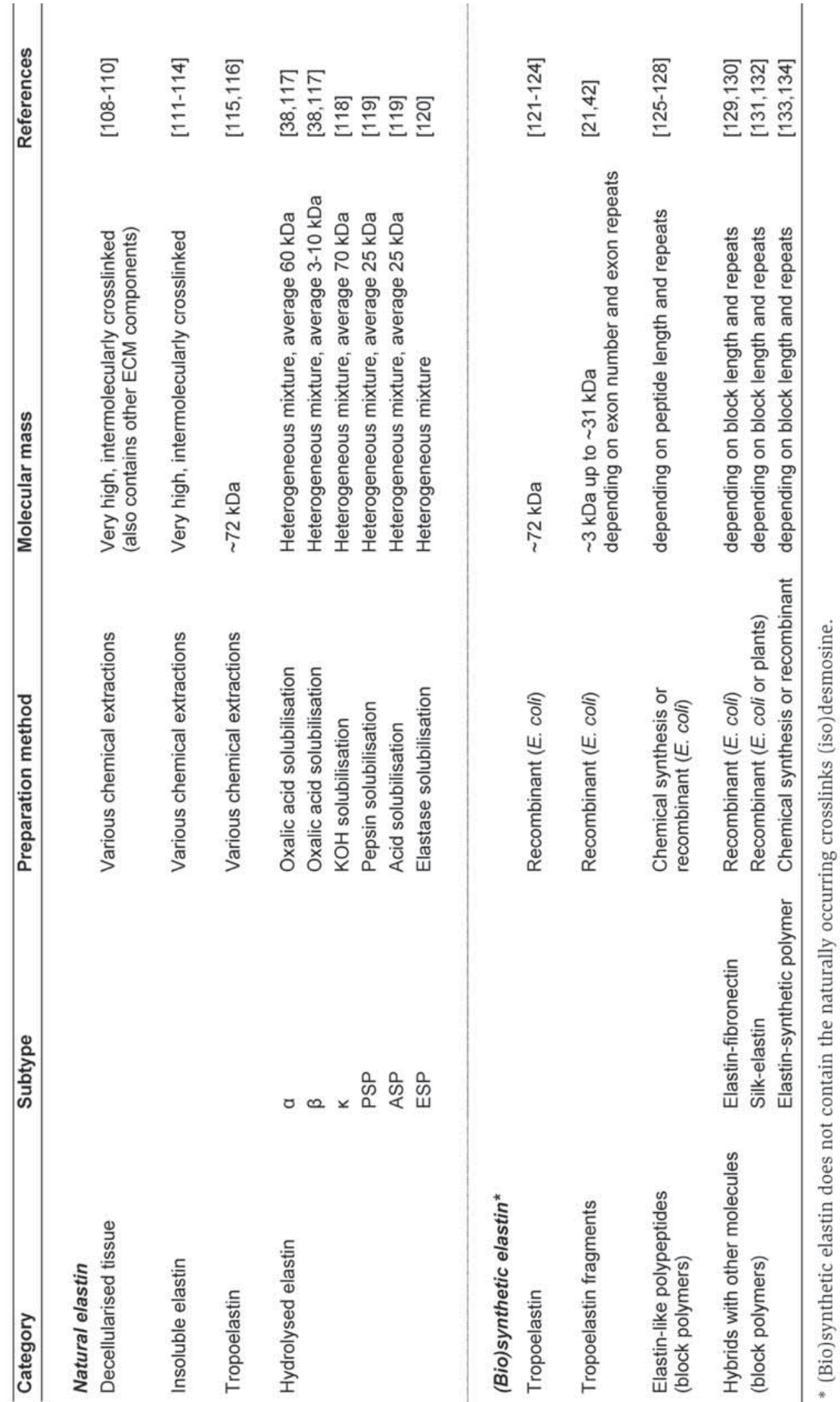




\section{BIOMATERIALS DERIVED FROM NATURAL ELASTIN}

\section{Elastin in autografts, allografts and xenografts}

Evidently, autografts, allografts and xenografts contain elastic fibres. Well-known examples are split-skin autografts for burn wounds, autologous saphenous veins and umbilical vein allografts for coronary artery bypass graft surgery, and aortic heart valve xenografts. However, it is beyond the scope of this article to discuss characteristics and performances of these grafts.

\section{Decellularised tissues containing elastin}

We define decellularised tissues as tissue pieces that are purified in such a way as to remove cells but to maintain the three-dimensional architecture of the tissue. Cells have to be removed from these tissues, because cellular remnants irrevocably lead to an immunological response, e.g. we showed a rather severe tissue reaction with subcutaneous implanted rinsed elastic ligament preparation containing damaged cells [135]. The apparent advantage of decellularised constructs is that the structural design of the tissue is preserved in contrast to the preparation of scaffolds from purified components. On the other hand, this limits its application primarily to the tissue it is obtained from, for example decellularised bladder for bladder augmentation [110] and decellularised heart valves and vasculature for heart valve replacement and vascular grafts $[102,136]$. Some tissues, however, could also be used for other applications, e.g. decellularised bovine pericardium to enhance bone formation [137]. Other drawbacks of decellularised tissue are that it is difficult to obtain highly purified preparations from intact tissue (compared to pulverised material), and that decellularised tissue may result in ill-defined preparations with large batch-to-batch variations. Decellularisation is performed with a wide variety of extraction methodologies, including detergents (Triton, SDS) and enzyme digestions (e.g. trypsin). Decellularisation by Triton or trypsin also changes the extracellular matrix composition [138]. It is difficult to compare results obtained from different laboratories, since each protocol will result in its own set of residual extracellular matrix components. In addition, it is unknown which molecule causes a specific effect with these complex preparations.

\section{Purified elastin preparations}

Purification is important when studying the effect of mature extracellular elastin in fibrous form (containing its natural crosslinks like (iso)desmosine) without introducing artefacts to the system by impurities. In applied research, like the use of elastin in biomaterials and tissue engineering, the purified intact fibres may be useful when preparing molecularly-defined bioscaffolds from scratch thus avoiding unwanted immunological reactions to contaminations, and allowing studies to the body's response to one single component: elastin [114]. Due to the intermolecular crosslinks in elastin, the protein is highly insoluble. In fact, elastin can only be dissolved after hydrolysing some peptide bonds. This insolubility is often used for isolation of elastin 
from tissues. Historically, bovine and equine ligamentum nuchae have been used as a source for insoluble elastin, because a large percentage of their dry weight is elastin. Lansing et al. [111] isolated elastin from ligamentum nuchae based on treatment with $0.1 \mathrm{M} \mathrm{NaOH}$ at $95^{\circ} \mathrm{C}$ for $45 \mathrm{~min}$. Rasmussen et al. [139] used a purification procedure based on autoclaving at $120^{\circ} \mathrm{C}$ for $5 \mathrm{~h}$. John and Thomas [112] obtained elastin from aorta and pulmonary tissues with a more gentle procedure using extraction steps with $\mathrm{NaCl}$, guanidine- $\mathrm{HCl}$, organic solvents, and digestions with collagenase and trypsin. Elastin has also been isolated by others from tissues like aorta [108], lung [140] and skin [141]. We have compared different purification protocols [142] and improved the purification protocol of John and Thomas [114] in such a way that no contaminations were observed with a number of analytical techniques including SDS-PAGE, amino acid and sulfhydryl analysis (microfibrillar proteins like fibrillin contain many Cys residues), and histological-based techniques including bright field microscopy (Verhoeff - Van Gieson and resorcin fuchsin - Van Gieson staining), fluorescence microscopy (immunostaining for type I and IV collagen and several fibrillin epitopes), and electron microscopy. We found that the most discriminative method to evaluate the purity of elastin was transmission electron microscopy. Microfibrillar-like remnants are electron-dense structures in electron microscopy, and are readily distinguished from the electron translucent elastin. We found microfibrillar-like remnants with all three traditional methods tested, but not with our adapted method [142]. Later, we optimised the purification procedure, because we found a precarious equilibrium to exist between purity and intactness of the elastic fibres. We then proposed the term 'elastin fibre' for an intact elastic fibre with elastin as its sole component (Fig. 5) [114]. An advantage of purified elastin is that it can be moulded into different shapes. Purified elastin allows the construction of highly-defined scaffolds, e.g. scaffolds can be composed consisting of elastin and collagen. Some collagen appeared to be essential to obtain coherent scaffolds. Properties of scaffolds can be controlled by varying different parameters, e.g. the ratio of collagen and elastin, extent/methodology of chemical crosslinking and the incorporation of other components, like glycosaminoglycans [143].

\section{Hydrolysed elastin: soluble forms of elastin}

Hydrolysed elastin (also known as solubilised elastin or elastin peptides) is also used in biomaterials. Most frequently used methods to prepare soluble elastin peptides are treatment with $0.25 \mathrm{M}$ oxalic acid at $100^{\circ} \mathrm{C}$ [117] and $1 \mathrm{M} \mathrm{KOH}$ in $80 \%$ ethanol at $37^{\circ} \mathrm{C}$ [118]. Proteolytic enzymes capable of degrading elastic fibres, including serinetype elastases from polymorphonuclear leukocytes and several metallo-elastases of monocyte/ macrophage origin, also result in solubilised elastin $[120,144]$. Pepsin in $0.5 \mathrm{M}$ acetic acid at $37^{\circ} \mathrm{C}$ [145] and $0.5 \mathrm{M} \mathrm{HCl}$ at $80^{\circ} \mathrm{C}$ [119] are rarely employed. All these methods are based on hydrolysis of some peptide bonds of the insoluble elastin. Elastin peptides obtained after oxalic acid hydrolysis can be coacervated after suspension in $10 \mathrm{mM}$ sodium acetate with $10 \mathrm{mM} \mathrm{NaCl}$ set to $\mathrm{pH} 5.5$ with acetic 

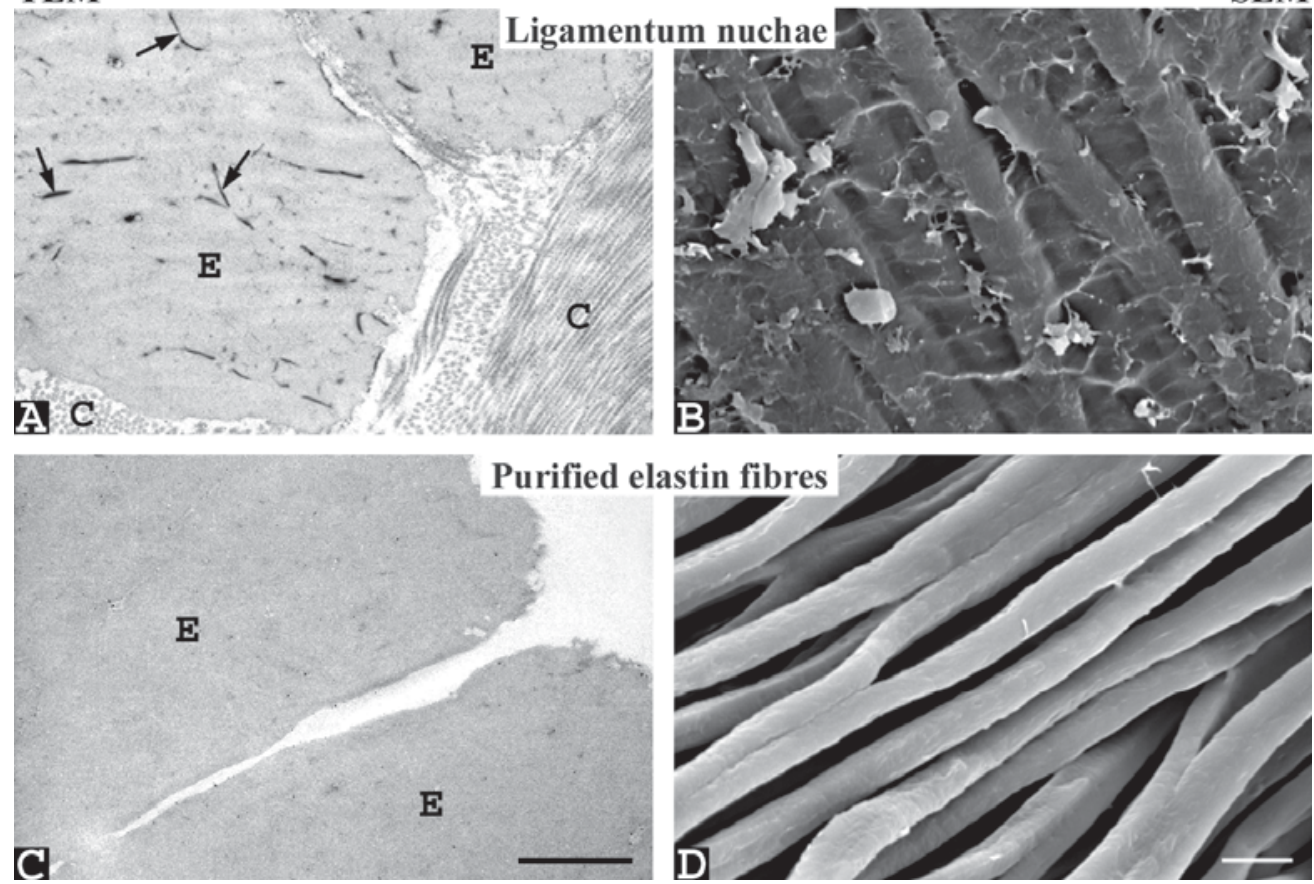

stin fibres

Figure 5. Transmission electron micrographs $(A, C)$ and scanning electron micrographs $(B, D)$ of intact equine ligamentum nuchae $(A, B)$ and elastin fibres $(C, D)$ purified hereof. $E=$ elastin; $C=$ collagen fibrils; arrows indicate microfibrils; Bar is $1 \mu \mathrm{m}$ in TEM micrographs and $10 \mu \mathrm{m}$ in SEM micrographs. Figure reproduced from [114] with permission.

acid, followed by heating and centrifugation at $37^{\circ} \mathrm{C}$. Two fractions will be formed: $\alpha$-elastin (a viscous coacervate) and $\beta$-elastin (in the supernatant) [38]. Using $\mathrm{KOH}$, $\kappa$-elastin is formed which is a heterogeneous mixture of elastin peptides with a mean molecular mass of approximately $70 \mathrm{kDa}$, soluble in aqueous solutions [118]. The great advantage of these preparations is obviously their solubility which makes handling and analysis of the material more straightforward. In addition, elastin peptides influence signalling, chemotaxis, proliferation and protease release via the elastin receptor [146]. Biomaterials containing solubilised elastin may thus exert biological effects (like increasing elastin synthesis) on a wide variety of cell types, and are especially beneficial when they can accomplish this effect over a longer period of time. A depot of these molecules in the biomaterial is thus recommendatory. Solid discs have been prepared from $\alpha$-elastin by polymerising coacervated elastin with a diepoxy crosslinker. The elastic modulus could to some extent be modulated by the degree of crosslinking. In a preliminary experiment, vascular smooth muscle cells adhered to elastin discs, but showed decreased proliferation on the material [147]. We recently showed that crosslinked scaffolds composed of insoluble collagen and solubilised elastin not only induced angiogenesis, but also increased elastic fibre synthesis, as shown with antibodies against rat fibrillin- 1 and rat elastin. In addition, these scaffolds showed no calcification in young Sprague Dawley rats (a sensitive calcification model) in contrast to scaffolds containing insoluble elastin [148]. The cell biological effect 
may be modulated by the amount of solubilised elastin in the scaffold and the extent of crosslinking. Materials based upon $\alpha$-elastin or elastin fibres with type I and III collagen can be prepared [149,150], in combination with glycosaminoglycans [151] or calcium phosphate [152]. Elastin preparations combined with fibrin have also been prepared [153]. The potential of collagen-elastin and collagen-fibrin materials were evaluated in in vivo models, e.g. as a tympanic membrane [154] and as a dural substitute [155]. Finally, solubilised elastin has been used to improve the biocompatibility of synthetic materials such as polyethylene glycol terephthalate (PET) [156].

BIOMATERIALS DERIVED FROM (BIO)SYNTHETIC ELASTIN

\section{General}

Using protein engineering, many different parameters of elastin-like molecules can be controlled; including amino acid sequence, peptide length, and -in the case of block copolymers- the length and number of the blocks. Another advantage is the opportunity to incorporate specific sequences that have cell biological effects, like the Arg-Gly-Asp (RGD) sequence [157]. With this method, tailor-made proteins can be made, e.g. combining the properties of two proteins. Recombinant expression systems result in highly homogeneous protein preparations (composition, sequence and molecular mass) as opposed to molecules prepared by peptide synthesis [158]. On the other hand, with peptide synthesis it is easier to incorporate non-natural amino acids which may be useful in modification or crosslinking reactions. The thermallyresponsive behaviour of elastin-like polypeptides may also be exploited in biomaterials (soluble below transition temperature $\mathrm{T}_{\mathrm{t}}$, but aggregated above $\mathrm{T}_{\mathrm{t}}$ ), for example as injectable biomaterials.

It is important to study the in vivo reaction to (bio)synthetic proteins, since it is not known what biological effects they may exhibit. For every variation in the engineered protein, the in vivo biocompatibility should be tested independently. Until now, few biomaterials containing elastin-like polypeptides have been studied in vivo.

\section{Tropoelastin}

Tropoelastin can be produced by two methods; either by isolation from copper-deficient animals $[115,116]$ or by molecular biological techniques [121]. The latter is preferred since isolation from copper-deficient animals is an animal-unfriendly method with low yield.

In 1990, the complete human tropoelastin molecule was expressed in a bacterial system [121]. Tropoelastin does not contain any crosslinks in contrast to purified elastin fibres. However, it was possible to crosslink tropoelastin using the enzyme lysyl oxidase in the absence of other macromolecules [159]. An advantage of recombinant elastin is that different tropoelastin isoforms can be prepared $[5,122]$, including those which 
rarely occur like the splice variant formed by inclusion of human exon 26A which is primarily expressed in certain diseases $[13,14]$. Weiss' group started to use whole recombinant tropoelastin molecules to build elastic patches. Recombinant human tropoelastin was crosslinked into existing elastin by adding it to neonatal rat aorta

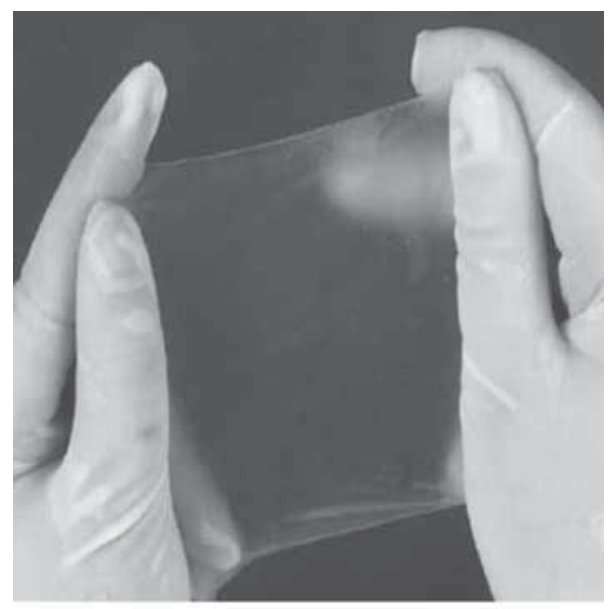

Figure 6. A sheet composed of recombinant tropoelastin. Figure is reproduced from [124] with permission. smooth-muscle cell cultures. As much as $12 \%$ of the supplemented recombinant protein was incorporated into the insoluble elastin with formation of the elastin crosslinks desmosine and isodesmosine in a time-dependent fashion. The capacity of elastin to self-assemble was also used to make biomaterials like sponges, sheets and tubes from human tropoelastin (Fig. 6). Tubes were made by coiling an elastin sheet. Biomaterials were subsequently crosslinked with bis(sulfosuccimidyl) suberate in PBS at $37^{\circ} \mathrm{C}$ to facilitate coacervation and crosslinking. Stress-strain curves showed elasticity up to $150 \%$ strain and Young's moduli ranged from 220-280 kPa [124]. These recombinant elastin biomaterials would be even more promising and closer to nature if they could be fully crosslinked by the enzyme lysyl oxidase.

\section{Tropoelastin fragments}

Fragments of the human tropoelastin molecule expressed in E. coli can also selfaggregate to form a coacervate [42]. Three hydrophobic domains flanking two crosslinking domains were sufficient to achieve self-assembly (Fig. 7) [21]. For example, human elastin peptides based on the sequences of exons 20-(21-23-24) ${ }_{2}$ of the elastin gene [hydrophobic (20 and 24) - crosslinking (21-23)], spontaneously formed fibrillar matrices after coacervation [39]. Coacervation of peptides based on the sequences of exons 20-(21-23-24) and exons 20-(21-23-24) ${ }_{2}$ caused aligning of Lys residues so that crosslinking with the oxidising agent pyrroloquinoline quinine (PQQ) in the presence of copper sulfate resulted in zero-length crosslinks, including desmosine and isodesmosine. A crosslinked sheet of this material had a lower elastic modulus than purified insoluble elastin from aorta (0.25 $\mathrm{MPa}$ vs. 0.81 MPa), but a similar resilience ( 80\%) [21]. Tropoelastin fragments based on exons 20-(21-23-24) may have potential to inhibit thrombosis in vascular grafts, and their application as a coating for synthetic materials has been explored. In vitro, platelet adhesion and activation were significantly reduced. In a rabbit model, a coating of these polypeptides on polyurethane catheters resulted in a marked increase in catheter patency and a significant decrease in fibrin accretion and embolism [160]. 


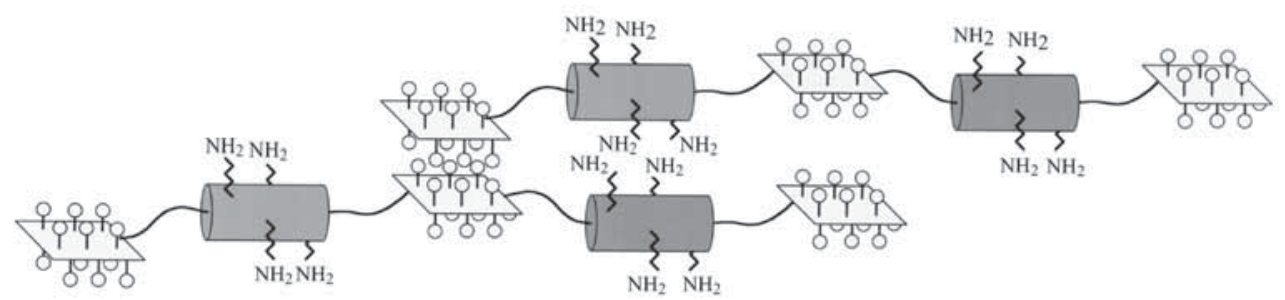

Figure 7. Postulated alignment of elastin peptides during coacervation juxtaposing side chains of lysine residues for the formation of covalent crosslinks. Hydrophobic domains (square planar structures) of two molecules interact with each other via hydrophobic side chains (spherical structures) and thus allow alignment of cross-linking domains (cylinders) with their pairs of lysine residues. Figure is reproduced from [39] with permission.

\section{Elastin-like polypeptides}

Urry and co-workers showed that physical properties of repetitive elastin-like polypeptides are highly dependent on the amino acid composition of the peptide repeat. One particular property of these polypeptides is the transition temperature $T_{t}$. The $T_{t}$ of polymers based on (Val-Pro-Gly-Xaa-Gly) ${ }_{\mathrm{n}}$ could be extensively manipulated by the amino acid at the Xaa position and resulted in a dependency on e.g. temperature, $\mathrm{pH}$, and electrochemical potential. As an example, a more hydrophobic amino acid (Trp) results in a lower $\mathrm{T}_{\mathrm{t}}$ than a more hydrophilic amino acid (Glu) [161].

For the preparation of functional materials, high molecular mass polymers and crosslinkable systems are favourable. Urry et al. prepared various elastin-like materials by polymerisation of elastin pentapeptides, first by chemical synthesis, and later by recombinant expression systems. These include (Val-Pro-Gly-Val-Gly), (Gly-Val-GlyVal-Pro) ${ }_{251}$, and (Gly-Val-Gly-Ile-Pro) ${ }_{260}$, which were coacervated and subsequently crosslinked by $\gamma$-irradiation $[125,162,163]$. The elastin-like polymers could be produced in large quantities. Several bioelastic materials have been tested in animal models for soft-tissue restoration, e.g. as interpositional materials in intervertebral-disc restoration in a rabbit model [164]. Other potential applications are filling material for urinary incontinence, urinary bladder reconstruction, and prevention of post-operative tissue adhesions [165].

In order to obtain a better defined crosslinkable system, McMillan et al. expressed the synthetic elastin sequence (Val-Pro-Gly-Val-Gly) ${ }_{n}$ where the bold Val residue was replaced with Lys every fifth repeat as a potential crosslinking site [127]. Huang et al. [166] prepared fibres and non-woven fabrics from 39 repeats of this (Val-Pro-Gly-ValGly) ${ }_{4}$ (Val-Pro-Gly-Lys-Gly) sequence using electrospinning (also see section 'Vascular constructs'). [167]. The coacervation temperature of this peptide is about $75^{\circ} \mathrm{C}$. When functionalising this sequence with methacrylate to facilitate site-specific solid-state photo-crosslinking, the coacervation temperature was reduced (up to $50^{\circ} \mathrm{C}$ ), but no appreciable effect on fibre morphology was observed [168]. Lee et al. constructed (Gly-Val-Gly-Val-Pro) $)_{n}$ where the bold Val residue was replaced with either Glu or Lys per 6 pentapeptides. The molecular mass of these polypeptides was 88 and $87 \mathrm{kDa}$, 
respectively. Hydrogels and fibres (by solution spinning) were prepared from this block polymer by chemically crosslinking 50\% Glu-substituted and 50\% Lys-substituted polypeptide with 1-ethyl-3-(3-dimethylaminopropyl) carbodiimide in the presence of N-hydroxybenzotriazole [125].

Tamburro's group have prepared block polymers from glycine-rich elastin regions (XaaGly-Gly-Yaa-Gly) ${ }_{\mathrm{n}}$ via chemical synthesis in solution, where Xaa/Yaa is Val/Leu, Leu/ Val, Lys/Val and Orn/Orn. Only (Lys-Gly-Gly-Val-Gly) ${ }_{\mathrm{n}}$, and (Orn-Gly-Gly-Orn-Gly) , both polydisperse polymers up to $14 \mathrm{kDa}$, were intermolecularly crosslinked either by glutaraldehyde and/or by the succinimidyl ester of glutaric acid to obtain biomaterials [169]. Although structural analysis was performed, mechanical and biocompatibility studies are lacking.

Another way to change material characteristics is to vary the composition of a complete protein block as was done in elastin-mimetic protein block copolymers containing identical hydrophobic endblock sequences separated by a central hydrophilic block (of varying composition). Mechanical properties of elastin-based protein films made from these protein block copolymers depended largely on the midblock amino acid sequence [128]. Hydrogels were made from elastin-mimetic proteins with a high molecular mass of up to $150 \mathrm{kDa}[170]$.

\section{Hybrids of elastin with other molecules}

Elastin-fibronectin polypeptides: The CS5 domain of fibronectin is important in promoting the attachment and spreading of endothelial cells over that of fibroblasts, vascular smooth muscle cells and blood platelets [171]. Artificial proteins consisting of elastin-like peptides interspersed with the CS5 domain were produced in E. coli, purified using its LCST behaviour and showed to be elastic and to promote human umbilical vascular endothelial cell (HUVEC) adhesion [130,172]. These elastinfibronectin polypeptides can be controlled by their amino acid sequence, length and spacing of the different blocks and degree of crosslinking [130]. Furthermore, the placement of Lys residues (for crosslinking purposes) in the artificial polypeptides is important in HUVEC spreading and their resistance to centrifugal detachment forces [129]. Initially, glutaraldehyde was used to crosslink elastin-CS5 materials [130]. Later, other crosslinkers including dissuccinimidyl suberate in DMF, hexamethylene diisocyanate in DMSO and bis(sulfosuccinimidyl) suberate were used, although tensile strength of materials crosslinked with the latter was less than of natural elastin $(\sim 0.2$ MPa vs. 0.3-0.6 MPa) $[173,174]$. Such materials may be used as synthetic grafts. Under physiological shear stress, $70 \%$ of the cells stayed attached [172].

Silk-elastin polymers: Spider dragline silk (spidroin) consists largely of glycine and alanine repeats and displays ultimate tensile strength, in combination with high elasticity. Spider silks can be expressed in plants by retention in the endoplasmatic 
reticulum [175]. Recently, spider silk-elastin fusion proteins of a $51.2 \mathrm{kDa}$ spider silk and a $94.2 \mathrm{kDa}$ elastin-like protein (separated by a c-myc tag for detection) were prepared by a similar approach and were cytocompatible for human chondrocytes [132].

Threads from the silk worm (fibroin) are mainly composed of glycine, alanine and serine. The fibroin molecule comprises a crystalline and amorphous region (ratio 2:1). Recombinant fibroin-like proteins can be synthesised, but have a low aqueous solubility which limits their biomedical application. Cappello et al. therefore synthesised polymers composed of fibroin-like crystalline blocks (Gly-Ala-Gly-Ala-Gly-Ser) and elastin-like blocks (Gly-Val-Gly-Val-Pro) in E. coli. Silk-elastins provide an example of customising material properties of proteins up to $\sim 1000$ amino acid residues [131]. Depending on sequence and composition, silk-elastin polymers display LCST behaviour. Stimuliresponsive silk-elastin polymers can be prepared since $\mathrm{T}_{t}$ decreases with increasing polymer length, polymer concentration and ionic strength. By replacing a Val by Glu, $\mathrm{T}_{\mathrm{t}}$ also responds to $\mathrm{pH}$ (until pH 7.0) [176]. Block composition and polymer length are of major importance for mechanical properties, biodegradability (which is primarily by enzymatic hydrolysis) and physiological properties of these proteins. Possible applications are drug-delivery [177] and gene delivery systems [178,179]. Unlike most of the other hybrid materials, silk-elastin polymers have been studied in vivo. However, as Megeed et al. clearly point out the in vivo response needs to be investigated into more depth, especially since some antibodies can be raised against the silk-block in some silk-elastin polymers [180,181].

Fusion proteins: Another biological application of elastin-like polymers such as the polypentapeptide (Val-Pro-Gly-Xaa-Gly) (Xaa is any amino acid except Pro) was drug delivery. Recombinant polypentapeptides expressed in E. coli could be purified based upon their phase transition [182], and when using the elastin-like polypeptide as a tag, other proteins could be purified based on this characteristic as well [183]. When drugs were conjugated to thermally-responsive polypeptides with a $\mathrm{T}_{\mathrm{t}}$ of $41^{\circ} \mathrm{C}$, delivery was possible to solid tumours based on local hyperthermia with enhanced endocytic uptake [184,185].

Synthetic polymers combined with elastin sequences: Furthermore, elastin-like sequences have been coupled to synthetic polymers. Ayres et al. prepared a block copolymer with a central poly ethylene glycol (PEG) chain and polymethacrylate flanking blocks whose side chains were functional with Val-Pro-Gly-Val-Gly. These hybrid materials maintained an LCST behaviour as they displayed a similar coacervation behaviour as tropoelastin [133]. Amino acid residues in the main chain of a linear elastin polypeptide have also been functionalised with methacrylate in order to obtain a photocrosslinkable site [168]. Another example are photopolymerisable hydrogels from PEG diacrylate derivatives that were mixed with Val-Ala-Pro-Gly-modified PEG monoacrylate derivatives to which smooth muscle cells could adhere, whereas platelets and fibroblasts could not [134]. Synthetic elastin peptides can also be added 
to scaffolds, hydrogels or surface coatings, e.g. elastin-laminin-like hybrid peptides to alginate dressings [186] and tropoelastin fragments coating for synthetic tubing [160].

\section{APPLICATIONS OF ELASTIN AS A BIOMATERIAL}

Elastin(-like) biomaterials have been suggested for a wide variety of applications, including skin substitutes [187], vascular grafts [188], heart valves [189], and elastic cartilage [190]. In this section, we will focus on skin, tubular constructs (for vascular grafts) and self-assembling materials.

\section{Skin}

Skin substitutes are usually applied to treat either burn wounds or chronic wounds. Elastic fibres are important components of the skin, but their production is usually limited in tissue engineered constructs. For instance in the skin substitute Apligraf, a type I collagen gel with cultured human neonatal foreskin dermal fibroblasts and keratinocytes, little elastin was synthesised in vitro and elastin was not organised in fibres [191]. In addition, elastin expression in burn wounds grafted with sheets of cultured epithelial autografts may take $4-5$ years [192]. Autologous skin grafting is still the gold standard for skin substitutes. Autografts, allografts, xenografts and deepidermised dermis of course still contain elastic fibres. The latter is made from fresh cadaver skin by removal of the epidermis and the cells from the dermis so that the extracellular matrix and basement membrane are maintained [193]. These materials have been extensively applied. However, only few researchers have explored the use of elastin(-like) containing materials as skin substitutes. These include a decellularised porcine membrane of approximately $70 \%$ collagen and 30\% insoluble elastin and minor amounts of glycosaminoglycans [194], scaffolds of type I collagen coated with $3 \% \alpha$-elastin [195], hybrid peptides of elastin covalently linked to alginate dressings [186] and injected $\alpha$-elastin [196]. The decellularised collagen/elastin membrane was used in a two-step procedure in a rat excised wound model; in the first step the membrane was employed while in the second step cultured keratinocytes were applied. This resulted in a histologically satisfactory result, but due to wound contraction the membrane formed pleats within the layer of elastic fibres [194]. Later, this collagen/ elastin membrane was chemically crosslinked by EDC to reduce degradation in vivo [197] and the inflammatory response was studied in both an in vitro culture system and the chorioallantoic membrane assay (CAM) of the chick embryo. The collagen/elastin membrane caused activation of macrophages and the formation of inflammatory tissue which pointed to a chronic process unwanted in a healing wound [198]. In a porcine excised wound model, a combination of collagen with $3 \% \alpha$-elastin as a dermal matrix substitute combined with meshed split skin grafts gave reduced wound 
contraction, improved tissue regeneration and absence of myofibroblasts compared to an epidermal transplantation only. Matrix remodelling and elastin regeneration occurred both in the upper and lower dermis [199]. In the same model, fibroblasts seeded in the collagen/ $\alpha$-elastin matrix survived and proliferated, reducing migration/ proliferation of (unwanted) subcutaneous fibroblasts into the wound and reducing degradation of the substitute [187]. In a clinical trial, split skin alone showed slightly better take than the graft with split skin, but no significant change in the number of regrafting procedures was found. Short term follow-up revealed that skin elasticity was considerably improved by the collagen/elastin dermal substitute as analysed by cutometer measurements [200]. The long-term objective evaluation (cutometer) with respect to elasticity was consistent, although the difference with controls decreased resulting in no statistical significancy after one year [201]. In the microscopical evaluation, promising differences were found for several parameters, including rete ridges, basement membrane maturation, and epidermal thickness [202].

A hybrid of elastin-laminin peptides promoted attachment and proliferation of normal human dermal fibroblasts in culture. In a rabbit ear skin defect model, alginate dressings linked with elastin-laminin peptides reepithelialised faster than controls [186].

Recently, it was found that a proteolytic digest of elastin induced elastic fibre deposition in stimulated dermal fibroblasts injected in the skin of nude mice as well as in cultured human skin explants [196].

\section{Vascular constructs}

There is a major need for small-diameter vascular grafts with long-term patency, especially for coronary artery bypass graft procedures. These grafts should preferably have 'off-the-shelf' availability with various diameters and lengths, easy storage and straightforward handling [136]. Briefly, biological requirements for tissue engineered grafts should include an endothelium which is confluent, adherent and quiescent, in order to resist thrombosis, and mechanical properties similar to the native vessel, like an elastin network for compliance and recoil [203].

Different approaches exist to obtain tubular constructs. One is to use decellularised blood vessels in which the tubular organisation is maintained, another is to prepare tubular scaffolds from individual matrix components followed by seeding of cells, and a third is to make cells produce the extracellular matrix [204]. We will not discuss the latter. Decellularised blood vessels have been obtained from rat aorta [205] and porcine carotid arteries [8,108]. In vivo, decellularised rat aorta (mainly elastic lamina) showed inflammation-resistant properties and inhibited smooth muscle cell proliferation compared with collagen-containing matrices while endothelial cell migration was maintained [205]. In another study, decellularised porcine carotid arteries covering an expanded metal stent also showed less smooth muscle cell proliferation and lumen stenosis [8]. These materials may therefore prevent neointima formation and thus occlusion of the graft. The last material did not calcify in the investigated 
time frame. However, calcification was observed upon subcutaneous implantation of decellularised porcine arteries [108]. Calcification needs to be thoroughly investigated in tissue-engineered grafts, since it may cause failure of the graft. With more extensive decellularisation (in combination with selective matrix removal), tubular constructs were obtained that were predominantly composed of elastin and could be repopulated with fibroblasts in vitro. However, in vivo studies of this material have not been performed [206].

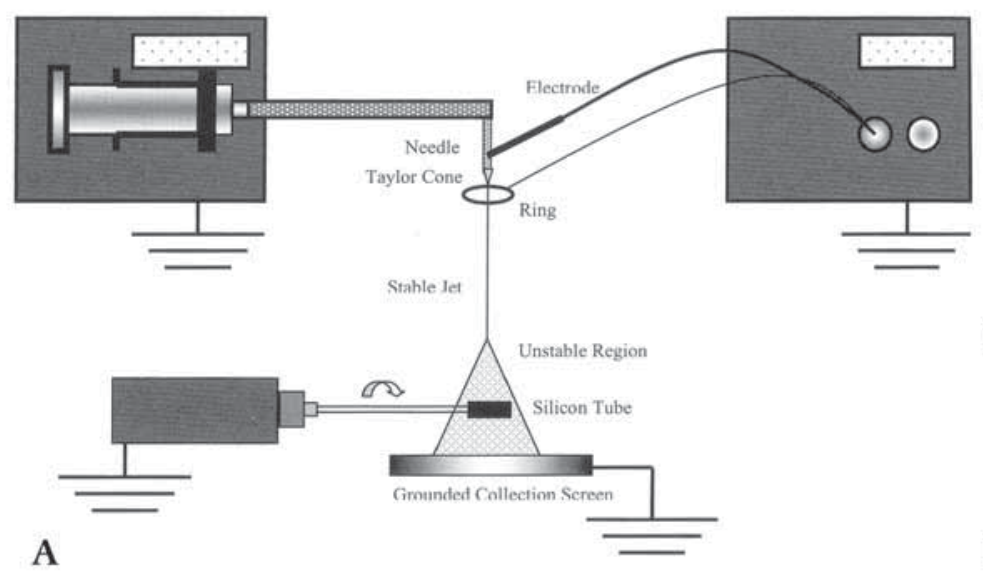

B

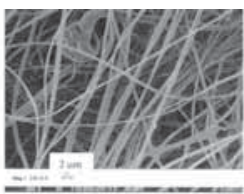

Figure 8. Experimental setup of an electrospinning system from soluble collagen and elastin (A). Elastin content in collagen/elastin solutions used for electrospinning influences fibre diameter. With higher elastin content, fibres had a larger diameter as shown for (B) collagen:elastin 1:3, $d=600 \mathrm{~nm}$; (C) collagen:elastin 1:2, $d=330 \mathrm{~nm}$; (D) collagen:elastin 2:1, $d=220 \mathrm{~nm}$. All fibres were spun at $22 \mathrm{kV}$. Bar is $2 \mu \mathrm{m}$ in $\mathrm{B}$, and 1 $\mu \mathrm{m}$ in C, D. Figure is reproduced from Buttafoco et al. [213] with permission.

Another method to prepare tubular scaffolds is by pouring a diluted acetic acid suspension of purified type I collagen fibrils and elastin fibres in a tubular mould, freezing at $-18^{\circ} \mathrm{C}$ and lyophilising. In static culture as well as under pulsatile flow, smooth muscle cells were able to adhere to and proliferate in these porous $3 \mathrm{D}$ collagenelastin tubes for up to 14 days while maintaining their contractile phenotype as evidenced from smooth muscle actin staining [207-209]. Tubes may also be prepared by winding of a sheet, as was performed with recombinant tropoelastin [124].

To prepare tubular constructs, protein spinning can also be used. Using wet spinning with air-drying of crosslinked (Gly-Val-Gly-Val-Pro), with the bold Val being Glu or Lys every sixth repeat, fibres of about $5 \mu \mathrm{m}$ in diameter could be spun [125]. With electrospinning $\mathrm{nm}$ scale fibres can be prepared in contrast to traditional wet and dry protein spinning processes [210]. Fig. 8 shows the experimental setup of an electrospinning system. Electrospinning is usually performed with synthetic polymers. It is accomplished by inducing a large electric potential $(15-30 \mathrm{kV})$ in a polymer solution or melt. By placing an oppositely charged target some distance from the charging solution, a static electric field is created. As the field strength grows, the charge between the two overcomes the surface tension of the solution and a thin jet is ejected from the polymer solution reservoir. This jet is further thinned by whipping 
in space and evaporation of the solvent. When the jet reaches the target, a dry fibre is collected. Consequently, tubular constructs can be made when using a rotating mandrel to collect the fibre [188].

Recently, electrospinning was also performed with soluble elastin. Huang et al. [166] used this method to spin an $81 \mathrm{kDa}$ recombinant protein based upon 39 repeats of the elastomeric peptide sequence of elastin (Val-Pro-Gly-Val-Gly) ${ }_{4}$ (Val-Pro-Gly-Lys-Gly) into fibres and nonwoven fabrics. Fibres had diameters from 0.2-3 $\mu \mathrm{m}$ and showed various different morphologies including beaded fibres, thin filaments, and broad ribbons. Morphology of structures was dependent on elastin concentration and flow rate. Electrospinning of the same elastomeric peptide sequence functionalised with methacrylate was also possible [168]. In both cases, electrospinning was carried out under mild conditions, in distilled deionised water at ambient temperatures. A relatively low-viscosity solution of the elastomeric peptide was capable of yielding electrospun fibres of uniform diameter, which may be related to molecular self-assembly processes of the elastin $[166,168]$. The solution used to spin fibres from was also of importance, especially when using protein multiblock copolymers, and can result in differences in fibre morphology [128]. Huang et al. [210] also spun acid-soluble rat tail collagen in 10 $\mathrm{mM} \mathrm{HCl}$ ( $\mathrm{pH}$ 2.0), but this was only possible in the presence of poly(ethylene) oxide to increase solution viscosity, and $\mathrm{NaCl}$ to increase solution conductivity. Bowlin's group used electrospinning to construct tubular constructs of acid soluble calf skin type I collagen in a 1,1,1,3,3,3-hexafluoro-2-propanol solution [211]. In an initial step towards vascular tissue engineering, they spun tubular constructs of acid soluble calf skin type I collagen, human placenta type III collagen and soluble elastin from bovine ligamentum nuchae and succeeded to seed fibroblasts, smooth muscle cells and human umbilical vein endothelial cells on glutaraldehyde-fixed scaffolds [188]. Although the method used is promising, the different cell types in the construct were not well characterised, no mechanical experiments were performed on the construct, and the use of organic solvents may significantly reduce biocompatibility. Furthermore, glutaraldehyde-fixed collagen scaffolds may be cytotoxic [212]. Buttafoco et al. used a more biological approach to electrospin tubular constructs composed of soluble collagen and elastin. Based on Huang's method to electrospin collagen nanofibres and fabrics [210], they used calf skin soluble type I collagen and bovine ligament soluble elastin in $10 \mathrm{mM} \mathrm{HCl}$ with poly(ethylene) oxide and $\mathrm{NaCl}$. Afterwards, crosslinking took place with EDC in the presence of N-hydroxysuccinimide (NHS). Poly(ethylene) oxide and $\mathrm{NaCl}$ could be fully leached out after crosslinking. The average fibre diameter was dependent on the collagen/elastin weight ratio; with more elastin, it was larger. Proliferation of smooth muscle cells was possible on these tubular scaffolds [213]. Electrospinning is a highly promising method for vascular reconstruction, but future research must establish its use in in vivo applications. 


\section{Self-assembling materials}

Processes involving self-assembly of polymers (including proteins) are currently the subject of much attention, particularly in the areas of nanotechnology and biomaterials [214]. Molecular self-assembly is per definition the spontaneous organisation of molecules under thermodynamical equilibrium conditions into structurally well-defined and rather stable arrangements through a number of non-covalent interactions [215]. Elastin is a biological example of a protein polymer that can self-organise. Upon heating, tropoelastin, solubilised elastin and (bio)synthetic elastin coacervate, caused by hydrophobic interactions between the hydrophobic domains in the molecule.
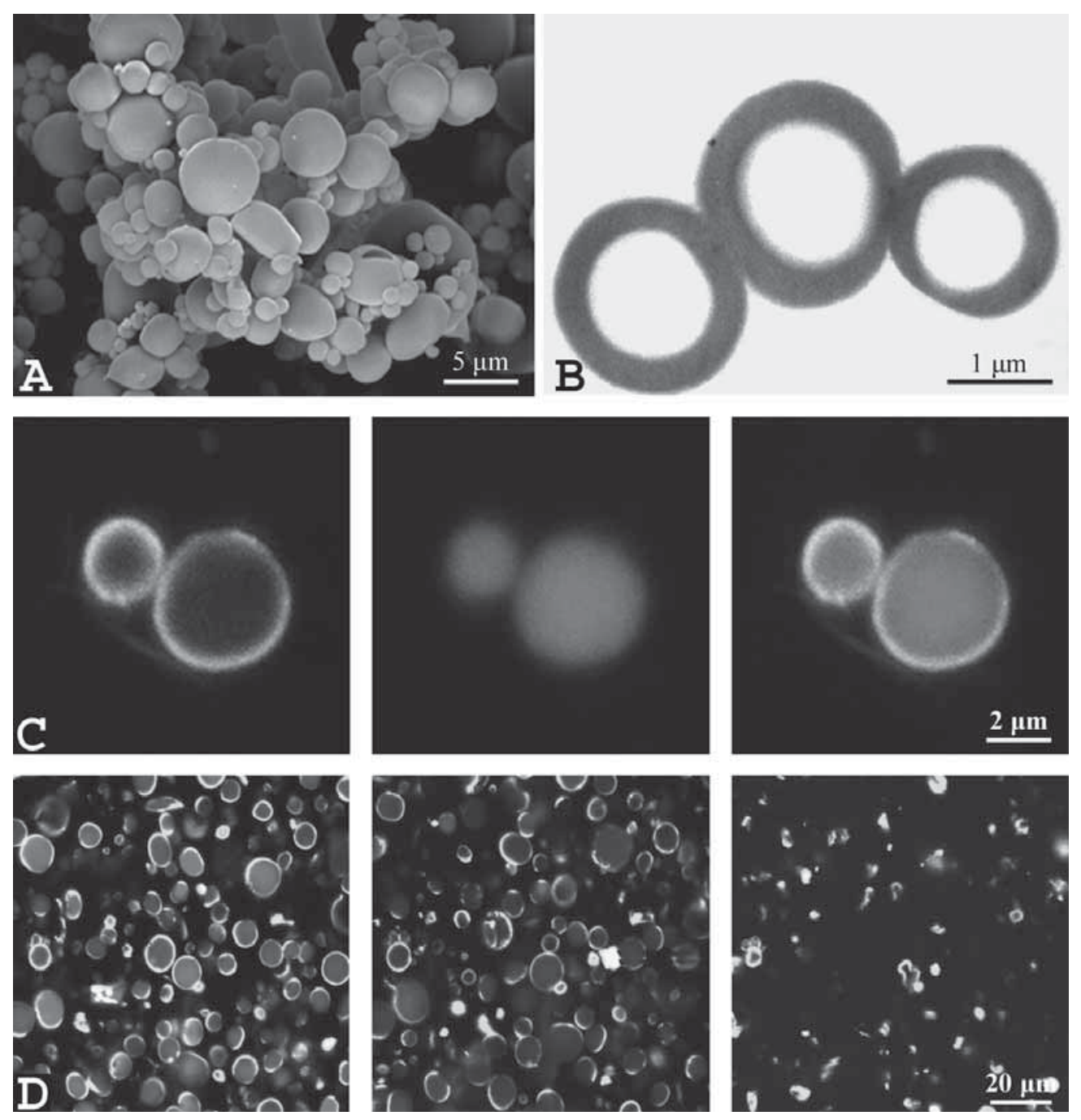

Figure 9. Elastin vesicles obtained by quench freezing solubilised elastin in diluted acetic acid followed by lyophilisation. (A) Scanning electron micrograph (SEM) shows that globular structures are formed. (B) Transmission electron micrograph (TEM) establishes vesicle nature of the globules in A. (C) Fluorescentlabelled macromolecules could be differentially incorporated in the vesicle wall and vesicle lumen as is shown for 10,000 Da dextran-conjugates labelled with Alexa Fluor488 (vesicle wall) and Alexa Fluor594 vesicle lumen). (D) Labelled macromolecules were released over time by digestion with elastase. Bar is $5 \mu \mathrm{m}$ in A, 1 $\mu \mathrm{m}$ in $B, 2 \mu \mathrm{m}$ in $C$ and $20 \mu \mathrm{m}$ in D. Figure adapted from [221], original colour figure on page 153. 
Self-assembly into fibrous structures is well-known, and was observed with tropoelastin [124], tropoelastin fragments [39], and synthetic elastin block polymers $[128,166,168]$.

Self-assembly is especially useful to prepare nano-scale materials. For polymers, selfassembled structures included nanotubes, nanofibres, nanocoatings and nanoporous films [216]. The self-assembling behaviour of elastin was used to obtain various elastin biomaterials, e.g. hydrogels [217], sheets [124], nanoparticles [218], spongelike isotropic networks [21] and nanoporous materials [219]. They may be valuable for cellular orientation, small-diameter blood vessels, and drug-delivery or growth factor delivery devices. Another application of elastin in biomaterials may be elastin biovesicles, as a potential drug delivery system. Vesicle structures have found ample applications as targetable drug carriers in cosmetics and pharmaceutics and other applications, but usually these are made of lipids or synthetic polymers. Vesicles from biological proteins may be the ultimate biocompatible and biodegradable product. Usually, protein vesicles from synthesised proteins are based on the amphiphilicity of the molecules [220]. However, we recently showed the preparation of vesicles (250 $\mathrm{nm}-10 \mu \mathrm{m}$ in diameter) from solubilised elastin (Fig. 9A, B) by a novel approach combining freezing and lyophilisation procedures where amphilicity is not necessary [221]. Vesicle formation was critically dependent on elastin concentration, solvent, freezing mode and pressure conditions during lyophilisation. Fluorescent-labelled (macro)molecules could be differentially incorporated in the vesicle wall and/or vesicle lumen (Fig. 9C) and were released by elastase digestion (Fig. 9D). Elastin vesicles are a highly promising release system, since they are highly adaptable.

\section{OUTLOOK}

Elastin-based materials are promising in the field of biomaterials and tissue engineering. They exhibit interesting biological, biomechanical, biochemical and biophysical properties, and may comprise novel approaches for improving tissue regeneration.

Before this can actually happen, certain aspects of elastin-based materials should be studied in order to attain a more predictable outcome in vivo, opposed to the trialand-error research as is often carried out at the moment. It would be advantageous to better incorporate results from basic research into applications for tissue engineering. For example, the effect of elastin peptide-containing biomaterials on a specific cell type may be predicted from the activation of signalling pathways activated by elastin peptides.

Another recommendation is to extend cytocompatibility and biocompatibility studies of elastin-based materials, especially of elastin-like block polymers. Polypeptides with new elastin sequences have been expressed without studying their biocompatibility. The choice of the experimental animal model is also of major importance. Currently, different materials are studied at different implantation sites in different animal 
models, making it impossible to compare results. It will thus be worthwhile to propose and standardise specific animal models and explicit operation protocols for specific applications, like small-diameter blood vessels. In addition, comparative studies of different elastin-based materials in in vivo applications will be valuable. This would lead to a more systematic approach of biomaterials in general and elastin-based biomaterials in particular.

Elastin-based materials should be well-defined in order to pinpoint a specific effect. Tailor-made materials are likely to have the best potential in various applications. Variables that are important to control include the chemical composition and the architecture. Purified elastin preparations and synthetic elastins may therefore have great potential in soft tissue regeneration. Self-assembling elastin-based materials are an emerging and promising topic within the elastin biomaterials field. The preparation of highly-defined polypeptides with a propensity to self-aggregate, resulting in biomaterials with defined mechanical properties, and likely also a specific biological activity, will increase the use of elastin in biomaterials. Self-assembly may also result in microtubes and nanotubes with promising applications in tissue engineering and beyond.

Tissue engineering of skin and blood vessels using elastin-based biomaterials are now getting into reach. In this respect, the Cinderella nature of elastin as a component in biomaterials may soon be over.

\section{AIM AND OUTLINE OF THIS THESIS}

Elastin preparations display remarkable properties, such as elasticity, long-term stability, self-assembly, and many cell biological effects, and this makes them valuable as biomaterials for tissue engineering. The aim of this thesis is to prepare highly-purified elastin fibres as well as solubilised products hereof for use in the field of tissue engineering. The purification of elastin, the 'makability' of the biomaterials and the in vitro and in vivo evaluation are emphasised. An overview of the preparation and application of elastin-based biomaterials is given in Chapter 1. The purification of insoluble elastin from equine ligamentum nuchae is described in Chapter 2 and 3. In Chapter 4, the development of scaffolds from elastin fibres, type I collagen fibrils, and chondroitin sulfate is presented. Scaffolds were designed to mimic the extracellular matrix composition. The preparation of scaffolds containing type I collagen fibrils and solubilised elastin is described in Chapter 6. The tissue response to scaffolds composed of type I collagen with elastin fibres and type I collagen with solubilised elastin are described in respectively Chapter 5 and 6. Special attention is given to calcification, vascularisation and elastic fibre formation. Chapter 7 deals with the preparation of vesicles from solubilised elastin as well as from other molecules. The ability to incorporate fluorescent macromolecules in the wall and/or lumen of these elastin vesicles is also discussed. Finally, a summary of the studies and future directions are given in Chapter 8. 


\section{REFERENCES}

1. Pasquali-Ronchetti I, Baccarani-Contri M. Elastic fiber during development and aging. Microsc Res Tech 1997;38:428-435.

2. Faury G. Function-structure relationship of elastic arteries in evolution: from microfibrils to elastin and elastic fibres. Pathol Biol (Paris) 2001;49:310-325.

3. Martyn CN, Greenwald SE. A hypothesis about a mechanism for the programming of blood pressure and vascular disease in early life. Clin Exp Pharmacol Physiol 2001;28:948-951.

4. Cox BA, Starcher BC, Urry DW. Communication: Coacervation of tropoelastin results in fiber formation. J Biol Chem 1974;249:997-998.

5. Wu WJ, Vrhovski B, Weiss AS. Glycosaminoglycans mediate the coacervation of human tropoelastin through dominant charge interactions involving lysine side chains. J Biol Chem 1999;274:2171921724.

6. Powell JT, Vine N, Crossman M. On the accumulation of D-aspartate in elastin and other proteins of the ageing aorta. Atherosclerosis 1992;97:201-208.

7. Fülöp Jr T, Jacob MP, Khalil J, Wallach J, Robert L. Biological effects of elastin peptides. Pathol Biol (Paris) 1998;46:497-506.

8. Karnik SK, Brooke BS, Bayes-Genis A, Sorensen L, Wythe JD, Schwartz RS, Keating MT, Li DY. A critical role for elastin signaling in vascular morphogenesis and disease. Development 2003;130:411-423.

9. Indik Z, Yeh H, Ornstein-Goldstein N, Sheppard P, Anderson N, Rosenbloom JC, Peltonen L, Rosenbloom J. Alternative splicing of human elastin mRNA indicated by sequence analysis of cloned genomic and complementary DNA. Proc Natl Acad Sci USA 1987;84:5680-5684.

10. Yeh H, Ornstein-Goldstein N, Indik Z, Sheppard P, Anderson N, Rosenbloom JC, Cicila G, Yoon K. Sequence variation of bovine elastin mRNA due to alternative splicing. Collagen Rel Res 1987;7:235-247.

11. Debelle L, Alix AJ. The structures of elastins and their function. Biochimie 1999;81:981-994.

12. Hsiao H, Stone PJ, Toselli P, Rosenbloom J, Franzblau C, Schreiber BM. The role of the carboxy terminus of tropoelastin in its assembly into the elastic fiber. Connect Tissue Res 1999;40:83-95.

13. Bisaccia F, Castiglione-Morelli MA, Spisani S, Ostuni A, Serafini-Fracassini A, Bavoso A, Tamburro AM. The amino acid sequence coded by the rarely expressed exon $26 \mathrm{~A}$ of human elastin contains a stable beta-turn with chemotactic activity for monocytes. Biochemistry 1998;37:11128-11135.

14. Ostuni A, Lograno MD, Gasbarro AR, Bisaccia F, Tamburro AM. Novel properties of peptides derived from the sequence coded by exon 26A of human elastin. Int $\mathrm{J}$ Biochem Cell Biol $\mathrm{J}$ 2002;34:130-135.

15. Jones PA, Scott-Burden T, Gevers W. Glycoprotein, elastin, and collagen secretion by rat smooth muscle cells. Proc Natl Acad Sci U S A 1979;76:353-357.

16. Mecham RP, Madaras J, McDonald JA, Ryan U. Elastin production by cultured calf pulmonary artery endothelial cells. J Cell Physiol 1983;116:282-288.

17. Madsen K, Moskalewski S, von der MK, Friberg U. Synthesis of proteoglycans, collagen, and elastin by cultures of rabbit auricular chondrocytes--relation to age of the donor. Dev Biol 1983;96:6373.

18. Sephel GC, Davidson JM. Elastin production in human skin fibroblast cultures and its decline with age. J Invest Dermatol 1986;86:279-285.

19. Long JL, Tranquillo RT. Elastic fiber production in cardiovascular tissue-equivalents. Matrix Biol 2003;22:339-350.

20. Ayad S, Boot-Handford RP, Humphries MJ, Kadler KE, Shuttleworth CA. The extracellular matrix facts book. London, GB: Academic Press, 1994.

21. Bellingham CM, Lillie MA, Gosline JM, Wright GM, Starcher BC, Bailey AJ, Woodhouse KA, Keeley FW. Recombinant human elastin polypeptides self-assemble into biomaterials with elastinlike properties. Biopolymers 2003;70:445-455.

22. Zarkadas CG, Zarkadas GC, Karatzas CN, Khalili AD, Nguyen Q. Rapid method for determining desmosine, isodesmosine, 5-hydroxylysine, tryptophan, lysinoalanine and the amino sugars in proteins and tissues. J Chromatogr 1986;378:67-76.

23. Yamaguchi Y, Haginaka J, Kunitomo M, Yasuda H, Bando Y. High-performance liquid chromatographic determination of desmosine and isodesmosine in tissues and its application to studies of alteration of elastin induced by atherosclerosis. J Chromatogr 1987;422:53-59.

24. Suyama K, Nakamura F. Isolation and characterization of new cross-linking amino acid 'allodesmosine' from hydrolysate of elastin. Biochem Biophys Res Commun 1990;170:713-718.

25. Brown-Augsburger P, Tisdale C, Broekelmann T, Sloan C, Mecham RP. Identification of an elastin cross-linking domain that joins three peptide chains. Possible role in nucleated assembly. J Biol 
Chem 1995;270:17778-17783.

26. Umeda H, Takeuchi M, Suyama K. Two new elastin cross-links having pyridine skeleton. implication of ammonia in elastin cross-linking in vivo. J Biol Chem 2001;276:12579-12587.

27. Rock MJ, Cain SA, Freeman LJ, Morgan A, Mellody KT, Marson A, Shuttleworth CA, Weiss AS, Kielty CM. Molecular basis of elastic fiber formation: critical interactions and a tropoelastin fibrillin-1 crosslink. J Biol Chem 2004.

28. Debelle L, Tamburro AM. Elastin: molecular description and function. Int J Biochem Cell Biol 1999;31:261-272.

29. Urry DW, Parker TM. Mechanics of elastin: molecular mechanism of biological elasticity and its relationship to contraction. J Muscle Res Cell Motil 2002;23:543-559.

30. Li B, Daggett V. Molecular basis for the extensibility of elastin. J Muscle Res Cell Motil 2002;23:561573 .

31. Gosline J, Lillie M, Carrington E, Guerette P, Ortlepp C, Savage K. Elastic proteins: biological roles and mechanical properties. Philos Trans R Soc Lond B Biol Sci 2002;357:121-132.

32. Vrhovski B, Weiss AS. Biochemistry of tropoelastin. Eur J Biochem 1998;258:1-18.

33. Urry DW, Hugel T, Seitz M, Gaub HE, Sheiba L, Dea J, Xu J, Parker T. Elastin: a representative ideal protein elastomer. Philos Trans R Soc Lond B Biol Sci 2002;357:169-184.

34. Kakivaya SR, Hoeve CA. The glass point of elastin. Proc Natl Acad Sci U S A 1975;72:3505-3507.

35. Lillie MA, Gosline JM. The effects of hydration on the dynamic mechanical properties of elastin. Biopolymers 1990;29:1147-1160.

36. Samouillan V, Andre C, Dandurand J, Lacabanne C. Effect of water on the molecular mobility of elastin. Biomacromolecules 2004;5:958-964.

37. Urry DW. On the molecular mechanisms of elastin coacervation and coacervate calcification. Faraday Discuss Chem Soc 1976;205-212.

38. Mecham RP, Lange G. Antigenicity of elastin: characterization of major antigenic determinants on purified insoluble elastin. Biochemistry 1982;21:669-673.

39. Keeley FW, Bellingham CM, Woodhouse KA. Elastin as a self-organizing biomaterial: use of recombinantly expressed human elastin polypeptides as a model for investigations of structure and self-assembly of elastin. Philos Trans R Soc Lond B Biol Sci 2002;357:185-189.

40. Vrhovski B, Jensen S, Weiss AS. Coacervation characteristics of recombinant human tropoelastin. Eur J Biochem 1997;250:92-98.

41. Van Hest JC, Tirrell DA. Protein-based materials, toward a new level of structural control. Chem Commun (Camb) 2001;1897-1904.

42. Bellingham CM, Woodhouse KA, Robson P, Rothstein SJ, Keeley FW. Self-aggregation characteristics of recombinantly expressed human elastin polypeptides. Biochim Biophys Acta 2001;1550:6-19.

43. Bressan GM, Pasquali-Ronchetti I, Fornieri C, Mattioli F, Castellani I, Volpin D. Relevance of aggregation properties of tropoelastin to the assembly and structure of elastic fibers. J Ultrastruct Mol Struct Res 1986;94:209-216.

44. Chrzanowski P, Keller S, Cerreta J, Mandl I, Turino GM. Elastin content of normal and emphysematous lung parenchyma. Am J Med 1980;69:351-359.

45. Rosenbloom J, Abrams WR, Mecham RP. Extracellular matrix 4: The elastic fiber. FASEB J 1993; 7:1208-1218.

46. Bancroft JD, Stevens A. Theory and practice of histological techniques. 3rd ed. Edinburgh (UK): Churchill Livingstone, 1990.

47. Ramirez F, Pereira L. The fibrillins. Int J Biochem Cell Biol 1999;31:255-259.

48. Hinek A, Rabinovitch M. 67-kD elastin-binding protein is a protective «companion» of extracellular insoluble elastin and intracellular tropoelastin. J Cell Biol 1994;126:563-574.

49. Robert L. Interaction between cells and elastin, the elastin-receptor. Connect Tissue Res 1999;40:7582.

50. Mecham RP, Hinek A, Entwistle R, Wrenn DS, Griffin GL, Senior RM. Elastin binds to a multifunctional 67-kilodalton peripheral membrane protein. Biochemistry 1989;28:3716-3722.

51. Hinek A, Wrenn DS, Mecham RP, Barondes SH. The elastin receptor: a galactoside-binding protein. Science 1988;239:1539-1541.

52. Mecham RP, Whitehouse L, Hay M, Hinek A, Sheetz MP. Ligand affinity of the 67-kD elastin/ laminin binding protein is modulated by the protein's lectin domain: visualization of elastin/ laminin-receptor complexes with gold-tagged ligands. J Cell Biol 1991;113:187-194.

53. Klevay LM. Cardiovascular disease from copper deficiency-a history. J Nutr 2000;130:489S-492S.

54. Kozel BA, Ciliberto $\mathrm{CH}$, Mecham RP. Deposition of tropoelastin into the extracellular matrix requires a competent elastic fiber scaffold but not live cells. Matrix Biol 2004;23:23-34.

55. Kielty CM, Sherratt MJ, Shuttleworth CA. Elastic fibres. J Cell Sci 2002;115:2817-2828.

56. Roark EF, Keene DR, Haudenschild CC, Godyna S, Little CD, Argraves WS. The association of human fibulin-1 with elastic fibers: an immunohistological, ultrastructural, and RNA study. J 
Histochem Cytochem 1995;43:401-411.

57. Midwood KS, Schwarzbauer JE. Elastic fibers: building bridges between cells and their matrix. Curr Biol 2002;12:R279-R281.

58. Yanagisawa H, Davis EC, Starcher BC, Ouchi T, Yanagisawa M, Richardson JA, Olson EN. Fibulin5 is an elastin-binding protein essential for elastic fibre development in vivo. Nature 2002;415:168171.

59. Liu X, Zhao Y, Gao J, Pawlyk B, Starcher B, Spencer JA, Yanagisawa H, Zuo J, Li T. Elastic fiber homeostasis requires lysyl oxidase-like 1 protein. Nat Genet 2004;36:178-182.

60. Gheduzzi D, Guerra D, Bochicchio B, Pepe A, Tamburro AM, Quaglino D, Mithieux S, Weiss AS, Pasquali R, I. Heparan sulphate interacts with tropoelastin, with some tropoelastin peptides and is present in human dermis elastic fibers. Matrix Biol 2005;24:15-25.

61. Grosso LE, Scott M. PGAIPG, a repeated hexapeptide of bovine tropoelastin, is a ligand for the 67-kDa bovine elastin receptor. Matrix 1993;13:157-164.

62. Grosso LE, Scott M. Peptide sequences selected by BA4, a tropoelastin-specific monoclonal antibody, are ligands for the 67-kilodalton bovine elastin receptor. Biochemistry 1993;32:1336913374.

63. Mochizuki S, Brassart B, Hinek A. Signaling pathways transduced through the elastin receptor facilitate proliferation of arterial smooth muscle cells. J Biol Chem 2002;277:44854-44863.

64. Faury G, Garnier S, Weiss AS, Wallach J, Fulop TJ, Jacob MP, Mecham RP, Robert L, Verdetti J. Action of tropoelastin and synthetic elastin sequences on vascular tone and on free Ca2 + level in human vascular endothelial cells. Circ Res 1998;82:328-336.

65. Senior RM, Griffin GL, Mecham RP. Chemotactic activity of elastin-derived peptides. J Clin Invest 1980;66:859-862.

66. Hance KA, Tataria M, Ziporin SJ, Lee JK, Thompson RW. Monocyte chemotactic activity in human abdominal aortic aneurysms: role of elastin degradation peptides and the 67-kD cell surface elastin receptor. J Vasc Surg 2002;35:254-261.

67. Wachi H, Sugitani H, Murata H, Nakazawa J, Mecham RP, Seyama Y. Tropoelastin inhibits vascular calcification via $67-\mathrm{kDa}$ elastin binding protein in cultured bovine aortic smooth muscle cells. J Atheroscler Thromb 2004;11:159-166.

68. Kamoun A, Landeau JM, Godeau G, Wallach J, Duchesnay A, Pellat B, Hornebeck W. Growth stimulation of human skin fibroblasts by elastin-derived peptides. Cell Adhes Commun 1995;3:273281.

69. Jung S, Rutka JT, Hinek A. Tropoelastin and elastin degradation products promote proliferation of human astrocytoma cell lines. J Neuropathol Exp Neurol 1998;57:439-448.

70. Hinek A, Jung S, Rutka JT. Cell surface aggregation of elastin receptor molecules caused by suramin amplified signals leading to proliferation of human glioma cells. Acta Neuropathol (Berl) 1999;97:399-407.

71. Fujimoto N, Tajima S, Ishibashi A. Elastin peptides induce migration and terminal differentiation of cultured keratinocytes via $67 \mathrm{kDa}$ elastin receptor in vitro: $67 \mathrm{kDa}$ elastin receptor is expressed in the keratinocytes eliminating elastic materials in elastosis perforans serpiginosa. J Invest Dermatol 2000;115:633-639.

72. Lograno MD, Bisaccia F, Ostuni A, Daniele E, Tamburro AM. Identification of elastin peptides with vasorelaxant activity on rat thoracic aorta. Int J Biochem Cell Biol 1998;30:497-503.

73. Brassart B, Randoux A, Hornebeck W, Emonard H. Regulation of matrix metalloproteinase2 (gelatinase A, MMP-2), membrane-type matrix metalloproteinase-1 (MT1-MMP) and tissue inhibitor of metalloproteinases-2 (TIMP-2) expression by elastin-derived peptides in human HT1080 fibrosarcoma cell line. Clin Exp Metastasis 1998;16:489-500.

74. Rodgers UR, Weiss AS. Integrin alpha(v)beta(3) binds a unique non-RGD site near the C-terminus of human tropoelastin. Biochimie 2004;86:173-178.

75. Ntayi C, Labrousse AL, Debret R, Birembaut P, Bellon G, Antonicelli F, Hornebeck W, Bernard P. Elastin-derived peptides upregulate matrix metalloproteinase-2-mediated melanoma cell invasion through elastin-binding protein. J Invest Dermatol 2004;122:256-265.

76. Brooke BS, Bayes-Genis A, Li DY. New insights into elastin and vascular disease. Trends Cardiovasc Med 2003;13:176-181.

77. Robinson PN, Godfrey M. The molecular genetics of Marfan syndrome and related microfibrillopathies. J Med Genet 2000;37:9-25.

78. Morris CA, Mervis CB. Williams syndrome and related disorders. Annu Rev Genomics Hum Genet 2000;1:461-484.

79. Dietz HC, Mecham RP. Mouse models of genetic diseases resulting from mutations in elastic fiber proteins. Matrix Biol 2000;19:481-488.

80. Kumar A, Olson TM, Thibodeau SN, Michels VV, Schaid DJ, Wallace MR. Confirmation of linkage of supravalvular aortic stenosis to the elastin gene on chromosome 7q. Am J Cardiol 1994;74:1281- 
1283.

81. Ewart AK, Jin W, Atkinson D, Morris CA, Keating MT. Supravalvular aortic stenosis associated with a deletion disrupting the elastin gene. J Clin Invest 1994;93:1071-1077.

82. Li DY, Toland AE, Boak BB, Atkinson DL, Ensing GJ, Morris CA, Keating MT. Elastin point mutations cause an obstructive vascular disease, supravalvular aortic stenosis. Hum Mol Genet 1997;6:1021-1028.

83. Li DY, Faury G, Taylor DG, Davis EC, Boyle WA, Mecham RP, Stenzel P, Boak B, Keating MT. Novel arterial pathology in mice and humans hemizygous for elastin. J Clin Invest 1998;102:1783-1787.

84. Arteaga-Solis E, Gayraud B, Ramirez F. Elastic and collagenous networks in vascular diseases. Cell Struct Funct 2000;25:69-72.

85. Wu WJ, Weiss AS. Deficient coacervation of two forms of human tropoelastin associated with supravalvular aortic stenosis. Eur J Biochem 1999;266:308-314.

86. Li DY, Brooke B, Davis EC, Mecham RP, Sorensen LK, Boak BB, Eichwald E, Keating MT. Elastin is an essential determinant of arterial morphogenesis. Nature 1998;393:276-280.

87. Chowdhury T, Reardon W. Elastin mutation and cardiac disease. Pediatr Cardiol 1999;20:103-107.

88. Rodriguez-Revenga L, Iranzo P, Badenas C, Puig S, Carrio A, Mila M. A novel elastin gene mutation resulting in an autosomal dominant form of cutis laxa. Arch Dermatol 2004;140:1135-1139.

89. Zhang MC, He L, Giro M, Yong SL, Tiller GE, Davidson JM. Cutis laxa arising from frameshift mutations in exon 30 of the elastin gene (ELN). J Biol Chem 1999;274:981-98.

90. Tassabehji M, Metcalfe K, Hurst J, Ashcroft GS, Kielty C, Wilmot C, Donnai D, Read AP, Jones CJ. An elastin gene mutation producing abnormal tropoelastin and abnormal elastic fibres in a patient with autosomal dominant cutis laxa. Hum Mol Genet 1998;7:1021-1028.

91. Milewicz DM, Urban Z, Boyd C. Genetic disorders of the elastic fiber system. Matrix Biol 2000;19:471-480.

92. Urban Z, Boyd CD. Elastic-fiber pathologies: primary defects in assembly-and secondary disorders in transport and delivery. Am J Hum Genet 2000;67:4-7.

93. Loeys B, Van Maldergem L, Mortier G, Coucke P, Gerniers S, Naeyaert JM, De Paepe A. Homozygosity for a missense mutation in fibulin-5 (FBLN5) results in a severe form of cutis laxa. Hum Mol Genet 2002;11:2113-2118.

94. Markova D, Zou Y, Ringpfeil F, Sasaki T, Kostka G, Timpl R, Uitto J, Chu ML. Genetic heterogeneity of cutis laxa: a heterozygous tandem duplication within the fibulin-5 (FBLN5) gene. Am J Hum Genet 2003;72:998-1004.

95. Nakamura T, Lozano PR, Ikeda Y, Iwanaga Y, Hinek A, Minamisawa S, Cheng CF, Kobuke K, Dalton N, Takada Y, Tashiro K, Ross JJ, Honjo T, Chien KR. Fibulin-5/DANCE is essential for elastogenesis in vivo. Nature 2002;415:171-175.

96. Maslen CL, Glanville RW. The molecular basis of Marfan syndrome. DNA Cell Biol 1993;12:561572 .

97. Ramirez F, Pereira L. Mutations of extracellular matrix components in vascular disease. Ann Thorac Surg 1999;67:1857-1858.

98. Pereira L, Andrikopoulos K, Tian J, Lee SY, Keene DR, Ono R, Reinhardt DP, Sakai LY, Biery NJ, Bunton T, Dietz HC, Ramirez F. Targetting of the gene encoding fibrillin-1 recapitulates the vascular aspect of Marfan syndrome. Nat Genet 1997;17:218-222.

99. Pereira L, Lee SY, Gayraud B, Andrikopoulos K, Shapiro SD, Bunton T, Biery NJ, Dietz HC, Sakai LY, Ramirez F. Pathogenetic sequence for aneurysm revealed in mice underexpressing fibrillin- 1 . Proc Natl Acad Sci U S A 1999;96:3819-3823.

100. Paule WJ, Bernick S, Strates B, Nimni ME. Calcification of implanted vascular tissues associated with elastin in an experimental animal model. J Biomed Mater Res 1992;26:1169-1177.

101. Nimni ME, Myers D, Ertl D, Han B. Factors which affect the calcification of tissue-derived bioprostheses. J Biomed Mater Res 1997;35:531-537.

102. Schoen FJ, Levy RJ. Tissue heart valves: current challenges and future research perspectives. J Biomed Mater Res 1999;47:439-465.

103. Schinke T, Karsenty G. Vascular calcification--a passive process in need of inhibitors. Nephrol Dial Transplant 2000;15:1272-1274.

104. Vyavahare N, Ogle M, Schoen FJ, Levy RJ. Elastin calcification and its prevention with aluminum chloride pretreatment. Am J Pathol 1999;155:973-982.

105. Anselme K, Petite H, Herbage D. Inhibition of calcification in vivo by acyl azide cross-linking of a collagen-glycosaminoglycan sponge. Matrix 1992;12:264-273.

106. Singla A, Lee CH. Inhibition of CEM calcification by the sequential pretreatment with ethanol and EDTA. J Biomed Mater Res 2003;64A:706-713.

107. Simionescu DT, Lovekamp JJ, Vyavahare NR. Glycosaminoglycan-degrading enzymes in porcine aortic heart valves: implications for bioprosthetic heart valve degeneration. J Heart Valve Dis $2003 ; 12: 217-225$. 
108. Hinds MT, Courtman DW, Goodell T, Kwong M, Brant-Zawadzki H, Burke A, Fox BA, Gregory KW. Biocompatibility of a xenogenic elastin-based biomaterial in a murine implantation model: The role of aluminum chloride pretreatment. J Biomed Mater Res 2004;69A:55-64.

109. Bader A, Schilling T, Teebken OE, Brandes G, Herden T, Steinhoff G, Haverich A. Tissue engineering of heart valves--human endothelial cell seeding of detergent acellularized porcine valves. Eur J Cardiothorac Surg 1998;14:279-284.

110. Brown AL, Farhat W, Merguerian PA, Wilson GJ, Khoury AE, Woodhouse KA. 22 week assessment of bladder acellular matrix as a bladder augmentation material in a porcine model. Biomaterials 2002;23:2179-2190.

111. Lansing AI, Rosenthal TB, Alex M, Dempsey W. The structure and chemical characterization of elastic fibers as revealed by elastase and by electron microscopy. Anat Rec 1952;114:555-575.

112. John R, Thomas J. Chemical compositions of elastins isolated from aortas and pulmonary tissues of humans of different ages. Biochem J 1972;127:261-269.

113. Starcher BC, Galione MJ. Purification and comparison of elastins from different animal species. Anal Biochem 1976;74:4417-447.

114. Daamen WF, Hafmans T, Veerkamp JH, Van Kuppevelt TH. Isolation of intact elastin fibers devoid of microfibrils. Tissue Eng 2005;11:1168-1176.

115. Sandberg LB, Wolt TB. Production and isolation of soluble elastin from copper-deficient swine. Methods Enzymol 1982;82 Pt A:657-665.

116. Rucker RB. Isolation of soluble elastin from copper-deficient chick aorta. Methods Enzymol 1982;82 Pt A:650-657.

117. Partridge SM, Davis HF, Adair GS. The chemistry of connective tissues. 2 - Soluble proteins derived from partial hydrolysis of elastin. Biochem J 1955;61:11-21.

118. Jacob MP, Hornebeck W. Isolation and characterisation of insoluble and kappa-elastins. In: Robert L, Moczar M, Moczar E, eds. Methods of Connective Tissue Research. Basel: Karger, 1985:92129.

119. Hattori M, Yamaji-Tsukamoto K, Kumagai H, Feng Y, Takahashi K. Antioxidative activity of soluble elastin peptides. J Agric Food Chem 1998;46:2167-2170.

120. Wei SM, Katona E, Fachet J, Fülöp Jr T, Robert L, Jacob MP. Epitope specificity of monoclonal and polyclonal antibodies to human elastin. Int Arch Allergy Immunol 1998;115:33-41.

121. Indik Z, Abrams WR, Kucich U, Gibson CW, Mecham RP, Rosenbloom J. Production of recombinant human tropoelastin: characterization and demonstration of immunologic and chemotactic activity. Arch Biochem Biophys 1990;280:80-86.

122. Martin SL, Vrhovski B, Weiss AS. Total synthesis and expression in Escherichia coli of a gene encoding human tropoelastin. Gene 1995;154:159-166.

123. Stone PJ, Morris SM, Griffin S, Mithieux S, Weiss AS. Building Elastin. Incorporation of recombinant human tropoelastin into extracellular matrices using nonelastogenic rat-1 fibroblasts as a source for lysyl oxidase. Am J Respir Cell Mol Biol 2001;24:733-739.

124. Mithieux SM, Rasko JE, Weiss AS. Synthetic elastin hydrogels derived from massive elastic assemblies of self-organized human protein monomers. Biomaterials 2004;25:4921-4927.

125. Lee J, Macosko CW, Urry DW. Elastomeric polypentapeptides cross-linked into matrixes and fibers. Biomacromolecules 2001;2:170-179.

126. Martino M, Tamburro AM. Chemical synthesis of cross-linked poly(KGGVG), an elastin-like biopolymer. Biopolymers 2001;59:29-37.

127. McMillan RA, Lee TAT, Conticello VP. Rapid Assembly of Synthetic Genes Encoding Protein Polymers. Macromolecules 1999;32:3643-3648.

128. Nagapudi K, Brinkman WT, Thomas BS, Park JO, Srinivasarao M, Wright E, Conticello VP, Chaikof EL. Viscoelastic and mechanical behavior of recombinant protein elastomers. Biomaterials 2005;26:4695-4706.

129. Heilshorn SC, Liu JC, Tirrell DA. Cell-binding domain context affects cell behavior on engineered proteins. Biomacromolecules 2005;6:318-323.

130. Welsh ER, Tirrell DA. Engineering the Extracellular Matrix: A Novel Approach to Polymeric Biomaterials. I. Control of the Physical Properties of Artificial Protein Matrices Designed to Support Adhesion of Vascular Endothelial Cells. Biomacromolecules 2000;1:23-30.

131. Cappello J, Crissman J, Dorman M, Mikolajczak M, Textor G, Marquet M, Ferrari F. Genetic engineering of structural protein polymers. Biotechnol Prog 1990;6:198-202.

132. Scheller J, Henggeler D, Viviani A, Conrad U. Purification of spider silk-elastin from transgenic plants and application for human chondrocyte proliferation. Transgenic Res 2004;13:51-57.

133. Ayres L, Koch K, Adams HHM, Van Hest JCM. Stimulus responsive behavior of elastin-based side chain polymers. Macromolecules 2005;38:1699-1704.

134. Gobin AS, West JL. Val-ala-pro-gly, an elastin-derived non-integrin ligand: smooth muscle cell adhesion and specificity. J Biomed Mater Res 2003;67A:255-259. 
135. Daamen WF, Nillesen ST, Hafmans T, Veerkamp JH, Van Luyn MJ, Van Kuppevelt TH. Tissue response of defined collagen-elastin scaffolds in young and adult rats with special attention to calcification. Biomaterials 2005;26:81-92.

136. Kakisis JD, Liapis CD, Breuer C, Sumpio BE. Artificial blood vessel: the Holy Grail of peripheral vascular surgery. J Vasc Surg 2005;41:349-354.

137. Rosa FP, Lia RC, de Souza KO, Goissis G, Marcantonio E. Tissue response to polyanionic collagen: elastin matrices implanted in rat calvaria. Biomaterials 2003;24:207-212.

138. Grauss RW, Hazekamp MG, Oppenhuizen F, van Munsteren CJ, Gittenberger-de Groot AC, DeRuiter MC. Histological evaluation of decellularised porcine aortic valves: matrix changes due to different decellularisation methods. Eur J Cardiothorac Surg 2005;27:566-571.

139. Rasmussen BL, Bruenger E, Sandberg LB. A new method for purification of mature elastin. Anal Biochem 1975;64:255-259.

140. Paz MA, Keith DA, Traverso HP, Gallop PM. Isolation, purification, and cross-linking profiles of elastin from lung and aorta. Biochemistry 1976;15:4912-4918.

141. Ritz-Timme S, Laumeier I, Collins MJ. Aspartic acid racemization: evidence for marked longevity of elastin in human skin. Br J Dermatol 2003;149:951-959.

142. Daamen WF, Hafmans T, Veerkamp JH, Van Kuppevelt TH. Comparison of five procedures for the purification of insoluble elastin. Biomaterials 2001;22:1997-2005.

143. Daamen WF, Van Moerkerk HThB, Hafmans T, Buttafoco L, Poot AA, Veerkamp JH, Van Kuppevelt TH. Preparation and evaluation of molecularly-defined collagen-elastin-glycosaminoglycan scaffolds for tissue engineering. Biomaterials 2003;24:4001-4009.

144. Uitto J. Elastic fibre abnormalities in skin disorders: what's new? J Eur Acad Dermatol Venereol 2001;15:303-304.

145. Hattori M, Takahashi K. Pepsin-solubilized elastin as a water/oil emulsifier. Food Hydrocolloids 1993;7:327-335.

146. Duca L, Floquet N, Alix AJ, Haye B, Debelle L. Elastin as a matrikine. Crit Rev Oncol Hematol 2004;49:235-244.

147. Leach JB, Wolinsky JB, Stone PJ, Wong JY. Crosslinked $\alpha$-elastin biomaterials: towards a processable elastin mimetic scaffold. Acta Biomaterialia 2005;1:155-164.

148. Daamen WF, Nillesen STM, Wismans R, Reinhardt DP, Hafmans T, Veerkamp JH, Van Kuppevelt TH. A biomaterial composed of collagen and solubilised elastin enhances angiogenesis and elastic fibre formation without calcification. This thesis 2006; Chapter 6.

149. Rabaud M, Lefebvre F, Ducassou D. In vitro association of type III collagen with elastin and with its solubilized peptides. Biomaterials 1991;12:313-319.

150. Lefebvre F, Gorecki S, Bareille R, Amedee J, Bordenave L, Rabaud M. New artificial connective matrix-like structure made of elastin solubilized peptides and collagens: elaboration, biochemical and structural properties. Biomaterials 1992;13:28-33.

151. Lefebvre F, Pilet P, Bonzon N, Daculsi G, Rabaud M. New preparation and microstructure of the EndoPatch elastin-collagen containing glycosaminoglycans. Biomaterials 1996;17:1813-1818.

152. Rovira A, Amedee J, Bareille R, Rabaud M. Colonization of a calcium phosphate/elastin-solubilized peptide-collagen composite material by human osteoblasts. Biomaterials 1996;17:1535-1540.

153. Barbie C, Angibaud C, Darnis T, Lefebvre F, Rabaud M, Aprahamian M. Some factors affecting properties of elastin-fibrin biomaterial. Biomaterials 1989;10:445-448.

154. Bonzon N, Carrat X, Deminière C, Daculsi G, Lefebvre F, Rabaud M. New artificial connective matrix made of fibrin monomers, elastin peptides and type I + III collagens: structural study, biocompatibility and use as tympanic membranes in rabbit. Biomaterials 1995;16:881-885.

155. San-Galli F, Deminière C, Guérin J, Rabaud M. Use of a biodegradable elastin-fibrin material, Neuroplast, as a dural substitute. Biomaterials 1996;17:1081-1085.

156. Dutoya S, Verna A, Lefebvre F, Rabaud M. Elastin-derived protein coating onto poly(ethylene terphtalate). Technical, microstructural, and biological studies. Biomaterials 2000;21:1521-1529.

157. Urry DW, Pattanaik A, Xu J, Woods TC, McPherson DT, Parker TM. Elastic protein-based polymers in soft tissue augmentation and generation. J Biomater Sci Polymer Edn 1998;9:1015-1048.

158. McGrath KP, Tirrell DA, Kawai M, Mason TL, Fournier MJ. Chemical and biosynthetic approaches to the production of novel polypeptide materials. Biotechnol Prog 1990;6:188-192.

159. Bedell-Hogan D, Trackman P, Abrams W, Rosenbloom J, Kagan H. Oxidation, cross-linking, and insolubilization of recombinant tropoelastin by purified lysyl oxidase. J Biol Chem 1993;268:1034510350.

160. Woodhouse KA, Klement P, Chen V, Gorbet MB, Keeley FW, Stahl R, Fromstein JD, Bellingham CM. Investigation of recombinant human elastin polypeptides as non-thrombogenic coatings. Biomaterials 2004;25:4543-4553.

161. Urry DW. Physical Chemistry of Biological Free Energy Transduction As Demonstrated by Elastic Protein-Based Polymers. J Phys Chem B 1997;101:11007-11028. 
162. Lee J, Macosko CW, Urry DW. Mechanical properties of cross-linked synthetic elastomeric polypentapeptides. Macromolecules 2000;34:5968-5974.

163. Wood SA, Lemons JE, Prasad KU, Urry DW. In vitro calcification and in vivo biocompatibility of the cross-linked polypentapeptide of elastin. J Biomed Mater Res 1986;20:315-335.

164. Alkalay RN, Kim DH, Urry DW, Xu J, Parker TM, Glazer PA. Prevention of postlaminectomy epidural fibrosis using bioelastic materials. Spine 2003;28:1659-1665.

165. Urry DW. Elastic molecular machines in metabolism and soft-tissue restoration. Trends Biotechnol 1999;17:249-257.

166. Huang L, McMillan RA, Apkarian RP, Pourdeyhimi B, Conticello VP, Chaikof EL. Generation of Synthetic Elastin-Mimetic Small Diameter Fibers and Fiber Networks. Macromolecules 2000;33:2989-2997.

167. McMillan RA, Conticello VP. Synthesis and characterisation of elastin-mimetic protein gels gerived from a well-defined polypeptide precursor. Macromolecules 2000;33:4809-4821.

168. Nagapudi K, Brinkman WT, Leisen JE, Huang L, McMillan RA, Apkarian RP, Conticello VP, Chaikof EL. Photomediated solid-state cross-linking of an elastin-mimetic recombinant protein polymer. Macromolecules 2002;35:1730-1737.

169. Martino M, Perri T, Tamburro AM. Biopolymers and biomaterials based on elastomeric proteins. Macromol Biosci 2002;2:319-328.

170. Wright ER, Conticello VP. Self-assembly of block copolymers derived from elastin-mimetic polypeptide sequences. Adv Drug Deliv Rev 2002;54:1057-1073.

171. Massia SP, Hubbell JA. Vascular endothelial cell adhesion and spreading promoted by the peptide REDV of the IIICS region of plasma fibronectin is mediated by integrin alpha 4 beta 1 . J Biol Chem 1992;267:14019-14026.

172. Heilshorn SC, DiZio KA, Welsh ER, Tirrell DA. Endothelial cell adhesion to the fibronectin CS5 domain in artificial extracellular matrix proteins. Biomaterials 2003;24:4245-4252.

173. Zio KD, Tirrell DA. Mechanical properties of artificial protein matrices engineered for control of cell and tissue behaviour. Macromolecules 2003;36:1553-1558.

174. Nowatzki PJ, Tirrell DA. Physical properties of artificial extracellular matrix protein films prepared by isocyanate crosslinking. Biomaterials 2004;25:1261-1267.

175. Scheller J, Guhrs KH, Grosse F, Conrad U. Production of spider silk proteins in tobacco and potato. Nat Biotechnol 2001;19:573-577.

176. Nagarsekar A, Crissman J, Crissman M, Ferrari F, Cappello J, Ghandehari H. Genetic engineering of stimuli-sensitive silkelastin-like protein block copolymers. Biomacromolecules 2003;4:602-607.

177. Cappello J, Crissman JW, Crissman M, Ferrari FA, Textor G, Wallis O, Whitledge JR, Zhou X, Burman D, Aukerman L, Stedronsky ER. In-situ self-assembling protein polymer gel systems for administration, delivery, and release of drugs. J Control Release 1998;53:105-117.

178. Megeed Z, Haider M, Li D, O’Malley BW, Jr., Cappello J, Ghandehari H. In vitro and in vivo evaluation of recombinant silk-elastinlike hydrogels for cancer gene therapy. J Control Release 2004;94:433-445.

179. Haider M, Leung V, Ferrari F, Crissman J, Powell J, Cappello J, Ghandehari H. Molecular engineering of silk-elastinlike polymers for matrix-mediated gene delivery: biosynthesis and characterization. Mol Pharm 2005;2:139-150.

180. Megeed Z, Cappello J, Ghandehari H. Genetically engineered silk-elastinlike protein polymers for controlled drug delivery. Adv Drug Deliv Rev 2002;54:1075-1091.

181. Haider M, Megeed Z, Ghandehari H. Genetically engineered polymers: status and prospects for controlled release. J Control Release 2004;95:1-26.

182. McPherson DT, Xu J, Urry DW. Product purification by reversible phase transition following Escherichia coli expression of genes encoding up to 251 repeats of the elastomeric pentapeptide GVGVP. Protein Expr Purif 1996;7:51-57.

183. Meyer DE, Chilkoti A. Purification of recombinant proteins by fusion with thermally-responsive polypeptides. Nat Biotechnol 1999;17:1112-1115.

184. Meyer DE, Kong GA, Dewhirst MW, Zalutsky MR, Chilkoti A. Targeting a genetically engineered elastin-like polypeptide to solid tumors by local hyperthermia. Cancer Res 2001;61:1548-1554.

185. Raucher D, Chilkoti A. Enhanced uptake of a thermally responsive polypeptide by tumor cells in response to its hyperthermia-mediated phase transition. Cancer Res 2001;61:7163-7170.

186. Hashimoto T, Suzuki Y, Tanihara M, Kakimaru Y, Suzuki K. Development of alginate wound dressings linked with hybrid peptides derived from laminin and elastin. Biomaterials 2004;25:14071414.

187. Lamme EN, van Leeuwen RT, Jonker A, van Marle J, Middelkoop E. Living skin substitutes: survival and function of fibroblasts seeded in a dermal substitute in experimental wounds. $\mathrm{J}$ Invest Dermatol 1998;111:989-995.

188. Boland ED, Matthews JA, Pawlowski KJ, Simpson DG, Wnek GE, Bowlin GL. Electrospinning 
collagen and elastin: preliminary vascular tissue engineering. Front Biosci 2004;9:1422-1432.

189. Neuenschwander S, Hoerstrup SP. Heart valve tissue engineering. Transpl Immunol 2004;12:359365.

190. Xu JW, Johnson TS, Motarjem PM, Peretti GM, Randolph MA, Yaremchuk MJ. Tissue-engineered flexible ear-shaped cartilage. Plast Reconstr Surg 2005;115:1633-1641.

191. Casasco M, Casasco A, Icaro CA, Farina A, Calligaro A. Differential distribution of elastic tissue in human natural skin and tissue-engineered skin. J Mol Histol 2004;35:421-428.

192. Jones I, Currie L, Martin R. A guide to biological skin substitutes. Br J Plast Surg 2002;55:185193.

193. Ruszczak Z. Effect of collagen matrices on dermal wound healing. Adv Drug Deliv Rev 2003;55:1595-1611.

194. Hafemann B, Ensslen S, Erdmann C, Niedballa R, Zuhlke A, Ghofrani K, Kirkpatrick CJ. Use of a collagen/elastin-membrane for the tissue engineering of dermis. Burns 1999;25:373-384.

195. De Vries HJ, Zeegelaar JE, Middelkoop E, Gijsbers G, van Marle J, Wildevuur CH, Westerhof W. Reduced wound contraction and scar formation in punch biopsy wounds. Native collagen dermal substitutes. A clinical study. Br J Dermatol 1995;132:690-697.

196. Hinek A, Wang Y, Liu K, Mitts TF, Jimenez F. Proteolytic digest derived from bovine Ligamentum Nuchae stimulates deposition of new elastin-enriched matrix in cultures and transplants of human dermal fibroblasts. J Dermatol Sci 2005.

197. Hafemann B, Ghofrani K, Gattner HG, Stieve H, Pallua N. Cross-linking by 1-ethyl-3- (3dimethylaminopropyl)-carbodiimide (EDC) of a collagen/elastin membrane meant to be used as a dermal substitute: effects on physical, biochemical and biological features in vitro. J Mater Sci Mater Med 2001;12:437-446.

198. Klein B, Schiffer R, Hafemann B, Klosterhalfen B, Zwadlo-Klarwasser G. Inflammatory response to a porcine membrane composed of fibrous collagen and elastin as dermal substitute. J Mater Sci Mater Med 2001;12:419-424.

199. Lamme EN, De Vries HJ, Van Veen H, Gabbiani G, Westerhof W, Middelkoop E. Extracellular matrix characterization during healing of full-thickness wounds treated with a collagen/elastin dermal substitute shows improved skin regeneration in pigs. J Histochem Cytochem 1996;44:13111322.

200. van Zuijlen PP, van Trier AJ, Vloemans JF, Groenevelt F, Kreis RW, Middelkoop E. Graft survival and effectiveness of dermal substitution in burns and reconstructive surgery in a one-stage grafting model. Plast Reconstr Surg 2000;106:615-623.

201. van Zuijlen PP, Vloemans JF, van Trier AJ, Suijker MH, van Unen E, Groenevelt F, Kreis RW, Middelkoop E. Dermal substitution in acute burns and reconstructive surgery: a subjective and objective long-term follow-up. Plast Reconstr Surg 2001;108:1938-1946.

202. van Zuijlen PP, Lamme EN, van Galen MJ, van Marle J, Kreis RW, Middelkoop E. Long-term results of a clinical trial on dermal substitution. A light microscopy and Fourier analysis based evaluation. Burns 2002;28:151-160.

203. Mitchell SL, Niklason LE. Requirements for growing tissue-engineered vascular grafts. Cardiovasc Pathol 2003;12:59-64.

204. L'Heureux N, Paquet S, Labbe R, Germain L, Auger FA. A completely biological tissue-engineered human blood vessel. FASEB J 1999;12:47-56.

205. Liu SQ, Tieche C, Alkema PK. Neointima formation on vascular elastic laminae and collagen matrices scaffolds implanted in the rat aortae. Biomaterials 2004;25:1869-1882.

206. Lu Q, Ganesan K, Simionescu DT, Vyavahare NR. Novel porous aortic elastin and collagen scaffolds for tissue engineering. Biomaterials 2004;25:5227-5237.

207. Buijtenhuijs P, Buttafoco L, Poot AA, Daamen WF, Van Kuppevelt TH, Dijkstra PJ, de Vos RA, Sterk LM, Geelkerken BR, Feijen J, Vermes I. Tissue engineering of blood vessels: characterization of smooth-muscle cells for culturing on collagen-and-elastin-based scaffolds. Biotechnol Appl Biochem 2004;39:141-149.

208. Buttafoco L, Engbers-Buijtenhuijs P, Poot AA, Dijkstra PJ, Vermes I, Feijen J. Dynamic versus static smooth muscle cell culture in tubular collagen/elastin matrices for vascular tissue engineering. Biomaterials 2005; submitted.

209. Engbers-Buijtenhuijs P, Buttafoco L, Poot AA, Geelkerken RH, de Vos RAI, Sterk LMT, Feijen J, Vermes I. Biological characterisation of vascular grafts cultured in a bioreactor. Biomaterials 2005; submitted.

210. Huang L, Nagapudi K, Apkarian RP, Chaikof EL. Engineered collagen-PEO nanofibers and fabrics. J Biomater Sci Polym Ed 2001;12:979-993.

211. Matthews JA, Wnek GE, Simpson DG, Bowlin GL. Electrospinning of collagen nanofibers. Biomacromolecules 2002;3:232-238.

212. Van Wachem PB, Van Luyn MJ, Olde Damink LH, Dijkstra PJ, Feijen J, Nieuwenhuis P. 
Biocompatibility and tissue regenerating capacity of crosslinked dermal sheep collagen. J Biomed Mater Res 1994;28:353-363.

213. Buttafoco L, Kolkman NG, Poot AA, Dijkstra PJ, Vermes I, Feijen J. Electrospinning collagen and elastin for tissue engineering small diameter blood vessels. J Control Release 2005;101:322-324.

214. Zhang S. Emerging biological materials through molecular self-assembly. Biotechnol Adv 2002;20:321-339.

215. Whitesides GM, Mathias JP, Seto CT. Molecular self-assembly and nanochemistry: a chemical strategy for the synthesis of nanostructures. Science 1991;254:1312-1319.

216. Zhang S. Fabrication of novel biomaterials through molecular self-assembly. Nat Biotechnol 2003;21:1171-1178.

217. Wright ER, McMillan RA, Cooper A, Apkarian RP, Conticello VP. Thermoplastic elastomer hydrogels via self-assembly of an elastin-mimetic triblock polypeptide. Adv Funct Mater 2002;12:149-154.

218. Herrero-Vanrell R, Rincon AC, Alonso M, Reboto V, Molina-Martinez IT, Rodriguez-Cabello JC. Self-assembled particles of an elastin-like polymer as vehicles for controlled drug release. J Control Release 2005;102:113-122.

219. Reguera J, Fahmi A, Moriarty P, Girotti A, Rodriguez-Cabello JC. Nanopore formation by self-assembly of the model genetically engineered elastin-like polymer [(VPGVG)2(VPGEG)(VPGVG)2]15. J Am Chem Soc 2004;126:13212-13213.

220. Bellomo EG, Wyrsta MD, Pakstis L, Pochan DJ, Deming TJ. Stimuli-responsive polypeptide vesicles by conformation-specific assembly. Nat Mater 2004;3:244-248.

221. Daamen WF, Geutjes PJ, Nillesen STM, Van Moerkerk HThB, Wismans R, Hafmans T, Van den Heuvel LPWJ, Pistorius AMA, Veerkamp JH, Van Hest JCM, Van Kuppevelt TH. Preparation of (elastin) biovesicles. This thesis 2006; Chapter 7 . 


\section{Chapter}

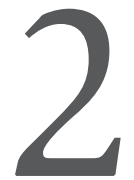

Comparison of five procedures for the isolation of insoluble elastin

Willeke Daamen,

Theo Hafmans,

Jacques Veerkamp,

Toin van Kuppevelt.

Biomaterials 2001;22:1997-2005. 


\begin{abstract}
Elastin is an insoluble, highly crosslinked protein providing elasticity to organs like lung, aorta and ligaments. Despite its remarkable mechanical properties, elastin has found little use as a biomaterial. Purification of elastin from elastic fibres presents a major challenge, among others for the intimate interwovenness of elastin and microfibrils. In this study, elastin was purified from equine ligamentum nuchae using five different procedures. One procedure was based on treatment with $0.1 \mathrm{M} \mathrm{NaOH}$, another on autoclaving and treatment with cyanogen bromide. Three other procedures were based on combinations of extraction steps and enzyme digestions. Purity of preparations was assessed by SDS-PAGE, amino acid analysis, and bright field, immunofluorescence and transmission electron microscopy. Only the procedure involving extractions/enzymes combined with an early application of 2-mercaptoethanol and cyanogen bromide gave a highly purified elastin preparation. Electron microscopic analysis showed that this preparation was devoid of microfibrillar components. This procedure is therefore the method of choice for preparation of insoluble elastin as a biomaterial for tissue engineering.
\end{abstract}




\section{INTRODUCTION}

Elastin is an important connective tissue protein that provides elasticity to organs, such as lung, aorta and ligaments. It is synthesised as a $\sim 72 \mathrm{kDa}$ soluble precursor (tropoelastin) that undergoes posttranslational modifications resulting in the formation of specific interchain crosslinks like (iso)desmosine and (dehydro)lysinonorleucine [1,2]. All but about 5 of the 34 Lys residues of tropoelastin participate in crosslinks, and this results in an insoluble polymer in which lysine-derived crosslinks occur approximately every 65-70 residues [3]. The elastic fibre is basically composed of two entities: amorphous elastin and microfibrils. During formation of the elastic fibre, the microfibrillar components act as a scaffold on which elastin is deposited. These components exist, among others, out of fibrillin, lysyl oxidase and microfibrilassociated glycoproteins (MAGPs) [1,4]. Despite its remarkable mechanical properties, elastin has found little use as a biomaterial [5-7]. A key issue in the use of proteins as a biomaterial is purity. Contamination with (globular) proteins irrevocably leads to immunological responses and precludes application as a biomaterial. Purification has always been a problem in the use of elastin $[8,9]$ and elastin preparations have a strong tendency to calcify $[10,11]$. Contaminations within the preparation, like calciumbinding microfibrillar components, may very well be of importance in this respect. Here, we compare five purification procedures for elastin from equine ligamentum nuchae, using various methods to analyse the purity of the end product, including transmission electron microscopy which to our knowledge has never been used before for this aim.

\section{MATERIALS \& METHODS}

\section{Materials}

Equine ligamentum nuchae was used as a source for insoluble elastin. Commercial bovine elastin products were used as a standard (E60, E61 and E70, Elastin Products Company, Owensville, MO, USA). Elastin E61 was purified using a method similar to procedure 1 (Fig. 1). Unless stated otherwise, this preparation was used in comparative studies. Collagenase I from Clostridium histolyticum (C-0130) and trypsin (T-8253) were purchased from Sigma (St Louis, MO, USA). Dithiobis(2-nitrobenzoic acid) (DTNB) was from Pierce (Rockford, IL, USA).

\section{Isolation of elastin}

Elastin was isolated from equine ligamentum nuchae using five different procedures (Fig. 1). In all cases ligamentum nuchae was freed from adhering non-elastinous material, cut into pieces of about $1 \mathrm{~cm}^{3}$ (working on ice), and minced to a fine powder under liquid nitrogen conditions. All following steps were performed at $22^{\circ} \mathrm{C}$, unless stated otherwise. 


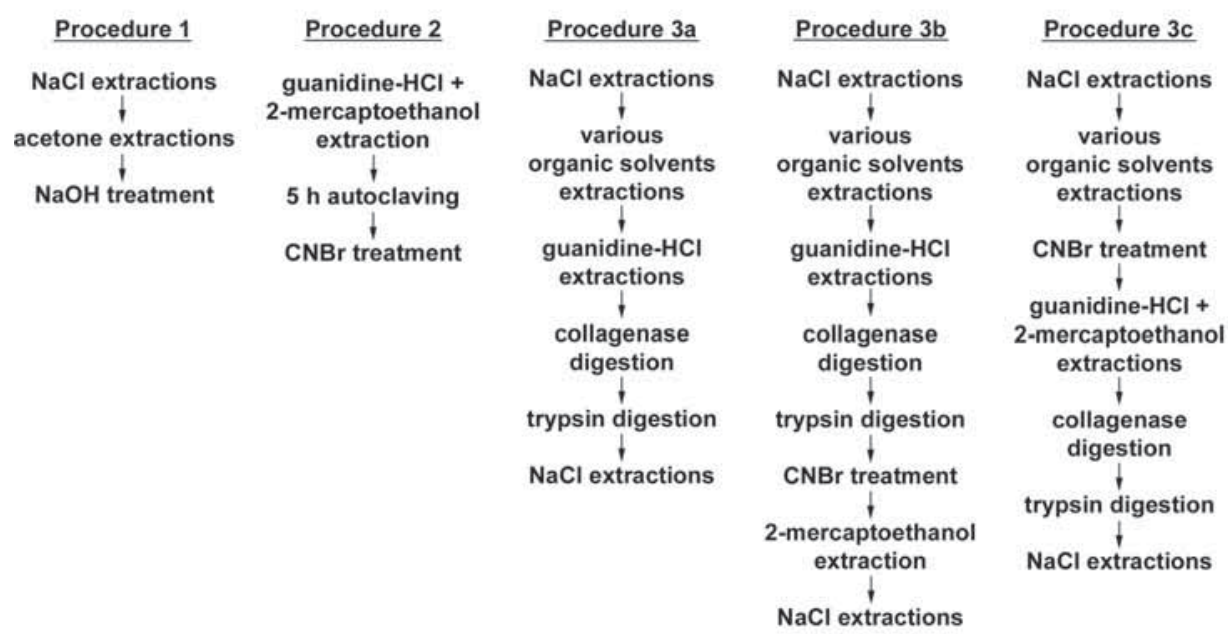

Figure 1. Outline of the five procedures used to isolate elastin from equine ligamentum nuchae.

Procedure 1 adapted from Lansing et al. [12]: This procedure makes use of three $24 \mathrm{~h}$ extractions with $10 \mathrm{vol}$. (10 ml/g) $1 \mathrm{M} \mathrm{NaCl}$ at $4^{\circ} \mathrm{C}$. After each extraction step insoluble material was recovered by centrifugation at $13000 \mathrm{~g}$ at $4{ }^{\circ} \mathrm{C}$ for $20 \mathrm{~min}$. After the last extraction step, the pellet was washed with water and defatted with 30 vol. acetone ( $3 \mathrm{x} 1 \mathrm{~h}$ ). The material was dried in a desiccator, subsequently suspended in $30 \mathrm{vol}$. 0.1 $\mathrm{M} \mathrm{NaOH}$, and heated at $95^{\circ} \mathrm{C}$ for $45 \mathrm{~min}$. The suspension was cooled, washed with water, and lyophilised.

Procedure 2 adapted from Rasmussen et al. [13]: In this procedure the minced tissue was extracted with 10 vol. $5 \mathrm{M}$ guanidine- $\mathrm{HCl}$ containing $1 \%$ (w/v) 2-mercaptoethanol (pH 7) for 24 h. The mixture was then diluted to the 4-fold volume with water and centrifuged at $13000 \mathrm{~g}$ for $20 \mathrm{~min}$. The pellet was suspended in 20 vol. water and autoclaved for $5 \mathrm{~h}$ at $120^{\circ} \mathrm{C}$. The mixture was filtered while still hot, washed with boiling water (3x 20 vol.) and dried in a desiccator. The dried product was suspended in $40 \mathrm{vol} .97 \%$ formic acid to which $1 \%(\mathrm{w} / \mathrm{v})$ cyanogen bromide was added, and incubated for $24 \mathrm{~h}$. The mixture was then diluted to the 4-fold volume with water, filtered, washed with water until pH 6 was reached, and lyophilised.

Procedure $3 a$ adapted from John and Thomas [14]: This procedure consists of different extraction steps and digestions with enzymes. The tissue was extracted three times overnight with 10 vol. $1 \mathrm{M} \mathrm{NaCl}$ containing $0.02 \%(\mathrm{w} / \mathrm{v}) \mathrm{NaN}_{3}$ at $4^{\circ} \mathrm{C}$. After each extraction step, insoluble material was recovered by centrifugation at $13000 \mathrm{~g}$ at $4^{\circ} \mathrm{C}$ for $20 \mathrm{~min}$. After the last extraction step the material was washed with water and resuspended in $10 \mathrm{vol}$. ethanol for $90 \mathrm{~min}$ and then filtered through a paper funnel. This procedure was repeated with 10 vol. chloroform/methanol (2:1) for 90 min, 10 vol. acetone for $30 \mathrm{~min}$, and $10 \mathrm{vol}$. ether for $30 \mathrm{~min}$. The insoluble material was 
dried in a desiccator. The dried powder was extracted three times with 10 vol. $5 \mathrm{M}$ guanidine- $\mathrm{HCl}$ containing $0.02 \%(\mathrm{w} / \mathrm{v}) \mathrm{NaN}_{3}(\mathrm{pH}$ ) for $24 \mathrm{~h}$. After the last extraction step the material was washed with water and incubated for $48 \mathrm{~h}$ at $37^{\circ} \mathrm{C}$ with $1000 \mathrm{U}$ collagenase/g substrate in 10 vol. $0.2 \mathrm{M}$ Tris- $\mathrm{HCl}$ (pH 7.4) containing $0.05 \mathrm{M} \mathrm{CaCl}_{2}$ and $0.02 \% \mathrm{NaN}_{3}$; after $24 \mathrm{~h}$ another $250 \mathrm{U}$ collagenase/g were added. The enzyme was inactivated by the addition of EDTA (final concentration $25 \mathrm{mM}$ ) and the preparation was washed with water. Then the pellet was resuspended in 10 vol. $0.1 \mathrm{M} \mathrm{NH}_{4} \mathrm{HCO}_{3}$ ( $\mathrm{pH} 8.2$ ) containing $0.02 \%(\mathrm{w} / \mathrm{v}) \mathrm{NaN}_{3}$ and $10,000 \mathrm{U}$ trypsin/g for $4 \mathrm{~h}$ at $37^{\circ} \mathrm{C}$. The reaction was stopped by phenylmethylsulphonylfluoride (PMSF, final concentration $1.86 \mathrm{mM}$ ). The pellet was washed with water, followed by three overnight extractions with 10 vol. $1 \mathrm{M} \mathrm{NaCl}$ containing $0.02 \%$ (w/v) $\mathrm{NaN}_{3}$, and washed again with water. The end product was lyophilised.

Procedure $3 \boldsymbol{b}$ modified from procedure $3 \boldsymbol{a}$ : This procedure resembles procedure 3a, but contains three modifications. First, aiming at removing more non-elastinous material, an extra $500 \mathrm{U}$ collagenase/g substrate was added after $24 \mathrm{~h}$, instead of 250 $\mathrm{U} / \mathrm{g}$. Second, after washing out the trypsin and PMSF, the pellet was incubated in 5 vol. $97 \%$ formic acid, and cyanogen bromide added to a final concentration of $1 \%$ for $24 \mathrm{~h}$. The mixture was then diluted to the 4-fold volume with water, filtered and washed with water until pH 6 was reached. After this step, an overnight treatment with $1 \mathrm{M}$ 2-mercaptoethanol in $0.5 \mathrm{M}$ Tris- $\mathrm{HCl}$ ( $\mathrm{pH}$ 6.8) containing $0.02 \%$ (w/v) $\mathrm{NaN}_{3}$ was performed. The preparation was washed, and the $\mathrm{NaCl}$ extractions were carried out as described above.

Procedure $3 \boldsymbol{c}$ modified from procedure $3 \boldsymbol{b}$ : This purification contains the same steps as procedure $3 \mathrm{~b}$, but in a different order. After three extractions with $1 \mathrm{M} \mathrm{NaCl}$ and the various organic solvents extractions, the cyanogen bromide step was carried out in 30 vol. formic acid. After washing, the pellet was extracted three times for $24 \mathrm{~h}$ with $5 \mathrm{M}$ guanidine- $\mathrm{HCl}$ and $1 \mathrm{M}$ 2-mercaptoethanol in $0.5 \mathrm{M}$ Tris- $\mathrm{HCl}$ containing $0.02 \%(\mathrm{w} / \mathrm{v}$ ) $\mathrm{NaN}_{3}$ (pH 6.8). After washing with water, the collagenase and trypsin digestions were carried out. No enzyme inhibitors were used. The final step consisted of the three extractions with $1 \mathrm{M} \mathrm{NaCl}$ and washings with water. The final elastin preparation was stored at $-80^{\circ} \mathrm{C}$.

\section{Determination of elastin purity}

Sodium dodecyl sulphate polyacrylamide gel electrophoresis (SDS-PAGE): All elastin preparations were incubated for $10 \mathrm{~min}$ at $95^{\circ} \mathrm{C}$ under reducing conditions $(5 \%(\mathrm{~V})$ v) 2-mercaptoethanol) and analysed on a $10 \%(\mathrm{w} / \mathrm{v})$ gel. Contaminants and elastin degradation products will penetrate the gel and are visualised by silver staining using a $0.1 \%(w / v) \mathrm{AgNO}_{3}$ solution [15]. 
Amino acid analysis: Elastin samples were hydrolysed under vacuum with $6 \mathrm{M} \mathrm{HCl}$ for $22 \mathrm{~h}$ at $110^{\circ} \mathrm{C}$, dried under vacuum and dissolved in $10 \mathrm{mM} \mathrm{HCl}$. Hydrolysed samples were first deproteinised by addition of an $18.8 \%$ (w/v) 5-sulphosalicylic acid solution (Fluka Chemie AG, Buchs, Switzerland), and contained norleucine (Sigma) as an internal standard. Separation of the components was obtained by column ion exchange chromatography on a Biochrom 20 amino acid analyzer (Amersham Pharmacia Biotech, Uppsala, Sweden) using lithium buffers with increasing pH.

Sulfhydryl quantification: Sulfhydryl content was measured using DTNB as a reagent at $\mathrm{pH}$ 8. This reagent reacts with sulfhydryl groups in solution, and yields a yellow colour that is measured spectrophotometrically at $412 \mathrm{~nm}$. The sulfhydryl content of the samples was calculated by comparison of a standard curve with L-cysteine [16].

Light microscopy: Purified elastin powders were embedded in $1.5 \%(\mathrm{w} / \mathrm{v})$ agarose, fixed in $4 \%$ formaldehyde in phosphate buffered saline (PBS pH 7,2), and embedded in paraffin. The starting material (ligamentum nuchae) was fixed in formaldehyde, and embedded. Sections of $5 \mu \mathrm{m}$ were mounted onto organosilane-coated slides, dewaxed in xylol and hydrated through a graded series of ethanol. Sections were stained for elastin, collagen, and nuclei according to resorcin fuchsin - Van Gieson [17] and Verhoeff - Van Gieson [18].

Immunofluorescence analysis (IFA): Elastin preparations were suspended in water and frozen in liquid nitrogen. Ligamentum nuchae was frozen directly in liquid nitrogen. Cryosections of $5 \mu \mathrm{m}$ were mounted onto organosilane coated glass slides. After blocking with $1 \%(\mathrm{w} / \mathrm{v}$ ) bovine serum albumin (BSA) in PBS (pH 7.2), sections were incubated overnight with rabbit anti-bovine type I collagen (1:50, Chemicon, Temecula, CA, USA), goat anti-bovine type IV collagen (1:50, Southern Biotechnology Associates, Birmingham, AC, USA), mouse anti-bovine fibrillin IgG (1:50, Chemicon), mouse anti-bovine fibrillin 1 IgG (1:50, Neomarkers, Fremont, CA, USA), or mouse anti-bovine elastin clone BA-4 IgG (1:500, Sigma) and washed with PBS. Subsequently, sections were incubated for $90 \mathrm{~min}$ with Alexa 488-labeled secondary antibodies (Molecular Probes, Eugene, OR, USA) diluted 1:100 in PBS containing 1\% (w/v) BSA. Sections were washed and mounted in mowiol.

Transmission electron microscopy (TEM): Elastin preparations were embedded in $1.5 \%(\mathrm{w} / \mathrm{v})$ agarose, fixed in $2 \%$ glutaraldehyde in $0.1 \mathrm{M}$ phosphate buffer $(\mathrm{pH} 7.4)$ for $12 \mathrm{~h}$ at $4^{\circ} \mathrm{C}$, and postfixed with $1 \%(\mathrm{w} / \mathrm{v}$ ) osmium tetroxide in $0.1 \mathrm{M}$ phosphate buffer ( $\mathrm{pH}$ 7.4). After a rinsing period of $3 \mathrm{~h}$ the samples were dehydrated in an ascending series of ethanols and embedded in Epon 812. Toluidine-blue stained semithin sections $(1 \mu \mathrm{m})$ were cut on a Reichert Ultracut E microtome to select appropriate areas. Ultrathin sections $(60 \mathrm{~nm})$ were picked up on formvar-coated grids, stained with uranyl acetate and lead citrate, and examined in a Philips 301 electron microscope. 


\section{RESULTS}

All procedures were applied at least in duplicate and gave a similar yield (21, 19, 23, 20 , and $20 \%$ on base of dry weight per dry tissue weight for procedures $1,2,3 \mathrm{a}, 3 \mathrm{~b}$, and $3 \mathrm{c}$, respectively).

\section{SDS-PAGE}

SDS-PAGE of the elastin preparations purified by the different procedures indicated no major contaminations with soluble proteins, except for the starting material, and the commercial elastin (Fig. 2). Using BSA as a reference, it was estimated that the contamination was less than $0.02 \%$. Contaminations in the commercial elastin consisted mainly of high molecular mass impurities ( $>70 \mathrm{kDa}$ ).

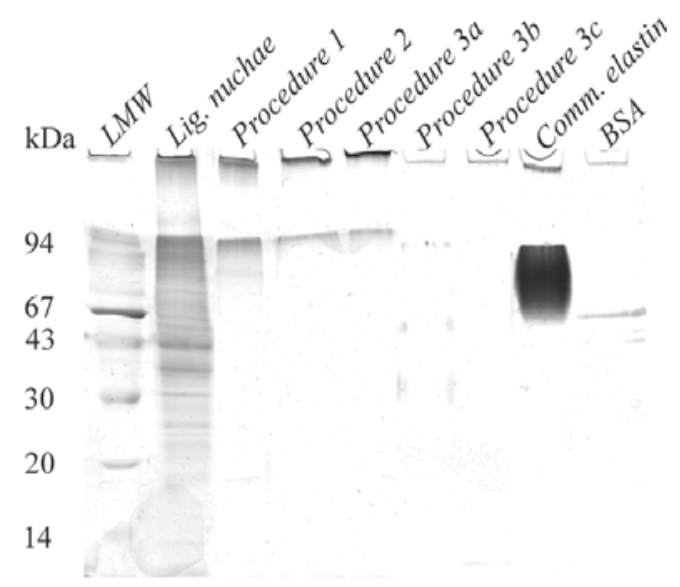

Figure 2. SDS-PAGE of ligamentum nuchae (100 $\mu \mathrm{g})$, elastin preparations purified by different procedures (500 $\mathrm{gg}$ ), commercial elastin (500 $\mu \mathrm{g})$, and BSA (100 ng). Amounts represent dry weights put on gel. Note that only soluble contaminants and/or elastin breakdown products will enter the gel, but not insoluble elastin, which represents the vast majority of the preparations.

\section{Amino acid analysis}

Amino acid analysis showed that all purification procedures removed Met, which does not occur in elastin (Table 1). Hydroxylysine (Hyl), which is characteristic for collagen, and absent in elastin, was removed with procedures 2 and 3, but not by procedure 1 . The commercial elastin preparation also contained some Hyl. Hydroxyproline (Hyp), which is present in both elastin and collagen, could still be detected. Furthermore, a high percentage of Gly, Ala, Val and Pro was present, typical for elastin. Desmosine (Des) and isodesmosine (Ide) contents were comparable to literature values $[8,9,14]$.

\section{Sulfhydryl quantification}

Microfibrils, an intrinsic component of elastic fibres, consist mainly of fibrillin. This protein contains approximately 14\% Cys residues, of which two-third form S-S bridges and one-third have free sulfhydryl groups [19]. Tropoelastin contains only two Cys residues at the C-terminus of the protein, which form an intramolecular disulfide bond [20]. 
Table 1. Amino acid composition of equine ligamentum nuchae (starting material), elastin purified by five different methods, and commercial elastin.

\begin{tabular}{|c|c|c|c|c|c|c|c|c|}
\hline & Lig. nuchae & Method 1 & Method 2 & Method 3a & Method 3b & Method $3 c$ & Comm. Elastin & Theory \\
\hline Ala & $186 \pm 10$ & $221 \pm 16$ & $222 \pm 6$ & $227 \pm 12$ & $228 \pm 3$ & $221 \pm 9$ & $212 \pm 4$ & 214 \\
\hline Arg & $21 \pm 1$ & $9 \pm 1$ & $8 \pm 1$ & $8 \pm 1$ & $8 \pm 1$ & $6 \pm 1$ & $6 \pm 0$ & 13 \\
\hline As $x$ & $21 \pm 1$ & $6 \pm 0$ & $6 \pm 0$ & $5 \pm 1$ & $5 \pm 1$ & $5 \pm 0$ & $8 \pm 0$ & 4 \\
\hline Cys & $7 \pm 1$ & $2 \pm 0$ & $3 \pm 0$ & $2 \pm 0$ & $3 \pm 1$ & $3 \pm 0$ & $1 \pm 1$ & 3 \\
\hline Glx & $39 \pm 2$ & $20 \pm 1$ & $20 \pm 1$ & $19 \pm 1$ & $18 \pm 1$ & $19 \pm 1$ & $20 \pm 1$ & 20 \\
\hline Gly & $207 \pm 12$ & $236 \pm 22$ & $235 \pm 8$ & $244 \pm 16$ & $244 \pm 3$ & $235 \pm 11$ & $242 \pm 5$ & 291 \\
\hline His & $2 \pm 0$ & $0 \pm 1$ & $0 \pm 1$ & $0 \pm 0$ & $0 \pm 0$ & $0 \pm 0$ & $0 \pm 0$ & 1 \\
\hline Hyl & $1 \pm 1$ & $1 \pm 1$ & $0 \pm 0$ & $0 \pm 1$ & $0 \pm 1$ & $0 \pm 0$ & $1 \pm 1$ & \\
\hline Hyp & $28 \pm 5$ & $9 \pm 4$ & $7 \pm 1$ & $6 \pm 1$ & $6 \pm 1$ & $7 \pm 2$ & $15 \pm 1$ & \\
\hline \|le & $22 \pm 1$ & $20 \pm 2$ & $21 \pm 1$ & $20 \pm 1$ & $20 \pm 1$ & $20 \pm 1$ & $32 \pm 1$ & 21 \\
\hline Leu & $69 \pm 3$ & $72 \pm 7$ & $72 \pm 2$ & $70 \pm 5$ & $69 \pm 1$ & $72 \pm 3$ & $80 \pm 1$ & 59 \\
\hline Lys & $13 \pm 1$ & $3 \pm 1$ & $3 \pm 0$ & $3 \pm 0$ & $4 \pm 2$ & $7 \pm 1$ & $3 \pm 0$ & 46 \\
\hline Met & $2 \pm 2$ & $0 \pm 0$ & $0 \pm 0$ & $0 \pm 0$ & $0 \pm 0$ & $0 \pm 0$ & $0 \pm 0$ & 0 \\
\hline Phe & $33 \pm 1$ & $36 \pm 4$ & $35 \pm 1$ & $34 \pm 2$ & $34 \pm 1$ & $35 \pm 2$ & $39 \pm 1$ & 21 \\
\hline Pro & $140 \pm 4$ & $145 \pm 11$ & $145 \pm 3$ & $144 \pm 6$ & $143 \pm 1$ & $147 \pm 4$ & $139 \pm 2$ & 126 \\
\hline Ser & $20 \pm 1$ & $10 \pm 1$ & $10 \pm 1$ & $10 \pm 1$ & $9 \pm 1$ & $8 \pm 1$ & $9 \pm 0$ & 18 \\
\hline Thr & $19 \pm 1$ & $13 \pm 1$ & $15 \pm 1$ & $15 \pm 1$ & $15 \pm 1$ & $15 \pm 1$ & $9 \pm 1$ & 14 \\
\hline Tyr & $22 \pm 1$ & $25 \pm 3$ & $24 \pm 1$ & $24 \pm 1$ & $24 \pm 1$ & $25 \pm 1$ & $11 \pm 1$ & 20 \\
\hline Val & $146 \pm 3$ & $172 \pm 11$ & $173 \pm 4$ & $170 \pm 7$ & $168 \pm 2$ & $174 \pm 6$ & $172 \pm 2$ & 128 \\
\hline Des & $0.3 \pm 0.2$ & $0.6 \pm 0.1$ & $0.6 \pm 0.0$ & $0.5 \pm 0.0$ & $0.5 \pm 0.0$ & $0.5 \pm 0.0$ & $0.7 \pm 0.0$ & \\
\hline Ide & $0.4 \pm 0.0$ & $0.5 \pm 0.1$ & $0.5 \pm 0.0$ & $0.5 \pm 0.0$ & $0.5 \pm 0.0$ & $0.5 \pm 0.0$ & $0.5 \pm 0.0$ & \\
\hline
\end{tabular}

* The amino acid composition of human elastin was theoretically calculated from the cDNA of tropoelastin. Posttranslational modifications are therefore not taken into account and consequently the values for Lys, Pro, Cys, Des, and Ide are not correct [21].

Values are mean $(n=4 \pm S D)$, expressed per 1000 amino acid residues and not corrected for losses during hydrolysis.

Analysis of the sulfhydryl content therefore gives information on the purity of the elastin preparation. Elastin prepared by procedure $3 \mathrm{~b}$ contained a substantial amount of sulfhydryl groups ( $2.51 \mathrm{mg}$ Cys equivalents per g elastin preparation), while starting material, and elastins prepared by procedure 1 and the commercial elastin preparation only had a moderate content of sulfhydryl groups $(0.30,0.25$, and $0.12 \mathrm{mg} / \mathrm{g}$, respectively). The preparations obtained by procedures 2 , 3a and $3 \mathrm{c}$ contained minor amounts $(0.04,0.05$, and $0.07 \mathrm{mg} / \mathrm{g}$, respectively). Procedures $2,3 \mathrm{~b}$ and $3 \mathrm{c}$ contain a 2-mercaptoethanol step in the purification, which will lead to reduction of disulfide bonds (including the one found in elastin). Sulfhydryl groups in elastin prepared by autoclaving (procedure 2) may be oxidised thereafter. Residual 2-mercaptoethanol will react with DTNB in procedures $3 \mathrm{~b}$ and $3 \mathrm{c}$, and may add to the sulfhydryl content. Even after additional washings of the elastin preparation purified by procedure $3 \mathrm{~b}$, the content of sulfhydryl groups did not substantially decrease, in contrast to procedure 3c. Procedure $3 \mathrm{c}$ would therefore become the procedure of choice regarding this topic.

\section{Bright field microscopy}

Major components of ligamentum nuchae are elastin and collagen as was indicated by resorcin fuchsin-Van Gieson and Verhoeff-Van Gieson staining procedures. Purified elastin preparations stained well for elastin, and showed no collagen, or nuclei. It was not possible to distinguish between more and less pure elastin preparations using these two staining techniques. 

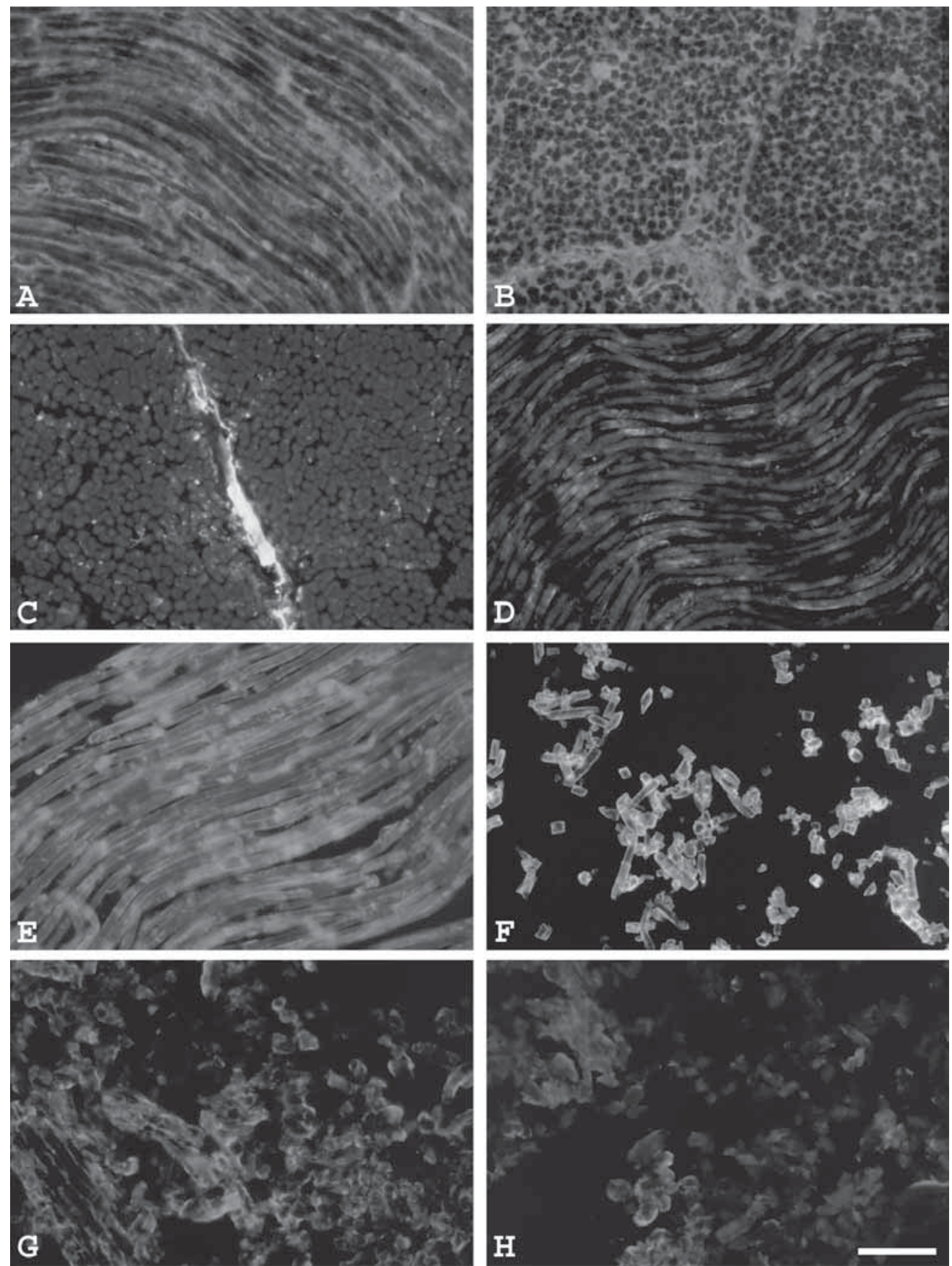

Figure 3. Immunostaining of ligamentum nuchae and elastin preparations for various components. (A-E) Ligamentum nuchae stained for type I collagen (A, B), type IV collagen (C), fibrillin (D), and elastin (E); $(F)$ elastin preparation purified by procedure $3 c$ stained for elastin; $(G-H)$ commercial preparation $E 60$ stained for type I collagen $(G)$, and fibrillin $(H)$. Bar indicates $50 \mu \mathrm{m}$. 


\section{Immunofluorescence microscopy}

Immunofluorescence microscopy was applied to detect molecules by specific antibodies. Next to elastin, type I collagen, type IV collagen (in blood vessels), and fibrillin (in microfibrils) are abundantly present in ligamentum nuchae (Fig. 3A-E). Type I collagen was found surrounding the elastic fibres. Type IV collagen was found in between the bundles of elastic fibres generally confined to blood vessels. Fibrillin was detected on both the inside and outside of the elastic fibre, closely associated to the fibre. After purification the intensity of elastin staining was increased (Fig. 3E, F), probably because of unmasking of elastin epitopes by removal of associated substances. In commercial preparation E60, type I collagen and fibrillin could still be detected (Fig. 3F, G). In all other elastin preparations immunostaining for the various components was absent. However, since epitopes may be destructed during purification, absence of staining does not prove the absence of a specific component in the preparation.

\section{Transmission electron microscopy}

TEM was used to identify impurities in the elastin preparations in detail (e.g. cell debris, collagen fibrils and microfibrils). Contaminations are visible as electron-dense material on the electron-translucent elastin. Representative results are shown in Fig. 4. Elastin preparations isolated by procedures $3 \mathrm{~b}$ and $3 \mathrm{c}$ were pure. Elastin purified by procedures 1,2, and 3a still contained non-elastinous material. According to the size and location of these contaminations, they probably represent (part of) the microfibrillar components of the elastic fibre.

\section{DISCUSSION}

In this study, elastin was purified from equine ligamentum nuchae using five different procedures, of which three consisted of consecutive extraction steps and enzyme digestions. One takes advantage of the fact that elastin is insoluble under many circumstances, like heating in $0.1 \mathrm{M} \mathrm{NaOH}$ at $95^{\circ} \mathrm{C}$, or autoclaving for $5 \mathrm{~h}$. Elastin may be affected by these procedures because of the high temperatures used. Three extraction procedures (3a, 3b, 3c) do not exceed ambient temperature levels, and are therefore preferred to gain a purified elastin preparation. These procedures use different extraction steps and enzyme digestions to remove contaminations. $\mathrm{NaCl}$ and guanidine- $\mathrm{HCl}$ will bring many proteins into solution, organic solvents will extract fats, collagenase and trypsin digestions will break down collagen and other proteins. Two procedures (3b, 3c) also use $\mathrm{CNBr}$ in formic acid, which will cleave proteins at Met residues (which are absent in elastin, but ubiquitous in for instance collagen), and 2mercaptoethanol, which will lead to reduction of disulfide bridges (rare in elastin, but abundantly present in for example fibrillin). 

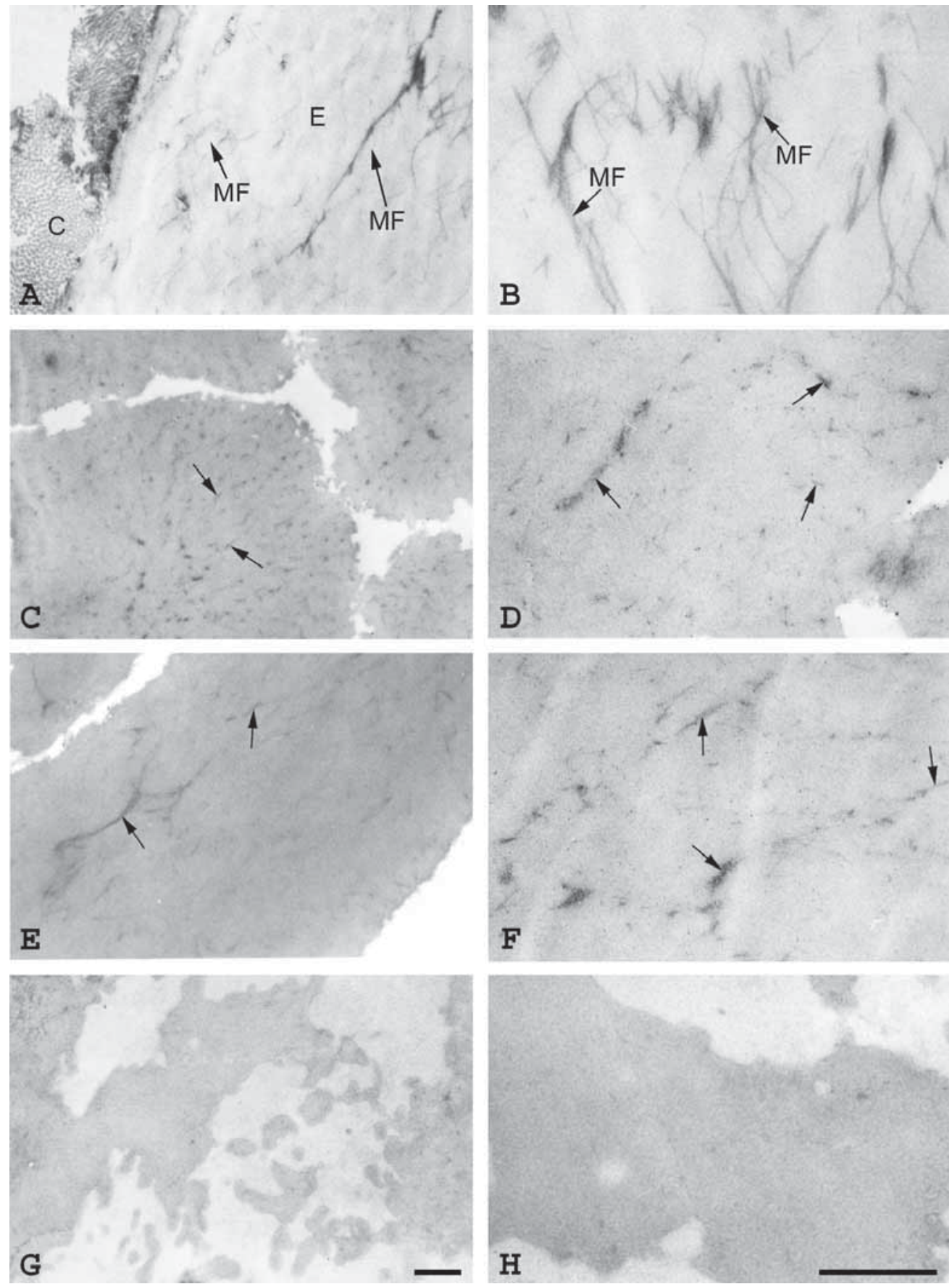

Figure 4. Transmission electron micrographs of ligamentum nuchae $(A, B)$, and elastin preparations purified by procedure $1(C, D)$, procedure $2(E, F)$, or procedure $3 c(G, H)$. E= elastin; $C=$ collagen fibrils; $M F=$ microfibrils, arrows = microfibrillar resembling structures. Bar indicates $0.5 \mu \mathrm{m}$. 
Table 2 gives a summary of the results of the purity assessment of the different elastin preparations and the commercial elastin. Soskel and Sandburg [8] analysed six methods for extracting elastin from hamster lungs. They used several criteria for elastin purity based on amino acid analysis, viz. low His ( $<5$ per 1000 amino acid residues), low Hyp (< 15 per 1000 amino acid residues), high Ala ( > 200 per 1000 amino acid residues), no Met and Hyl, high Val (> 75 per 1000 amino acid residues), and an Ile : Leu ratio of 0.6 . It is now known that this last criterion should be 0.36 instead of 0.6 [21]. Elastin purified by all but one of the procedures described, meet these criteria. Procedure 1 results in a preparation that still contains Hyl, as does the commercial elastin which also has an Ile/Leu ratio of 0.47 in stead of 0.36 . Since amino acid analysis is a rather insensitive method for the detection of impurities, we turned to other methods. SDS-PAGE, sulfhydryl analysis, light microscopy, and TEM were also used to assess purity. Using these methods, only procedure $3 \mathrm{c}$ was found satisfactory, especially with respect to remnants of microfibrils.

Elastin and elastic fibres have often been implied as the major site of calcification in aorta and heart valves, for both natural elastic fibres and biomaterials [11,22-24]. Elastic fibres do not only contain elastin, so calcification can be due to other components within the fibre. Calcification often occurs at the outside of the elastic fibre, where microfibrils are present [10,25]. There are some clues that components other than elastin are involved in the process of calcification. An increase of the calcium content is paralleled by an increase in the number of acidic amino acid residues (Glu and Asp) in elastic fibres [26]. The percentage of these residues is about $1 \%$ in elastin, but is $10 \%$ in fibrillin, the major microfibrillar component [21]. Some other microfibrilassociated proteins also have a large amount of acidic amino acid residues [27]. A similar association of calcification with an increase in the number of polar amino acid residues, abundantly present in microfibrils, has been suggested [26]. Fibrillin may be a candidate protein in the elastic fibre that causes calcification. It contains 47 EGFlike domains, of which 43 have a calcium-binding consensus sequence [28,29], and it actually binds calcium [30,31].

Our TEM results prove that elastin purified by traditional methods still contains nonelastinous material of microfibrillar nature. Elastin preparations have been used that were ill-defined and may have contained impurities. By using isolation procedures based on autoclaving, for instance, microfibrillar components are not completely removed. If impurities are of importance in the process of calcification, removal of them should lead to better elastin-based biomaterials. Using procedure $3 \mathrm{c}$, a highly pure elastin preparation was isolated.

Future experiments will be devoted to study whether calcification of insoluble elastin can be prevented by application of our highly purified preparations. If these studies are promising, elastin may become an important molecule, especially in biomaterials aimed at replacing organs in which elasticity is crucial, e.g. small diameter blood vessels. 
Table 2. Overview of purity of various elastin preparations according to six criteria.

\begin{tabular}{lcccccc}
\hline & Procedure 1 & Procedure 2 & Procedure 3a & Procedure 3b & Procedure 3c & Comm. elastin \\
\hline SDS PAGE & + & + & + & + & + & + \\
Amino acid analysis & - & + & + & + & + & + \\
Sulfhydryl content & \pm & + & + & + & + & + \\
Bright field microscopy: & & + & + & + & + & + \\
$\quad$-VVG & + & + & + & + & + & + \\
$\quad$ - RFVG & + & + & + & + & + & + \\
IFA for anti-elastin & - & - & + & + & + \\
TEM & & & + & + & + & + \\
\hline
\end{tabular}

SDS PAGE is + if no bands are seen on the gel. Amino acid analysis is + if His and Hyl are not detectable. Sulfhydryl content is - if $>0.5 \mathrm{mg}$ Cys equivalents/g elastin; \pm if $0.1<$ value $<0.5 ;+$ if $<0.1$. Bright field microscopy is + if no collagen can be detected. Immunofluorescence microscopy is + if elastin can be readily detected. TEM is + if no microfibrillar structures are present. VVG = Verhoeff - Van Gieson staining; RFVG $=$ resorcin fuchsin - Van Gieson staining; IFA = immune fluorescence assay. ${ }^{*}$ N.D. $=$ not done.

\section{REFERENCES}

1. Rosenbloom J, Abrams WR, Mecham RP. Extracellular matrix 4: The elastic fiber. FASEB J 1993;7:1208-1218.

2. Bisaccia F, Castiglione-Morelli MA, Spisani S, Ostuni A, Serafini-Fracassini A, Bavoso A, Tamburro AM. The amino acid sequence coded by the rarely expressed exon 26A of human elastin contains a stable beta-turn with chemotactic activity for monocytes. Biochemistry 1998;37:11128-11135.

3. Debelle L, Tamburro AM. Elastin: molecular description and function. Int J Biochem Cell Biol 1999;31:261-272.

4. Fauvel-Lafeve F. Microfibrils from the arterial subendothelium. Int Rev Cytol 1999;188:1-40.

5. Chalain T de, Phillips JH, Hinek A. Bioengineering of elastic cartilage with aggregated porcine and human auricular chondrocytes and hydrogels containing alginate, collagen, and $\kappa$-elastin. J Biomed Mater Res 1999;244:280-288.

6. Samouillan V, Dandurand-Lods J, Lamure A, Maurel E, Lacabanne C, Gerosa G, Venturini A, Casarotto D, Gherardini L, Spina M. Thermal analysis characterization of aortic tissues for cardiac valve bioprostheses. J Biomed Mater Res 1999;46:531-538.

7. Lamme EN, De Vries JC, Van Veen H, Gabbiani G, Westerhof W, Middelkoop E. Extracellular matrix characterization during healing of full-thickness wounds treated with a collagen/elastin dermal substitute shows improved skin regeneration in pigs. J Histochem Cytochem 1996;44:1311-1322.

8. Starcher BC, Galione MJ. Purification and comparison of elastins from different animal species. Anal Biochem 1976;74:4417-447.

9. Soskel NT, Sandburg LB. A comparison of six methods of extracting elastin residue from hamster lungs. Exp Lung Res 1983;4:109-119.

10. Paule WJ, Bernick S, Strates B, Nimni ME. Calcification of implanted vascular tissues associated with elastin in an experimental animal model. J Biomed Mater Res 1992;26:1169-1177.

11. Vyavahare N, Ogle M, Schoen FJ, Levy RJ. Elastin calcification and its prevention with aluminum chloride pretreatment. Am J Pathol 1999;155:973-982.

12. Lansing AI, Rosenthal TB, Alex M, Dempsey W. The structure and chemical characterization of elastic fibers as revealed by elastase and by electron microscopy. Anat Rec 1952;114:555-575.

13. Rasmussen BL, Bruenger E, Sandberg LB. A new method for purification of mature elastin. Anal Biochem 1975;64:255-259.

14. John R, Thomas J. Chemical compositions of elastins isolated from aortas and pulmonary tissues of humans of different ages. Biochem J 1972;127:261-269.

15. Laemmli UK. Cleavage of structural proteins during the assembly of the head of bacteriophage T4. Nature 1970;227:680-689.

16. Riddles PW, Blakeley RL, Zerner B. Reassessment of Ellman's reagent. Methods Enzymol 1983;91:4960 .

17. Vacca LL. Elastica. In: Vacca, editor. Laboratory manual of histochemistry. New York (USA): Raven Press, 1985. p. 297-302.

18. Bradbury P, Gordon KC. Connective tissues and stains. In: Bancroft and Stevens, editors. Theory and practice of histological techniques. Edinburgh (UK): Churchill Livingstone, 1990. p. 119-142. 
19. Sakai LY, Keene DR, Glanville RW, Bachinger HP. Purification and partial characterization of fibrillin, a cysteine-rich structural component of connective tissue microfibrils. J Biol Chem 1991;266:1476314770 .

20. Brown-Augsburger P, Broekelmann T, Rosenbloom J, Mecham RP. Functional domains on elastin and microfibril-associated glycoprotein involved in elastic fibre assembly. Biochem J 1996;318:149155 .

21. Ayad S, Boot-Handford RP, Humphries MJ, Kadler KE, Shuttleworth CA. The extracellular matrix facts book. London, GB. Academic Press, 1994.

22. Bobryshev YV, Lord RS, Warren BA. Calcified deposit formation in intimal thickenings of the human aorta. Atherosclerosis 1995;118:9-21.

23. Chanda J, Kuribayashi R, Abe T. Heparin coupling in inhibition of calcification of vascular bioprostheses. Biomaterials 1999;20:1753-1757.

24. Nimni ME, Myers D, Ertl D, Han B. Factors which affect the calcification of tissue-derived bioprostheses. J Biomed Mater Res 1997;35:531-537.

25. Chanda J, Kondoh K, Ijima K, Matsukawa M, Kuribayashi R. In vitro and in vivo calcification of vascular bioprostheses. Biomaterials 1998;19:1651-1656.

26. Atkinson J. Arterial calcification. Mechanisms, consequences and animal models. Pathol Biol (Paris) 1999;47:677-684.

27. Robinson PN, Godfrey M. The molecular genetics of Marfan syndrome and related microfibrillopathies. J Med Genet 2000;37:9-25.

28. Knott V, Downing AK, Cardy CM, Handford P. Calcium binding properties of an epidermal growth factor-like domain pair from human fibrillin-1. J Mol Biol 1996;255:22-27.

29. Ashworth JL, Murphy G, Rock MJ, Sherratt MJ, Shapiro SD, Shuttleworth CA, Kielty CM. Fibrillin degradation by matrix metalloproteinases: implications for connective tissue remodelling. Biochem J 1999;340:171-181.

30. Cardy CM, Handford PA. Metal ion dependency of microfibrils supports a rod-like conformation for fibrillin-1 calcium-binding epidermal growth factor-like domains. J Mol Biol 1998;276:855-860.

31. Reinhardt DP, Mechling DE, Boswell BA, Keene DR, Sakai LY, Bachinger HP. Calcium determines the shape of fibrillin. J Biol Chem 1997;272:7368-7373. 


\section{Chapter}

Isolation of intact elastin fibres devoid of microfibrils

Willeke Daamen,

Theo Hafmans,

Jacques Veerkamp,

Toin van Kuppevelt.

Tissue Engineering 2005;11:68-76. 


\begin{abstract}
Purification protocols for elastin generally result in greatly damaged elastin fibres and this likely influences the biological response. We here describe a novel protocol for the isolation of elastin where the fibres stay intact, and introduce the term 'elastin fibre' for intact elastic fibres with elastin as their sole component. As opposed to elastic fibres, elastin fibres do not contain any microfibrils or associated molecules. Elastin fibres were isolated from equine elastic ligaments according to various protocols and analysed by SDS-PAGE, amino acid quantification, immunofluorescence assay, transmission/ scanning electron microscopy, and cellular reactivity in vivo. The optimal protocol comprised several extraction steps and trypsin digestion. Elastin fibres were free of contaminants and had a smooth, regular appearance. The cellular response towards purified, intact elastin fibres was different in comparison to purified, but affected, fibres and to contaminated fibres. Intact fibres consisting of only elastin may be important for both fundamental and applied research, e.g. tissue engineering, which need welldefined preparations to study the cellular biological effect of individual components.
\end{abstract}




\section{INTRODUCTION}

Elastic fibres are widely distributed over the body, especially in organs where elasticity is a major issue, like lung and blood vessels [1]. Elastic fibres are composed of elastin and microfibrils. The latter is an intrinsic component of elastic fibres and is present on both the inside and the outside of elastic fibres. Microfibrils consist of and are associated with a variety of molecules including fibrillins, microfibril-associated (glyco)proteins, latent TGF $\beta$-binding proteins, fibulins, emilins, proteoglycans and lysyl oxidase [2]. Elastic fibres are crucial in tissue homeostasis, but are not readily replaced in case of damage $[3,4]$. This seriously hampers tissue regeneration, e.g. in case of skin injury, and could be due to difficulties in recapitulating the complex spatio temporal expression patterns of proteins like tropoelastin, lysyl oxidase and fibrillins [5-7].

Evidence exists that the biological behaviour of cells towards proteins organised in fibrillar form differs from that towards single proteins, e.g. in case of collagen where fibrillar and monomeric collagen give different responses [8]. This possibly also holds for elastin $[9,10]$. Elastin in fibrous form is not identical to its monomer, due to the formation of specific crosslinks like (iso)desmosines. Cell biological studies of the effect of elastin in its native conformation, i.e. as a fibre, have been hampered by a lack of efficient isolation methodology. Current methods, such as treatment with $0.1 \mathrm{M}$ $\mathrm{NaOH}$ at $95^{\circ} \mathrm{C}$ or autoclaving, are not able to adequately remove extracellular matrix components, such as collagen and microfibrillar components, and result in partial degradation of the elastic fibre [11,12]. It is therefore impossible to study the cellular effect of elastin fibres per se.

We have previously presented a purification protocol for insoluble elastin [13]. Although this protocol resulted in a highly purified elastin preparation, additional experiments showed that this method was not adequate to obtain intact fibres. Therefore, we adapted several steps in this purification procedure to develop a novel method to obtain both highly purified and intact fibrillar elastin. We introduce the term 'elastin fibre' to indicate an elastic fibre in which the only component is elastin and show that the biological response to elastin preparations depends on the integrity and purity of the fibre.

\section{MATERIALS \& METHODS}

\section{Elastin purification}

Equine ligamentum nuchae was used as a source for insoluble elastin. Elastic ligament was pulverised under liquid nitrogen conditions using a Fritsch Pulverisette 19 with a $1 \mathrm{~mm}$ sieve (Idar-Oberstein, Germany). Three purification procedures were compared (Fig. 1). 
Procedure A: Procedure A is a traditional method based on treatment with $0.1 \mathrm{M}$ $\mathrm{NaOH}$ at $95^{\circ} \mathrm{C}$ for $45 \mathrm{~min}$ [11]. This procedure makes use of three $24 \mathrm{~h}$ extractions with 10 vol. (10 ml/g wet weight tissue) $1 \mathrm{M} \mathrm{NaCl}$ at $4{ }^{\circ} \mathrm{C}$. After each extraction step insoluble material was recovered by centrifugation at $13000 \mathrm{~g}$ at $4^{\circ} \mathrm{C}$ for $20 \mathrm{~min}$. After the last extraction step, the pellet was washed with demineralised water, and defatted with 30 vol. acetone ( $3 \times 1 \mathrm{~h}$ ). The material was dried in a desiccator, subsequently suspended in 30 vol. 0.1 M NaOH, and heated at $95^{\circ} \mathrm{C}$ for $45 \mathrm{~min}$. The suspension was cooled, washed with demineralised water, and stored at $-80^{\circ} \mathrm{C}$.

Procedure A

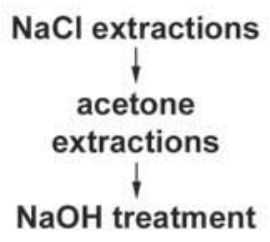

Procedure B

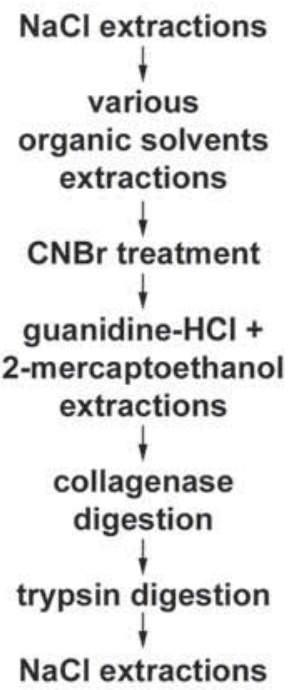

Procedure C

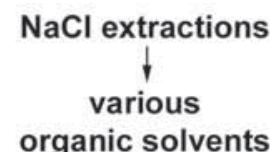

organic solvents

extractions

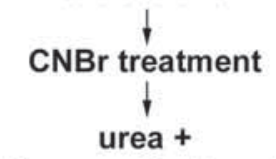

2-mercaptoethanol

extractions

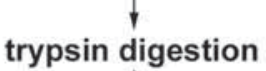

$\mathrm{NaCl}$ extractions

Figure 1. Outline of the procedures used to isolate elastin from equine ligamentum nuchae.

Procedure B: Procedure B is adapted from Daamen et al. [13] and John and Thomas [14] and results in a highly purified elastin preparation in which the fibres, however, are greatly affected. The procedure consists of different extraction steps and digestions with enzymes. Pulverised ligament was extracted 3 times overnight with 10 vol. of $1 \mathrm{M} \mathrm{NaCl}$ containing $0.02 \%(\mathrm{w} / \mathrm{v}) \mathrm{NaN}_{3}$ at $4{ }^{\circ} \mathrm{C}$. After each extraction step, insoluble material was recovered by centrifugation at $13000 \mathrm{~g}$ at $4^{\circ} \mathrm{C}$ for $20 \mathrm{~min}$, washed with demineralised water and resuspended in $10 \mathrm{vol}$. ethanol for $90 \mathrm{~min}$. The mixture was then filtered through a paper funnel and resuspended in 10 vol. chloroform/methanol (2:1) for 90 min. The mixture was filtered again through a paper funnel and resuspended in 10 vol. acetone for $30 \mathrm{~min}$, and the same procedure was repeated with 10 vol. of ether. The insoluble material was dried in a desiccator. The dried powder was incubated in 15 vol. $97 \%$ formic acid, and cyanogen bromide was added to a final concentration of $1 \%$, and left to react for $24 \mathrm{~h}$ under non-oxidising conditions. The mixture was then diluted with 45 vol. demineralised water, filtered and washed with demineralised water until a $\mathrm{pH}$ of 6 was reached. After washing, the pellet was extracted three times ( $24 \mathrm{~h}$ each) with $0.5 \mathrm{M}$ Tris $\mathrm{HCl}$, containing $5 \mathrm{M}$ guanidium chloride, $1 \mathrm{M}$ 2-mercaptoethanol, and 
$0.02 \%(\mathrm{w} / \mathrm{v}) \mathrm{NaN}_{3}(\mathrm{pH}$ 6.8). After the last extraction step the material was washed with demineralised water and incubated for $48 \mathrm{~h}$ at $37^{\circ} \mathrm{C}$ with $1000 \mathrm{U}$ collagenase per gram of substrate in 10 vol. $0.2 \mathrm{M}$ Tris $\mathrm{HCl}$ (pH 7.4) containing $0.05 \mathrm{M} \mathrm{CaCl}_{2}$ and $0.02 \%$ $\mathrm{NaN}_{3}$; after $24 \mathrm{~h}$ another $500 \mathrm{U}$ collagenase/g was added. The preparation was washed with demineralised water and between each washing step recovered by centrifugation at $13000 \mathrm{~g}$ for $20 \mathrm{~min}$. After the last wash the pellet was resuspended in $10 \mathrm{vol} .0 .1 \mathrm{M}$ $\mathrm{NH}_{4} \mathrm{HCO}_{3}(\mathrm{pH} 8.2)$ containing $0.02 \%(\mathrm{w} / \mathrm{v}) \mathrm{NaN}_{3}$, and 10,000 $\mathrm{U}$ trypsin for $4 \mathrm{~h}$ at $37^{\circ} \mathrm{C}$. The pellet was washed with demineralised water, followed by three overnight extractions with 10 vol. $1 \mathrm{M} \mathrm{NaCl}$ containing $0.02 \%(\mathrm{w} / \mathrm{v}) \mathrm{NaN}_{3}$, and washed again with demineralised water. The end product was stored at $-80{ }^{\circ} \mathrm{C}$. Collagenase $(\mathrm{C}-0130)$ and trypsin (T-4665) were from Sigma (St Louis, MO, USA).

Procedure C: In the optimised procedure (procedure C), procedure B was adapted. A number of parameters was varied (see Results \& Discussion section) including the nature of the chaotropic agent, the presence of $\mathrm{CNBr}$, the nature of the reducing agent, the presence of trypsin, and the presence, concentration and duration of collagenase digestion. In the final procedure, $5 \mathrm{M}$ guanidine- $\mathrm{HCl}$ was replaced by $4 \mathrm{M}$ urea and the collagenase digestion was omitted.

\section{Analysis of elastin fibre purity}

Sodium dodecyl sulphate polyacrylamide gel electrophoresis (SDS-PAGE): Elastin preparations were incubated at $95^{\circ} \mathrm{C}$ for 10 min under reducing conditions $(5 \%(\mathrm{v} / \mathrm{v})$ 2-mercaptoethanol) and analysed on a $10 \%(\mathrm{w} / \mathrm{v})$ polyacrylamide gel. This method is particularly useful for analysing purity since contaminants and elastin degradation products, but not fibrillar elastin, will penetrate the gel. Proteins were visualised by silver staining using a $0.1 \%(\mathrm{w} / \mathrm{v}) \mathrm{AgNO}_{3}$ solution.

Amino acid analysis: Elastin samples were hydrolysed under vacuum with $6 \mathrm{M} \mathrm{HCl}$ for $22 \mathrm{~h}$ at $110{ }^{\circ} \mathrm{C}$, dried under vacuum over $\mathrm{NaOH}$ pellets and dissolved in $10 \mathrm{mM}$ $\mathrm{HCl}$. Hydrolysed samples were first deproteinised by addition of an $18.8 \%$ (w/v) 5-sulphosalicylic acid solution (Fluka Chemie, Buchs, Switzerland), containing norleucine (Sigma) as an internal standard. Separation of amino acids was obtained by ion exchange column chromatography on a Biochrom 20 amino acid analyser (Amersham Pharmacia Biotech) using lithium buffers with increasing $\mathrm{pH}$.

Immunohistochemistry: Immunofluorescence microscopy was used to study the presence of elastin, type I collagen and fibrillin in the elastin preparations. Elastin preparations were suspended in demineralised water and frozen in liquid nitrogen. Ligamentum nuchae was frozen directly in liquid nitrogen. Cryosections of frozen preparations were mounted onto glass slides. After blocking with $1 \%(\mathrm{w} / \mathrm{v})$ bovine serum albumin (BSA) in PBS, sections were incubated with mouse anti-bovine elastin 
IgG (1:1000, Sigma), rabbit anti-bovine type I collagen IgG (1:100, Chemicon, Temecula, CA, USA) and mouse anti-bovine fibrillin IgG (1:50, Chemicon) for $90 \mathrm{~min}$, washed with PBS, followed by a $1 \mathrm{~h}$ incubation with Alexa-labelled secondary antibodies (1:100, Molecular Probes, Eugene, OR, USA). All antibodies were diluted in PBS containing $1 \%(\mathrm{w} / \mathrm{v})$ BSA. Sections were washed and mounted in mowiol.

Transmission electron microscopy (TEM): Elastin preparations were embedded in $1.5 \%(\mathrm{w} / \mathrm{v})$ agarose, fixed in $2 \%(\mathrm{v} / \mathrm{v})$ glutaraldehyde in $0.1 \mathrm{M}$ phosphate buffer $(\mathrm{pH}$ 7.4), postfixed with $1 \%(\mathrm{w} / \mathrm{v})$ osmium tetroxide, dehydrated in an ascending series of ethanols and embedded in Epon 812. Ultrathin sections $(60 \mathrm{~nm})$ were picked up on formvar-coated grids, post stained with lead citrate and uranyl acetate, and examined in a JEOL 1010 electron microscope (Tokyo, Japan).

\section{Analysis of elastin fibre integrity}

Scanning electron microscopy (SEM): SEM was used to study the intactness of the elastin fibres. Lyophilised elastin preparations were mounted on stubs and sputtered with an ultrathin layer of gold in a Polaron E5100 SEM coating system. Specimens were studied with a JEOL JSM-6310 SEM apparatus operating at $15 \mathrm{kV}$.

\section{Subcutaneous implantation}

NIH guidelines for the care and use of laboratory animals (NIH publication 85-23 Rev. 1985) were observed. The study was approved by the Ethical Committee of the University of Nijmegen. Sprague-Dawley rats (male, 21 days old) were purchased from Harlan (Zeist, The Netherlands). The animals were fed pelleted diet (RMH-B $10 \mathrm{~mm}$ ) and water ad libitum. Scaffolds composed of 50\% purified collagen fibrils [15] and $50 \%$ elastin fibres (isolated according to procedure A, B and C) were washed in $70 \%$ $(\mathrm{v} / \mathrm{v})$ ethanol (4 x $30 \mathrm{~min})$ and in sterile phosphate buffered saline (pH 7.2) (8 x 30 $\min )$ at $22^{\circ} \mathrm{C}$. Rats were anaesthetised with isoflurane. After disinfection, subcutaneous pockets were made to the right and left of two midline incisions on the back. Punches (ø $6 \mathrm{~mm}$, thickness $6 \mathrm{~mm}$ ) of the scaffolds were implanted in the pockets at a distance of about $1 \mathrm{~cm}$ from the incisions (4 implants/rat). For each scaffold two rats received two punches of the same scaffold. Implants with surrounding tissue were harvested after 3 days, fixed in $4 \%(\mathrm{v} / \mathrm{v})$ formaldehyde in phosphate buffer ( $\mathrm{pH} 7.2$ ) for $24 \mathrm{~h}$ at $4^{\circ} \mathrm{C}$, and embedded in paraffin. Sections of $5 \mu \mathrm{m}$ were mounted onto glass slides, dewaxed in xylol, hydrated through a graded series of ethanol and haematoxylin-eosin stained [16]. 

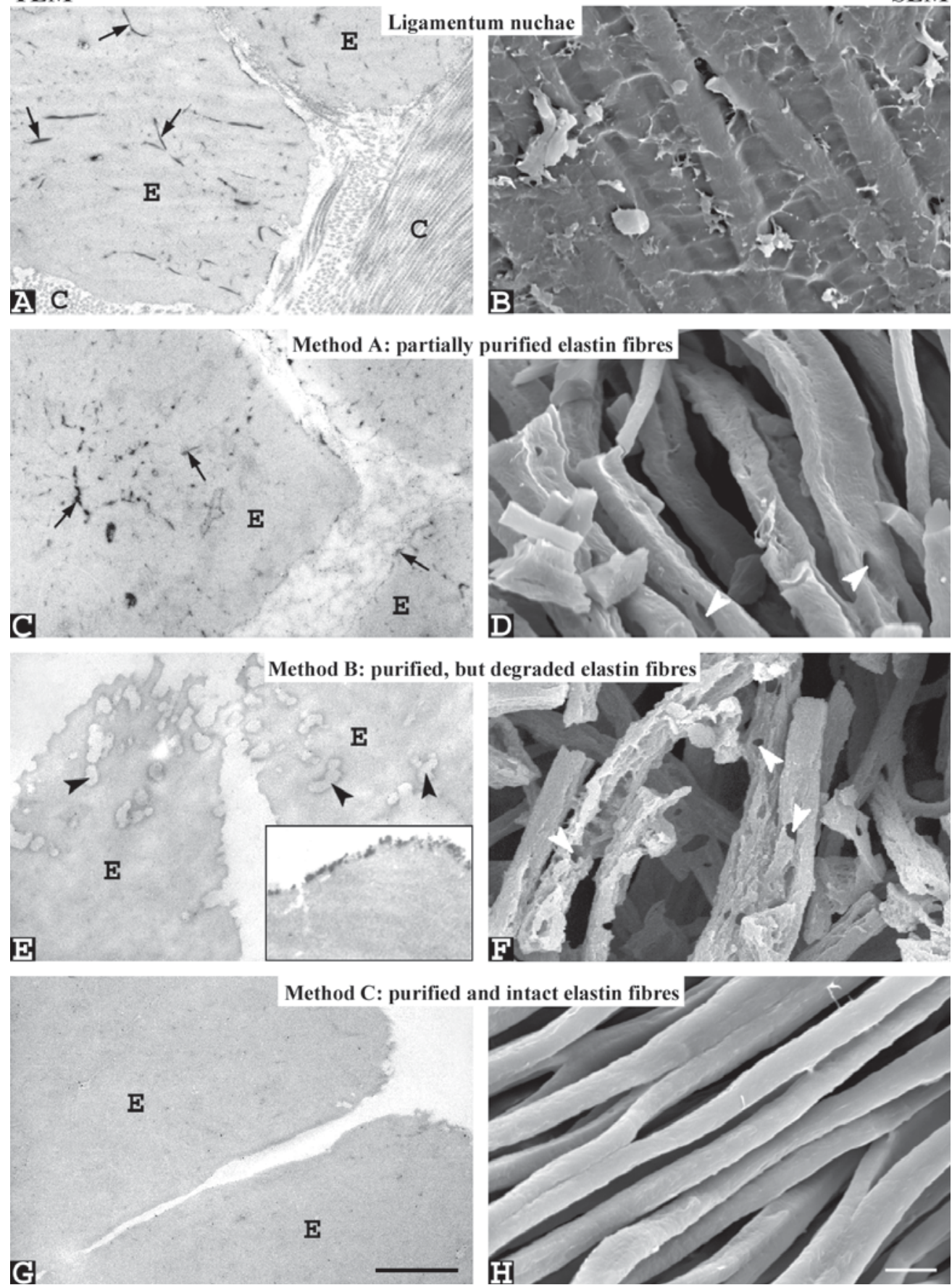

Figure 2. Transmission $(A, C, E, G)$ and scanning electron micrographs $(B, D, F, H)$ of equine ligamentum nuchae $(A, B)$, elastin purified according to procedure $A(C, D)$, procedure $B(E, F)$, and procedure $C(G, H)$. Inset in $\mathrm{E}$ shows $\mathrm{SiO}_{2}$ attached to an elastin fibre. Note the disruption of fibres using procedures $\mathrm{A}$ and $\mathrm{B}$, and the smooth, regular appearance of fibres using procedure $C$. $E=$ elastin; $C=$ collagen fibrils; arrows indicate microfibrillar remnants; arrows heads indicate holes in the fibres. Bar is 1 pm in TEM micrographs and 10 $\mu \mathrm{m}$ in SEM micrographs. 


\section{RESULTS \& DISCUSSION}

The general strategy to isolate elastin is to remove/degrade all other biomolecules. Initially the tissue is rinsed with $\mathrm{NaCl}$-containing solutions to remove salt-soluble proteins, and with organic solvents to remove lipid-containing molecules. Traditional methods (as exemplified by method A) then solubilise remaining proteins by partial hydrolysis using harsh methods like $\mathrm{NaOH}$ treatment at high temperature. Elastin is largely resistant to these treatments. Alternative methods (as exemplified by method B) rely on further washings using chaotropic salts (guanidine- $\mathrm{HCl}$ ), and cleavage of proteins by using $\mathrm{CNBr}$ treatment (cleaves at the site of methionine residues present in virtually all proteins, but not in elastin) and/or proteases (e.g. collagenase and trypsin). The methods used so far, however, result in either contaminated and/or disrupted elastin fibres. In this study we developed a novel isolation protocol, based on method B, which resulted in purified and intact elastin fibres. A number of different analytical techniques including SDS-PAGE, amino acid analysis, immunofluorescence microscopy, and transmission and scanning electron microscopy were used to study purity and intactness. The advantages and disadvantages of each of these techniques have been discussed [13]. In ligamentum nuchae (the source of elastin fibres), elastic fibres are surrounded by collagen fibrils and other (extra)cellular components, and contain microfibrils at the periphery and within the fibres. The elastic fibres are present as bundles and are connected by collagen (Fig. 2A, B). EM showed that elastic fibres purified using conventional procedures, like procedure $\mathrm{A}$, still contained microfibrillar remnants and that they were partially damaged (Fig. 2C, D). SDS-PAGE of elastin purified by method A gave a smear of high molecular mass impurities on a silver-stained gel (elastin fibres are too large to enter the gel), whereas method B resulted in an empty lane (results not shown). Method B resulted in highly purified elastin, but the intactness of the fibres was severely comprised as indicated by EM analysis (Fig. 2E, F). We therefore adapted this method to obtain purified as well as intact elastin fibrils.

A number of parameters was varied. Omission of the CNBr step resulted in damaged as well as impure fibres. Replacement of 2-mercaptoethanol with dithiothreitol (DTT) did result in pure elastin, but the fibres were damaged. Omission of both the collagenase and trypsin enzyme digestions led to intact, but impure fibres. Omission of only trypsin resulted in pure, but damaged, fibrils. SEM analysis of elastic fibres after various extraction steps indeed indicated that the collagenase treatment led to destruction of the fibres (Fig. 3, compare 3D with 3E). The collagenase preparation used may contain other proteases (according to the manufacturer's data sheet), possibly elastase. Reduction of the amount of collagenase and/or time of digestion, however, still resulted in damaged fibres. We therefore omitted the collagenase treatment. To evaluate if collagen was still removed, immunofluorescence and TEM were applied. No collagen fibrils and no immunoreactivity with anti-collagen antibodies were detected (Fig. 2G and Fig. 4). Elastin purified with method $\mathrm{C}$ did not show immunoreactivity with 
anti-fibrillin antibodies either (results not shown). Immunostaining for elastin, however, was highly positive. Collagen fibrils were largely removed by chaotropic salt/ mercaptoethanol/CNBr treatments. Trypsin was necessary for the removal of remnants of microfibrillar components, and although, in principal, trypsin is capable to digest elastin (it cleaves near Lys and Arg residues which are present in elastin), results showed that with a $4 \mathrm{~h}$ digestion, the elastin fibres remained intact (Fig. 2H). Using TEM, it was noticed that an electron-dense precipitate was present (see insert Fig. 2E). This could be attributed to the guanidine- $\mathrm{HCl}$ step. Guanidine- $\mathrm{HCl}$ sometimes contains an anti-caking agent $\left(\mathrm{SiO}_{2}\right)$ that sticks to elastin fibres and can not be removed anymore. Omission of guanidine-HCl, however, did not result in a pure elastin preparation and therefore it was replaced by urea, another chaotropic agent, which gave satisfactory results. Taken together, the omission of collagenase and the replacement of guanidine$\mathrm{HCl}$ by urea (procedure C) resulted in highly purified, intact elastin fibres (Fig. 2G, H). SDS-PAGE, immunofluorescence and transmission electron microscopy gave similar results for method $\mathrm{B}$ and $\mathrm{C}$, indicating that method $\mathrm{C}$ results in highly purified elastin.
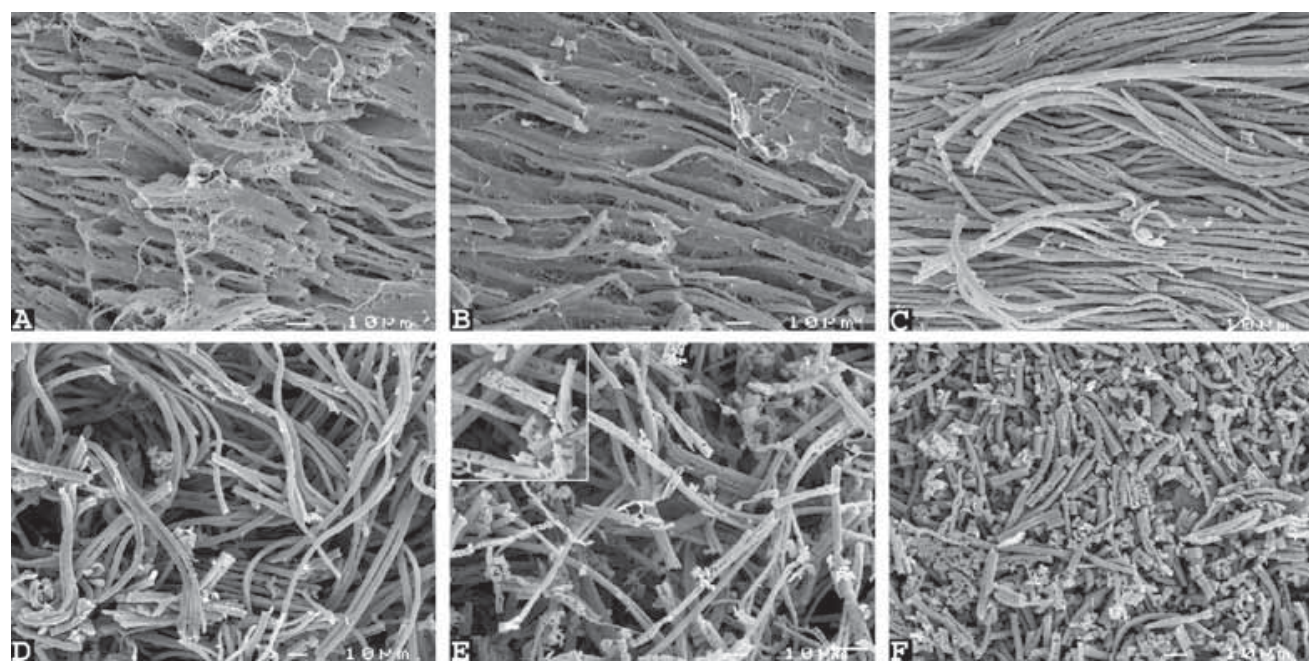

Figure 3. Scanning electron micrographs of partly purified elastin after each of method B's purification steps (see Fig. 1 for sequential steps). (A) after NaCl extraction, (B) after organic solvents steps, (C) after CNBr in formic acid step, (D) after guanidium chloride/ 2-mercaptoethanol extractions, (E) after collagenase digestion, (F) after trypsin digestions, e.g. elastin in Fig. $3 \mathrm{C}$ was isolated with the $\mathrm{NaCl}$ extraction, organic solvents steps and guanidium chloride/ 2-mercaptoethanol extractions. Insert in E shows an enlargement of affected fibres. Note that elastin fibres get damaged after the collagenase digestion. Bar is $10 \mu \mathrm{m}$.

However, amino acid analysis for method $\mathrm{B}$ and $\mathrm{C}$ gave slightly different findings (Table 1). For elastin purified according to method $C$, frequently occurring amino acid residues like Gly, Pro and Val, resemble the theoretical amino acid composition of bovine more closely than method B (equine cDNA was not available). Because method $C$ also resulted in intact elastin fibres, this may indicate that these elastin molecules are less prone to proteolysis compared to method B elastin. This may be crucial for correct cell adhesion, for instance mediated by integrin $\alpha_{V} \beta_{3}$ which binds to the C-terminal 

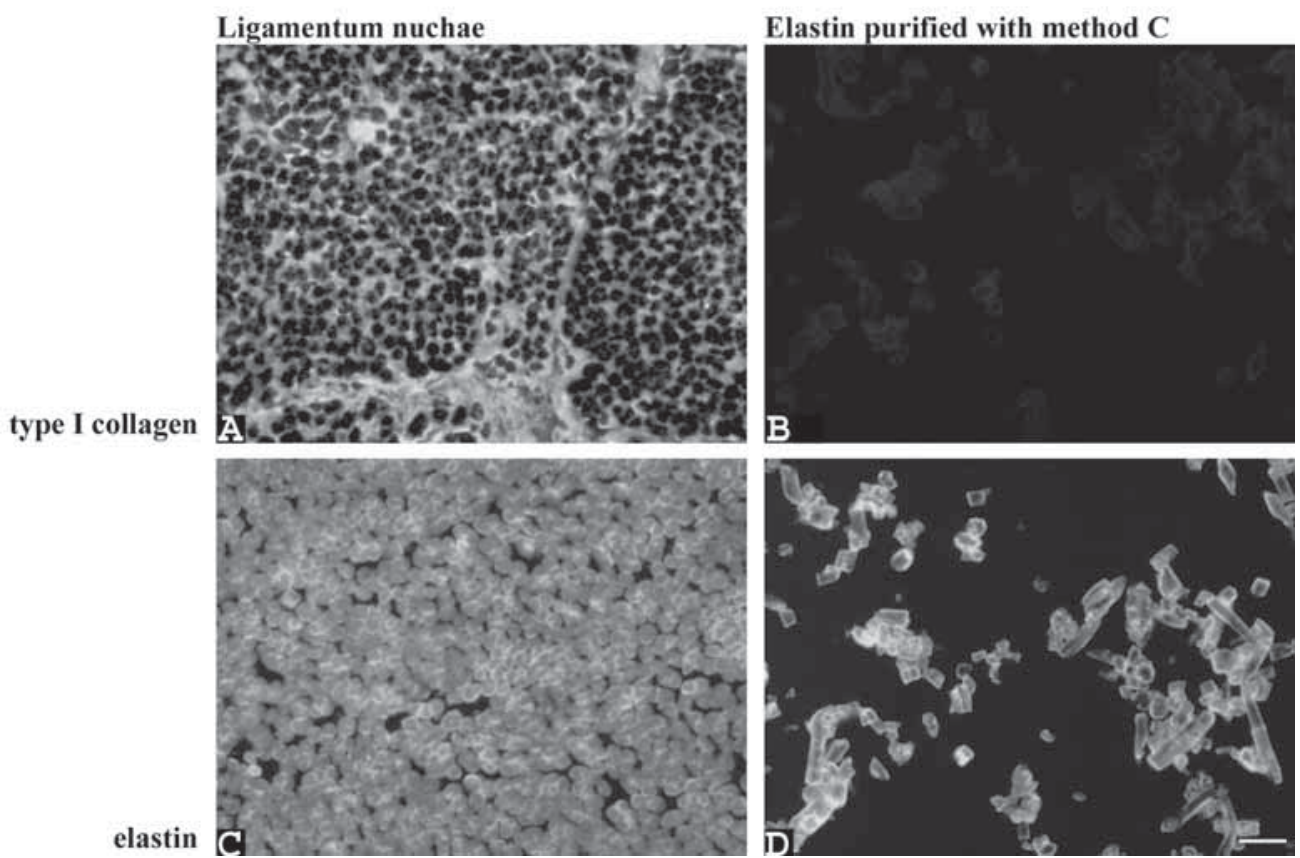

Figure 4. Immunostaining for type I collagen $(A, B)$ and elastin $(C, D)$ in ligamentum nuchae $(A, C)$ and elastin purified according to method $C(B, D)$. Bar is $20 \mu \mathrm{m}$.

Table 1. Amino acid composition of elastin purified by methods B and C.

\begin{tabular}{cccc}
\hline & Theory $^{*}$ & Method B & Method C \\
\hline Ala & 211 & $221 \pm 9$ & $241 \pm 10$ \\
Arg & 7 & $6 \pm 1$ & $8 \pm 2$ \\
Asx & 4 & $5 \pm 0$ & $4 \pm 1$ \\
Cys & 3 & $3 \pm 0$ & $3 \pm 0$ \\
Glx & 14 & $19 \pm 1$ & $22 \pm 2$ \\
Gly & 319 & $235 \pm 11$ & $289 \pm 14$ \\
His & 0 & $0 \pm 0$ & $0 \pm 0$ \\
Hyl & & $0 \pm 0$ & $0 \pm 0$ \\
Hyp & & $7 \pm 2$ & $6 \pm 1$ \\
Ile & 25 & $20 \pm 1$ & $22 \pm 8$ \\
Leu & 60 & $72 \pm 3$ & $51 \pm 12$ \\
Lys & 53 & $7 \pm 1$ & $5 \pm 2$ \\
Met & & $0 \pm 0$ & $0 \pm 0$ \\
Phe & 29 & $35 \pm 2$ & $34 \pm 5$ \\
Pro & 119 & $147 \pm 4$ & $129 \pm 4$ \\
Ser & 10 & $8 \pm 1$ & $7 \pm 3$ \\
Thr & 11 & $15 \pm 1$ & $16 \pm 2$ \\
Trp & 0 & $0 \pm 0$ & $0 \pm 0$ \\
Tyr & 10 & $25 \pm 1$ & $12 \pm 4$ \\
Val & 126 & $174 \pm 6$ & $150 \pm 12$ \\
Des & & $0.5 \pm 0.0$ & $0.6 \pm 0.1$ \\
Ide & & $0.5 \pm 0.0$ & $0.5 \pm 0.0$ \\
\hline
\end{tabular}

* The amino acid composition of bovine elastin was theoretically calculated from the cDNA of tropoelastin. Posttranslational modifications and alternative splicings are therefore not taken into account $[24,25]$. hydrolysis. Des = desmosine; Ide $=$ isodesmosine. Amino acid composition of elastin purified according to method B are from method 3c [13]. 
end of elastin [17]. Fig. 5 shows that elastin was present homogeneously in the elastin fibres purified according to method $\mathrm{C}$. Yields for the different purification procedures $\mathrm{A}, \mathrm{B}$, and $\mathrm{C}$ were similar and were on basis of dry weight 21,20 and $22 \%$ of the original ligament, respectively.
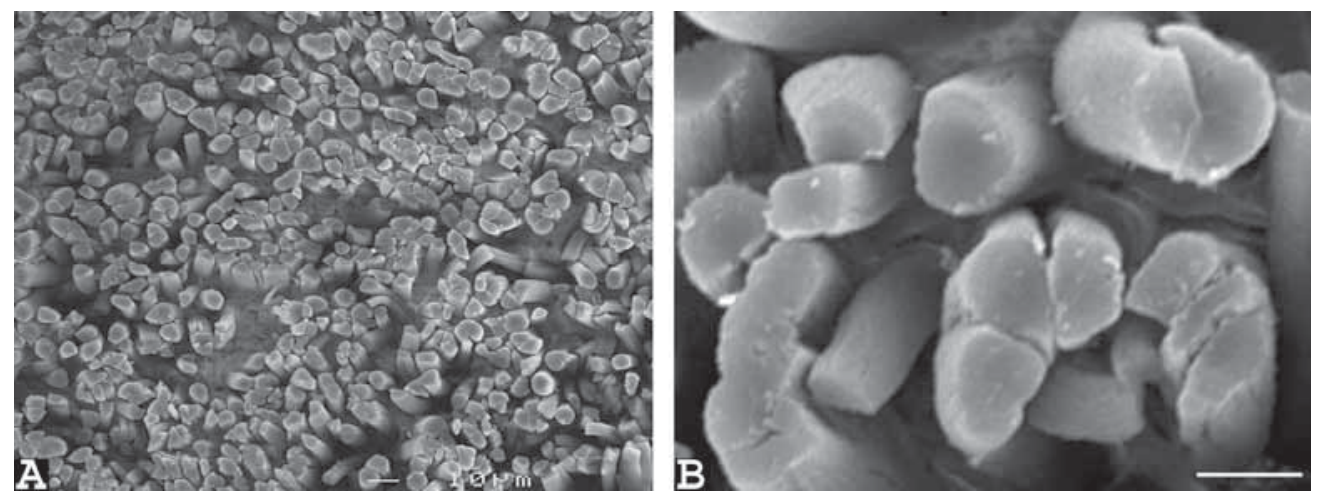

Figure 5. Scanning electron micrographs of cross-sectioned elastin fibres purified according to procedure C. Elastin is distributed throughout the whole fibre, and no holes are present. Bar is $10 \mu \mathrm{m}$ in A and $5 \mu \mathrm{m}$ in B.

The cellular response toward elastin preparations made by procedure A, B, or C was clearly different (Fig. 6). Upon implantation of impure, partially affected elastin (procedure A), many cells (including macrophages, fibroblasts and neutrophiles) infiltrated the scaffold. Implantation of pure, but severely affected elastin (procedure B) gave rise to the influx of large amounts of neutrophiles. However, pure and intact fibres (procedure C) resulted in only a mild cellular response with few cells infiltrating the scaffold. Differences in the purity of insoluble elastin preparations thus gave a distinct cellular response upon implantation.

Moreover, these results indicated that the intactness of elastin fibres is of major influence to the cellular response. It has been demonstrated that elastin degradation is accompanied by an inflammatory response e.g. in animal models of elastase-induced emphysema [18] and elastase-induced abdominal aortic aneurysms [19,20]. Therefore, degraded elastin fibres (as obtained by method B) likely induce an inflammatory response. Also, partly purified elastin (as in method A) contains (degradation products of) microfibrillar components that may attract neutrophiles. Similarly, an impure preparation of collagen-elastin (a mildly cleansed membrane of porcine origin composed of mainly collagen (70\%) and elastin) resulted in inflammation, activation of macrophages and angiogenesis [21].

The availability of isolated elastin in its native, fibrillar conformation may be important for both fundamental and applied research. For cell biological studies to elastin it is now possible to study the effect of mature extracellular elastin in fibrous form, without introducing artefacts to the system caused by affected fibres and/or impurities. It is also possible to test whether conflicting data, e.g. to the specificity of matrix metalloproteinases [22], are due to impurities still present within or associated with the elastic fibre. In applied research, like the use of elastin in biomaterials and 
Method A:

partially purified elastin fibres

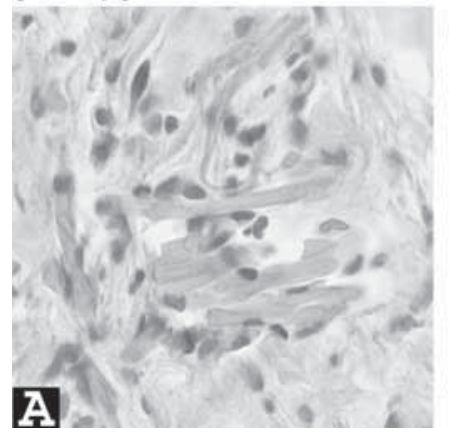

Method B:

purified, but degraded elastin fibres

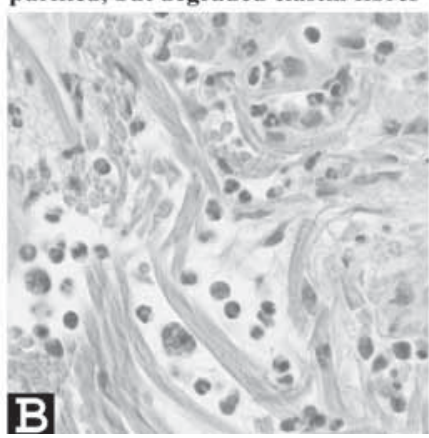

Method C:

purified and intact elastin fibres

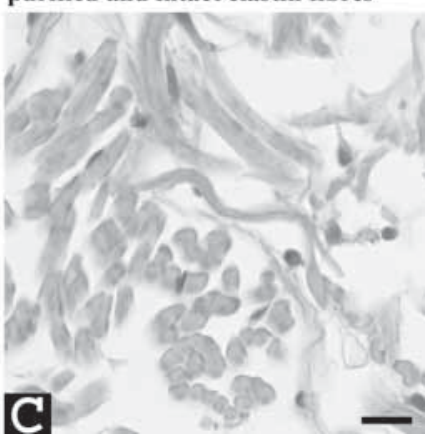

Figure 6. Light microscopical overview of the cellular response to scaffolds 3 days after subcutaneous implantation in Sprague Dawley rats. Scaffolds composed of elastin and collagen 1:1 were used. (A-C) elastin prepared according to procedure $A, B$, and $C$, respectively. Note that few cells were found upon implantation of pure intact elastin fibres (procedure $C$ ), whereas many cells were present when using other elastin preparations. Sections were HE stained. Bar is $10 \mu \mathrm{m}$.

tissue engineering, the purified intact fibres may be useful when preparing defined bioscaffolds from scratch [23], thus avoiding unwanted immunological reactions to contaminations, and allowing studies to the body's response to one single component: elastin.

In summary, we have developed a purification method which results in highly purified, intact fibres of elastin. We called these fibres 'elastin fibres' opposed to elastic fibres.

\section{REFERENCES}

1. Debelle L, Tamburro AM. Elastin: molecular description and function. Int J Biochem Cell Biol 1999;31:261-72.

2. Kielty CM, Sherratt MJ, Shuttleworth CA. Elastic fibres. J Cell Sci 2002;115:2817-28.

3. Berthod F, Germain L, Li H, Xu W, Damour O, Auger FA. Collagen fibril network and elastic system remodeling in a reconstructed skin transplanted on nude mice. Matrix Biol 2001;20:463-73.

4. Kadoya K, Amano S, Inomata S, Tsunenaga M, Matsuzaki K, Oshima H, Tanabe M, Kumagai N, Nishiyama T. Evaluation of autologous cultured epithelium as replacement skin after tattoo excision: correlation between skin texture and histological features. Br J Dermatol 2003;149:377-80.

5. Bujan J, Gimeno MJ, Jimenez JA, Kielty CM, Mecham RP, Bellon JM. Expression of elastic components in healthy and varicose veins. World J Surg 2003;27:901-5.

6. Visconti RP, Barth JL, Keeley FW, Little CD. Codistribution analysis of elastin and related fibrillar proteins in early vertebrate development. Matrix Biol 2003;22:109-21.

7. Liu X, Zhao Y, Gao J, Pawlyk B, Starcher B, Spencer JA, Yanagisawa H, Zuo J, Li T. Elastic fiber homeostasis requires lysyl oxidase-like 1 protein. Nat Genet 2004;36:178-82.

8. Ichii T, Koyama H, Tanaka S, Kim S, Shioi A, Okuno Y, Raines EW, Iwao H, Otani S, Nishizawa Y. Fibrillar collagen specifically regulates human vascular smooth muscle cell genes involved in cellular responses and the pericellular matrix environment. Circ Res 2001;88:460-7.

9. Tobias JW, Bern MM, Netland PA, Zetter BR. Monocyte adhesion to subendothelial components. Blood 1987;69:1265-8.

10. Svitkina TM, Parsons DF. Binding of some metastatic tumor cell lines to fibrous elastin and elastin peptides. Int J Cancer 1993;53:824-8.

11. Lansing AI, Rosenthal TB, Alex M, Dempsey W. The structure and chemical characterization of elastic fibers as revealed by elastase and by electron microscopy. Anat Rec 1952;114:555-75.

12. Rasmussen BL, Bruenger E, Sandberg LB. A new method for purification of mature elastin. Anal Biochem 1975;64:255-9.

13. Daamen WF, Hafmans T, Veerkamp JH, Van Kuppevelt TH. Comparison of five procedures for the purification of insoluble elastin. Biomaterials 2001;22:1997-2005.

14. John R, Thomas J. Chemical compositions of elastins isolated from aortas and pulmonary tissues of humans of different ages. Biochem J 1972;127:261-9.

15. Pieper JS, Oosterhof A, Dijkstra PJ, Veerkamp JH, Van Kuppevelt TH. Preparation and characterization of porous crosslinked collagenous matrices containing bioavailable chondroitin sulphate. Biomaterials 1999;20:847-58, 
16. Bancroft JD, Stevens A. Theory and practice of histological techniques. 3rd ed. Edinburgh (UK): Churchill Livingstone, 1990.

17. Rodgers UR, Weiss AS. Integrin alpha(v)beta(3) binds a unique non-RGD site near the C-terminus of human tropoelastin. Biochimie 2004;86:173-8.

18. Snider GL, Lucey EC, Stone PJ. Animal models of emphysema. Am Rev Respir Dis 1986;133:14969.

19. Anidjar S, Salzmann JL, Gentric D, Lagneau P, Camilleri JP, Michel JB. Elastase-induced experimental aneurysms in rats. Circulation 1990;82:973-81.

20. Halpern VJ, Nackman GB, Gandhi RH, Irizarry E, Scholes JV, Ramey WG, Tilson MD. The elastase infusion model of experimental aortic aneurysms: synchrony of induction of endogenous proteinases with matrix destruction and inflammatory cell response. J Vasc Surg 1994;20:51-60.

21. Klein B, Schiffer R, Hafemann B, Klosterhalfen B, Zwadlo-Klarwasser G. Inflammatory response to a porcine membrane composed of fibrous collagen and elastin as dermal substitute. J Mater Sci Mater Med 2001;12:419-24.

22. Aoki Y, Yamazaki-Hase T. Both medullasin and human leukocyte elastase are essentially devoid of elastinolytic activity. J Biochem (Tokyo) 1993;114:122-5.

23. Daamen WF, Van Moerkerk HThB, Hafmans T, Buttafoco L, Poot AA, Veerkamp JH, Van Kuppevelt TH. Preparation and evaluation of molecularly-defined collagen-elastin-glycosaminoglycan scaffolds for tissue engineering. Biomaterials 2003;24:4001-9.

24. Yeh H, Ornstein-Goldstein N, Indik Z, Sheppard P, Anderson N, Rosenbloom JC, Cicila G, Yoon K. Sequence variation of bovine elastin mRNA due to alternative splicing. Collagen Rel Res 1987;7:23547.

25. Raju K, Anwar RA. Primary structures of bovine elastin a, b, and c deduced from the sequences of cDNA clones. J Biol Chem 1987;262:5755-62. 


\section{Chapter 4}

Preparation and evaluation of molecularly-defined collagen-elastin-glycosaminoglycan scaffolds for tissue engineering

Willeke Daamen,

Herman van Moerkerk,

Theo Hafmans,

Laura Buttafoco,

André Poot,

Jacques Veerkamp,

Toin van Kuppevelt.

Biomaterials 2003;24:4001-4009. 


\begin{abstract}
Extracellular matrix components are valuable building blocks for the preparation of biomaterials involved in tissue engineering, especially if their biological, chemical and physical characteristics can be controlled. In this study, isolated type I collagen fibrils, elastin fibres and chondroitin sulfate (CS) were used for the preparation of molecularly-defined collagen-elastin-glycosaminoglycan scaffolds. A total of twelve different scaffolds were prepared with four different ratios of collagen and elastin (1:9, 1:1, 9:1 and 1:0), with and without chemical crosslinking, and with and without CS. Collagen was essential to fabricate coherent, porous scaffolds. Electron microscopy showed that collagen and elastin physically interacted with each other and that elastin fibres were enveloped by collagen. By carbodiimide-crosslinking, amine groups were coupled to carboxylic groups and CS could be incorporated. More CS could be bound to collagen scaffolds $(10 \%)$ than to collagen-elastin scaffolds (2.4-8.5\% depending on the ratio). The attachment of CS increased the water-binding capacity to up to $65 \%$. Scaffolds with a higher collagen content had a higher tensile strength whereas addition of elastin increased elasticity. Scaffolds were biocompatible as was established using human myoblast and fibroblast culture systems. It is concluded that molecularlydefined composite scaffolds can be composed from individual, purified, extracellular matrix components. Data are important in the design and application of tailor-made biomaterials for tissue engineering.
\end{abstract}




\section{INTRODUCTION}

Tissue engineering is a field of research, which aims at regenerating tissues and organs. Tissues are basically made up of cells and extracellular matrix. Cells taken out of their context will lose their shape and function. A major goal of tissue engineering is the preparation of a suitable scaffold for cells to proliferate, migrate and differentiate. The scaffold should assist cells to form the desired tissue. To reproducibly prepare bioscaffolds and to study the biological effect of a single component, molecularly-defined scaffolds have to be prepared. In tissues and organs, major extracellular matrix components are collagens, elastin, and glycosaminoglycans. Each tissue/organ has its own unique set and content of these biomolecules. Type I collagen is an extracellular matrix protein that is widely used as scaffold material [1]. It provides adhesive properties and tensile strength. Elastin provides elasticity to tissues/organs and is crucial for e.g. blood vessels in order to cope with variations in blood pressure [2]. Glycosaminoglycans (GAGs) are negatively charged polysaccharides with biocharacteristics like hydration of the extracellular matrix $[3,4]$ and binding of effector molecules (e.g. growth factors and cytokines) [5-8]. In contrast to collagen, elastin is rarely used in bioscaffolds and when applied only poorly-defined elastin preparations have been used. Aprahamian et al. [9] made a matrix of elastin with fibrin in the presence of type I collagen. Rabaud et al. [10] prepared a gel from a collagenous preparation and insoluble elastin. Others used elastin present in isolated blood vessels [11, 12] or heart valves [13]. Also, elastin hydrolysates have been added to biomaterials. For example, Singla and Lee [14] prepared glutaraldehyde-crosslinked matrices from soluble $\alpha$-elastin and collagen to study the calcification rate in a rat model. To our knowledge, well-defined highlypurified insoluble elastin fibres have never been used to prepare defined scaffolds for tissue engineering.

Here, we report the preparation of defined collagen-elastin-GAG scaffolds. Twelve different scaffolds were prepared using four different ratios of collagen and elastin (1:0; 9:1; 1:1; 1:9), with and without chemical crosslinking, and with and without chondroitin sulfate. All scaffolds were characterised biochemically, biomechanically and immunohistologically, and their effect on cell proliferation and differentiation was studied in vitro.

\section{MATERIALS \& METHODS}

\section{Materials}

Mouse anti-chicken chondroitin sulfate monoclonal antibody (clone CS-56, C-8035), and FITC-labelled goat anti-mouse IgM (F-9259) were from Sigma (St Louis, MO, USA). Chondroitin sulfate A (C-9819) was also from Sigma, and was basically a mixture of $60 \%$ chondroitin 4-sulfate and $40 \%$ chondroitin 6-sulfate. No other GAGs could be detected 
using agarose gel electrophoresis with silver staining; also no protein contaminations could be detected as analysed by SDS-PAGE applying $1 \mathrm{mg}$ of material and Coomassie Brilliant Blue staining. Rabbit anti-bovine type I collagen antibody was from Chemicon (Temecula, CA, USA). Alexa 594-labeled goat anti-rabbit IgG was from Molecular Probes (Eugene, OR, USA). Chondroitinase ABC was from Seikagaku (Tokyo, Japan).

\section{Isolation of collagen and elastin}

Insoluble type I collagen was isolated from bovine achilles tendon (deep flexor) using neutral salt and dilute acid extractions as described [15]. Purity of collagen was analysed using SDS-PAGE and amino acid analysis. The collagen preparation was essentially free of other proteins.

Elastin fibres were isolated from equine ligamentum nuchae essentially as described, but with omission of the collagenase digestion [16]. Purity of elastin was assessed using SDS-PAGE, amino acid analysis, and transmission electron microscopy. No impurities could be detected by any of these methods. Microfibrillar components (present in unpurified elastic fibres) were absent.

\section{Preparation of collagen-elastin-GAG scaffolds}

In total, twelve different scaffolds were prepared with different ratios of collagen and elastin, with and without 1-ethyl-3-(3-dimethyl aminopropyl)carbodiimide (EDC) crosslinking and with and without chondroitin sulfate.

Non-EDC-crosslinked type I collagen scaffolds were prepared as described [15]. Briefly, a $2 \%(\mathrm{w} / \mathrm{v})$ collagen suspension was prepared in $0.5 \mathrm{M}$ acetic acid $(\mathrm{pH} 2.5)$ and shaken at $4{ }^{\circ} \mathrm{C}$ for $16 \mathrm{~h}$. This suspension was then diluted to $1 \%(\mathrm{w} / \mathrm{v})$ with ice-cold distilled water, homogenised, and deaerated under vacuum to remove entrapped air bubbles. The collagen suspension was poured into a mould, frozen at $-80^{\circ} \mathrm{C}$ and lyophilised, resulting in porous collagen scaffolds. Non-EDC-crosslinked composite scaffolds of type I collagen and elastin were prepared similarly using suspensions of type I collagen and elastin in a 9:1, 1:1, or 1:9 ratio.

To increase the strength of the scaffolds, chemical crosslinking of collagen and collagenelastin scaffolds was performed using EDC and N-hydroxysuccinimide (NHS) [17]. Scaffolds were incubated for $0.5 \mathrm{~h}$ in $20 \mathrm{ml} 50 \mathrm{mM}$ 2-morpholinoethane sulfonic acid (MES) (pH 5.5) in the presence of $40 \%(\mathrm{v} / \mathrm{v}$ ) ethanol. Subsequently, the scaffolds were crosslinked by immersion in $20 \mathrm{ml} 50 \mathrm{mM}$ MES (pH 5.5) containing $33 \mathrm{mM}$ EDC and $6 \mathrm{mM}$ NHS. After reaction for $4 \mathrm{~h}$ at $22{ }^{\circ} \mathrm{C}$, the scaffolds were washed twice in $0.1 \mathrm{M}$ $\mathrm{Na}_{2} \mathrm{HPO}_{4}$ (pH 9.1) for $1 \mathrm{~h}$. Finally, the scaffolds were washed with $1 \mathrm{M} \mathrm{NaCl}$ and $2 \mathrm{M}$ $\mathrm{NaCl}$ for $2 \mathrm{~h}$ and 1 day (with 6 changes of washing solution), respectively, followed by washings with distilled water. EDC-crosslinking of the scaffolds was also performed in the presence of $2.75 \%(\mathrm{w} / \mathrm{v}) \mathrm{CS}$ which results in the covalent attachment of CS to the scaffold. 


\section{Characterisation of the scaffolds}

Amine group content: The amine group content of scaffolds was determined spectrophotometrically after reaction with 2,4,6-trinitrobenzene sulfonic acid [18]. The presence of CS did not interfere with this assay.

CS content: The CS content of scaffolds was determined by hexosamine analysis using p-dimethylamino-benzaldehyde $[15,19]$. Scaffolds were hydrolysed with $6 \mathrm{M} \mathrm{HCl}$ for $6 \mathrm{~h}$ at $105^{\circ} \mathrm{C}$. Samples were dried under vacuum and dissolved in distilled water for hexosamine analysis. CS was used as a standard.

Water-binding capacity: Scaffold samples of about $5 \mathrm{mg}$ dry weight were incubated in $3 \mathrm{ml} \mathrm{PBS}\left(\mathrm{pH} 7.2\right.$ ) at $20^{\circ} \mathrm{C}$. After $1 \mathrm{~h}$, the wet weight was determined and the water-binding capacity calculated using the equation: water-binding capacity $=[$ (wet weight-dry weight) $\cdot 100 \%] /$ (dry weight).

Scanning electron microscopy (SEM): Scaffolds were critical point dried using $\mathrm{CO}_{2}$ with a Polaron E3000 critical point drying apparatus, mounted on stubs and sputtered with an ultrathin layer of gold in a Polaron E5100 SEM coating system. Specimens were studied with a JEOL JSM-6310 SEM apparatus operating at $15 \mathrm{kV}$.

Transmission electron microscopy (TEM): Scaffolds were fixed in $2 \%(\mathrm{v} / \mathrm{v})$ glutaraldehyde in $0.1 \mathrm{M}$ phosphate buffer ( $\mathrm{pH} \mathrm{7.4)}$ ) for $12 \mathrm{~h}$ at $4{ }^{\circ} \mathrm{C}$, and postfixed with $1 \%(\mathrm{w} / \mathrm{v}$ ) osmium tetroxide in $0.1 \mathrm{M}$ phosphate buffer $(\mathrm{pH} 7.4)$. After a rinsing period of $3 \mathrm{~h}$, the samples were dehydrated in an ascending series of ethanols and embedded in Epon 812. Ultrathin sections $(60 \mathrm{~nm})$ were post stained with lead citrate and uranyl acetate, picked up on formvar-coated grids and examined in a JEOL 1010 electron microscope.

Light microscopy: For conventional histochemical analysis, scaffolds were fixed in $4 \%$ ( $\mathrm{v} / \mathrm{v})$ formaldehyde in phosphate buffer ( $\mathrm{pH}$ 7.2) and embedded in paraffin. Sections of $5 \mu \mathrm{m}$ were mounted onto organosilane-coated slides, dewaxed in xylol and hydrated through a descending series of ethanols. Sections were stained for elastin and collagen according to Verhoeff -Van Gieson [20].

Immunofluorescence microscopy: Immunofluorescence microscopy was used to study the distribution of CS in the scaffolds. Scaffolds were hydrated in $0.1 \mathrm{M}$ phosphate buffer (pH 7.2) and frozen in liquid nitrogen. Cryosections of $5 \mu \mathrm{m}$ were mounted onto organosilane-coated glass slides. After blocking with $1 \%(\mathrm{w} / \mathrm{v}$ ) bovine serum albumin (BSA) in PBS (pH 7.2), sections were incubated with mouse anti-chicken chondroitin sulfate monoclonal antibody (1:50) and rabbit anti-bovine type I collagen antibody 
(1:500) for 90 min, washed with PBS, followed by a $1 \mathrm{~h}$ incubation with FITC-labelled goat anti-mouse IgM (1:100) and Alexa 594-labeled goat anti-rabbit IgG (1:100). Antibodies were diluted in PBS containing 1\% (w/v) BSA. The sections were washed and mounted in mowiol. Elastin was detected on the basis of its autofluorescence using UV optics.

To study if scaffold-bound CS was available for biological interactions, its degradation by chondroitinase $\mathrm{ABC}$ was studied. Cryosections of $5 \mu \mathrm{m}$ were incubated for $30 \mathrm{~min}$ in $25 \mathrm{mM}$ Tris-HCl (pH 8.0) + $1 \mathrm{mM}$ magnesium acetate, followed by an incubation with $1 \mathrm{U} / \mathrm{ml}$ chondroitinase $\mathrm{ABC}$ in the same buffer for $16 \mathrm{~h}$ at $37^{\circ} \mathrm{C}$. Subsequently, sections were immunostained for CS as described above.

Mechanical properties: Stress-strain analysis of scaffolds was performed by uniaxial measurements using a Zwick Z020 mechanical tester. Scaffolds were hydrated for $24 \mathrm{~h}$ in PBS (pH 7.2) and drawn at a speed of $5 \mathrm{~mm} / \mathrm{min}$. The elastic modulus was calculated from the inclination of the stress-strain graph; the tensile strength was monitored after rupture of the scaffolds.

\section{Effects of scaffolds on cells in vitro}

The in vitro cytotoxicity of scaffolds was evaluated on the basis of cell morphology, viability, and proliferation. Human myoblasts [21] and human HFL1 lung fibroblasts (ATCC cell line CCL153) were used. All scaffolds were washed with 70\% (v/v) ethanol and sterile PBS (pH 7.2).

Proliferation of cells indirectly in contact with scaffolds: To analyse possible release of toxic products by the scaffolds, $4.0 \cdot 10^{4}$ /well fibroblasts were grown in proliferation medium $(10 \%(\mathrm{v} / \mathrm{v})$ foetal bovine serum, $4 \mathrm{mM}$ glutamine, penicillin $(100 \mathrm{U} / \mathrm{ml})$ and streptomycin $(100 \mu \mathrm{g} / \mathrm{ml})$ in Dulbecco's modified Eagle medium (DMEM)) on culture plastic (Falcon, Becton Dickinson Labware, New Jersey, USA). After $24 \mathrm{~h}$, scaffolds (Ø $8 \mathrm{~mm}$ ) were added onto the cell inserts (Falcon). Cells were allowed to grow for another 48 h. Trypsinised cells were counted using trypan blue in a Bürker countingchamber. Trypan-blue positive cells indicate non-viable cells. Therefore, only Trypanblue negative cells were counted. The cell proliferation inhibition index ( $\mathrm{CPII}_{\text {indirect }}$ ) was calculated according to: $\mathrm{CPII}_{\text {indirect }}=100 \%$ - [(number of cells in cultures with scaffold / number of cells in culture without scaffold) x 100\%] [15]. Cells with no added scaffold will have a $\mathrm{CPII}_{\text {indirect }}$ of $0 \%$.

Proliferation of cells directly in contact with scaffolds: Fibroblast proliferation was assessed by measuring the mitochondrial dehydrogenase activity using the tetrazolium salt 4-[3-(4-iodophenyl)-2-(4-nitrophenyl)-2H-5-tetrazolio]-1,3-benzene disulfonate (WST-1) (Boehringer Mannheim, Germany), according to the manufacturer's protocol. 
Ø $6 \mathrm{~mm}$ scaffolds were placed in 96-wells plates. Cells were seeded on the scaffolds ( $10^{4}$ cells in $200 \mu \mathrm{l}$ per well) and cultured for 3 days at $37^{\circ} \mathrm{C} / 5 \% \mathrm{CO}_{2}$ in proliferation medium (10\% (v/v) foetal bovine serum, $4 \mathrm{mM}$ glutamine, penicillin $(100 \mathrm{U} / \mathrm{ml})$ and streptomycin $(100 \mu \mathrm{g} / \mathrm{ml})$ in DMEM). After the addition of $20 \mu \mathrm{l}$ WST-1 per well and subsequent incubation for $3 \mathrm{~h}$ at $37^{\circ} \mathrm{C} / 5 \% \mathrm{CO}_{2}$, the absorption was measured at 490 $\mathrm{nm}$. The mitochondrial dehydrogenase activity of day 3 cultures was divided by the activity of day 1 cultures. The enzyme activity ratio was expressed as a percentage of the ratio of cells grown on culture plastic. The cell proliferation inhibition index $\left(\mathrm{CPII}_{\text {direct }}\right)$ was calculated according to: $\mathrm{CPII}_{\text {direct }}=100 \%-[($ enzyme activity of cells in cultures with scaffold / enzyme activity of cells in culture without scaffold) x 100\%].

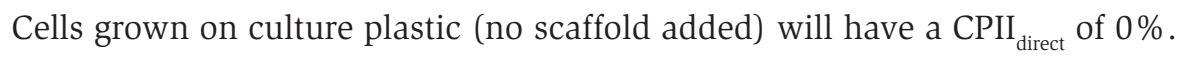

Cell morphology: Cell morphology was assessed using SEM. Ø $16 \mathrm{~mm}$ scaffolds were placed in 24-well culture dishes and cells were seeded on top. Human fibroblasts were seeded on the airside of the scaffolds with a density of about $10^{5}$ cells per $\mathrm{cm}^{2}$ in proliferation medium (10\% (v/v) foetal bovine serum, $4 \mathrm{mM}$ glutamine, penicillin (100 $\mathrm{U} / \mathrm{ml})$ and streptomycin $(100 \mu \mathrm{g} / \mathrm{ml})$ in DMEM). Cells were cultured at $37^{\circ} \mathrm{C}$ and $5 \%$ $\mathrm{CO}_{2}$ for 3 days after which the proliferation medium was changed for differentiation medium which contained $2 \%(\mathrm{v} / \mathrm{v})$ horse serum, $4 \mathrm{mM}$ glutamine, penicillin (100 $\mathrm{U} / \mathrm{ml})$ and streptomycin $(100 \mu \mathrm{g} / \mathrm{ml})$ in DMEM. Human myoblasts were cultured on the scaffolds using similar conditions, but different media. The proliferation medium contained 4\% (v/v) Ultroser G (Sopar-Biochem, Brussels, Belgium), $10 \%$ (v/v) rat brain extract, $4 \mathrm{mM}$ glutamine, penicillin (100 U/ml) and streptomycin $(100 \mu \mathrm{g} / \mathrm{ml})$ in DMEM. The differentiation medium contained $0.4 \%(\mathrm{v} / \mathrm{v})$ Ultroser $\mathrm{G}, 10 \%(\mathrm{v} / \mathrm{v})$ rat brain extract, $4 \mathrm{mM}$ glutamine, penicillin $(100 \mathrm{U} / \mathrm{ml})$ and streptomycin $(100 \mu \mathrm{g} / \mathrm{ml})$ in DMEM. After culturing for 14 days, scaffolds were fixed by immersion in $2 \%(\mathrm{v} / \mathrm{v})$ glutaraldehyde in $0.1 \mathrm{M}$ phosphate buffer ( $\mathrm{pH}$ 7.2) for $1 \mathrm{~h}$ at $4^{\circ} \mathrm{C}$, and prepared for SEM.

\section{RESULTS}

\section{Biochemical and biophysical properties of the scaffolds}

Table 1 gives an overview of the composition and properties of the twelve scaffolds used in this study. The amine group content of the pure collagen scaffold was 281 $\mathrm{nmol} / \mathrm{mg}$ scaffold. The composite collagen-elastin scaffolds contained less $\mathrm{NH}_{2}$ groups, since elastin contained less amine groups than type I collagen (elastin had 27 $\pm 2 \mathrm{nmol} \mathrm{NH}_{2}$ groups/mg elastin). We were not able to construct a stable scaffold made of only elastin, even not after crosslinking. Collagen-elastin crosslinking using $\mathrm{EDC} / \mathrm{NHS}$ results in the formation of crosslinks between carboxylic and amine groups, and thus in a reduction of the number of amine groups. Crosslinking efficiency was 
highest for collagen scaffolds (about $100 \mathrm{nmol}$ amine groups/mg scaffold were utilised upon crosslinking), and smallest for collagen-elastin 1:9 scaffolds (about $30 \mathrm{nmol}$ amine groups/mg scaffold were utilised in the crosslinking process). Under the same conditions, collagen could be crosslinked to a higher extent than collagen-elastin scaffolds, because more amine groups are present. Collagen-elastin crosslinking using $\mathrm{EDC} / \mathrm{NHS}$ in the presence of CS results, besides the formation of crosslinks between these proteins, in the covalent attachment of CS through its carboxylic groups. Coupling of CS to scaffolds generally had no effect on crosslinking efficiency. Since collagen contains more amine groups than elastin, the CS content incorporated into the scaffold is dependent on the collagen-elastin ratio. The content of CS was $10.0 \%(\mathrm{w} / \mathrm{w})$ for the collagen scaffold, and decreased concomitantly with the collagen content of the collagen-elastin scaffolds.

Table 1. Biochemical and biomechanical characteristics of collagen-elastin-chondroitin sulfate scaffolds.

\begin{tabular}{|c|c|c|c|c|c|c|}
\hline Scaffold & $\begin{array}{l}\text { Crosslinked with } \\
\text { EDC/NHS }\end{array}$ & $\begin{array}{l}\text { Amine group } \\
\text { content } \\
\text { [nmol/mg] }\end{array}$ & $\begin{array}{c}\text { Amount of CS in } \\
\text { scaffold } \\
\text { [mg] }\end{array}$ & $\begin{array}{l}\text { Water-binding } \\
\text { capacity } \\
\text { [\# times dry weight] }\end{array}$ & $\begin{array}{c}\text { Tensile strength } \\
\text { [kPa] }\end{array}$ & $\begin{array}{c}\text { E-modulus } \\
\text { [MPa] }\end{array}$ \\
\hline $\mathrm{COL}$ & - & $281 \pm 7$ & 0 & $20 \pm 1$ & $103 \pm 15$ & $0.39 \pm 0.07$ \\
\hline $\mathrm{COL}$ & + & $185 \pm 3$ & 0 & $20 \pm 1$ & $677 \pm 191$ & $1.03 \pm 0.08$ \\
\hline $\mathrm{COL}_{-\mathrm{CS}^{*}}$ & + & $186 \pm 8$ & $100 \pm 4$ & $33 \pm 3$ & $520 \pm 105$ & $0.97 \pm 0.07$ \\
\hline COL-EL 9:1 & - & $256 \pm 8$ & 0 & $19 \pm 2$ & $67 \pm 6$ & $0.42 \pm 0.10$ \\
\hline COL-EL 9:1 & + & $159 \pm 4$ & 0 & $19 \pm 1$ & $420 \pm 35$ & $0.78 \pm 0.07$ \\
\hline COL-EL-CS 9:1** & + & $164 \pm 1$ & $85 \pm 5$ & $29 \pm 4$ & $394 \pm 42$ & $0.76 \pm 0.13$ \\
\hline COL-EL $1: 1$ & - & $147 \pm 12$ & 0 & $16 \pm 1$ & $63 \pm 23$ & $0.24 \pm 0.06$ \\
\hline COL-EL 1:1 & + & $87 \pm 5$ & 0 & $16 \pm 3$ & $142 \pm 8$ & $0.42 \pm 0.04$ \\
\hline COL-EL-CS $1: 1^{* * *}$ & + & $83 \pm 2$ & $58 \pm 5$ & $21 \pm 3$ & $128 \pm 10$ & $0.54 \pm 0.11$ \\
\hline COL-EL 1:9 & - & $67 \pm 7$ & 0 & $11 \pm 1$ & N.D. & N.D. \\
\hline COL-EL 1:9 & + & $57 \pm 5$ & 0 & $11 \pm 1$ & N.D. & N.D. \\
\hline COL-EL-CS $1: 9^{* \ldots * *}$ & + & $35 \pm 4$ & $24 \pm 2$ & $12 \pm 1$ & N.D. & N.D. \\
\hline
\end{tabular}

* $\quad 1 \mathrm{~g}$ of COL-CS scaffold contains $900 \mathrm{mg}$ collagen and $100 \mathrm{mg} \mathrm{CS}$.

** $\quad 1 \mathrm{~g}$ of COL-EL-CS 9:1 scaffold contains $823 \mathrm{mg}$ collagen, $92 \mathrm{mg}$ elastin and $85 \mathrm{mg}$ CS.

$* * * \quad 1 \mathrm{~g}$ of COL-EL-CS 1:1 scaffold contains $471 \mathrm{mg}$ collagen, $471 \mathrm{mg}$ elastin and $58 \mathrm{mg}$ CS.

$* * * * \quad 1 \mathrm{~g}$ of COL-EL-CS 1:9 scaffold contains $98 \mathrm{mg}$ collagen, $878 \mathrm{mg}$ elastin and $24 \mathrm{mg}$ CS.

$\mathrm{COL}=$ collagen; $\mathrm{EL}=$ elastin; $\mathrm{CS}=$ chondroitin sulfate. N.D. = Not done; scaffolds were to weak to measure tensile strength and E-modulus. Results are mean \pm SD of 3 independent experiments.

The coupling of CS to the scaffolds increased the water-binding capacity. This effect was most prominent for the collagen scaffold. In the collagen-elastin scaffolds, less CS was present, and thus the increase in water-binding capacity was less. EDC-crosslinking without CS did not influence the water-binding capacity of the scaffolds.

Regarding the mechanical characteristics of the non-crosslinked scaffolds, the tensile strength of the pure collagen scaffold was the highest (about $100 \mathrm{kPa}$ ), and introduction of elastin to the scaffold lowered the tensile strength as well as the Emodulus. Crosslinking of the scaffolds increased the tensile strength and increased the E-modulus. Attachment of CS to a scaffold did not result in a significant change of tensile strength. When manually pulling at a hydrated non-crosslinked scaffold that was glued to a petri dish, it became clear that scaffolds containing a larger content of 
elastin could be extended further, and recoiled faster upon release of the force. The collagen and collagen-elastin 9:1 scaffolds could be extended to $125 \%$, the collagenelastin 1:1 scaffold to $140 \%$ and the collagen-elastin 1:9 scaffold to almost 150\% (see movie at http://www.ncmls.kun.nl/biochemistry/matrix/movies/scaffolds.avi).
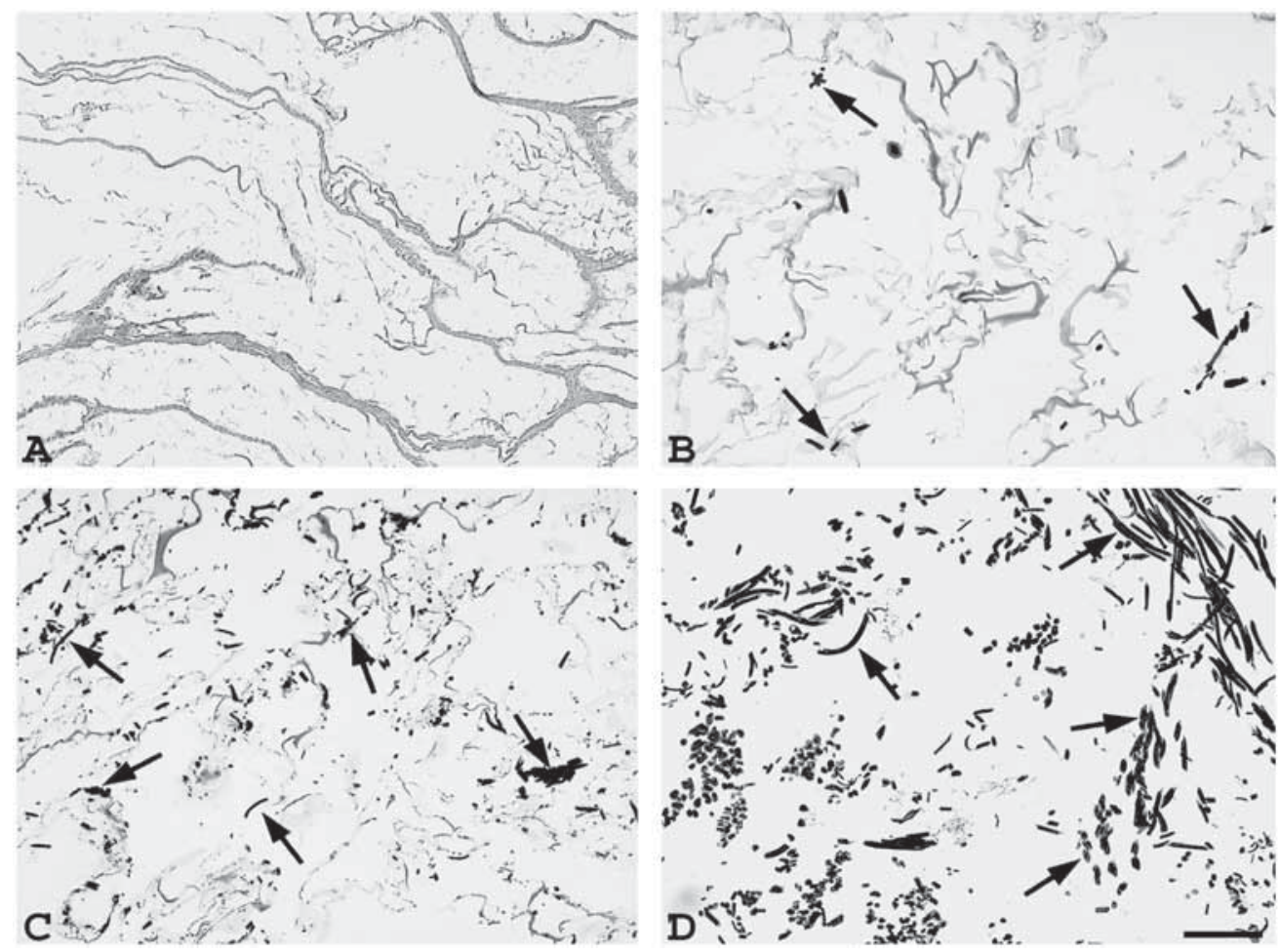

Figure 1. Verhoeff-Van Gieson staining of a collagen scaffold (A), a 9:1 collagen-elastin scaffold (B), a 1:1 collagen-elastin scaffold (C), and a 1:9 collagen-elastin scaffold (D). Collagen has a grey colour, elastin is black. Arrows indicate elastin fibres. Bar is $100 \mu \mathrm{m}$.

\section{Morphological properties of the scaffolds and distribution of single components}

All scaffolds showed a porous structure with pores ranging from 20-100 $\mu \mathrm{m}$. Elastin fibres were much thicker than collagen fibrils and therefore scaffolds containing more elastin had larger pores, since the dry weight $/ \mathrm{cm}^{3}$ was constant for all scaffolds. EDCcrosslinking and coupling of CS to the scaffolds did not alter the porosity. Collagen and elastin were randomly distributed in the scaffolds, although elastin tended to be present in small clusters consisting of up to twenty elastin fibres, especially when a scaffold contained a high amount of elastin (Fig. 1). SEM (Fig. 2) clearly showed thick elastin fibres and thin collagen fibrils. Collagen was also present as lattice-like lamellae, mostly orientated parallel or perpendicular to the surface, but the more elastin was present, the less lamellae were found. SEM indicated that elastin fibres and collagen fibrils physically interact with one another, which was confirmed by TEM (Fig.3). 

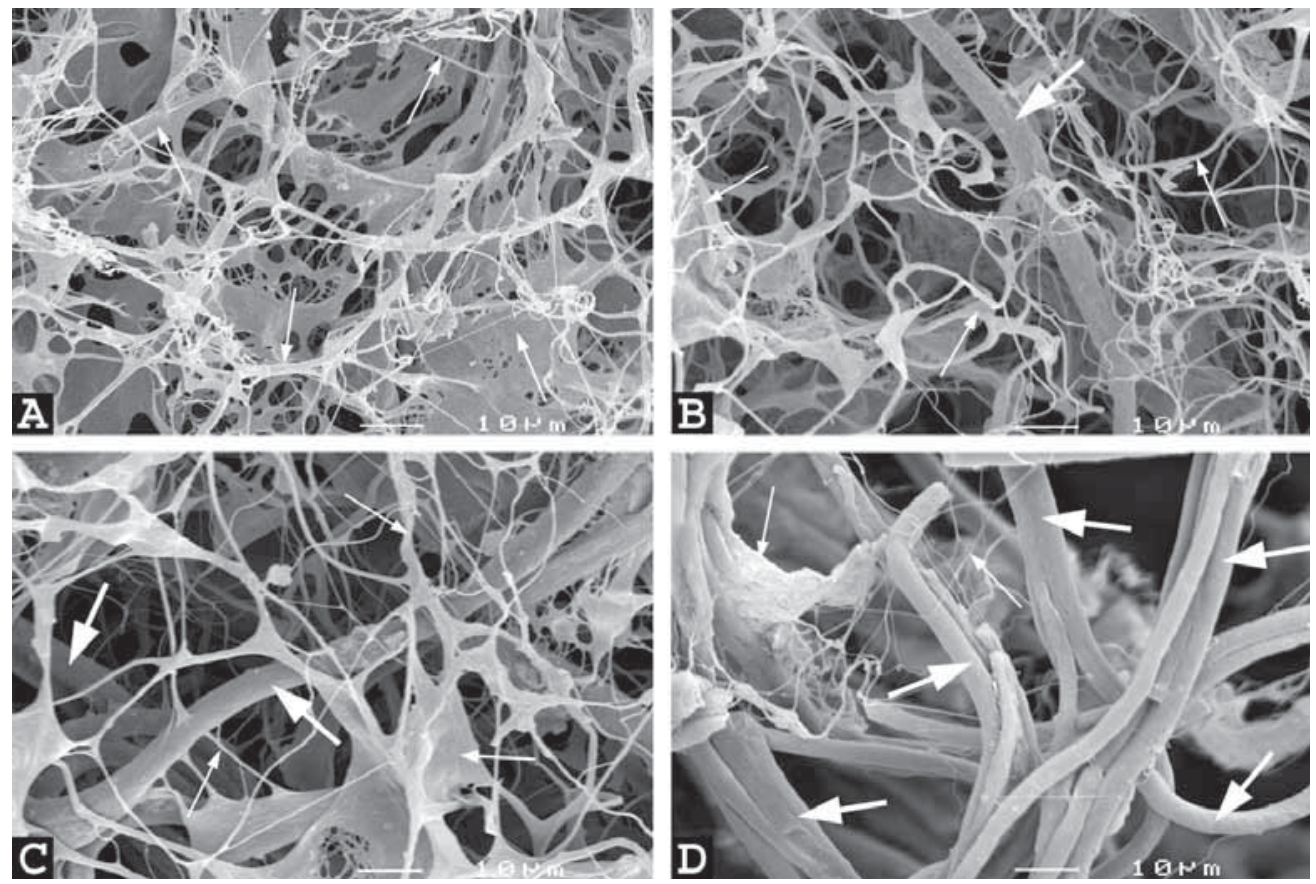

Figure 2. Scanning electron micrographs of the air side of a collagen scaffold (A), a 9:1 collagen-elastin scaffold (B), a 1:1 collagen-elastin scaffold (C), and a 1:9 collagen-elastin scaffold (D). Collagen is present as fibrils and sheets. Note interactions between (thick) elastin fibres (large arrows) and collagen fibrils (small arrows). Bar is $10 \mu \mathrm{m}$.
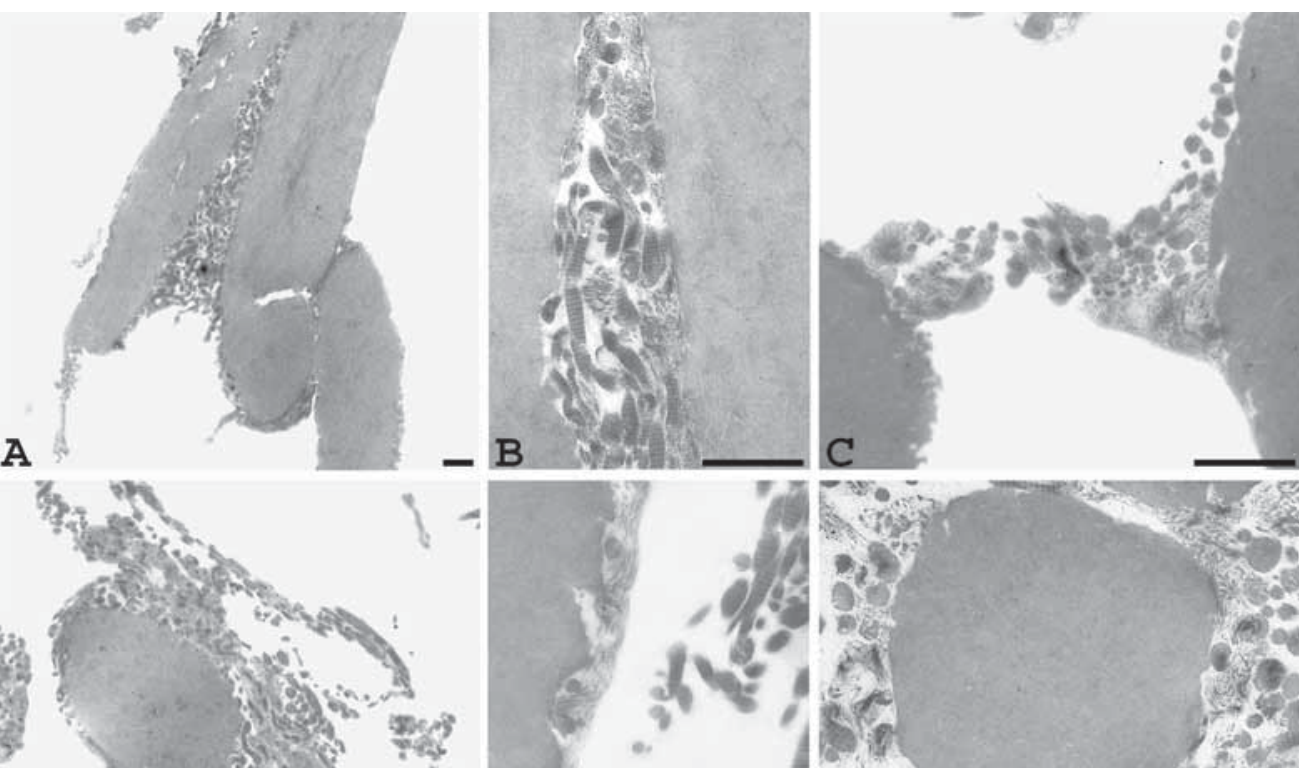

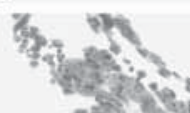
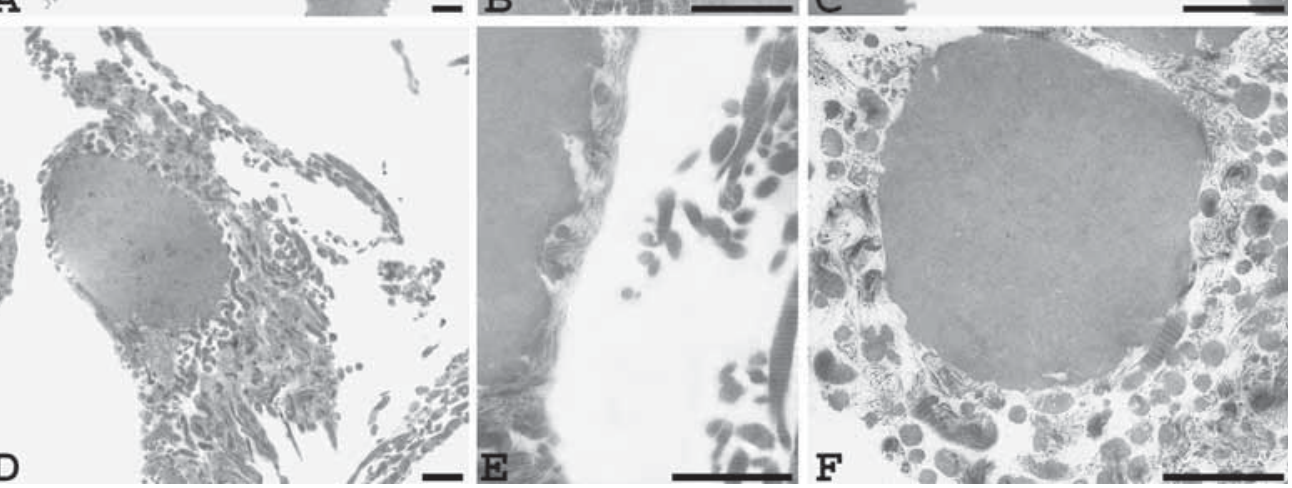

Figure 3. Transmission electron micrograph of a collagen-elastin 1:1 scaffold at several magnifications. A, B and $C$ show connections between separate thick elastin fibres by thin collagen fibrils. $D, E$ and $F$ demonstrate the ensheathment of single elastin fibres by a layer of collagen fibrils that are often frayed at sites of contact with elastin. Bar is $1 \mu \mathrm{m}$. 
Collagen connected separate elastin fibres, and elastin fibres were ensheathed by a layer of collagen fibrils. In many occasions, the native collagen fibril was frayed into protofibrils at places where it contacted elastin.

Immunofluorescence indicated that CS colocalised primarily with collagen and could be removed from the scaffolds by specific digestion using the enzyme chondroitinase $\mathrm{ABC}$ (Fig. 4). This suggests that the CS bound to the scaffolds preserves its natural conformation and remains biologically available (i.e. capable to display its biocharacteristics).

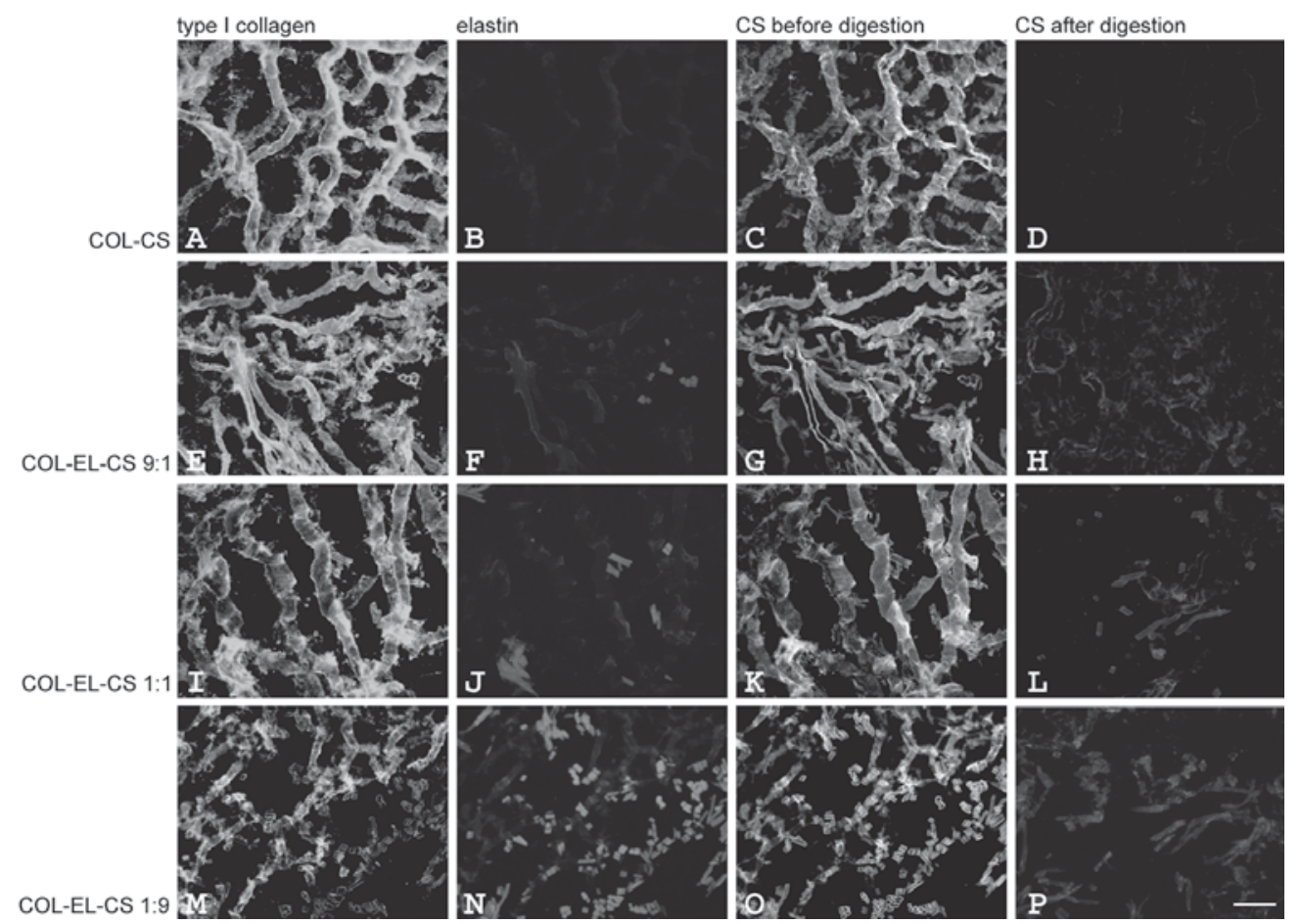

Figure 4. Localisation of scaffold components by immunofluorescence staining for type I collagen (A, E, I, $M$ ), $C S$ ( $C, G, K, O$ before chondroitinase $A B C$ digestion; $D, H, L, P$ after chondroitinase $A B C$ digestion), and by UV optics for elastin (B, F, J, N) of a collagen-CS scaffold (A-D), a 9:1 collagen-elastin-CS scaffold (E-H), a 1:1 collagen-elastin-CS scaffold (I-L), and a 1:9 collagen-elastin-CS scaffold (M-P). Bar is $50 \mu \mathrm{m}$. Colour figure on page 152.

\section{Biocompatibility of scaffolds in vitro}

\section{Proliferation of cells indirectly or directly in contact with scaffolds}

To analyse possible release of toxic products by the scaffolds, fibroblasts were grown indirectly in contact with scaffolds. The values of the indirect cell proliferation inhibition index $\left(\mathrm{CPII}_{\text {indirect }}\right)$ did not show negative effects on the proliferation of fibroblasts for all scaffolds. The direct cell proliferation inhibition index $\left(\mathrm{CPII}_{\text {direct }}\right)$ also did not show effects on the proliferation of fibroblasts for collagen, collagen-elastin 9:1 and 1:1 scaffolds, but a small decrease was found for fibroblast proliferation on collagenelastin 1:9 scaffolds (Table 2 ). 
Table 2. Results of in vitro cell proliferation of human fibroblasts grown indirectly and directly in contact with scaffolds.

\begin{tabular}{lccc}
\hline Scaffold & $\begin{array}{c}\text { Crosslinked } \\
\text { with EDC/NHS }\end{array}$ & $\begin{array}{c}\text { CPII }_{\text {indirect }}{ }^{*} \\
{[\% \text { of control }]}\end{array}$ & $\begin{array}{c}\text { CPII }_{\text {direct }}{ }^{* *} \\
{[\% \text { of control] }}\end{array}$ \\
\hline - (culture plastic) & - & 0 & 0 \\
COL & + & $-2 \pm 10$ & $5 \pm 13$ \\
COL & + & $-1 \pm 14$ & $3 \pm 6$ \\
COL-CS & - & $7 \pm 7$ & $2 \pm 10$ \\
COL-EL 9:1 & + & $2 \pm 15$ & $0 \pm 2$ \\
COL-EL 9:1 & + & $8 \pm 3$ & $7 \pm 11$ \\
COL-EL-CS 9:1 & - & $10 \pm 14$ & $2 \pm 1$ \\
COL-EL 1:1 & + & $15 \pm 5$ & $7 \pm 5$ \\
COL-EL 1:1 & + & $14 \pm 7$ & $7 \pm 13$ \\
COL-EL-CS 1:1 & - & $13 \pm 1$ & $11 \pm 3$ \\
COL-EL 1:9 & + & $8 \pm 11$ & $18 \pm 14$ \\
COL-EL 1:9 & + & $10 \pm 9$ & $15 \pm 8$ \\
COL-EL-CS 1:9 & $+14 \pm 2$ & $26 \pm 2$ \\
\hline
\end{tabular}

$*$ CPII $=$ cell proliferation inhibition index; CPI $_{\text {indirect }}$ of cells grown on culture plastic was set to $0 \%$.

${ }^{* *} \mathrm{CPII}_{\text {direct }}$ was calculated from mitochondrial dehydrogenase activity using WST-1. The enzyme activity of cells grown on culture plastic was set to $0 \%$. Values are mean \pm SD of 3 independent experiments.
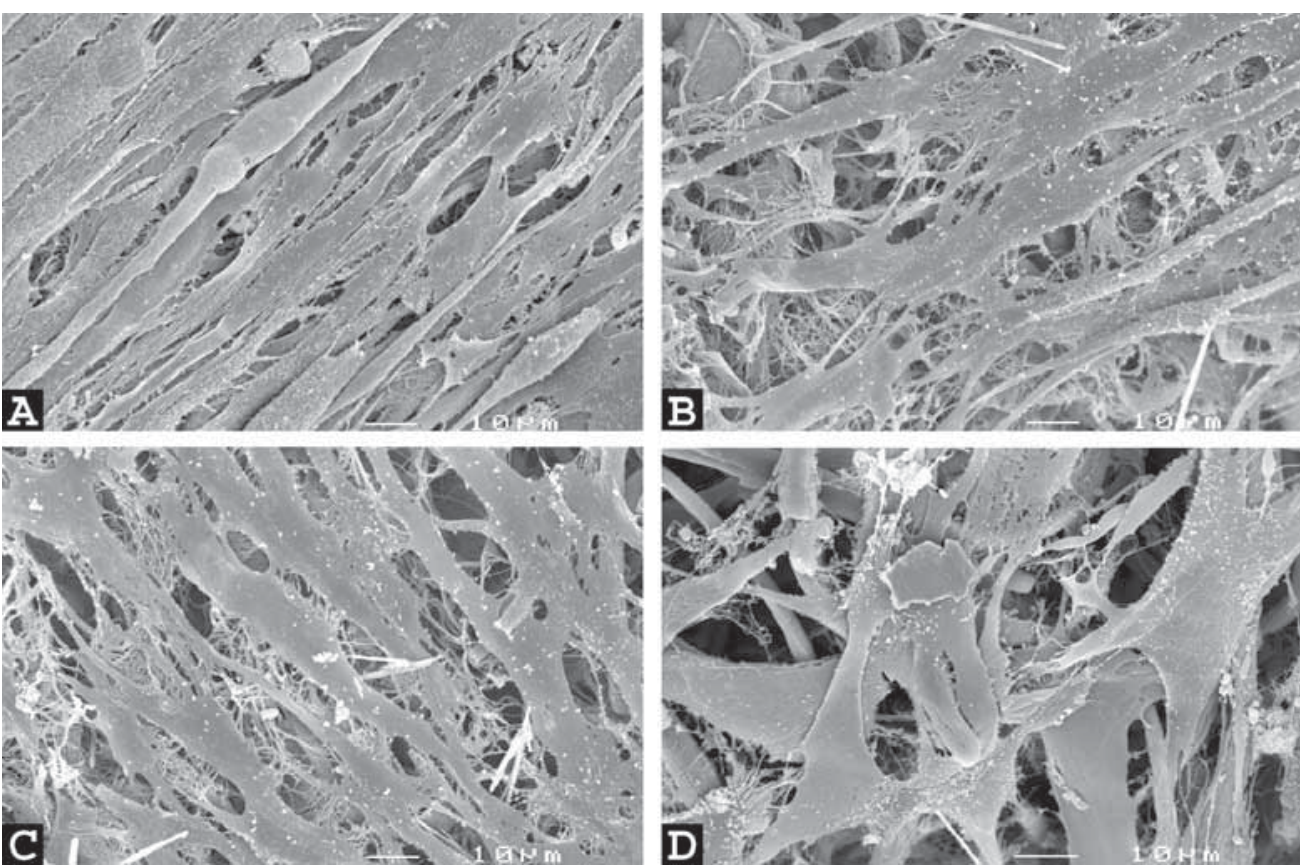

Figure 5. SEM images of human muscle cells grown on a collagen scaffold (A), a 9:1 collagen-elastin scaffold (B), a 1:1 collagen-elastin scaffold (C), and a 1:9 collagen-elastin scaffold (D). Myoblasts were cultured for 14 days. Myotubes were formed on all scaffolds, except collagen:elastin 1:9 scaffolds. Bar is $10 \mu \mathrm{m}$. 


\section{Cell morphology}

The cell morphology of fibroblasts and myoblasts was studied on the scaffolds after 14 days of culturing. Fibroblasts formed normal spindle-shaped cells on all scaffolds (data not shown). Myoblasts adhered, aligned, and fused to form multinucleated myotubes of several hundreds of $\mu \mathrm{m}$ in length on all scaffolds, except on the collagenelastin 1:9 scaffolds (Fig. 5). On the latter, cells did not have an elongated form, but a rounder form with small sprout-like structures. This could be caused by a diminished proliferation of myoblasts on the collagen-elastin 1:9 scaffolds, because myoblasts only start to differentiate when cells contact one another. Another possibility is that myoblasts do not fully differentiate on an elastin surface. Cells generally followed the direction of the collagen fibrils or elastin fibres of the scaffolds beneath them. No differences of morphology were found between cells cultured on non-EDC-crosslinked and crosslinked scaffolds, or on scaffolds with and without CS.

\section{DISCUSSION}

For a rational design of scaffolds for tissue engineering, it is essential to study the effect of individual components. To do so, scaffolds have to be designed starting with highly purified molecules and the contribution of each component in the scaffold has to be controlled. This is also crucial when scaffolds are to be constructed which mimic nature's extracellular matrices, and which vary considerably from tissue to tissue. For instance, when making a scaffold for an artery construct, a much larger content of elastin is necessary than when preparing a scaffold for artificial skin. In skin, the ratio collagen:elastin is about 9:1, whereas in an artery this ratio is $1: 1$ averaging all artery layers, and 1:9 when considering the lamina elastica only [22]. In ligaments, the ratio collagen-elastin is also about 1:9 [22], and in lung about 1:1 [23]. Likewise, the amount (and type) of glycosaminoglycans, another major scaffold component, varies from matrix to matrix. In cartilage for example, chondroitin sulfate is the main glycosaminoglycan making up $20 \%$ of the dry weight. In skin, dermatan sulfate is most abundant (about $1 \%$ of the dry weight), whereas in the vitrous body of the eye it is hyaluronate [24]. Given the large heterogeneity in the body's scaffolds, it was the purpose of this study to demonstrate that tailor-made, molecularly-defined scaffolds can be produced from the main components of the extracellular matrix.

We prepared twelve scaffolds with different ratios of highly purified collagen, elastin and CS, and compared them to each other. With more collagen, the tensile strength of the scaffold was generally higher, whereas increase of elastin increased elasticity. Collagen-elastin 1:1 scaffolds could be extended to about $140 \%$ of the original length; collagen-elastin 1:9 scaffolds to almost $150 \%$. Under normal physiological conditions, circumferential stress-strain extensions of blood vessels are about $20 \%$ of the original diameter [25]. This extension, caused by differences in blood pressure, can easily be reached with these scaffolds, which also provides the elasticity necessary for coping 
with changes in blood pressure. Elastin reduced, but CS increased the water-binding capacity. SEM and TEM data indicated that elastin fibres and collagen fibrils interacted with each other. Collagen formed a small layer of fibrils around the elastin fibres, thus incorporating elastin in the scaffolds. Collagen may act as a glue that holds the elastin fibres together. This may explain the inability to construct a stable scaffold of elastin only. Collagen-elastin 1:9 scaffolds are difficult to handle, indicating that a certain amount of collagen is necessary to prepare a coherent scaffold. The inability to prepare scaffolds composed of only elastin could be due to the low number of amine groups in elastin. The introduction of amine groups (e.g. by a diamine compound) may be a solution for this. In case the amines are too distant from the carboxylic groups in order to be crosslinked, bridging may be accomplished by e.g. aminocaproic acid. Next to the biochemical composition of the scaffolds, the mechanical properties of the scaffold can be controlled, e.g. by the composition (choice of ECM components and their ratio), the type and extent of chemical crosslinking, and the pore size of the scaffold. The pore sizes can be varied by changing the freezing rate in the manufacturing process. Fast freezing will result in small ice crystals and smaller pores after lyophilisation. The shape of the scaffold can easily be controlled by the mould that is chosen. The waterbinding capacity of the scaffolds can be influenced by the attachment of GAGs, as shown with CS. Glycosaminoglycans can also be used as slow-release vehicles for e.g. growth factors [26]. Using specific growth factors, a scaffold may be able to selectively interact with surrounding cells to improve tissue regeneration in vivo.

In conclusion, a variety of biological scaffolds have been prepared with defined biochemical, biomechanical, and morphological characteristics. The methodology applied may be instrumental to produce organ-specific scaffolds for tissue engineering.

\section{REFERENCES}

1. Lee CH, Singla A, Lee Y. Biomedical applications of collagen. Int J Pharm 2001;221:1-22.

2. Debelle L, Tamburro AM. Elastin: molecular description and function. Int J Biochem Cell Biol 1999;31:261-272.

3. Watanabe H, Yamada Y, Kimata K. Role of aggrecan, a large chondroitin sulfate proteoglycan, in cartilage structure and function. J Biochem (Tokyo) 1998;124:687-693.

4. Esko JD, Selleck SB. Order out of chaos: Assembly of ligand binding sites in heparan sulfate. Annu Rev Biochem 2002;71:435-471.

5. Babensee JE, McIntire LV, Mikos AG. Growth factor delivery for tissue engineering. Pharm Res 2000;17:497-504.

6. Iozzo RV. Matrix proteoglycans: from molecular design to cellular function. Annu Rev Biochem 1998;67:609-652.

7. Wissink MJ, Beernink R, Poot AA, Engbers GH, Beugeling T, Van Aken WG, Feijen J. Improved endothelialization of vascular grafts by local release of growth factor from heparinized collagen matrices. J Control Release 2000;64:103-114.

8. Wissink MJ, Beernink R, Pieper JS, Poot AA, Engbers GH, Beugeling T, Van Aken WG, Feijen J. Binding and release of basic fibroblast growth factor from heparinized collagen matrices. Biomaterials 2001;22:2291-2299.

9. Aprahamian M, Lambert A, Balboni G, Lefebvre F, Schmitthaeusler R, Damge C, Rabaud M. A new reconstituted connective tissue matrix: preparation, biochemical, structural and mechanical studies. J Biomed Mater Res 1987;21:965-977.

10. Rabaud M, Lefebvre F, Ducassou D. In vitro association of type III collagen with elastin and with its solubilized peptides. Biomaterials 1991;12:313-319. 
11. Goissis G, Suzigan S, Parreira DR, Maniglia JV, Braile DM, Raymundo S. Preparation and characterization of collagen-elastin matrices from blood vessels intended as small diameter vascular grafts. Artif Organs 2000;24:217-223.

12. Courtman DW, Errett BF, Wilson GJ. The role of crosslinking in modification of the immune response elicited against xenogenic vascular acellular matrices. J Biomed Mater Res 2001;55:576-586.

13. Schoen FJ, Levy RJ. Tissue heart valves: current challenges and future research perspectives. J Biomed Mater Res 1999;47:439-465.

14. Singla A, Lee $\mathrm{CH}$. Effect of elastin on the calcification rate of collagen-elastin matrix systems. J Biomed Mater Res 2002;60:368-374.

15. Pieper JS, Oosterhof A, Dijkstra PJ, Veerkamp JH, Van Kuppevelt TH. Preparation and characterization of porous crosslinked collagenous matrices containing bioavailable chondroitin sulphate. Biomaterials 1999;20:847-858.

16. Daamen WF, Hafmans T, Veerkamp JH, Van Kuppevelt TH. Comparison of five procedures for the purification of insoluble elastin. Biomaterials 2001;22:1997-2005.

17. Pieper JS, Hafmans T, Veerkamp JH, Van Kuppevelt TH. Development of tailor-made collagenglycosaminoglycan matrices: EDC/NHS crosslinking, and ultrastructural aspects. Biomaterials 2000;21:581-593.

18. Olde Damink LH, Dijkstra PJ, Van Luyn MJ, Van Wachem PB, Nieuwenhuis P, Feijen J. Cross-linking of dermal sheep collagen using a water-soluble carbodiimide. Biomaterials 1996;17:765-773.

19. Yannas IV, Burke JF, Gordon PL, Huang C, Rubenstein RH. Design of an artificial skin. II. Control of chemical composition. J Biomed Mater Res 1980;14:107-132.

20. Bradbury P, Gordon KC. Connective tissues and stains. In: Bancroft and Stevens, editors. Theory and practice of histological techniques. Edinburgh (UK): Churchill Livingstone, 1990. p. 119-142.

21. Benders AA, Van Kuppevelt TH, Oosterhof A, Veerkamp JH. The biochemical and structural maturation of human skeletal muscle cells in culture: the effect of the serum substitute Ultroser G. Exp Cell Res 1991;195:284-294.

22. Royce PM, Steinman B. Connective tissue and its heritable disorders - molecular, genetic and medical aspects. New York (USA). Wiley-Liss, 2002.

23. Van Kuppevelt TH, Veerkamp JH, Timmermans JA. Immunoquantification of type I, III, IV and V collagen in small samples of human lung parenchyma. Int J Biochem Cell Biol 1995;27:775-782.

24. Iozzo RV. Proteoglycans: structure, biology, and molecular interactions. New York, USA. Marcel Dekker Inc., 2000.

25. Nichols WW, O’Rourke MF. Mc Donald's blood flow in arteries. London UK. Arnold, 1998.

26. Pieper JS, Hafmans T, Van Wachem PB, Van Luyn MJ, Brouwer LA, Veerkamp JH, Van Kuppevelt TH. Loading of collagen-heparan sulfate matrices with bFGF promotes angiogenesis and tissue generation in rats. J Biomed Mater Res 2002;62:185-194. 


\section{Chapter}

Tissue response of defined collagen-elastin scaffolds in young and adult rats with special attention to calcification

Willeke Daamen, Suzan Nillesen, Theo Hafmans, Jacques Veerkamp, Marja van Luyn, Toin van Kuppevelt.

Biomaterials 2005;26:81-92. 


\begin{abstract}
Collagen-elastin scaffolds may be valuable biomaterials for tissue engineering because they combine tensile strength with elasticity. In this study, the tissue response to and the calcification of these scaffolds were evaluated. In particular, the hypothesis was tested that calcification, a common phenomenon in biomaterials, may be due to microfibrils within the elastic fibre, and that these microfibrils might generate a tissue response. Four scaffolds were subcutaneously implanted, viz. collagen, collagen + pure elastin, collagen + microfibril-containing elastin, and collagen + pulverised elastic ligament (the source for elastin). Explants were evaluated at day 3, 7 and 21 . In young Sprague Dawley rats, collagen + ligament calcified substantially, whereas collagen + elastin (with and without microfibrils) calcified less, and collagen did not. Calcification started at elastic fibres. In both Sprague Dawley and Wistar adult rats, however, none of the scaffolds calcified. Mononuclear cell infiltration was prominent in young and adult Sprague Dawley rats. In adult Wistar rats, this infiltration was associated with the presence of microfibrils.
\end{abstract}




\section{INTRODUCTION}

Tissue engineering involves the development of innovative biomaterials to replace or repair damaged and defective tissue. Type I collagen and elastin are structural extracellular matrix proteins that are abundantly present in human tissues and form natural scaffolds in the body. Collagen provides tensile strength and is widely used as a biomaterial, e.g. in skin substitutes, vascular grafts, scaffolds for cartilage repair, and bone implants [1-3]. Elastin provides elasticity to tissues. This, together with its stability due to specific interchain crosslinks, makes elastin a desirable protein for tissue engineering [4]. Recently, it has been demonstrated that elastin is capable to regulate proliferation, migration and differentiation of vascular smooth muscle cells, and that it reduces the vascular proliferative response to arterial injury in vivo [5]. This makes the application of elastin in tissue engineering even more significant. However, unlike type I collagen, elastin has found little use as a biomaterial [6-8]. One reason is that elastin preparations have a strong tendency to calcify upon implantation [9]. Another is that purification of elastin is complex [10]. Calcification may be due to microfibrillar components within the elastic fibre that are difficult to remove. A major component in this respect is fibrillin, which binds calcium due to its many calcium-binding EGF domains [11]. In dystrophic calcinosis cutis, mineralisation of the elastic fibre has been shown to start at microfibrils present within and surrounding the elastic fibre [12]. In general, calcification is a major, not well-understood problem in biomaterial application. Especially cardiovascular prosthetic implants such as bioprosthetic heart valves, aortic homografts and trileaflet polymeric valve prostheses are prone to calcify. Crosslinked cellular debris, collagen and elastin have been suggested as the onsets for calcification [13-15].

We previously described the preparation and biochemical, biomechanical, immunohistochemical and in vitro evaluation of collagen-elastin-glycosaminoglycan scaffolds [16]. In this study, we investigated whether purification of elastin, i.e. removal of microfibrils, can (partially) prevent calcification and may influence the tissue response such as cellular events and matrix remodelling. For this reason, we prepared four different scaffolds using purified collagen, purified elastin, partly purified elastin (i.e. with microfibrils) and elastic ligament (the source for elastin), and implanted these subcutaneously in rats. Different rat models were used to monitor variations between rat strain and age on the outcome of the experiment. 


\section{MATERIALS \& METHODS}

\section{Materials}

Four different biomaterials were prepared: 1) purified type I collagen, 2) purified insoluble elastin, 3) partly purified insoluble elastin, still containing microfibrils and some collagen, and 4) pulverised ligamentum nuchae, the source for elastin. Insoluble type I collagen was purified from bovine achilles tendon using diluted acetic acid, $\mathrm{NaCl}$, urea, and acetone extractions as described [17]. Insoluble elastin was isolated from equine ligamentum nuchae using extractions with $\mathrm{NaCl}$, organic solvents, $\mathrm{CNBr}$ in formic acid, urea with diluted 2-mercaptoethanol, and digestion with trypsin, essentially as described, but with omission of the collagenase digestion [10]. Microfibril-containing insoluble elastin was prepared using only one $\mathrm{NaCl}$ extraction, organic solvents extractions and $\mathrm{CNBr}$ in formic acid treatment. Pulverised equine ligamentum nuchae was prepared using a Fritsch Pulverisette 19 with a $1 \mathrm{~mm}$ sieve (Idar-Oberstein, Germany).

Mouse anti-bovine elastin IgG (clone BA-4) was purchased from Sigma Chemical Co. (St Louis, MO, USA). Rabbit anti-bovine type I collagen, rabbit anti-rat type I collagen, and rabbit anti-rat type III collagen IgGs were from Chemicon (Temecula, CA, USA). Goat anti-human type IV collagen IgG was from Southern Biotechnology Inc. (Birmingham, AL, USA). Alexa 488-labelled goat anti-mouse IgG, goat anti-rabbit IgG, and donkey anti-goat IgG were from Molecular Probes Europe (Leiden, The Netherlands).

\section{Preparation of scaffolds}

Four different scaffolds were prepared composed of purified collagen (COL), purified collagen + purified elastin in a 1:1 ratio (COL-EL), purified collagen + microfibrilcontaining elastin in a 1:1 ratio (COL-mfEL), and purified collagen + pulverised elastic ligament in a 1:1 ratio (COL-Ligament). Collagen was incorporated into all scaffolds, because we were unable to prepare coherent scaffolds of elastin only. Scaffolds were prepared by lyophilising an acidic $1 \%$ suspension of the various preparations. All scaffolds were chemically crosslinked for $4 \mathrm{~h}$ with $33 \mathrm{mM}$ 1-ethyl-3-(3-dimethyl aminopropyl)carbodiimide (EDC) and $6 \mathrm{mM}$ N-hydroxysuccinimide (NHS) in $50 \mathrm{mM} 2$ morpholinoethane sulfonic acid (MES) ( $\mathrm{pH} \mathrm{5.5)} \mathrm{in} \mathrm{the} \mathrm{presence} \mathrm{of} 40 \%$ (v/v) ethanol. After reaction, the scaffolds were washed in $0.1 \mathrm{M} \mathrm{Na}_{2} \mathrm{HPO}_{4}(\mathrm{pH} 9.1$ ), $1 \mathrm{M} \mathrm{NaCl}, 2 \mathrm{M}$ $\mathrm{NaCl}$, and demineralised water [16,17].

\section{Characterisation of elastin-containing preparations and scaffolds}

Sodium dodecyl sulphate polyacrylamide gel electrophoresis (SDS-PAGE): Purified elastin, microfibril-containing elastin, and pulverised ligamentum nuchae preparations 
were incubated at $95^{\circ} \mathrm{C}$ for 10 min under reducing conditions ( $5 \%$ (v/v) 2-mercaptoethanol) and analysed on a $10 \%(\mathrm{w} / \mathrm{v})$ gel. Non-elastin components will penetrate the gel and are visualised by a Coomassie Brilliant Blue solution (0.1\% (w/v)) [18].

Transmission electron microscopy (TEM): TEM was used to analyse the presence/ absence of microfibrils and other (extra)cellular components. Purified elastin, microfibril-containing elastin, and pulverised ligamentum nuchae preparations were embedded in $1.5 \%(\mathrm{w} / \mathrm{v})$ agarose, fixed in $2 \%(\mathrm{v} / \mathrm{v})$ glutaraldehyde in $0.1 \mathrm{M}$ phosphate buffer (pH 7.4) for $12 \mathrm{~h}$ at $4{ }^{\circ} \mathrm{C}$, and post fixed with $1 \%(\mathrm{w} / \mathrm{v}$ ) osmium tetroxide in 0.1 $\mathrm{M}$ phosphate buffer ( $\mathrm{pH}$ 7.4) for $1 \mathrm{~h}$. After a rinsing period of $3 \mathrm{~h}$ with $0.1 \mathrm{M}$ phosphate buffer ( $\mathrm{pH}$ 7.4), the samples were dehydrated in an ascending series of ethanols and embedded in Epon 812. Ultrathin sections $(60 \mathrm{~nm})$ were picked up on formvar-coated grids, post stained with lead citrate and uranyl acetate, and examined in a JEOL 1010 electron microscope.

Scanning electron microscopy (SEM): SEM was used to analyse the morphology of the scaffolds. Scaffolds were mounted on stubs and sputtered with an ultrathin layer of gold in a Polaron E5100 SEM coating system. Specimens were studied with a JEOL JSM-6310 SEM apparatus with an accelerating voltage of $15 \mathrm{kV}$.

Amine group content: The amine group content of scaffolds was determined spectrophotometrically after reaction with 2,4,6-trinitrobenzene sulfonic acid [19].

\section{Implantation of scaffolds}

NIH guidelines for the care and use of laboratory animals (NIH publication 85-23 Rev. 1985) were observed. The study was approved by the Ethical Committee of the University of Nijmegen. Sprague-Dawley rats (male, 21 days old and 3 months old) and Wistar rats (male, 3 months old) were purchased from Harlan (Zeist, The Netherlands). Young rats were housed per 3 , and adult rats per 2 . The animals were fed pelleted diet (RMH-B $10 \mathrm{~mm}$ ) and water ad libitum.

Scaffolds were washed in $70 \%(\mathrm{v} / \mathrm{v})$ ethanol $(4 \times 30 \mathrm{~min})$ and sterile phosphate buffered saline (PBS) (pH 7.2) ( 8 x $30 \mathrm{~min})$ at $22^{\circ} \mathrm{C}$. Rats were anaesthetised with halothane. After disinfection, subcutaneous pockets were made to the right and left of two midline incisions on the back. Punches ( $\varnothing 6 \mathrm{~mm}$ ) of the scaffolds were implanted in the pockets at a distance of about $1 \mathrm{~cm}$ from the incisions ( 4 implants/rat). For each implantation time, two rats received two punches of the same scaffold on one side of the midline incision. Implants with surrounding tissue were harvested from Sprague Dawley rats at 3, 7 and 21 days after implantation, from Wistar rats at 21 days only. 


\section{Processing of explants}

Immediately after explantation, scaffolds were divided in two halves. One half was processed for conventional light microscopy, the other half for immunohistochemistry.

Conventional histology: Scaffolds and surrounding tissue were fixed in $4 \%(\mathrm{v} / \mathrm{v})$ formaldehyde in phosphate buffer ( $\mathrm{pH}$ 7.2) immediately after explantation for at least $24 \mathrm{~h}$ at $4{ }^{\circ} \mathrm{C}$, and embedded in paraffin. Consecutive sections of $5 \mu \mathrm{m}$ were mounted onto glass slides, dewaxed in xylol and hydrated through a graded series of ethanol. Sections were routinely haematoxylin-eosin stained. Elastin and collagen were stained according to Elastin Van Gieson (EVG), and calcium deposits were visualised by Von Kossa staining [20]. Sections of the explants were semi-quantitatively scored independently by at least two experienced investigators.

Immunohistochemistry: Immunofluorescence microscopy was used to study the biodegradation of scaffold collagen and elastin, and the formation of new collagens by the host. Scaffolds were frozen in liquid nitrogen. Cryosections were mounted onto glass slides. After blocking with $1 \%(\mathrm{w} / \mathrm{v}$ ) bovine serum albumin (BSA) in PBS, sections were incubated with mouse anti-bovine elastin (1:1000), rabbit anti-bovine type I collagen, rabbit anti-rat type I collagen, rabbit anti-rat type III collagen (all 1:100), or goat anti-human type IV collagen (1:50) for $90 \mathrm{~min}$, washed with PBS, followed by a $1 \mathrm{~h}$ incubation with Alexa 488-labelled secondary antibodies (1:100). All antibodies were diluted in PBS containing $1 \%(\mathrm{w} / \mathrm{v})$ BSA. Sections were washed and mounted in mowiol. The antibody to bovine elastin also reacts with equine elastin; the antibody to human type IV collagen cross-reacts with rat type IV collagen; the antibody to bovine type I collagen does not substantially cross-react with rat type I collagen or vice versa.

\section{RESULTS}

\section{Characteristics of elastin preparations}

Elastin preparations were studied using SDS-PAGE and TEM (Fig. 1). SDS-PAGE of the elastin preparations indicated no contamination with other proteins in purified elastin, whereas microfibril-containing elastin and pulverised elastic ligament contained a large number of additional proteins. TEM indicated that the purified elastin fibres were free of microfibrils and no other structural elements could be detected. In microfibrilcontaining elastin, microfibrils could be easily observed as well as some residual collagen fibrils, but without any other contaminations. Pulverised elastic ligament contained all tissue elements, including damaged cells. 


\section{Characteristics of scaffolds}

The 3D morphology of the scaffolds was analysed with SEM (Fig. 2). Collagen was present as fine fibrillar and sheet-like structures, whereas elastin was observed as thick fibres. Pulverised ligament showed bundles of elastic fibres, since the collagenous meshwork between individual elastic fibres was not removed. The amine group content was measured to investigate the extent of EDC/NHS crosslinking. In all scaffolds, 35$40 \%$ of amine groups were used in crosslinking. Collagen possesses a larger amount of amine groups than elastin, which explains the absolute values for the different preparations (Table 1).
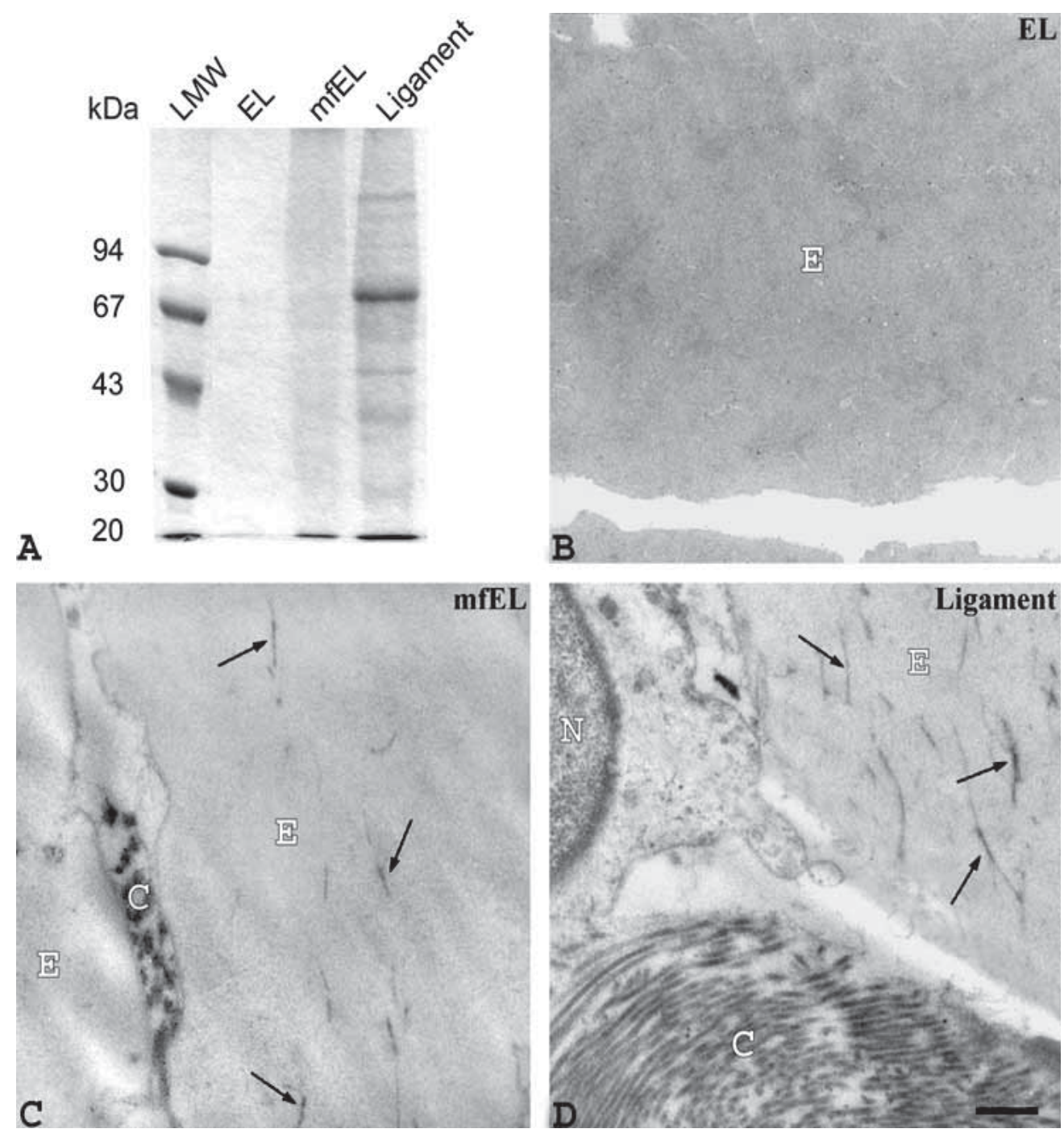

Figure 1. (A) SDS-PAGE gel of highly purified elastin (EL; $0.5 \mathrm{mg}$ ), microfibril-containing elastin (mfEL; $0.5 \mathrm{mg}$ ) and pulverised ligament $(0.1 \mathrm{mg})$. Only soluble contaminants and/or elastin breakdown products will enter the gel; insoluble elastin, which represents the vast majority of the preparations, does not. (B-D) Transmission electron micrographs of highly-purified elastin (B), partly-purified microfibril-containing elastin $(C)$, and pulverised elastic ligament $(D) . C=$ collagen; $E=$ elastin; $N=$ nucleus of fibroblast; arrows indicate microfibrils. Bar is $0.5 \mu \mathrm{m}$. 

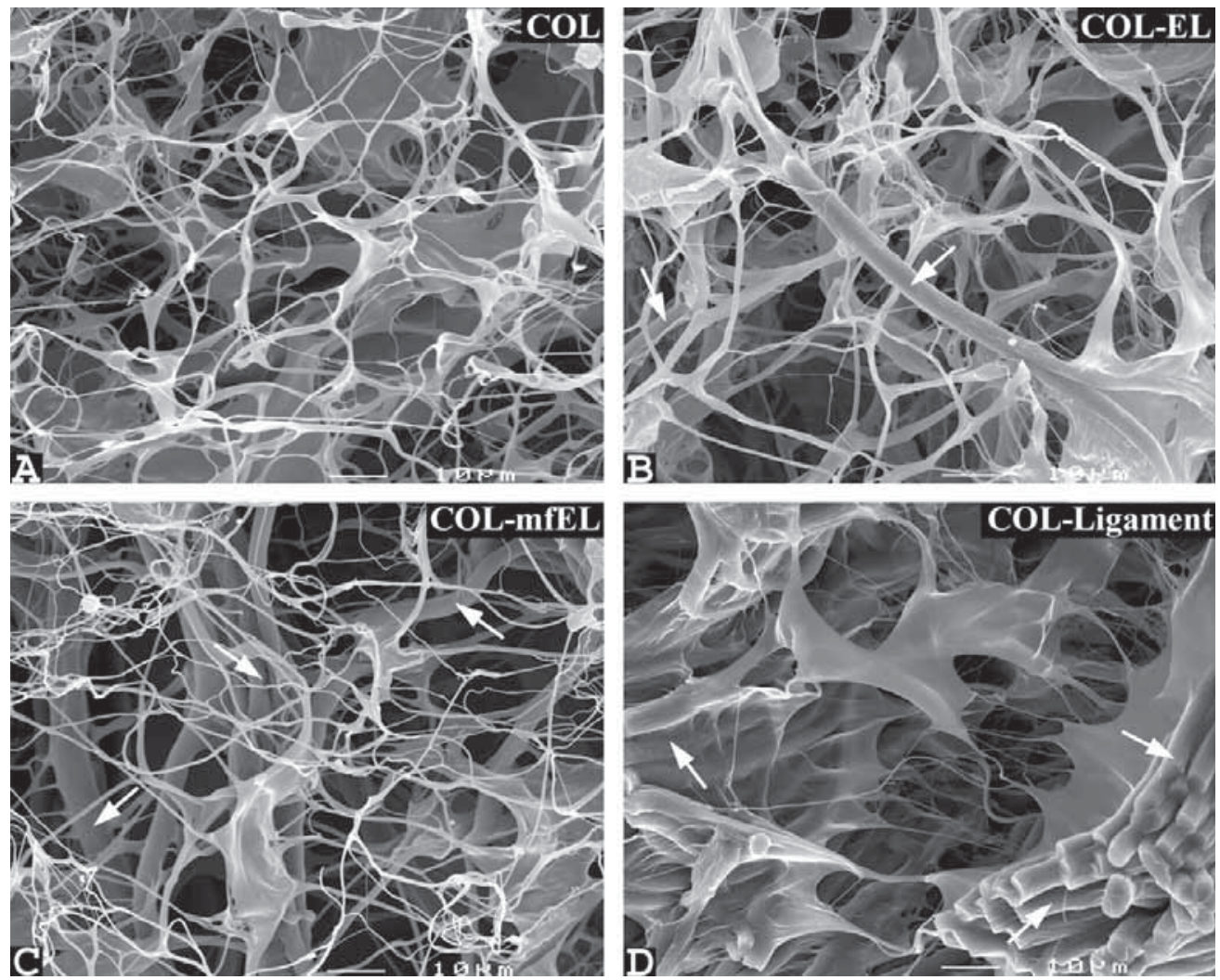

Figure 2. Scanning electron micrographs of the crosslinked scaffolds. (A) COL, (B) COL-EL, (C), COL-mfEL, and (D) COL-Ligament. Collagen is present as thin fibrils and sheets, elastin as thick fibres. Arrows indicate elastic fibres. Bar is $10 \mu \mathrm{m}$.

Table 1. Amine group content of various scaffolds.

\begin{tabular}{lcc}
\hline Scaffold & $\begin{array}{c}\text { Crosslinked with } \\
\text { EDC/NHS }\end{array}$ & $\begin{array}{c}\text { Amine group } \\
\text { content } \\
{[\mathrm{nmol} / \mathrm{mg}]}\end{array}$ \\
\hline COL & - & $294 \pm 1$ \\
COL & + & $191 \pm 10$ \\
COL-EL & - & $155 \pm 8$ \\
COL-EL & + & $98 \pm 8$ \\
COL-mfEL & - & $163 \pm 11$ \\
COL-mfEL & + & $97 \pm 17$ \\
COL-Ligament & - & $232 \pm 7$ \\
COL-Ligament & + & $137 \pm 10$ \\
\hline
\end{tabular}

$\mathrm{COL}=$ scaffold composed of collagen only; $\mathrm{COL}-\mathrm{EL}=$ scaffold composed of equal amounts of collagen and highly purified elastin; COL-mfEL = scaffold composed of equal amounts of collagen and microfibrilcontaining elastin; COL-Ligament $=$ scaffold composed of equal amounts of collagen and pulverised ligamentum nuchae. Results are mean \pm SD of three individual experiments. 


\section{Calcification of scaffolds}

All animals remained in good condition and no infectious problems occurred. Macroscopically, a thin capsule was observed around the scaffolds at explantation. In Table 2 an overview of calcification behaviour and cellular response is given.

\section{Young Sprague Dawley rats}

COL did not calcify in young Sprague Dawley rats except one out of 4 at day 21 as was assessed by Von Kossa staining. At day 3, some calcification could be observed in COL-Ligament where it was present within the elastic fibres. Calcification did not seem to be dependent on local cell infiltration, since calcification developed in cell-

free as well as cell-dense areas. All other scaffolds showed no calcification at this time point. At day 7, all of the composite scaffolds (COL-EL, COL-mfEL, COL-Ligament) showed calcification to some extent. COL-Ligament showed intensive calcification at elastic fibres only. At day 21, calcification of COL-EL, COL-mfEL, and COL-Ligament had increased (Fig. 3). COL-EL and COL-mfEL calcified to about the same extent. In COL-Ligament, calcification had extended to collagen.

\section{Adult Sprague Dawley rats}

\section{Adult Wistar rats}

All scaffolds implanted in adult rats did not show any calcification up to day 21 .

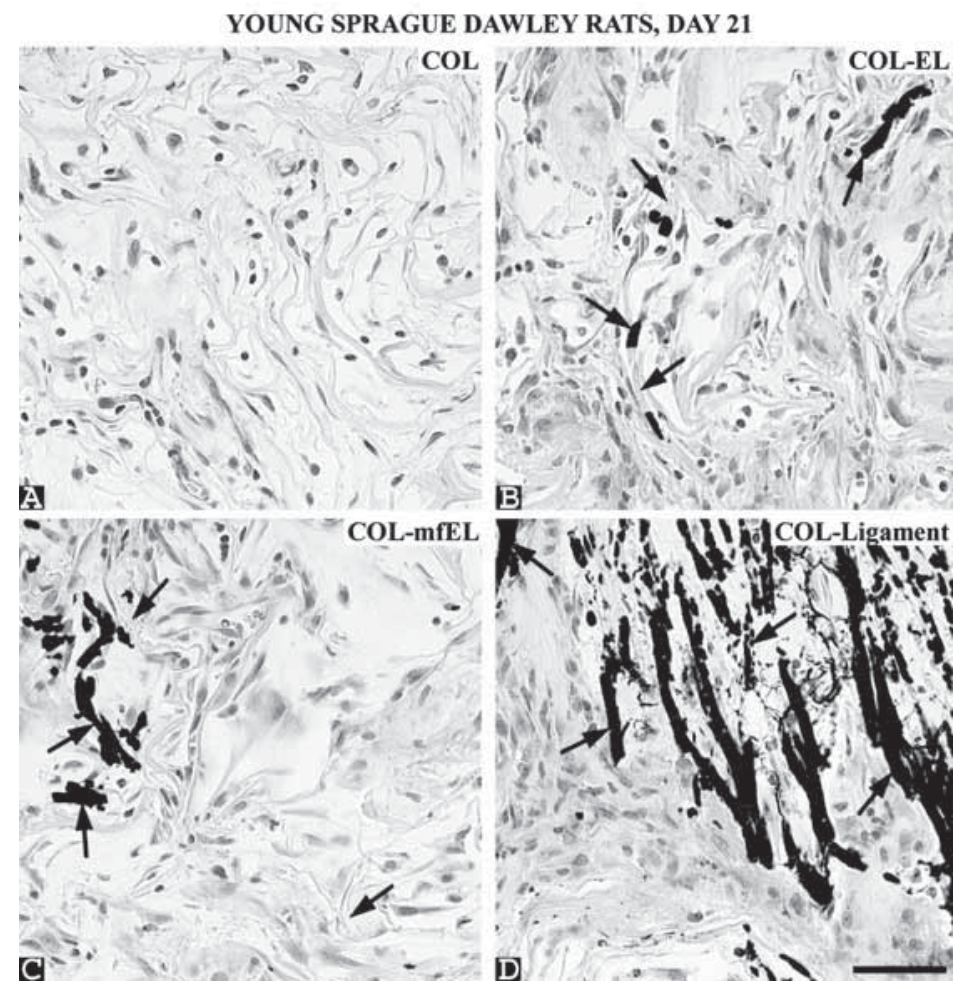

Figure 3. Light microscopical evaluation of the calcification of scaffolds, 21 days after implantation in young Sprague Dawley rats. (A) COL, (B) COL-EL, (C), COL-mfEL, and (D) COL-Ligament. Calcium deposits have an intense black colour due to Von Kossa staining. Arrows indicate elastic fibres. Bar is $50 \mu \mathrm{m}$. 
Table 2. General overview of calcification and cellular events after subcutaneous implantation of the scaffolds in rats.

\begin{tabular}{|c|c|c|c|c|c|c|c|}
\hline Scaffold & $\begin{array}{l}\text { Rat strain } \\
\text { and age }\end{array}$ & $\begin{array}{l}\text { Implantation } \\
\text { time (days) }\end{array}$ & Calcification & PMNs & $\begin{array}{l}\text { Phagocytic } \\
\text { cells }\end{array}$ & $\begin{array}{c}\text { Non-phagocytic } \\
\text { cells }\end{array}$ & $\begin{array}{c}\text { Blood } \\
\text { vessels** }\end{array}$ \\
\hline \multirow[t]{3}{*}{$\overline{\mathrm{COL}}$} & Sprague Dawley & 3 & - & $\mathrm{sp}$ & $s p$ & - & - \\
\hline & 3 weeks & 7 & - & $s p$ & + & sp & $s p$ \\
\hline & & 21 & $\cdots$ & $\because$ & \pm & \pm & \pm \\
\hline \multirow[t]{3}{*}{ COL-EL } & Sprague Dawley & 3 & $\cdot$ & \pm & \pm & $\cdot$ & $\cdot$ \\
\hline & 3 weeks & 7 & \pm & sp & + & sp & \pm \\
\hline & & 21 & + & $\therefore$ & + \pm & + & + \pm \\
\hline \multirow[t]{3}{*}{ COL-mfEL } & Sprague Dawley & 3 & - & + & \pm & - & - \\
\hline & 3 weeks & 7 & \pm & sp & \pm & sp & \pm \\
\hline & & 21 & + & - & + & + & + \\
\hline \multirow[t]{3}{*}{ COL-Ligament } & Sprague Dawley & 3 & sp & + & $\mathrm{sp}$ & - & sp \\
\hline & 3 weeks & 7 & + & sp & \pm & + & \pm \\
\hline & & 21 & + \pm & - & + & + \pm & + \\
\hline \multirow[t]{3}{*}{$\overline{\mathrm{COL}}$} & Sprague Dawley & 3 & - & sp & sp & sp & - \\
\hline & 3 months & 7 & - & \pm & \pm & + & sp \\
\hline & & 21 & - & sp & + & sp & \pm \\
\hline \multirow{3}{*}{ COL-EL } & Sprague Dawley & 3 & - & sp & $\mathrm{sp}$ & sp & $\mathrm{sp}$ \\
\hline & 3 months & 7 & - & sp & + & sp & + \\
\hline & & 21 & - & sp & + \pm & \pm & + \pm \\
\hline \multirow[t]{3}{*}{ COL-mfEL } & Sprague Dawley & 3 & - & \pm & sp & sp & $\mathrm{sp}$ \\
\hline & 3 months & 7 & - & sp & + \pm & \pm & \pm \\
\hline & & 21 & - & sp & ++ & \pm & + \\
\hline \multirow[t]{3}{*}{ COL-Ligament } & Sprague Dawley & 3 & - & + & sp & sp & $\mathrm{sp}$ \\
\hline & 3 months & 7 & - & sp & ++ & \pm & \pm \\
\hline & & 21 & - & sp & ++ & \pm & + \\
\hline \multirow[t]{2}{*}{$\overline{\mathrm{COL}}$} & Wistar & & & & & & \\
\hline & 3 months & 21 & . & - & sp & - & - \\
\hline \multirow[t]{2}{*}{ COL-EL } & Wistar & & & & & & \\
\hline & 3 months & 21 & - & . & \pm & - & - \\
\hline \multirow[t]{2}{*}{$\overline{C O L-m f E L}$} & Wistar & & & & & & \\
\hline & 3 months & 21 & - & - & + & \pm & sp \\
\hline \multirow[t]{2}{*}{ COL-Ligament } & Wistar & & & & & & \\
\hline & 3 months & 21 & - & - & \pm & \pm & sp \\
\hline
\end{tabular}

* Absolute numbers of phagocytic cells were higher than of PMNs or non-phagocytic cells, e.g. + for phagocytic cells refers to more cells than + for PMNs or non-phagocytic cells. ${ }^{* *}$ Blood vessels were assessed by immunostaining for rat type IV collagen, present in vascular basement membranes. ${ }^{* *} 1$ out of 4 implanted collagen scaffolds showed moderate calcification at this time point.

PMNs = polymorphic nuclear cells, i.e. granulocytes; phagocytic cells include monocyte-derived macrophages and monocytes; non-phagocytic cells include lymphocytes, plasma cells and mast cells. Events were scored ranging from sporadic $(\mathrm{sp})$ to severe $(++)$. -: not present.

\section{Tissue response to scaffolds}

Fig. 4 and Fig. 5 show some representative examples of the tissue response to scaffolds in young and adult Sprague Dawley rats and adult Wistar rats at different time points (see Table 2).

\section{Young Sprague Dawley rats}

At day 3, several macrophages and some polymorphic nuclear granulocytes (PMNs) were present, mostly at the periphery of the scaffolds. More PMNs were present near elastic fibres than near collagen, especially in COL-Ligament and COL-mfEL. At day 7, a fibrous capsule was observed around the scaffolds. Some capillaries were located in the capsule and at the periphery of the scaffolds. At this time, PMNs were only sporadically present, while early events of mononuclear cell infiltrations were found. Mononuclear cells include phagocytic cells like active monocyte-derived macrophages, monocytes as well as non-phagocytic cells such as lymphocytes, plasma cells and mast cells. Foreign body giant cells (fused macrophages with multiple nuclei) were encountered in variable amount. At day 21, capillaries were present in between the fibres of the scaffolds. Phagocytic cells dominated the scaffolds, while the amount of non-phagocytic cells increased at the periphery, especially near COL-Ligament and COL-mfEL (Fig. 4). 

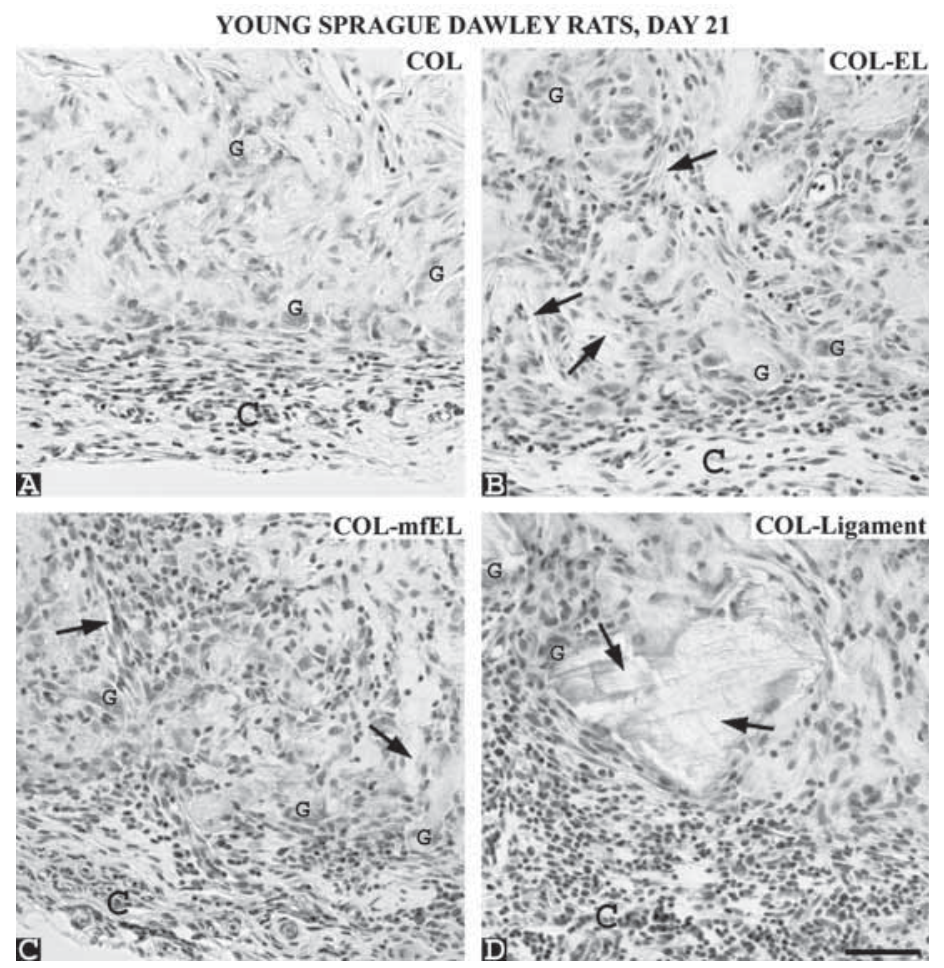

Figure 4. Light microscopical overview of the cellular response to scaffolds at day 21 in young Sprague Dawley rats. (A) COL, (B) COL-EL, (C), COL-mfEL, and (D) COL-Ligament. Note the increased amount of mononuclear cell infiltration, especially in COL-Ligament scaffolds. Sections were HE stained. C= capsule; $G=$ giant cell; arrows indicate elastic fibres. Bar is $50 \mu \mathrm{m}$.

\section{Adult Sprague Dawley rats}

At day 3, all implants were encapsulated with a fibrous capsule. Some PMNs had infiltrated mainly COL-mfEL and COL-Ligament (Fig. 5A, B), while some phagocytic cells infiltrated COL and COL-EL. At day 7, PMNs were only sporadically found. Increased fibrous encapsulation was commonly present with capillaries both intracapsularly and at the periphery of the scaffolds. Phagocytic cells accumulated both at the periphery and to less extent in the scaffold. Most of these cells were present in COL-Ligament, less in COL-mfEL and COL-EL, and only at the periphery of COL. (Fig. 5C, D). At day 21, capillaries were found throughout COL-Ligament, COL-mfEL and COL-EL and these scaffolds were almost completely infiltrated with phagocytic cells, but to less extent in COL.

\section{Adult Wistar rats}

Scaffolds from adult Wistar rats were only explanted at day 21 (Fig. 5E, F). At this time, a fibrous capsule was formed around all scaffolds. In general, the tissue response of adult Wistar rats to implanted scaffolds was distinctly milder compared to Sprague Dawley rats. Few cells had infiltrated the scaffolds. COL and COL-EL showed few mononuclear and giant cells at the periphery. In COL-mfEL and COL-Ligament, these cells had infiltrated deeper into the scaffolds. 
ADULT RATS
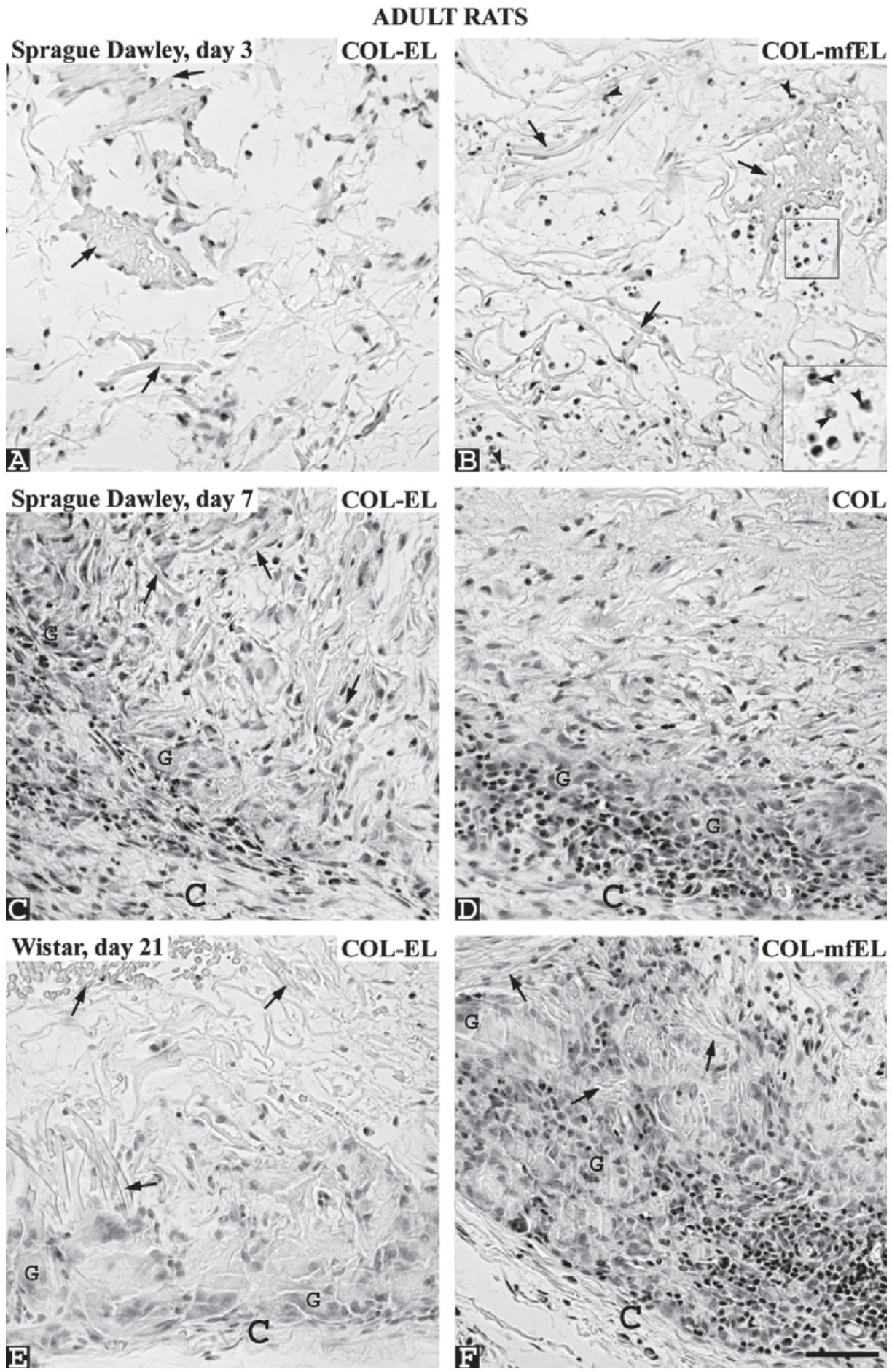

Figure 5. Light microscopical evaluation of the cellular response to scaffolds implanted in adult Sprague Dawley rats (A-D) and adult Wistar rats (E-F). (A) COL-EL and (B) COL-mfEL 3 days after implantation. Note that more PMN's (neutrophiles) are present in COL-mfEL than in COL-EL. (C) COL-EL and (D) COL 7 days after implantation. In COL, an increase of mononuclear cells, especially non-phagocytic cells, was found at the periphery of the scaffold. (E) COL-EL and $(F)$ COL-mfEL 21 days after implantation. In COL-mfEL, locally an increase of mononuclear cells was found. Sections were HE stained. $C=$ capsule; $G=$ giant cell; arrow heads indicate neutrophiles; arrows indicate elastic fibres. Bar is $50 \mu \mathrm{m}$. 


\section{Vascularisation of the scaffolds}

\section{Young Sprague Dawley rats}

Few small blood vessels, visualised by immunostaining for type IV collagen present in endothelial basement membranes, were found at day 7 at the periphery of the scaffolds. At day 21, some blood vessels were found at the periphery of COL, while other scaffolds showed more vascularisation at that time, both at the periphery and within the scaffolds.

\section{Adult Sprague Dawley rats}

Vascularisation increased over time. In general, COL-EL, COL-mfEL and COL-Ligament contained more blood vessels than COL. At day 7, vascularisation of COL-EL, COL-mfEL and COL-Ligament was mainly in the capsule and at the periphery of the scaffolds; at day 21 it was also within the scaffold (Fig 6A, B).

\section{Adult Wistar rats}

Few blood vessels were only found at the periphery of COL-mfEL and COL-Ligament.

ADULT SPRAGUE DAWLEY RATS, COL-EL SCAFFOLDS
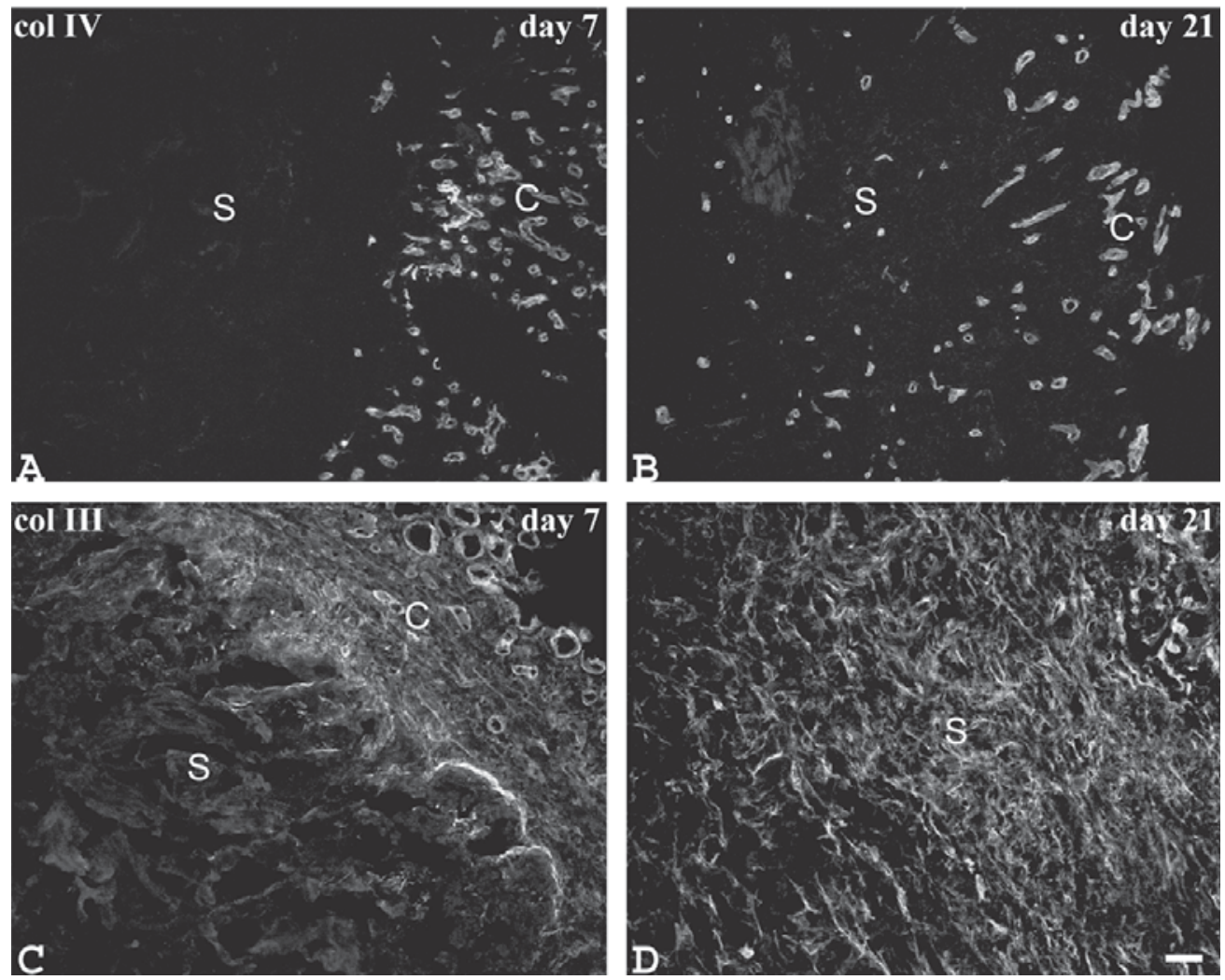

Figure 6. Immunostaining of COL-EL scaffolds for type IV and type III collagen as indicators of vascularisation and matrix production after subcutaneous implantation in adult Sprague Dawley rats. (A) COL-EL after 7 and (B) after 21 days immunostained for type IV collagen. At day 7, type IV collagen staining is mainly present at the periphery, at day 21 in the whole scaffold. (C) COL-EL after 7 days and (D) after 21 days immunostained for type III collagen. At day 7, type III collagen staining is mainly present at the scaffold periphery, at day 21 it is found throughout the scaffold. $C=$ capsule; $S=$ scaffold. Bar is $50 \mu \mathrm{m}$. 


\section{Scaffold degradation and matrix synthesis}

Table 3 gives an overview of the immunofluorescence staining for scaffold components and for newly formed extracellular matrix molecules at different time points.

Table 3. Overview of immunostaining results of explants for scaffold and rat extracellular matrix components.

\begin{tabular}{|c|c|c|c|c|c|c|}
\hline & $\begin{array}{l}\text { Rat strain } \\
\text { and age }\end{array}$ & $\begin{array}{l}\text { Implantation } \\
\text { time (days) }\end{array}$ & Scaffold collagen & Scaffold elastin & Rat type I collagen & Rat type III collagen \\
\hline \multirow[t]{3}{*}{$\overline{\mathrm{COL}}$} & Sprague Dawley & 3 & ++ & - & $\mathrm{sp}$ & - \\
\hline & 3 weeks & 7 & ++ & - & \pm & \pm \\
\hline & & 21 & + \pm & - & \pm & + \\
\hline \multirow[t]{3}{*}{ COL-EL } & Sprague Dawley & 3 & ++ & ++ & sp & - \\
\hline & 3 weeks & 7 & ++ & ++ & \pm & + \\
\hline & & 21 & + & + & + & ++ \\
\hline \multirow[t]{3}{*}{ COL-mfEL } & Sprague Dawley & 3 & ++ & ++ & sp & $\cdot$ \\
\hline & 3 weeks & 7 & ++ & ++ & \pm & + \\
\hline & & 21 & + & + & + & ++ \\
\hline \multirow[t]{3}{*}{ COL-Ligament } & Sprague Dawley & 3 & ++ & ++ & sp & \pm \\
\hline & 3 weeks & 7 & ++ & + \pm & + & + \\
\hline & & 21 & + & \pm & \pm \pm & ++ \\
\hline \multirow[t]{3}{*}{$\overline{\mathrm{COL}}$} & Sprague Dawley & 3 & ++ & $=$ & sp & - \\
\hline & 3 months & 7 & ++ & - & \pm & + \\
\hline & & 21 & + \pm & - & \pm & + \\
\hline \multirow[t]{3}{*}{ COL-EL } & Sprague Dawley & 3 & ++ & ++ & sp & sp \\
\hline & 3 months & 7 & + \pm & + \pm & \pm & + \\
\hline & & 21 & + & + & + & ++ \\
\hline \multirow[t]{3}{*}{ COL-mfEL } & Sprague Dawley & 3 & ++ & ++ & sp & sp \\
\hline & 3 months & 7 & + \pm & + \pm & \pm & + \\
\hline & & 21 & + & + & $\#$ & t+ \\
\hline \multirow[t]{3}{*}{ COL-Ligament } & Sprague Dawley & 3 & +t+ & ++ & sp & \pm \\
\hline & 3 months & 7 & + & + & + & + \\
\hline & & 21 & \pm & \pm & \pm & ++ \\
\hline \multirow[t]{2}{*}{$\overline{\mathrm{COL}}$} & Wistar & & & & & \\
\hline & 3 months & 21 & ++ & - & sp & \pm \\
\hline COL-EL & $\begin{array}{l}\text { Wistar } \\
3 \text { months }\end{array}$ & 21 & t+ & t+ & sp & \pm \\
\hline COL-mfEL & $\begin{array}{l}\text { Wistar } \\
3 \text { months }\end{array}$ & 21 & ++ & ++ & so & + \\
\hline \multirow[t]{2}{*}{ COL-Ligament } & Wistar & & & & & \\
\hline & 3 months & 21 & ++ & ++ & sp & + \\
\hline
\end{tabular}

Events were scored ranging from sporadic $(\mathrm{sp})$ to abundant $(++)$. -: not present.

\section{Scaffold degradation}

\section{Young Sprague Dawley rats}

Conventional histology showed small amounts of degraded collagen which were locally visible from day 7 on at the periphery. At day 21, degraded collagen was also found deeper within the scaffolds, but especially centrally a large amount of intact scaffold collagen remained present. Immunostaining for bovine type I collagen supported these findings. At day 21, the presence of thin and fragmented collagen structures were most profound at the scaffold periphery. Locally, fragmented elastin in COL-EL, COL-mfEL and COL-Ligament was found from day 7 on. At day 21, the total amount of elastic fibres was decreased and more fragmented elastic fibres were observed, suggesting resorption and degradation of the fibres. Both calcified elastin/elastic fibres and non-calcified elastin/elastic fibres were found within macrophages and giant cells. Immunofluorescence results showed that staining for elastin gave the best signal for COL-EL, most likely due to unmasking of the epitope during purification. Calcified elastin could also be visualised with the antibody. Fragments of elastin (smaller than elastic fibres) were found in all elastin-containing scaffolds at day 21. 


\section{Adult Sprague Dawley rats}

Degraded collagen was visible at the periphery at day 7. Fragmented elastin (both EL and mfEL) was visible locally from day 7 on. Especially in COL-Ligament scaffolds, severely fragmented elastic fibres were present at day 21, suggesting fastest degradation of these scaffolds.

\section{Adult Wistar rats}

At day 21, a large amount of scaffold collagen and elastin was still present in adult Wistar rats, implying the lowest degradation rate of scaffolds in all rat models used. Only locally, degraded collagen fibrils and elastic fibres were observed at the periphery for all scaffolds.

\section{Matrix synthesis}

\section{Young Sprague Dawley rats}

Newly formed rat type I collagen was generally found in the fibrous capsule surrounding the implant and aligning with the collagen fibrils in the scaffold. At day 21, young Sprague Dawley rats showed more staining for type I collagen in elastin-containing scaffolds than in collagen scaffolds.

From day 7 on, type III collagen could be clearly observed in the fibrous capsule and at the periphery of the scaffolds. At day 21, type III collagen was present throughout the scaffolds, aligning with the collagenous and elastinous scaffold components. Staining for type III collagen in COL was less intense than in the other scaffolds.

\section{Adult Sprague Dawley rats}

In adult Sprague Dawley rats, staining for rat type I and III collagen was similar to staining in young Sprague Dawley rats. Whereas at day 7 type III collagen was mainly present in the capsule and the outer part of the scaffolds, at day 21 it was found throughout the scaffold (Fig. 6C, D).

\section{Adult Wistar rats}

At day 21, minor amounts of new matrix collagens were observed in scaffolds implanted in adult Wistar rats. Type I collagen was sporadically found in all scaffolds, more type III collagen was found in COL-mfEL and COL-Ligament scaffolds than in COL and COL-EL.

\section{DISCUSSION}

Tissue response to new biomaterials has to be evaluated before their use in tissue engineering for clinical purpose. Here, we studied the tissue response and calcification of subcutaneous implanted porous biomaterials composed of either collagen only (COL), collagen + highly-purified insoluble elastin in a 1:1 ratio (COL-EL), collagen + microfibril-containing (i.e. partly purified) elastin in a 1:1 ratio (COL-mfEL), and collagen + pulverised ligament in a 1:1 ratio (COL-Ligament). Young and adult Sprague 
Dawley rats and adult Wistar rats were used as animal models.

The juvenile rat is widely accepted as a sensitive model to evaluate calcification $[9,13,21,22]$. In our experiment, calcification only occurred when elastin-containing scaffolds were implanted in young Sprague Dawley rats (3 weeks old at implantation), but no calcification was found when scaffolds were implanted in adult Sprague Dawley or Wistar rats (3 months old). Calcification of implanted biomaterials depends on many variables. One of them is the animal's age. Nimni et al. already found that after two weeks skin collagen subcutaneously implanted in young Long Evans rats (one month old) calcified much more than in older ones (8 months old) [23]. Another parameter for calcification may be the purity of the material. In our experiment, collagen scaffolds did not give rise to calcification in young rats (only 1 out of 12 showed calcification). Using a purified acellular intestinal collagen layer, Abraham et al. did not find calcification either [24]. With less-defined collagen preparations, calcium deposits are formed indicating that contaminants may trigger calcification $[14,23,25]$. This partially applies to elastin as well. Calcification started within the elastic fibre [15]. Calcification was seen from day 3 for COL-Ligament scaffolds, and from day 7 for COL-mfEL and COL-EL scaffolds. Although absence of microfibrils from the elastic fibre did not result in a decrease of calcification, calcification was more severe if an impure preparation (i.e. pulverised ligament) was used. Our hypothesis that calcification may be partly due to the presence of microfibrils within the elastic fibre could be rejected in this study. Another calcification variable might be imputed to the intactness of the elastic fibre. Bailey et al. recently found that fragmented and damaged aortic elastic fibres are associated with more severe calcification than intact ones [26]. Our purified elastic fibres are still intact, though. Calcification may be genetically controlled by molecules that actively inhibit calcification and may occur passively when these inhibitors are absent [27]. Other possible solutions to prevent calcification are aluminium chloride treatment [9], ethanol/EDTA treatment [28], and attachment of glycosaminoglycans [29,30].

This study underlines that young Sprague Dawley rats are a sensitive model to study calcification. Apart from that, an accompanying strong tissue response was characteristic for these rats. Major cellular infiltrations were found in COL-EL, COL-mfEL and COL-Ligament scaffolds at day 21. Van Wachem et al. observed huge infiltration of lymphocytes, including numerous plasma cells, after subcutaneous implantation of porcine heart valve cusps and walls into young Sprague Dawley rats [31]. However, in our scaffolds, we found substantially less mononuclear cells in both young and adult Sprague Dawley rats. Adult Wistar rats showed an even milder tissue response to the implanted scaffolds. Elastin without microfibrils resulted in less infiltration of mononuclear cells compared to microfibril-containing elastin. For tissue engineering purposes, fibres of highly purified elastin are thus preferred to microfibril-containing elastic fibres. 
Scaffolds showed to be biodegradable by all hosts, as expected, but none of the scaffolds was fully resorbed at day 21. Degradation was associated with phagocytic cells, and calcified elastic fibres were found in macrophages and to a certain extent in giant cells. More degradation was found in Sprague Dawley rats, which was underlined by the higher numbers of phagocytic cells in these scaffolds. Minor collagen degradation of crosslinked collagen scaffolds took place in Wistar rats, which was comparable with results described by Pieper et al. [32]. In this rat strain, elastin was only locally degraded. Collagen-elastin scaffolds may thus function as a temporary elastic matrix here [16].

Type I and type III collagens were made by all hosts. Generally, with a more extensive tissue response, new matrix formation and vascularisation occurred both earlier in time and to a larger extent. This means that in both young and adult Sprague Dawley rats more new matrix components were produced than in Wistar rats. In most cases, the presence of elastin in the scaffold was associated with a higher degree of vascularisation.

Elastin-containing scaffolds did not calcify in adult rats. In young rats, however, calcification of scaffolds containing elastin or elastic fibres was observed and removal of microfibrils from the elastic fibre did not prevent or reduce this. Absence of microfibrils reduced the tissue response in adult Wistar rats. Tissue response to and calcification of scaffolds differed with age, strain and purity of the materials and therefore the choice of animal model is of key importance when evaluating biomaterials for their capacity to function as a temporary matrix for tissue engineering and matrix remodelling.

\section{REFERENCES}

1. Kim BS, Baez CE, Atala A. Biomaterials for tissue engineering. World J Urol 2000;18:2-9.

2. Van Susante JLC, Pieper J, Buma P, Van Kuppevelt TH, Van Beuningen H, Van Der Kraan PM, Veerkamp JH, Van Den Berg WB, Veth RPH. Linkage of chondroitin-sulfate to type I collagen scaffolds stimulates the bioactivity of seeded chondrocytes in vitro. Biomaterials 2001;22:2359-2369.

3. Lee CH, Singla A, Lee Y. Biomedical applications of collagen. Int J Pharm 2001;221:1-22.

4. Kielty CM, Sherratt MJ, Shuttleworth CA. Elastic fibres. J Cell Sci 2002;115:2817-2828.

5. Karnik SK, Brooke BS, Bayes-Genis A, Sorensen L, Wythe JD, Schwartz RS, Keating MT, Li DY. A critical role for elastin signaling in vascular morphogenesis and disease. Development 2003;130:411423.

6. Samouillan V, Dandurand-Lods J, Lamure A, Maurel E, Lacabanne C, Gerosa G, Venturini A, Casarotto D, Gherardini L, Spina M. Thermal analysis characterization of aortic tissues for cardiac valve bioprostheses. J Biomed Mater Res 1999;46:531-538.

7. Lamme EN, De Vries JC, Van Veen H, Gabbiani G, Westerhof W, Middelkoop E. Extracellular matrix characterization during healing of full-thickness wounds treated with a collagen/elastin dermal substitute shows improved skin regeneration in pigs. J Histochem Cytochem 1996;44:1311-1322.

8. Rabaud M, Elie JY, Lefebvre F, Ducassou D, Mettetal P, Le Guillou M, Collet D, Perissat J, Fradin D, Fontan F. A new biodegradable elastin-fibrin material; its use in urological, digestive and cardiovascular surgery. J Biomater Appl 1992;7:20-46.

9. Vyavahare N, Ogle M, Schoen FJ, Levy RJ. Elastin calcification and its prevention with aluminum chloride pretreatment. Am J Pathol 1999;155:973-982.

10. Daamen WF, Hafmans T, Veerkamp JH, Van Kuppevelt TH. Comparison of five procedures for the purification of insoluble elastin. Biomaterials 2001;22:1997-2005.

11. Handford PA. Fibrillin-1, a calcium binding protein of extracellular matrix. Biochim Biophys Acta 2000;1498:84-90.

12. Fartasch M, Haneke E, Hornstein OP. Mineralization of collagen and elastic fibers in superficial dystrophic cutaneous calcification: an ultrastructural study. Dermatologica 1990;181:187-192. 
13. Paule WJ, Bernick S, Strates B, Nimni ME. Calcification of implanted vascular tissues associated with elastin in an experimental animal model. J Biomed Mater Res 1992;26:1169-1177.

14. Nimni ME, Myers D, Ertl D, Han B. Factors which affect the calcification of tissue-derived bioprostheses. J Biomed Mater Res 1997;35:531-537.

15. Schoen FJ, Levy RJ. Tissue heart valves: current challenges and future research perspectives. J Biomed Mater Res 1999;47:439-465.

16. Daamen WF, Van Moerkerk HThB, Hafmans T, Buttafoco L, Poot AA, Veerkamp JH, Van Kuppevelt TH. Preparation and evaluation of molecularly-defined collagen-elastin-glycosaminoglycan scaffolds for tissue engineering. Biomaterials 2003;24:4001-4009.

17. Pieper JS, Oosterhof A, Dijkstra PJ, Veerkamp JH, Van Kuppevelt TH. Preparation and characterization of porous crosslinked collagenous matrices containing bioavailable chondroitin sulphate. Biomaterials 1999;20:847-858.

18. Daamen WF, Hafmans T, Veerkamp JH, Van Kuppevelt TH. Comparison of five procedures for the purification of insoluble elastin. Biomaterials 2001;22:1997-2005.

19. Laemmli UK. Cleavage of structural proteins during the assembly of the head of bacteriophage T4. Nature 1970;227:680-689.

20. Olde Damink LH, Dijkstra PJ, Van Luyn MJ, Van Wachem PB, Nieuwenhuis P, Feijen J. Cross-linking of dermal sheep collagen using a water-soluble carbodiimide. Biomaterials 1996;17:765-773.

21. Bancroft JD, Stevens A. Theory and practice of histological techniques. Edinburgh (UK). Churchill Livingstone, 1990.

22. Vyavahare N, Ogle M, Schoen FJ, Levy RJ. Elastin calcification and its prevention with aluminum chloride pretreatment. Am J Pathol 1999;155:973-982.

23. Paule WJ, Bernick S, Strates B, Nimni ME. Calcification of implanted vascular tissues associated with elastin in an experimental animal model. J Biomed Mater Res 1992;26:1169-1177.

24. Van Luyn MJ, Van Wachem PB, Dijkstra PJ, Olde Damink LH, Feijen J. Calcification of subcutaneously implanted collagens in relation to cytotoxicity, cellular interactions and crosslinking. J Mat Sci 1995;6:288-296.

25. Chanda J, Kuribayashi R, Abe T. Heparin coupling in inhibition of calcification of vascular bioprostheses. Biomaterials 1999;20:1753-1757.

26. Nimni ME, Bernick S, Cheung DT, Ertl DC, Nishimoto SK, Paule WJ, Salka C, Strates BS. Biochemical differences between dystrophic calcification of cross-linked collagen implants and mineralization during bone induction. Calcif Tissue Int 1988;42:313-320.

27. Abraham GA, Murray J, Billiar K, Sullivan SJ. Evaluation of the porcine intestinal collagen layer as a biomaterial. J Biomed Mater Res 2000;51:442-452.

28. Nimni ME, Myers D, Ertl D, Han B. Factors which affect the calcification of tissue-derived bioprostheses. J Biomed Mater Res 1997;35:531-537.

29. Nimni ME, Bernick S, Cheung DT, Ertl DC, Nishimoto SK, Paule WJ, Salka C, Strates BS. Biochemical differences between dystrophic calcification of cross-linked collagen implants and mineralization during bone induction. Calcif Tissue Int 1988;42:313-320.

30. Van Wachem PB, Van Luyn MJ, Olde Damink LH, Dijkstra PJ, Feijen J, Nieuwenhuis P. Biocompatibility and tissue regenerating capacity of crosslinked dermal sheep collagen. J Biomed Mater Res 1994;28:353-363.

31. Schoen FJ, Levy RJ. Tissue heart valves: current challenges and future research perspectives. J Biomed Mater Res 1999;47:439-465.

32. Bailey MT, Pillarisetti S, Xiao H, Vyavahare NR. Role of elastin in pathologic calcification of xenograft heart valves. J Biomed Mater Res 2003;66A:93-102.

33. Schinke T, McKee MD, Karsenty G. Extracellular matrix calcification: where is the action? Nat Genet 1999;21:150-151.

34. Vyavahare N, Ogle M, Schoen FJ, Levy RJ. Elastin calcification and its prevention with aluminum chloride pretreatment. Am J Pathol 1999;155:973-982.

35. Singla A, Lee $\mathrm{CH}$. Inhibition of CEM calcification by the sequential pretreatment with ethanol and EDTA. J Biomed Mater Res 2003;64A:706-713.

36. Andre-Frei V, Chevallay B, Orly I, Boudeulle M, Huc A, Herbage D. Acellular mineral deposition in collagen-based biomaterials incubated in cell culture media. Calcif Tissue Int 2000;66:204-211.

37. Simionescu DT, Lovekamp JJ, Vyavahare NR. Glycosaminoglycan-degrading enzymes in porcine aortic heart valves: implications for bioprosthetic heart valve degeneration. J Heart Valve Dis 2003;12:217-225.

38. Van Wachem PB, Brouwer LA, Zeeman R, Dijkstra PJ, Feijen J, Hendriks M, Cahalan PT, Van Luyn MJ. In vivo behavior of epoxy-crosslinked porcine heart valve cusps and walls. J Biomed Mater Res 2000;53:18-27.

39. Pieper JS, Van Wachem PB, Van Luyn MJ, Brouwer LA, Hafmans T, Veerkamp JH, Van Kuppevelt TH. Attachment of glycosaminoglycans to collagenous matrices modulates the tissue response in rats. Biomaterials 2000;21:1689-1699. 


\section{Chapter 6}

\section{A biomaterial composed of collagen and solubilised elastin enhances angiogenesis and elastic fibre formation without calcification}

Willeke Daamen, Suzan Nillesen, Ronnie Wismans, Dieter Reinhardt, Theo Hafmans, Jacques Veerkamp, Toin van Kuppevelt. 


\begin{abstract}
Elastin is the prime protein in elastic tissues that contributes to elasticity of e.g. lung, aorta, and skin. Upon injury, elastic fibres are not readily replaced which hampers tissue regeneration. Incorporation of solubilised elastin (hydrolysed insoluble elastin fibres or elastin peptides) in biomaterials may improve regeneration, since solubilised elastin is able to promote proliferation as well as elastin synthesis.

Porous biomaterials composed of highly purified collagen and solubilised elastin were prepared by freezing and lyophilisation. Solubilised elastin formed spherical structures that were incorporated in the collagenous part of the scaffolds and that persisted after chemical crosslinking of the scaffolds. Crosslinked collagen-solubilised elastin scaffolds were subcutaneously implanted in young Sprague Dawley rats where they formed a depot for solubilised elastin. The scaffolds showed no calcification in this sensitive calcification model, in contrast to scaffolds containing elastin fibres. Scaffolds also induced angiogenesis, as was revealed by type IV collagen staining, and promoted elastic fibre synthesis, as was shown with antibodies against rat elastin and fibrillin-1. It is concluded that scaffolds produced from collagen and solubilised elastin present a non-calcifying biomaterial with a capacity for soft tissue regeneration, especially in relation to elastic fibre synthesis.
\end{abstract}




\section{INTRODUCTION}

Elastin is the major insoluble protein present in elastic tissue contributing to the elasticity of lung, aorta, ligaments and skin. Elastic fibres are not readily replaced upon injury, probably due to difficulties in recapitulating normal developmental expression patterns of tropoelastin and associated molecules $[1,2]$. This seriously hampers tissue regeneration.

Solubilised elastin (obtained by hydrolysing insoluble elastin) may markedly improve tissue regeneration, since it exhibits multiple biological effects. These include enhanced cell migration [3], cell proliferation [4] and elastin synthesis [5,6]. Solubilised elastin interacts with the elastin-laminin receptor which is composed of three subunits; two transmembrane subunits of 61 and $55 \mathrm{kDa}$ and one extracellular subunit of $67 \mathrm{kDa}$, the latter binding tropoelastin and other elastin-like molecules. The receptor is present on a large number of cells, including fibroblasts, vascular smooth muscle cells, endothelial cells, chondrocytes, monocytes, lymphocytes and polymorphonuclear leukocytes and its signal transduction pathway is mediated through a pertussis toxin sensitive Gprotein [7-10]. In addition to the elastin-laminin receptor, other receptors may play a role as well, e.g. integrins [11]. Biomaterials containing solubilised elastin may thus exert biological effects on a wide variety of cell types.

We have previously prepared biomaterials composed of highly purified type I collagen and elastin fibres and studied their tissue reaction $[12,13]$. In young Sprague Dawley rats (but not in adult rats), implantation of these scaffolds resulted in calcification of elastin fibres. Although initiation of tissue calcification does not require a cellular response [14], the in vivo milieu can accelerate the process [15], e.g. through the extracellular release of enzymes by macrophages and giant cells involved in elastin degradation [16-18].

In this study, we prepared porous scaffolds containing solubilised elastin. Solubilised elastin may improve synthesis of elastin through interaction with the elastin-laminin receptor [5]. Furthermore, if enzymes involved in elastin degradation indeed play a role in increasing calcification, application of solubilised elastin may reduce the presence of macrophages and giant cells and thus reduce calcification. In addition, solubilised elastin is less hydrophobic and additionally charged compared to insoluble elastin. Negative charges from C-terminal carboxylic groups may prevent positively charged calcium ions from precipitating in the same way as negatively charged sulfate groups have been shown to suppress calcium-binding to e.g. polyurethane [19]. In this study, we prepared and characterised collagen-solubilised elastin scaffolds and studied their in vivo behaviour with respect to calcification, angiogenesis and elastin synthesis. 


\section{MATERIALS \& METHODS}

\section{Materials}

Mouse anti-bovine elastin IgG clone BA-4 was purchased from Sigma Chemical Co. (St Louis, MO, USA); goat anti-rat alpha-elastin from Elastin Products Co. (Owensville, MO, USA); rabbit anti-bovine type I collagen, rabbit anti-rat type I collagen, and rabbit anti-rat type III collagen IgGs from Chemicon (Temecula, CA, USA); goat anti-human type IV collagen IgG from Southern Biotechnology Inc. (Birmingham, AL, USA). Rabbit anti-human fibrillin-1 (pAb-rF6H) and rabbit anti-human fibrillin-2 (anti-rFBN21) antisera were prepared as described [20,21]. Alexa488- and Alexa594-labelled secondary antibodies were from Molecular Probes Europe (Leiden, The Netherlands), rabbit anti-goat peroxidase and 3,3-diaminobenzidine tetrahydrochloride (DAB) were from DAKO (Glostrup, Denmark).

\section{Isolation of scaffold components}

Insoluble type I collagen was purified from bovine achilles tendon. Briefly, tendons were cleaned from non-collagenous tissue, pulverised under liquid nitrogen conditions using a Pulverisette 19 with a $0.5 \mathrm{~mm}$ sieve (Fritsch, Idar-Oberstein, Germany) and extensively rinsed with consecutively $0.1 \mathrm{M} \mathrm{NaCl}$ in $50 \mathrm{mM}$ Tris- $\mathrm{HCl} \mathrm{pH} \mathrm{7.2,} 1.0 \mathrm{M}$ $\mathrm{NaCl}$ in $50 \mathrm{mM}$ Tris- $\mathrm{HCl} \mathrm{pH}$ 7.2, $4 \mathrm{M}$ urea in $0.5 \mathrm{M}$ acetic acid, $0.5 \mathrm{M}$ acetic acid, acetone and demineralised water [22].

Insoluble elastin fibres $\left(\mathrm{EL}_{\text {fibre }}\right)$ were isolated from equine ligamentum nuchae. Nonelastinous tissue was removed and ligaments were pulverised under liquid nitrogen conditions through a $1.0 \mathrm{~mm}$ sieve. The pulverised ligament was then washed/treated with $1 \mathrm{M} \mathrm{NaCl}$ in $10 \mathrm{mM}$ phosphate buffer $\mathrm{pH} 7.4$ (PB), various organic solvents, formic acid with CNBr, $4 \mathrm{M}$ urea $+1 \mathrm{M}$ 2-mercaptoethanol in $0.1 \mathrm{M} \mathrm{PB}$, trypsin and 1 $\mathrm{M} \mathrm{NaCl}$ in $10 \mathrm{mM} \mathrm{PB}$ [23].

Solubilised elastin $\left(\mathrm{EL}_{\text {sol }}\right)$ was prepared from insoluble elastin fibres by oxalic acid hydrolysis [24]. Briefly, 10 g elastin was hydrolysed for $1 \mathrm{~h}$ with $75 \mathrm{ml} 0.25 \mathrm{M}$ oxalic acid at $95^{\circ} \mathrm{C}$. Then, the preparation was quickly cooled on ice, centrifuged and the supernatant collected. The pellet was hydrolysed again for $1 \mathrm{~h}$ with oxalic acid, followed by cooling and centrifuging. This procedure was repeated until all insoluble material was solubilised (generally after a total of 14 steps). Supernatants were pooled, dialysed against $10 \mathrm{mM}$ PB and subsequently dialysed against MilliQ water using Amicon Ultra1510 kDa MWCO filter tubes (Millipore, Billerica, MA, USA). 


\section{Characterisation of solubilised elastin preparation}

The amount of solubilised elastin in the elastin pool was determined by Lowry [25], size of elastin using 1D gel electrophoresis (4\% polyacrylamide gel with silver staining) [26] and gel permeation chromatography [27] (column material: Sephacryl S-500, reference samples: ferritin $(0.88 \mathrm{MDa})$, dextran blue (2 $\mathrm{MDa})$, and Helix pomatia heamocyanin (9 $\mathrm{MDa}$ ), size-charge distribution using 2D gel electrophoresis [28], amine group content after reaction with 2,4,6-trinitrobenzene sulphonic acid [29], and amino acid composition using a Biochrom 20 amino acid analyser (Amersham Pharmacia Biotech, Uppsala, Sweden) [30].

\section{Preparation of scaffolds}

Various scaffolds were prepared composed of collagen only (COL), collagen + insoluble elastin fibres in a 1:1 ratio (COL-EL $\mathrm{L}_{\text {fibre }}$ ), or collagen with solubilised elastin in 97:3, 9:1 and $1: 1$ ratios $\left(\mathrm{COL}_{\mathrm{EL}} \mathrm{EL}_{\mathrm{sol}}\right)$.

Briefly, a $2 \%(\mathrm{w} / \mathrm{v})$ protein suspension (collagen without or with elastin fibres) was shaken overnight in $0.5 \mathrm{M}$ acetic acid at $4^{\circ} \mathrm{C}$. If appropiate, $\mathrm{EL}_{\text {sol }}$ was added and the suspension diluted to $1 \%(\mathrm{w} / \mathrm{v})$ with cold MilliQ water and homogenised on ice using a Potter-Elvehjem homogeniser. Air-bubbles were removed by centrifuging at $250 \mathrm{~g}$ for $10 \mathrm{~min}$ at $4^{\circ} \mathrm{C}$. The suspension was then slowly poured into a plastic mould, frozen in a bath of ethanol and solid $\mathrm{CO}_{2}\left(-80^{\circ} \mathrm{C}\right)$ and lyophilised in a Zirbus lyophiliser (Bad Grund, Germany). For scaffolds composed of collagen $+\mathrm{EL}_{\text {sol }}$ in a 1:1 ratio, a suspension with a final concentration of $1.6 \%$ was used as well.

Scaffolds were applied as such (non-crosslinked), or crosslinked. For crosslinking, 200 mg scaffold was incubated for $4 \mathrm{~h}$ at $22^{\circ} \mathrm{C}$ with $20 \mathrm{ml} 33 \mathrm{mM}$ 1-ethyl-3-(3-dimethyl aminopropyl)carbodiimide (EDC) and $6 \mathrm{mM} \mathrm{N}$-hydroxysuccinimide (NHS) in $50 \mathrm{mM}$ 2-morpholinoethane sulphonic acid (MES) pH 5.0 containing 40\% ethanol. EDC/NHScrosslinked scaffolds were then washed with $0.1 \mathrm{M} \mathrm{Na}_{2} \mathrm{HPO}_{4}$ (twice for $1 \mathrm{~h}$ ), $1 \mathrm{M} \mathrm{NaCl}$ (twice for $2 \mathrm{~h}$ ), $2 \mathrm{M} \mathrm{NaCl}$ (once overnight, 5 times $30 \mathrm{~min}$ ) and MilliQ water (6 times $30 \mathrm{~min})$. The scaffolds were then frozen in ethanol/ $\mathrm{CO}_{2}$ again and lyophilised $[12,31]$. For in vivo experiments, EDC/NHS-crosslinked COL and COL-EL fibre $_{1: 1}$ scaffolds from a $1.0 \%$ suspension were used along with COL-EL $\mathrm{sol}_{\text {ol }} 1: 1$ scaffolds from a $1.6 \%$ suspension.

\section{Characterisation of scaffolds}

The amine group content was measured to evaluate the degree of crosslinking [29]. The amount of $\mathrm{El}_{\text {sol }}$ bound to collagen was established by estimating the protein content in the solution after crosslinking. Proteins in this solution were precipitated with $10 \%$ TCA on ice for $2 \mathrm{~h}$ and centrifuged. The pellet was then dissolved in $10 \mathrm{mM} \mathrm{NaOH}$ 
and the protein amount assayed according to Lowry [25]. The same procedure was applied to evaluate the in vitro release of $\mathrm{EL}_{\text {sol }}$ from the scaffolds. Both non-crosslinked and EDC/NHS-crosslinked collagen scaffolds did not give any release of protein from the scaffolds after $24 \mathrm{~h}$ or 7 days in PBS, and therefore the protein release from COL$\mathrm{EL}_{\text {sol }}$ scaffolds could be attributed to $\mathrm{EL}_{\text {sol }}$ only. Water-binding capacity of scaffolds was determined as previously described [12]. Scanning electron microscopy (SEM) was used to analyse the morphology of the scaffolds [12], transmission electron microscopy (TEM) to determine the ultrastructure of the scaffolds [23] and immunofluorescence microscopy to study the distribution of $\mathrm{EL}_{\text {sol }}$ in the scaffolds using mouse anti-bovine elastin (1:1000) as a primary antibody [13].

\section{In vivo evaluation of scaffolds}

The study was approved by the Ethical Committee of the Radboud University Nijmegen Medical Centre. Sprague Dawley rats (male, 3 weeks old) were purchased from Harlan (Zeist, The Netherlands) and housed per 2. The animals were fed pelleted diet and water ad libitum. Scaffolds were washed in $70 \%$ (v/v) ethanol (4 x $30 \mathrm{~min}$ ) and sterile PBS ( 8 x $30 \mathrm{~min}$ ). Rats were anaesthetised with isoflurane. Subcutaneous pockets were made to the right and left of two midline incisions on the back. Punches ( $66 \mathrm{~mm}$ ) of the scaffolds were implanted in the pockets at a distance of about $1 \mathrm{~cm}$ from the

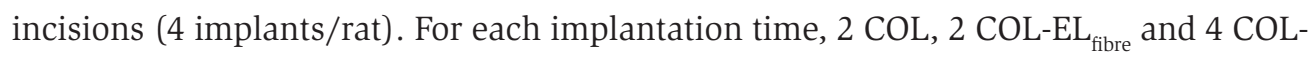

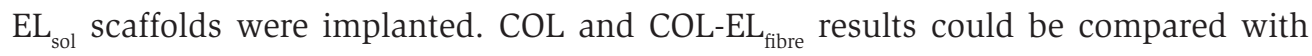
previous experiments $[13,32]$. Implants with surrounding tissue were harvested at 3,7 and 21 days after implantation. Immediately after explantation, scaffolds were divided in two halves. One half was processed for conventional light microscopy, the other half for immunohistochemistry.

For conventional light microscopy, explants were fixed in $4 \%$ (v/v) formaldehyde in $\mathrm{PB}$ for at least $24 \mathrm{~h}$ at $4^{\circ} \mathrm{C}$, and embedded in paraffin. $5 \mu \mathrm{m}$ sections were either haematoxylin-eosin (HE), Elastin Van Gieson (EVG; visualisation of elastin and collagen) or Von Kossa-stained (VK; visualisation of calcium deposits) [33]. Histological evaluation was performed independently by at least two persons.

Immunohistochemistry (both immunofluorescence and peroxidase-antiperoxidase) was used to study the biodegradation of scaffold components and the formation of extracellular matrix by the host. Scaffolds were frozen in liquid nitrogen, $5 \mu \mathrm{m}$ cryosections were mounted on superfrost slides and air-dried. Immunofluorescence assay was performed as described [13]. Primary antibodies used were mouse antibovine elastin (1:1000), rabbit anti-bovine type I collagen, goat anti-rat elastin, rabbit anti-rat type I collagen, rabbit anti-rat type III collagen (all 1:100), rabbit anti-human fibrillin-1 and rabbit anti-human fibrillin-2 (both 1:500). Antibodies were visualised with Alexa488 or Alexa594-conjugated secondary antibodies diluted in PBS containing $5 \%$ normal rat serum. The antibody to bovine elastin also reacted with equine elastin, 
the antibodies against human fibrillin also reacted with rat fibrillin, and the antibody to bovine type I collagen did not substantially cross-react with rat type I collagen or vice versa. For immunohistochemistry with the peroxidase-antiperoxidase (PAP) method, cryosections were fixed with $4 \%$ paraformaldehyde in PBS for 20 min. Endogenous peroxidase was inhibited with $0.3 \% \mathrm{H}_{2} \mathrm{O}_{2}$ for 10 min. After blocking for 30 min with $2 \%$ BSA in PBS containing $0.1 \%$ Tween (PBST), sections were incubated with goat antihuman type IV collagen (1:50) for $1 \mathrm{~h}$, washed, and incubated for $1 \mathrm{~h}$ with rabbit antigoat IgG peroxidase (1:100), and washed. Antibodies were diluted in PBST containing $5 \%$ normal rabbit serum, washings were with PBST. Sections were washed with 50 $\mathrm{mM}$ Tris- $\mathrm{HCl}(\mathrm{pH}$ 7.6) and incubated for $10 \mathrm{~min}$ with diaminobenzidine (DAB; 0.5 $\mathrm{mg} / \mathrm{ml}$ ) and ammonium nickel-sulfate $(7.5 \mathrm{mg} / \mathrm{ml})$ in Tris-HCl. Finally, the reaction substrate was added $\left(0.2 \mu \mathrm{l} 30 \% \mathrm{H}_{2} \mathrm{O}_{2} / \mathrm{ml}\right)$. Sections were washed, counterstained with haematoxylin, dehydrated and embedded. The antibody to human type IV collagen cross reacted with rat type IV collagen.

\section{RESULTS}

\section{Analysis of solubilised elastin preparation}

The solubilised elastin preparation was analysed by SDS-PAGE which revealed that the molecular mass range of the solubilised elastin was between 70 and $>>880 \mathrm{kDa}$. Gel permeation chromatography gave a mean molecular mass of the solubilised elastin of about $1100 \mathrm{kDa}$. 2D gel electrophoresis showed that the elastin peptides had an isoelectric point of around 6 . The amine group content of the solubilised elastin was $292 \pm 5 \mathrm{nmol}$ amine groups / mg protein. Amino acid composition of solubilised elastin was similar to elastin fibres for all amino acid residues, including desmosine and isodesmosine (both $0.5 \pm 0.0$ per 1000 amino acid residues).

\section{Analysis of scaffolds containing solubilised elastin}

Porous scaffolds were prepared using various ratios of collagen with $\mathrm{EL}_{\text {sol }}$. After $4 \mathrm{~h}$ of crosslinking, less than $5 \%$ of $\mathrm{EL}_{\text {sol }}$ could be retrieved from the remaining crosslinking solution. Hence, the crosslinking efficiency of $\mathrm{EL}_{\text {sol }}$ to the scaffolds was at least $95 \%$. In Table 1, the biochemical characteristics of the scaffolds are summarised. EDC/NHScrosslinking coupled $\mathrm{EL}_{\text {sol }}$ firmly to the scaffolds, since the in vitro release was only $2 \%$ after 7 days in case of EDC/NHS-crosslinked collagen $+\mathrm{EL}_{\text {sol }}$ scaffolds, whereas this was about $60 \%$ after only $24 \mathrm{~h}$ when crosslinking was omitted. Both collagen and $\mathrm{EL}_{\text {sol }}$ possessed about $300 \mathrm{nmol}$ amine groups per mg. Therefore scaffolds made from these components had the same amount of amine groups for all ratios prior to crosslinking. After EDC/NHS-crosslinking, approximately $60 \%$ of the amine groups remained for all scaffolds, indicating that $40 \%$ of the amine groups was used in the crosslinking reaction. 
Table 1. Biochemical characteristics of scaffolds prepared from collagen, collagen + elastin fibres and collagen + solubilised elastin.

\begin{tabular}{|c|c|c|c|c|c|}
\hline$\overline{\text { Scaffold }}$ & $\begin{array}{l}\text { Crosslinked } \\
\text { with EDC/NHS }\end{array}$ & $\begin{array}{l}\text { Release after } \\
24 \mathrm{~h} \text { in PBS } \\
\text { [\% of total EL } \\
\end{array}$ & $\begin{array}{l}\text { Release after } \\
7 \text { days in PBS } \\
\left.\text { [\% of total EL } L_{\text {sol }}\right]\end{array}$ & $\begin{array}{l}\text { Amine group } \\
\text { content } \\
\text { [nmol/mg scaffold] }\end{array}$ & $\begin{array}{l}\begin{array}{l}\text { Water-binding } \\
\text { capacity }\end{array} \\
\text { [\# times dry weight] }\end{array}$ \\
\hline $\mathrm{EL}_{\text {sol }}{ }^{*}$ & & & & $292 \pm 5$ & \\
\hline $\mathrm{COL}$ & - & $0 \pm 0.0$ & ND & $297 \pm 14$ & $20 \pm 1$ \\
\hline COL-EL/fore 1:1 & - & ND & ND & $160 \pm 9$ & $16 \pm 2$ \\
\hline COL-EL sol $_{10} 97: 3$ & . & $58.0 \pm 11.8$ & ND & $300 \pm 3$ & $19 \pm 2$ \\
\hline COL-EL $L_{\text {sol }} 9: 1$ & . & $59.3 \pm 9.4$ & ND & $290 \pm 13$ & $19 \pm 1$ \\
\hline COL-EL sol 1:1 & . & $62.3 \pm 15.3$ & ND & $298 \pm 18$ & $13 \pm 1$ \\
\hline COL-EL sol 1:1 & . & $66.2 \pm 7.2$ & ND & $290 \pm 10$ & $12 \pm 1$ \\
\hline $\mathrm{COL}$ & + & ND & $0 \pm 0.0$ & $189 \pm 5$ & $20 \pm 2$ \\
\hline COL-EL fitse 1:1 & + & ND & ND & $98 \pm 6$ & $16 \pm 1$ \\
\hline COL-EL sol $97: 3$ & + & ND & $2.4 \pm 1.5$ & $190 \pm 15$ & $19 \pm 2$ \\
\hline COL-EL & + & ND & $1.0 \pm 0.8$ & $171 \pm 4$ & $18 \pm 2$ \\
\hline COL-EL sol 1:1 & + & ND & $0.8 \pm 0.7$ & $163 \pm 5$ & $14 \pm 1$ \\
\hline COL-EL sol 1:1 (1.6)* & + & ND & $0.5 \pm 0.3$ & $154 \pm 12$ & $12 \pm 1$ \\
\hline
\end{tabular}

* No scaffolds could be prepared of $\mathrm{EL}_{\mathrm{sol}}$ alone.

** COL-EL $\mathrm{Esl}_{\text {sol }} 1: 1$ (1.6) scaffold was prepared from a $1.6 \%$ suspension of collagen and $\mathrm{EL}_{\text {sol }}$.

$\mathrm{ND}=$ not determined; $\mathrm{COL}=$ collagen; $\mathrm{EL}_{\text {fibre }}=$ insoluble elastin fibres; $\mathrm{EL}_{\text {sol }}=$ solubilised elastin. Results are mean $\pm \mathrm{SD}$ of 3 individual experiments.

$\mathrm{EL}_{\text {sol }}$ did not contribute to the water-binding activity of scaffolds. At a higher percentage of $\mathrm{EL}_{\text {sol }}$, the water-binding capacity of COL-EL $\mathrm{sol}_{\text {s }}$ scaffolds was decreased.

On the scanning EM level (Fig. 1), non-crosslinked COL-EL ${ }_{\text {sol }}$ scaffolds showed spherical structures attached to collagenous fibrils/sheets. Spheres of different sizes (ranging from about $200 \mathrm{~nm}$ to $10 \mu \mathrm{m}$ ) were found throughout the scaffolds. After crosslinking, these spheres deformed to some extend. COL and COL-EL $\mathrm{L}_{\text {fibre }}$ scaffolds did not show this spherical organization. Immunofluorescence staining using an antibody against bovine elastin demonstrated that the spheres in COL- $\mathrm{EL}_{\text {sol }}$ scaffolds were composed of $\mathrm{EL}_{\text {sol }}$. The same was found based on the autofluorescence of elastin (Fig. 2A, B). In semi-thin epon sections, COL-EL ${ }_{\text {sol }}$ show both closed and open elastin spheres (Fig. 2C, D). TEM showed that $\mathrm{EL}_{\text {sol }}$ spheres in EDC/NHS-crosslinked COL-EL $\mathrm{Esl}_{\text {sol }}$ scaffolds had a wide size distribution and were mostly incorporated into the collagen network (Fig. 2E, F). The latter figure also shows a sphere with a less-dense outer core. Crosslinking does not occur instantaneously which may cause this effect. 

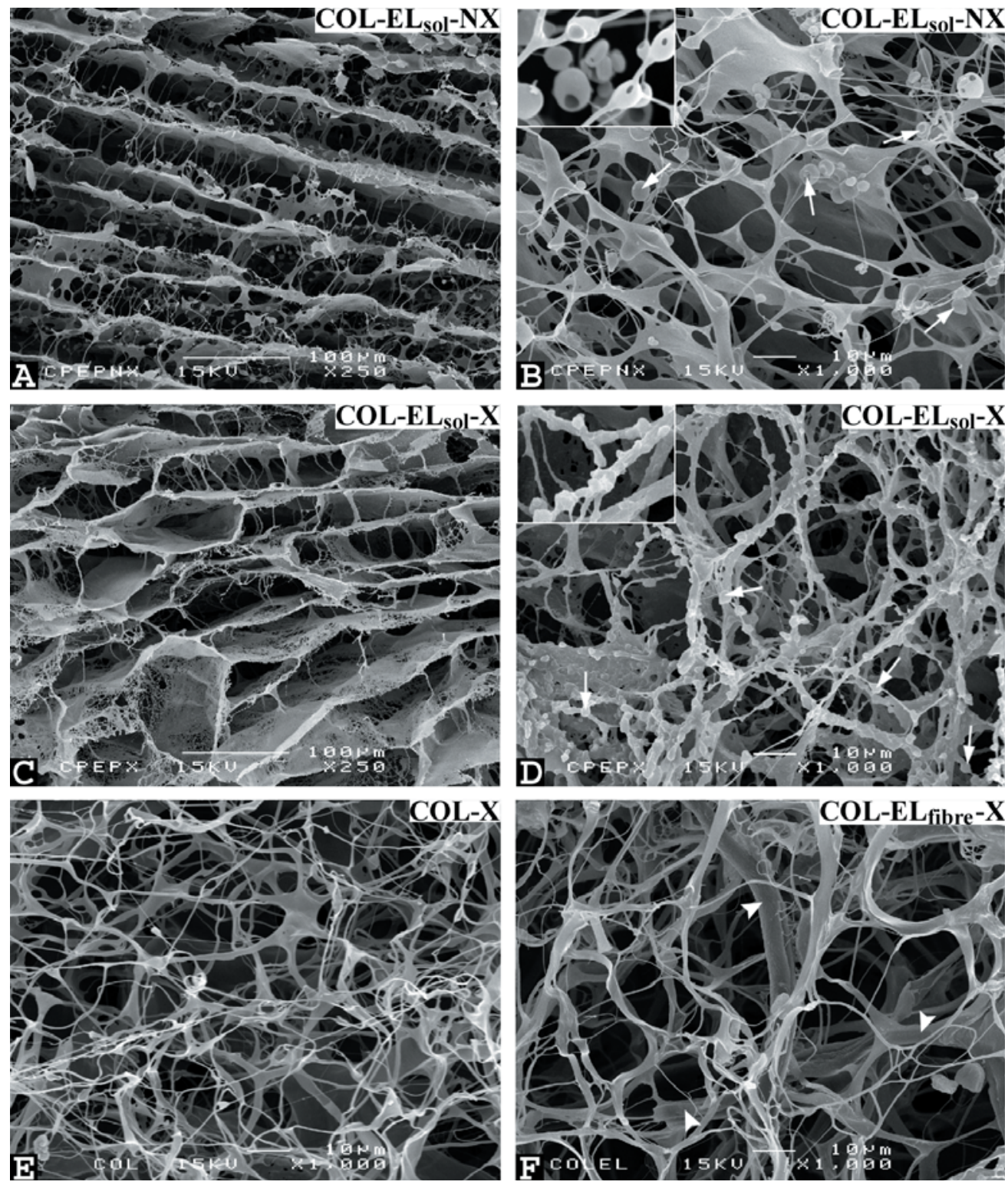

Figure 1. Morphology of scaffolds as analysed by scanning electron microscopy. (A, B) non-crosslinked (NX) COL-EL $L_{\text {sol }}$ (C,D) EDC/NHS-crosslinked (X) COL-EL sol; (E) COL and (F) COL-EL fibre scaffolds. A and C represent cross-sectional views, whereas $B, D, E$ and $F$ are enlarged top views. Arrowheads indicate insoluble elastin fibres in COL-EL $L_{\text {fibre }}$, whereas arrows indicate spherical structures that are only present in the COL-EL ${ }_{\text {sol }}$. Spherical structures in EDC/NHS-crosslinked COL-EL $L_{\text {sol }}$ are somewhat deformed compared to non-crosslinked $C O L-E L_{\text {sol }}$ (inserts in B and D). Bar is $100 \mu \mathrm{m}$ in $A$ and $C$, and $10 \mu \mathrm{m}$ in other images. 

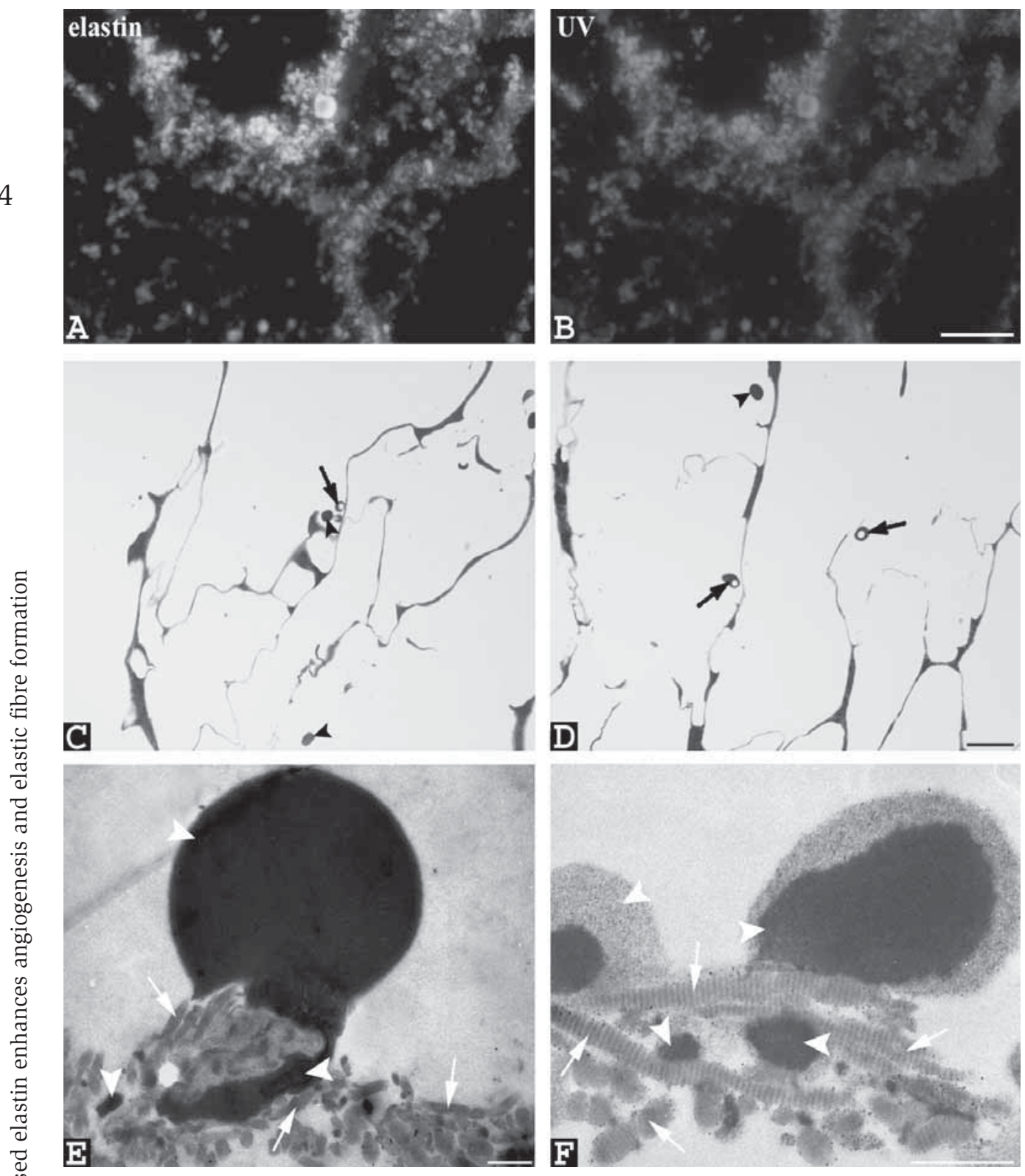

Figure 2. Light microscopical and transmission electron microscopical evaluation of spherical structures in $C O L-E L_{\text {sol }}$ scaffolds. (A) Immunofluorescence staining for elastin and (B) autofluorescence visualisation using $U V$ optics in EDC/NHS-crosslinked scaffolds show that spherical structures are composed of $E L_{\text {sol }}(C, D)$ Toluidine blue-stained semi-thin epon sections show that $E L_{\text {sol }}$ spheres are either closed (black arrowheads) or open (black arrows) in non-crosslinked scaffolds. (E-F) TEM images display that $E L_{\text {sol }}$ spheres (white arrowheads) are incorporated in the collagenous structures (white arrows) of EDC/NHS-crosslinked scaffolds. Bar is $50 \mu \mathrm{m}$ in $A, B, 20 \mu \mathrm{m}$ in $C, D$ and $0.25 \mu \mathrm{m}$ in $E, F$. 


\section{Tissue response to implanted scaffolds}

All animals remained in good condition and no infections were observed. Macroscopically, a thin capsule was seen around the scaffolds at explantation. In Table 2 an overview of calcification behaviour and cellular response is given for the three different scaffolds.

Table 2. General overview of calcification and cellular events after subcutaneous implantation of the EDC/ NHS-crosslinked scaffolds in young Sprague Dawley rats.

\begin{tabular}{|c|c|c|c|c|c|c|}
\hline Scaffold & $\begin{array}{l}\text { Implantation } \\
\text { time (days) }\end{array}$ & Calcification & PMNs & $\begin{array}{c}\text { Phagocytic } \\
\text { cells* }\end{array}$ & $\begin{array}{c}\text { Non-phagocytic } \\
\text { cells }\end{array}$ & $\begin{array}{c}\text { Blood } \\
\text { vessels** }\end{array}$ \\
\hline \multirow[t]{3}{*}{ COL } & 3 & - & $\mathrm{sp}$ & sp & - & - \\
\hline & 7 & - & - & \pm & sp & sp \\
\hline & 21 & . & - & + & \pm & \pm \\
\hline \multirow[t]{3}{*}{ COL-EL-mat } & 3 & - & \pm & \pm & $\mathrm{sp}$ & $\cdot$ \\
\hline & 7 & \pm & sp & + & \pm & \pm \\
\hline & 21 & + & - & + \pm & + & + \\
\hline \multirow[t]{3}{*}{$\overline{\mathrm{COL}-\mathrm{EL}_{8 d}}$} & 3 & - & + \pm & \pm & $\mathrm{sp}$ & - \\
\hline & 7 & $=$ & $\mathrm{sp}$ & + & \pm & + \\
\hline & 21 & - & - & ++ & ++ & ++ \\
\hline
\end{tabular}

* Absolute numbers of phagocytic cells were higher than of PMNs or non-phagocytic cells, e.g. + for phagocytic cells refers to more cells than + for PMNs or non-phagocytic cells.

** Blood vessels were assessed by immunostaining for rat type IV collagen, present in vascular basement membranes.

PMNs = polymorphic nuclear cells, i.e. granulocytes; phagocytic cells include monocyte-derived macrophages and giant cells; non-phagocytic cells include lymphocytes, plasma cells and mast cells. Events were scored ranging from sporadic $(\mathrm{sp})$ to severe $(++)$. -: not present.

\section{Calcification of scaffolds}

In young Sprague Dawley rats, COL-EL ${ }_{\text {sol }}$ did not calcify at all in the time span investigated in contrast to COL-EL $\mathrm{fibre}_{\text {(Fig. 3). In COL-EL }}$ fibre, part of the elastin fibres calcified from day 7 on, whereas the collagen fibrils did not. COL did not show any calcification.

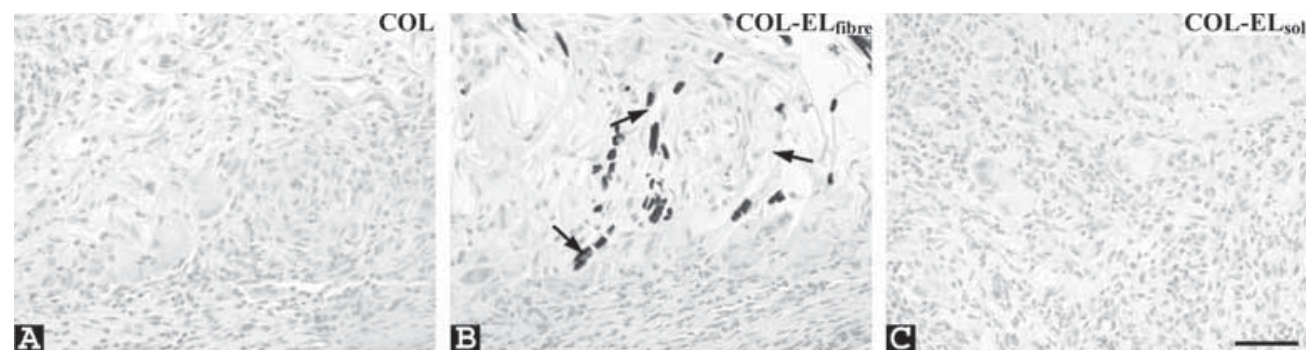

Figure 3. Light microscopical evaluation of calcification of scaffolds, 21 days after implantation in young Sprague Dawley rats. (A) COL, (B) COL-EL fibre (C) COL-EL sol scaffold. Calcium deposits have an intense black colour due to Von Kossa staining and are only found in $C O L-E L_{\text {fibre }}$. Arrows indicate elastin fibres. Bar is $50 \mu \mathrm{m}$.

\section{Cellular response to scaffolds}

At day 3, cellular response to COL-EL $\mathrm{L}_{\text {sol }}$ showed moderate infiltration of neutrophilic granulocytes throughout the scaffold, whereas at day 7 fibroblasts and other mononuclear cells, and few giant cells were found. At day 21 , an increased number of phagocytic cells was observed with strong proliferation of fibroblasts. Cellular reactions to COL and COL-EL $\mathrm{fibre}_{\mathrm{e}}$ were considerably less. COL gave the mildest reaction; after 21 days macrophages and giant cells were present mainly at the periphery of the scaffolds. At 
day 3, cellular response to COL-EL $\mathrm{L}_{\text {fibre }}$ included some neutrophilic granulocytes which had entered the outer part of the scaffold. At day 7, fibroblasts and other mononuclear cells were found in the scaffold with some giant cells at the periphery of the scaffold, and at day 21 phagocytic cells like macrophages and giant cells dominated the scaffold while the number of non-phagocytic cells increased at the periphery. Although more macrophages were found in COL-EL ${ }_{\text {sol }}$, the amount of giant cells in COL-EL $\mathrm{E}_{\text {sol }}$ and COL$\mathrm{EL}_{\text {fibre }}$ was similar.

\section{Vascularisation of scaffolds}

Staining for type IV collagen, present in endothelial basement membranes, was used to study the presence of blood vessels (Fig. 4). Blood vessels were most abundant in COL-EL $_{\text {sol }}$, both at the periphery and within the scaffold. These scaffolds also contained more large blood vessels than COL-EL $\mathrm{fibre}_{\text {and }}$ COL. In COL-EL $\mathrm{L}_{\text {fibre }}$, vascularisation was also present at the periphery, but considerably less vessels were found within the scaffold. In COL, blood vessels were found only at the periphery of the scaffolds.

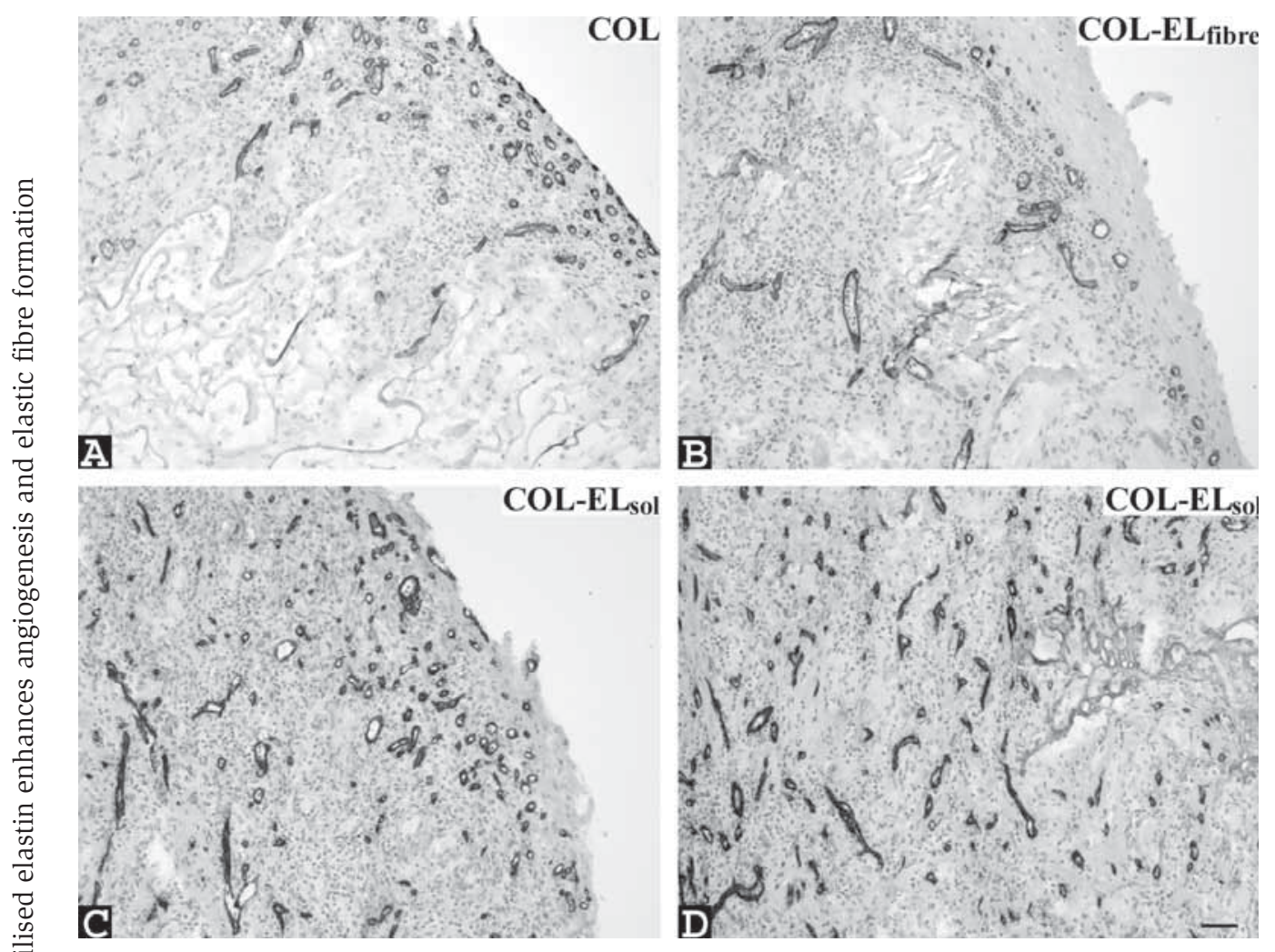

Figure 4. Light microscopical evaluation of angiogenesis in scaffolds, 21 days after implantation in young Sprague Dawley rats. Sections were stained for type IV collagen as a marker for blood vessels. (A) COL, (B) $C O L-E L_{\text {fibre }}$ (C) periphery of COL-EL $L_{\text {sol }}$, (D) within COL-EL $L_{\text {sol }}$ scaffold. Note increase in blood vessels in the

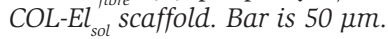




\section{Scaffold degradation and new matrix synthesis}

Table 3 gives an overview of the immunostaining for scaffold components and newly formed extracellular matrix molecules at different time points.

Table 3. Overview of immunostaining results of explants for scaffold and rat extracellular matrix components.

\begin{tabular}{|c|c|c|c|c|c|c|}
\hline Scaffold & $\begin{array}{c}\text { Implantation } \\
\text { time (days) }\end{array}$ & $\begin{array}{c}\text { Scaffold } \\
\text { elastin }\end{array}$ & $\begin{array}{l}\text { Scaffold } \\
\text { collagen }\end{array}$ & $\begin{array}{c}\text { Rat } \\
\text { elastin }\end{array}$ & $\begin{array}{c}\text { Rat } \\
\text { type I collagen }\end{array}$ & $\begin{array}{c}\text { Rat } \\
\text { type III collagen }\end{array}$ \\
\hline \multirow[t]{3}{*}{$\mathrm{COL}$} & 3 & - & ++ & - & $s p$ & - \\
\hline & 7 & - & ++ & sp & \pm & \pm \\
\hline & 21 & - & + \pm & sp & \pm & + \\
\hline \multirow[t]{3}{*}{$\mathrm{COL}-\mathrm{EL}_{\text {insol }}$} & 3 & ++ & ++ & $\cdot$ & $s p$ & $\cdot$ \\
\hline & 7 & ++ & ++ & sp & \pm & + \\
\hline & 21 & + & + & \pm & + & ++ \\
\hline \multirow[t]{3}{*}{ COL-ELsd } & 3 & +4 & ++ & - & sp & sp \\
\hline & 7 & ++ & + \pm & \pm & \pm & + \\
\hline & 21 & + & + & + & + \pm & ++ \\
\hline
\end{tabular}

Events were scored ranging from sporadic $(\mathrm{sp})$ to abundant $(++)$. -: not present.

\section{Scaffold degradation}

Scaffold degradation was studied using both conventional histology and immunohistochemistry with antibodies for scaffold elastin and collagen. From day 7, elastin staining in $\mathrm{COL}_{-} \mathrm{EL}_{\mathrm{sol}}$ decreased and after 21 days, elastin staining was reduced even more. Elastin spheres were still present at this time point, especially in the central part of the scaffolds (Fig. 5A, B). At the periphery of the scaffolds, staining intensity was less and spheres were smaller, suggesting resorption and degradation. Macrophages were able to incorporate elastin spheres (Fig. 5C). Collagen gradually decreased with time. Elastin fibre fragments (smaller than the implanted elastin fibres) were found from day 7 on in COL-EL $\mathrm{fibre}_{\text {e }}$ At day 21, less elastin staining and more elastin fragments were observed in these scaffolds.

In COL-EL $\mathrm{L}_{\text {sol }}$ and $\mathrm{COL}-\mathrm{EL}_{\text {fibre }}$, thinner and fragmented collagen structures were visible mainly at the periphery of the scaffolds from day $7 \mathrm{on}$. More degraded collagen was found in COL-EL $\mathrm{L}_{\text {sol }}$ at this time point. At day 21, degraded collagen was also found more central in COL-EL $\mathrm{sol}_{\text {sol }}$ and COL-EL $\mathrm{E}_{\text {fibre }}$, whereas only minor amounts of fragmented collagen were found in COL.

\section{Collagen formation}

Generally, most staining for rat type I and type III collagen was found in COL-EL ${ }_{\text {sol }}$, somewhat less in COL-EL $\mathrm{fibre}_{\text {end }}$ and the least in COL. In all scaffolds, staining for type I and III collagen started in the fibrous capsule and at the periphery of the scaffolds from day 7 on. In general, new rat collagen fibres aligned with original scaffold components. However, in COL-EL $\mathrm{L}_{\text {sol }}$ flattened cells aligned only with the lamellar scaffold structures, and not with elastin spheres, and this was accompanied with extracellular matrix formation (Fig. 5D). Type IV collagen staining was present in blood vessels as shown under vascularisation (Fig. 4).

At day 21, COL-EL $L_{\text {sol }}$ showed most new rat elastin, not only in blood vessels, but also as 


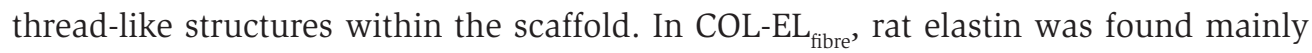
in blood vessels present in the capsule around the implant and sporadically small amounts of thin elastic fibres were found at the periphery of the scaffolds. In COL, rat elastin was present only in blood vessels in the capsule. In blood vessels, rat elastin colocalised with fibrillin-1 and fibrillin-2 staining (Fig. 6). Fibrillin-2 staining was mainly present in blood vessels, but not all blood vessels contained elastin. Only fibrillin-1 staining colocalised with thin elastic fibres which were formed mainly in COL-EL ${ }_{\text {sol }}$, to less extent in COL-EL $\mathrm{E}_{\text {fibre }}$ and scarcely in COL. Fibrillin-1 staining was found earlier in time than elastin and was more abundant than elastin staining (Fig. 6C, F).
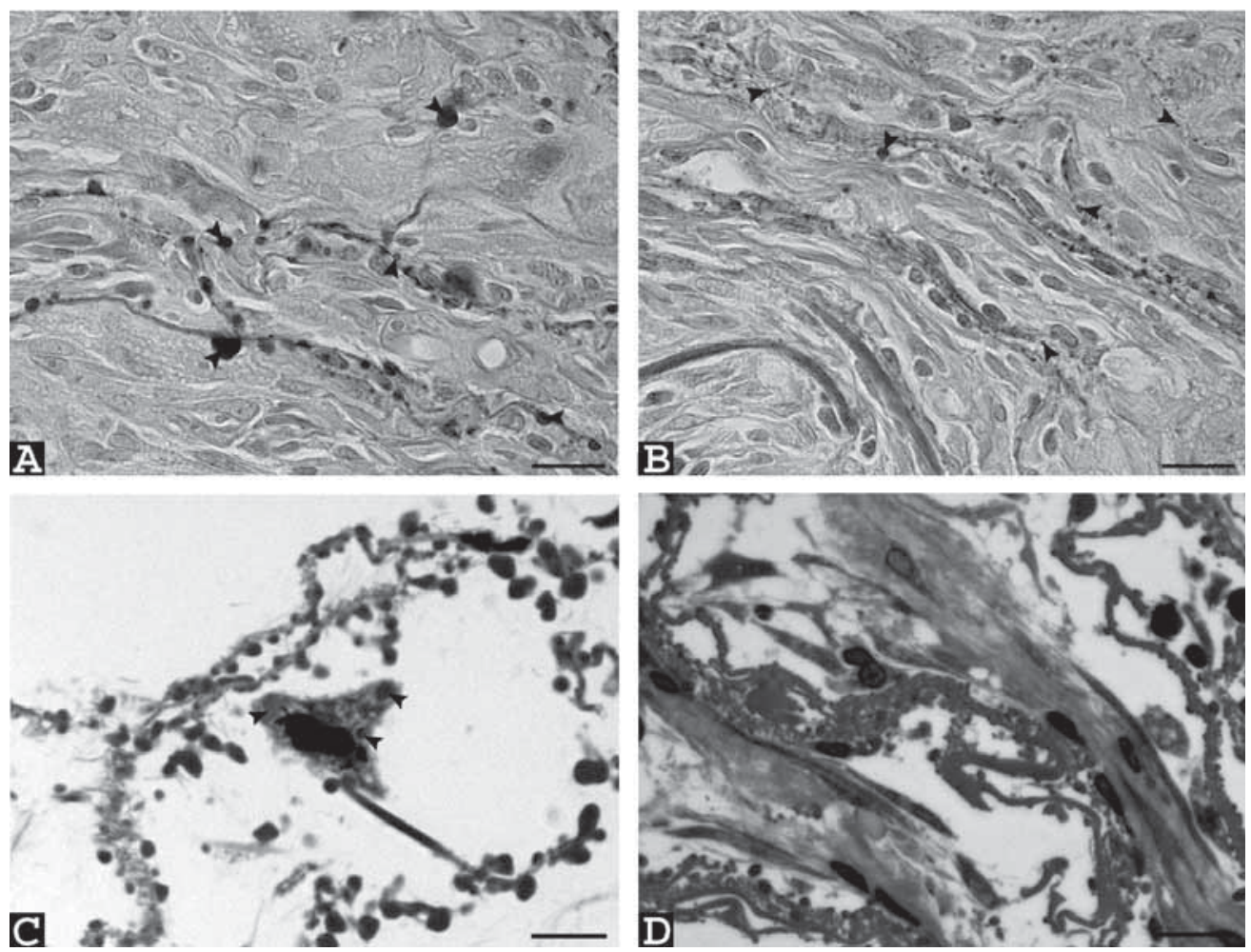

Fig. 5. (A-B) Elastin Van Gieson stained paraffin sections of COL-EL $L_{\text {sol }}$ scaffolds shows that $E L_{\text {sol }}$ spheres from the scaffold are still present 21 days after implantation in young Sprague Dawley rats. Within the scaffolds, elastin spheres (arrowheads) are still quite large (A), but at the periphery of the scaffolds the elastin spheres have reduced sizes (B). Elastin Van Gieson stains elastin black and collagen pink/red. (C-D) Semi-thin epon sections of crosslinked COL-EL $L_{\text {sol }}$ 1:1 scaffolds that were implanted for 7 days in young Sprague Dawley rats stained with toluidine blue and basic fuchsin. Macrophages are able to incorporate solubilised elastin spheres (arrowheads) (C). Flattened cells aligned with the scaffold lamellar structures and were accompanied with extracellular matrix formation (D). Cells stain blue, new extracellular matrix stains light pink, and scaffold material stains dark pink. Bars represent $20 \mu \mathrm{m}$ in $A, B$ and $10 \mu \mathrm{m}$ in $C, D$. Colour figure on page 152.

\section{DISCUSSION}

In biomaterials, some principal difficulties are observed including limited vascularisation and poor elastogenesis [1,34]. With regard to the application of elastin as a biomaterial, another difficulty arises since elastin tends to calcify [13,35]. 


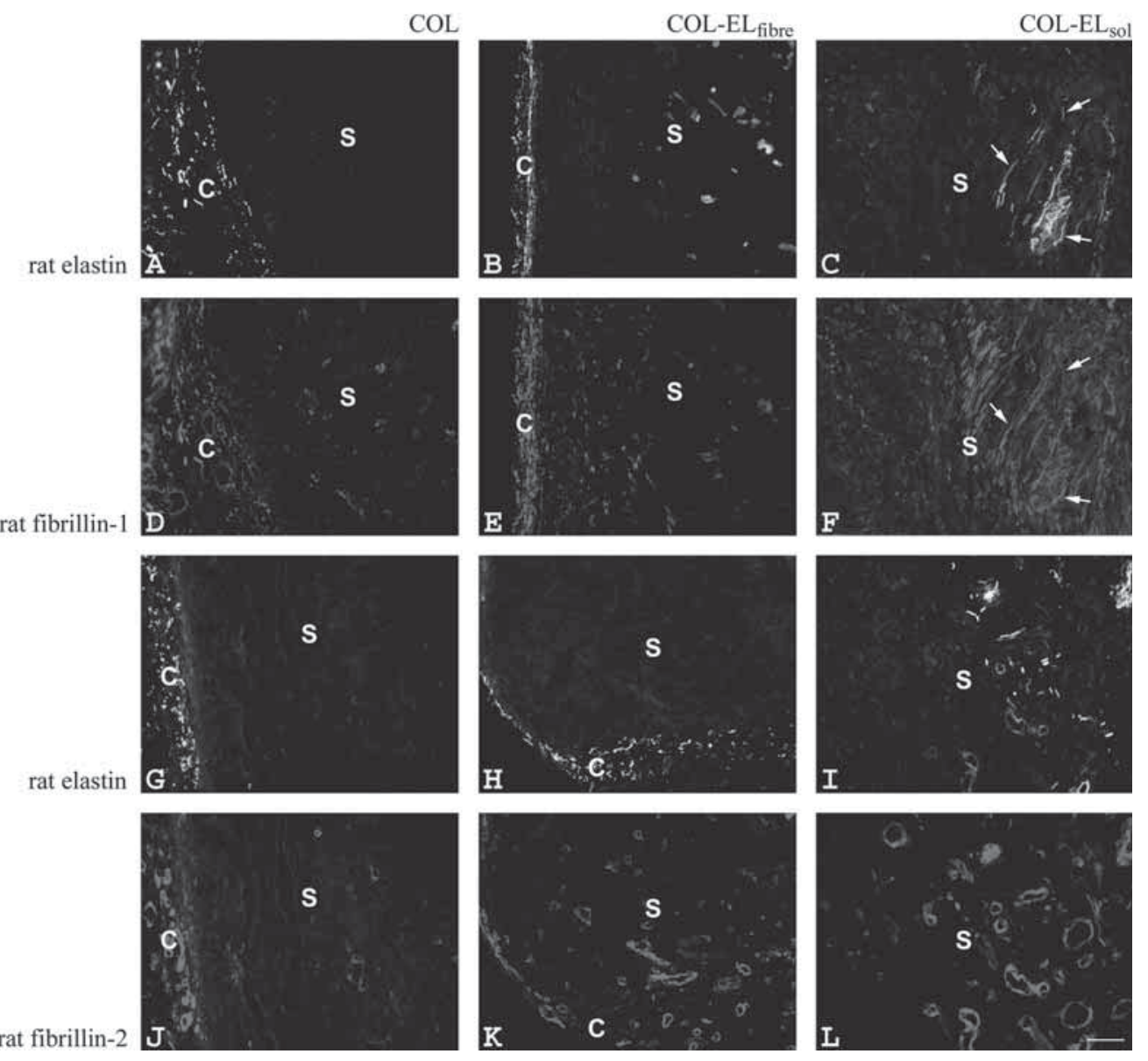

Figure 6. Light microscopical evaluation of newly formed elastic fibres in scaffolds, 21 days after implantation in young Sprague Dawley rats. Sections were stained for rat elastin (A-C, G-I), fibrillin-1 (D-F) and fibrillin-2 $(J-L)$. Especially in COL-EL ${ }_{\text {sol }}$ scaffolds, thread-like structures (arrows) positive for rat elastin and fibrillin-1, but not for fibrillin-2 were observed. Blood vessels mainly colocalised with fibrillin-2, and to less extent with fibrillin-1 staining. $C=$ capsule; $S=$ scaffold. Bar is $50 \mu \mathrm{m}$. Colour figure on page 153 .

In order to induce vascularisation and tissue formation, an initial tissue reaction seems to be necessary. COL scaffolds show less reaction than COL-EL fibre $_{\text {or COL-EL }}$, and little tissue formation was observed after three weeks. Tissue reaction is also dependent on the animal model that is used. In a previous study, we showed that (young and adult) Sprague Dawley rats showed more tissue reaction to subcutaneously implanted scaffolds compared to (adult) Wistar rats [13]. As a consequence, more vascularisation and collagen production was observed in the Sprague Dawley rats. In this study, COL-EL sol $_{\text {gave more }}$ tissue reaction than $\mathrm{COL}-\mathrm{EL}_{\text {fibre }}$, and vascularisation and tissue formation was further

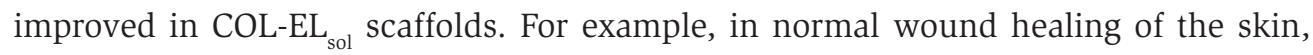
chemotactic signals recruit inflammatory cells to the wound site, initiating the process of reepithelialisation and connective tissue contraction, and stimulating the angiogenic response. It is important that this tissue reaction, including the presence of neutrophiles, does not persist over time since it is an indication of a grossly infected 
wound [36]. In COL-EL $\mathrm{sol}_{\text {' }}$, neutrophiles were only sporadically found at day 7. Soluble elastin seems to be able to trigger a cascade for angiogenesis and tissue regeneration. Robinet et al. [37] recently demonstrated that $\mathrm{k}$-elastin (solubilised elastin prepared by $\mathrm{KOH}$ treatment) triggered angiogenesis by promoting cell migration and tubulogenesis of human vascular endothelial cells through the elastin receptor.

COL-EL ${ }_{\text {sol }}$ scaffolds were in particular able to stimulate the synthesis of elastic fibres in vivo, especially as thread-like structures to which fibrillin-1 staining colocalised. Additional fibrillin-1 staining was found surrounding these structures suggesting that fibrillin-1 synthesis preceded elastin deposition and that elastin deposition was still in progress. Fibrillin-2 colocalised mainly with elastic fibres in blood vessels, and not with loose thread-like elastic fibres found in $\mathrm{COL}_{-} \mathrm{EL}_{\text {sol }}$. From mice experiments, it has been suggested that fibrillin-2 directs elastogenesis during embryogenesis whereas fibrillin-1 is more important in tissue homeostasis [38,39]. Our experimental setup may resemble tissue regeneration rather than embryogenesis. Furthermore, our results indicate that fibrillin-2 may be more involved in cardiovascular aspects, while fibrillin1 may be more significant in skin. Another study where skin biopsies were taken from healthy volunteers suggests a similar phenomenon: fibrillin-1 was the major contributor to dermal elastic fibre formation during acute wound repair, whereas fibrillin-2 was expressed only in wounds of the aged and expression was confined to areas proximal to dermal blood vessels [40]. Fibrillin-1 may be the template for elastic fibre synthesis in thread-like ('skin-like') elastic fibres, whereas fibrillin-2 may be the template for elastogenesis in blood vessels. However, time-resolved expression patterns of fibrillin-1 and -2 would be necessary to further confirm this. Solubilised elastin may be a means to enhance elastic fibre synthesis. It has been suggested that elastin peptides stimulate elastin synthesis through the receptor [5]. In a porcine skin excision model, improved extracellular matrix remodelling (including elastin regeneration) was found with a collagen/solubilised elastin dermal substitute [41]. For a sustained effect of both angiogenesis and tissue formation in vivo, a depot of solubilised elastin is recommendatory. EDC/NHS-crosslinked COL-EL ${ }_{\text {sol }}$ scaffolds contained solubilised elastin spheres that could still be detected 21 days after implantation and may thus accomplish their biological effect over a longer period of time.

Calcification is an undesirable phenomenon in soft biomaterial application. Young Sprague Dawley rats have proven to be a sensitive model to study calcification [13]. With COL-EL $\mathrm{sol}_{\text {sol }}$ we could not detect any calcification in the analysed time frame, whereas COL-EL $\mathrm{L}_{\text {fibre }}$ showed calcification starting at insoluble elastin fibres. This effect was not due to the presence of fewer macrophages and giant cells in COL-EL ${ }_{\text {sol }}$ (and therefore a diminished release of extracellular enzymes involved in elastin degradation), as amounts of these cells were comparable in $\mathrm{COL}-\mathrm{EL}_{\text {fibre }}$ and $\mathrm{COL}-\mathrm{EL}_{\text {sol }}$ scaffolds. Negative charges from C-terminal carboxylic groups may be involved in preventing positively charged calcium ions from precipitating, but other mechanisms cannot be excluded from this study alone. Others did observe calcification of solubilised elastin 
preparations. In a similar rat model, Singla and Lee found calcification with collagen/ $\alpha$-elastin films stabilised by glutaraldehyde fixation [35], but it is well-known that this treatment increases calcification of biomaterials [42]. In a cranial lesion in adult rats, a polypentapeptide based on elastin with an amino acid sequence of (Val-Pro-Gly-ValGly) ${ }_{\mathrm{n}}$ was also able to initiate calcification in vivo [43], but it only calcified in a rabbit tibial non-union model with $\mathrm{n}>200$ [44].

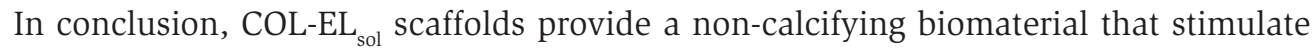
angiogenesis and extracellular matrix formation (collagens and elastic fibres), and may be useful in soft tissue engineering.

\section{REFERENCES}

1. Kadoya K, Amano S, Inomata S, Tsunenaga M, Matsuzaki K, Oshima H, Tanabe M, Kumagai N, Nishiyama T. Evaluation of autologous cultured epithelium as replacement skin after tattoo excision: correlation between skin texture and histological features. Br J Dermatol 2003;149:377-380.

2. Berthod F, Germain L, Li H, Xu W, Damour O, Auger FA. Collagen fibril network and elastic system remodeling in a reconstructed skin transplanted on nude mice. Matrix Biol 2001;20:463-473.

3. Senior RM, Griffin GL, Mecham RP. Chemotactic activity of elastin-derived peptides. J Clin Invest 1980;66:859-862.

4. Kamoun A, Landeau JM, Godeau G, Wallach J, Duchesnay A, Pellat B, Hornebeck W. Growth stimulation of human skin fibroblasts by elastin-derived peptides. Cell Adhes Commun 1995;3:273281.

5. Fülöp Jr T, Jacob MP, Khalil J, Wallach J, Robert L. Biological effects of elastin peptides. Pathol Biol (Paris) 1998;46:497-506.

6. Hinek A, Wang Y, Liu K, Mitts TF, Jimenez F. Proteolytic digest derived from bovine Ligamentum Nuchae stimulates deposition of new elastin-enriched matrix in cultures and transplants of human dermal fibroblasts. J Dermatol Sci 2005.

7. Robert L. Interaction between cells and elastin, the elastin-receptor. Connect Tissue Res 1999;40:7582.

8. Karnik SK, Brooke BS, Bayes-Genis A, Sorensen L, Wythe JD, Schwartz RS, Keating MT, Li DY. A critical role for elastin signaling in vascular morphogenesis and disease. Development 2003;130:411423.

9. Mochizuki S, Brassart B, Hinek A. Signaling pathways transduced through the elastin receptor facilitate proliferation of arterial smooth muscle cells. J Biol Chem 2002;277:44854-44863.

10. Varga Z, Jacob MP, Robert L, Fulop T, Jr. Identification and signal transduction mechanism of elastin peptide receptor in human leukocytes. FEBS Lett 1989;258:5-8.

11. Rodgers UR, Weiss AS. Integrin alpha(v)beta(3) binds a unique non-RGD site near the C-terminus of human tropoelastin. Biochimie 2004;86:173-178.

12. Daamen WF, Van Moerkerk HThB, Hafmans T, Buttafoco L, Poot AA, Veerkamp JH, Van Kuppevelt TH. Preparation and evaluation of molecularly-defined collagen-elastin-glycosaminoglycan scaffolds for tissue engineering. Biomaterials 2003;24:4001-4009.

13. Daamen WF, Nillesen ST, Hafmans T, Veerkamp JH, Van Luyn MJ, Van Kuppevelt TH. Tissue response of defined collagen-elastin scaffolds in young and adult rats with special attention to calcification. Biomaterials 2005;26:81-92.

14. Basalyga DM, Simionescu DT, Xiong W, Baxter BT, Starcher BC, Vyavahare NR. Elastin degradation and calcification in an abdominal aorta injury model: role of matrix metalloproteinases. Circulation 2004;110:3480-3487.

15. Abolhoda A, Yu S, Oyarzun JR, McCormick JR, Bogden JD, Gabbay S. Calcification of bovine pericardium: glutaraldehyde versus No-React biomodification. Ann Thorac Surg 1996;62:169-174.

16. Hinds MT, Courtman DW, Goodell T, Kwong M, Brant-Zawadzki H, Burke A, Fox BA, Gregory KW. Biocompatibility of a xenogenic elastin-based biomaterial in a murine implantation model: The role of aluminum chloride pretreatment. J Biomed Mater Res 2004;69A:55-64.

17. Bailey MT, Pillarisetti S, Xiao H, Vyavahare NR. Role of elastin in pathologic calcification of xenograft heart valves. J Biomed Mater Res 2003;66A:93-102.

18. Rossi MA, Santos CS. Sepsis-related microvascular myocardial damage with giant cell inflammation and calcification. Virchows Arch 2003;443:87-92.

19. Kim YH, Han DK, Park KD, Kim SH. Enhanced blood compatibility of polymers grafted by sulfonated PEO via a negative cilia concept. Biomaterials 2003;24:2213-2223.

20. Lin G, Tiedemann K, Vollbrandt T, Peters H, Batge B, Brinckmann J, Reinhardt DP. Homo- and heterotypic fibrillin-1 and -2 interactions constitute the basis for the assembly of microfibrils. J Biol Chem 2002;277:50795-50804.

21. Tiedemann K, Batge B, Muller PK, Reinhardt DP. Interactions of fibrillin-1 with heparin/heparan 
sulfate, implications for microfibrillar assembly. J Biol Chem 2001;276:36035-36042.

22. Pieper JS, Oosterhof A, Dijkstra PJ, Veerkamp JH, Van Kuppevelt TH. Preparation and characterization of porous crosslinked collagenous matrices containing bioavailable chondroitin sulphate. Biomaterials 1999;20:847-858.

23. Daamen WF, Hafmans T, Veerkamp JH, Van Kuppevelt TH. Isolation of intact elastin fibers devoid of microfibrils. Tissue Eng 2005;11:1168-1176.

24. Partridge SM, Davis HF, Adair GS. The chemistry of connective tissues. 2 - Soluble proteins derived from partial hydrolysis of elastin. Biochem J 1955;61:11-21.

25. Lowry OH, Rosebrough NJ, Farr AL, Randall RJ. Protein measurement with the Folin-Phenol reagents. J Biol Chem 1951;193:265-275.

26. Laemmli UK. Cleavage of structural proteins during the assembly of the head of bacteriophage T4. Nature 1970;227:680-689.

27. Porath J, Flodin P. Gel filtration: a method for desalting and group separation. Nature 1959;183:16571659.

28. Görg A. Two-dimensional electrophoresis. Nature 1991;349:545-546.

29. Olde Damink LH, Dijkstra PJ, Van Luyn MJ, Van Wachem PB, Nieuwenhuis P, Feijen J. Cross-linking of dermal sheep collagen using a water-soluble carbodiimide. Biomaterials 1996;17:765-773.

30. Daamen WF, Hafmans T, Veerkamp JH, Van Kuppevelt TH. Comparison of five procedures for the purification of insoluble elastin. Biomaterials 2001;22:1997-2005.

31. Pieper JS, Hafmans T, Veerkamp JH, Van Kuppevelt TH. Development of tailor-made collagenglycosaminoglycan matrices: EDC/NHS crosslinking, and ultrastructural aspects. Biomaterials 2000;21:581-593.

32. Pieper JS, Van Wachem PB, Van Luyn MJ, Brouwer LA, Hafmans T, Veerkamp JH, Van Kuppevelt TH. Attachment of glycosaminoglycans to collagenous matrices modulates the tissue response in rats. Biomaterials 2000;21:1689-1699.

33. Bancroft JD, Stevens A. Theory and practice of histological techniques. 3rd ed. Edinburgh (UK): Churchill Livingstone, 1990.

34. Mooney DJ, Mikos AG. Growing new organs. Sci Am 1999;280:60-65.

35. Singla A, Lee $\mathrm{CH}$. Effect of elastin on the calcification rate of collagen-elastin matrix systems. J Biomed Mater Res 2002;60:368-374.

36. Martin P. Wound healing--aiming for perfect skin regeneration. Science 1997;276:75-81.

37. Robinet A, Fahem A, Cauchard JH, Huet E, Vincent L, Lorimier S, Antonicelli F, Soria C, Crepin M, Hornebeck W, Bellon G. Elastin-derived peptides enhance angiogenesis by promoting endothelial cell migration and tubulogenesis through upregulation of MT1-MMP. J Cell Sci 2005;118:343-356.

38. Ramirez F, Pereira L. The fibrillins. Int J Biochem Cell Biol 1999;31:255-259.

39. Pereira L, Andrikopoulos K, Tian J, Lee SY, Keene DR, Ono R, Reinhardt DP, Sakai LY, Biery NJ, Bunton T, Dietz HC, Ramirez F. Targetting of the gene encoding fibrillin-1 recapitulates the vascular aspect of Marfan syndrome. Nat Genet 1997;17:218-222.

40. Ashcroft GS, Kielty CM, Horan MA, Ferguson MW. Age-related changes in the temporal and spatial distributions of fibrillin and elastin mRNAs and proteins in acute cutaneous wounds of healthy humans. J Pathol 1997;183:80-89.

41. Lamme EN, De Vries HJ, Van Veen H, Gabbiani G, Westerhof W, Middelkoop E. Extracellular matrix characterization during healing of full-thickness wounds treated with a collagen/elastin dermal substitute shows improved skin regeneration in pigs. J Histochem Cytochem 1996;44:1311-1322.

42. Nimni ME, Myers D, Ertl D, Han B. Factors which affect the calcification of tissue-derived bioprostheses. J Biomed Mater Res 1997;35:531-537.

43. Hollinger JO, Schmitz JP, Yaskovich R, Long MM, Prasad KU, Urry DW. A synthetic polypentapeptide of elastin for initiating calcification. Calcif Tissue Int 1988;42:231-236.

44. Wood SA, Lemons JE, Prasad KU, Urry DW. In vitro calcification and in vivo biocompatibility of the cross-linked polypentapeptide of elastin. J Biomed Mater Res 1986;20:315-335. 


\section{Chapter}

\section{Preparation of (elastin) biovesicles}

Willeke Daamen*,

Paul Geutjes*,

Herman van Moerkerk,

Suzan Nillesen,

Ronnie Wismans,

Theo Hafmans,

Bert van den Heuvel,

Arthur Pistorius,

Jacques Veerkamp,

Jan van Hest,

Toin van Kuppevelt.

* Authors contributed equally to this work. 


\begin{abstract}
The preparation of vesicles from natural, biological macromolecules offers a major challenge in biomaterial and pharmacological science. We here report on a novel, general method to prepare biovesicles combining freezing and lyophilisation procedures. The protein elastin, obtained by solubilisation of purified elastin fibres, was taken as an example. Vesicles ranging from $250 \mathrm{~nm}-10 \mu \mathrm{m}$ in diameter could be prepared and separated on basis of size. Vesicle features, such as diameter, were critically dependent on elastin concentration, type of solvent, and freezing/lyophilisation regime. Fluorescent-labelled (macro)molecules could be differentially incorporated in the vesicle wall and in the lumen, and were released by elastase digestion. Vesicles thus have potential as a binary delivery and release system. Vesicles were also obtained using other biomacromolecules such as albumin, atelocollagen and heparin, hence generalising the concept. Vesicle formation does not seem to rely on the amphiphilicity of the molecules used, thus establishing a new, widely applicable procedure.
\end{abstract}




\section{INTRODUCTION}

Vesicle structures have found ample use as targetable drug carriers in pharmaceutics and cosmetics, and in special applications such as gene transfer [1]. A vesicle is defined as a small sac that can contain gas or liquid. Vesicles in biological systems are usually lipid-based. Another class of self-assembled hollow spheres are proteinbased capsules such as virus capsids [2,3]. A new development involves polymeric and synthetic polypeptide vesicles (polymersomes) built up out of e.g. polyacrylic acid-polystyrene diblock copolymers or polymers based on ethylene glycol-modified amino acid residues [4,5]. Properties of polymersomal vesicles can be adjusted by the structure of the block copolymer [6] and solvent conditions [7], but are always based on the engineered amphiphilicity of the monomers [8]. In general, vesicles are prepared by mixing amphiphilic molecules in aqueous solutions, their formation being based on the tendency of hydrophobic parts of the molecules to self-associate while the more hydrophilic parts face the inner and outer water phase [2]. With respect to in vivo applications (biocompatiblity and biodegradability), it would be a major advantage if vesicles could be prepared from natural biomolecules. However, vesicles from tissue-derived macromolecules such as (high molecular mass) proteins have not been reported yet. We here describe a general method to prepare vesicles by freezing and lyophilisation and which are solely based upon natural molecules. Solubilised elastin, obtained from purified elastin fibres by oxalic acid hydrolysis, was taken as a model compound, but the method works equally well with other macromolecules such as albumin, atelocollagen and heparin. To our knowledge, both the methodology for the preparation of vesicles and the use of natural proteins and other macromolecules for this purpose have never been realised before.

\section{MATERIALS \& METHODS}

\section{Materials}

Purified insoluble elastin fibres were prepared as described [9] and hydrolysed with a procedure based on Partridge's method [10]. Generally, elastin was solubilised after $141 \mathrm{~h}$ hydrolysis steps with $0.25 \mathrm{M}$ oxalic acid at $100^{\circ} \mathrm{C}$. Supernatants were pooled, dialysed against $10 \mathrm{mM}$ phosphate buffer $\mathrm{pH} 7.4$ and then against MilliQ water. The solubilised elastin preparation (further called 'elastin') had a mean molecular mass of about $1100 \mathrm{kDa}$ with a large molecular mass distribution and an isoelectric point of about 6. Amino acid composition of purified insoluble elastin fibres and solubilised elastin were similar, including the specific crosslinks (iso)desmosine [11]. 


\section{Preparation of vesicles}

The standard procedure for the preparation of vesicles was to drop $20 \mu \mathrm{l} 2.0 \%(\mathrm{w} / \mathrm{v}$ ) elastin in $0.25 \mathrm{M}$ acetic acid in liquid nitrogen, keep the frozen droplets at -10 to $20^{\circ} \mathrm{C}$ for about $3 \mathrm{~h}$ and then lyophilise the sample in a Zirbus lyophiliser (Bad Grund, Germany) using the program plotted in Fig. 1. Fixation of elastin vesicles was performed in vapour of $25 \%(\mathrm{w} / \mathrm{v})$ glutaraldehyde/ $38 \%$ formaldehyde $(\mathrm{w} / \mathrm{v}) 1: 1$ for $48 \mathrm{~h}$, and was followed by wet fixation in $0.5 \%(\mathrm{v} / \mathrm{v}$ ) glutaraldehyde in phosphate buffer $\mathrm{pH} 7.4$ (PB) for $4 \mathrm{~h}$. Adaptations to this procedure included elastin concentration $(0.2-5.0 \%$ $(\mathrm{w} / \mathrm{v})$ ), solvent $(0.25 \mathrm{M}$ formic acid, propionic acid, butyric acid, oxalic acid or sodium acetate, and $50 \mathrm{mM}$ and $0.25 \mathrm{M} \mathrm{HCl})$, freezing temperature $\left(-196\right.$ to $\left.-20^{\circ} \mathrm{C}\right)$, pressure settings during lyophilisation (20-400 Pa), and type of macromolecule, i.e. 0.25\% type I atelocollagen (Symatese, Chaponost, France), $0.25 \%$ bovine serum albumin (Sigma, St. Louis, MO, USA) and 1.0\% heparin (Sigma).

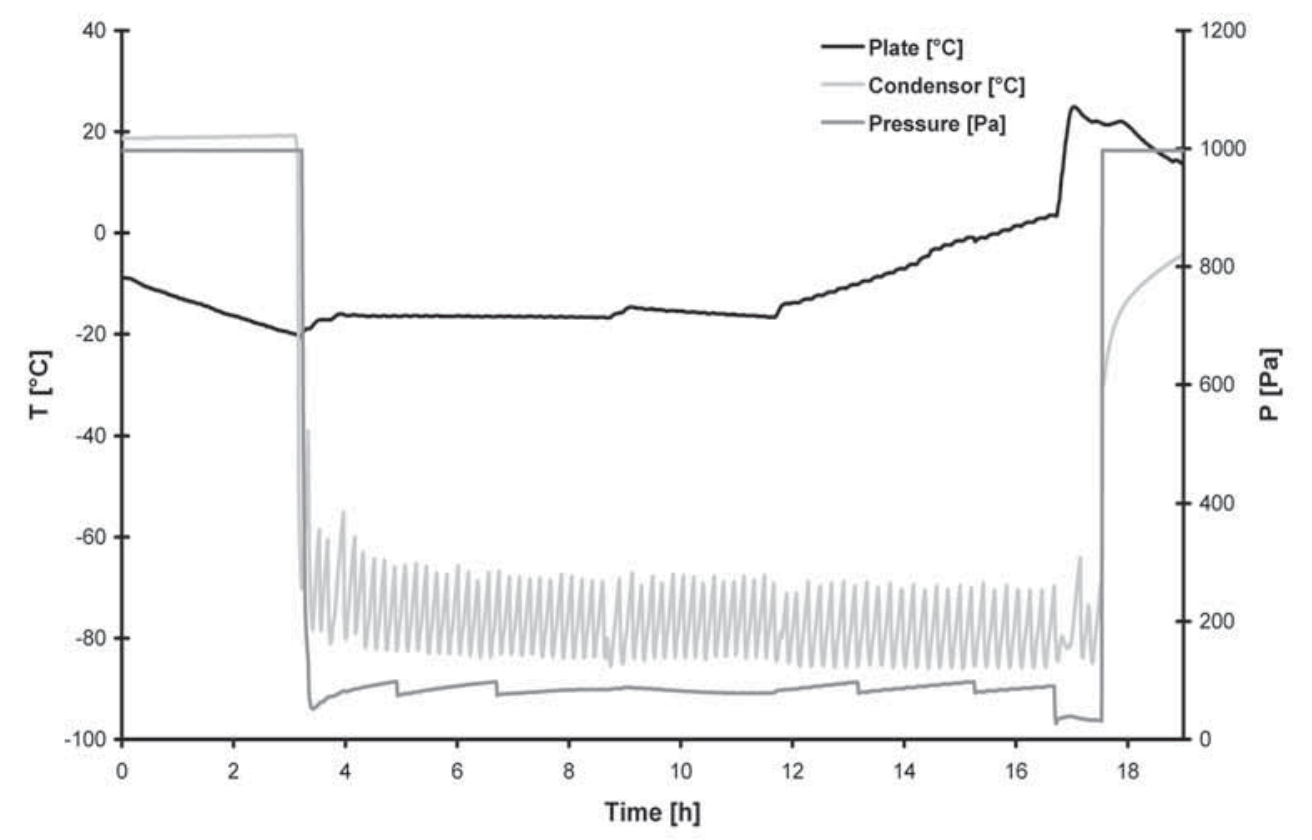

Figure 1. A representative run of the standard lyophiliser program for the preparation of elastin vesicles. Note that the pressure sensor can only accurately measure pressures under $1000 \mathrm{~Pa}$.

\section{Incorporation of fluorescent-labelled (macro)molecules into elastin vesicles}

Incorporation of fluorescent probes in the vesicle wall was accomplished by addition of $50 \mu \mathrm{g}$ probe $/ \mathrm{ml} 2.0 \%(\mathrm{w} / \mathrm{v})$ elastin solution prior to freezing and lyophilisation. Fluorescent probes included Alexa Fluor594 labelled goat anti-mouse antibody and Alexa Fluor488/594-labelled dextran (10,000 Da). Incorporation of fluorescent probes in the vesicle lumen was performed by a $96 \mathrm{~h}$ incubation of vapour-fixed vesicles in a 
solution of $50 \mu \mathrm{g}$ probe/ml in either MilliQ (dextrans) or ethanol ( $\mathrm{DiOC}_{18}$ see below), followed by wet fixation, and 3 washings with MilliQ or $100 \%$ ethanol to remove nonincluded probe. Probes included Alexa Fluor488 or 594-labelled dextran (10,000 Da) and 3,3'-dioctadecyloxacarbocyanine perchlorate $\mathrm{DiOC}_{18}$; all from Molecular Probes Europe (Leiden, The Netherlands).

\section{Degradation studies with elastin vesicles containing fluorescent probes}

Enzymatic degradation of vesicles containing fluorescent probes was assessed after incubation with elastase (Sigma) in $100 \mathrm{mM}$ Tris-HCl pH 8.0 and analysed with confocal microscopy and scanning electron microscopy (SEM). Elastin vesicles containing Alexa Fluor488-labelled dextran in the vesicle wall and Alexa Fluor594-labelled dextran in the vesicle lumen were used for these experiments. In digestion experiments analysed by SEM, specimens were treated with $0.3 \mathrm{U} / \mathrm{ml}$ elastase and analysed after $0,5,10,15,20$ and $30 \mathrm{~min}$ at $22^{\circ} \mathrm{C}$. In experiments analysed by confocal microscopy, specimens were digested with $0.4 \mathrm{U} / \mathrm{ml}$ elastase and analysed for $30 \mathrm{~min}$ at $22^{\circ} \mathrm{C}$ at $5 \mathrm{~min}$ intervals.

\section{Fourier Transform Infrared (FT-IR) measurements}

FT-IR spectra were obtained from 512 co-added double-sided interferograms at $2 \mathrm{~cm}^{-1}$ with a Bruker IFS-66 FT-IR spectrometer (Bruker, Karlsruhe, Germany). Spectroscopic grade deuterium oxide (D-content $>99.9 \%$ ) and tetradeuteroacetic acid (D-content $>99.5 \%$ ) were from Merck (Darmstadt, Germany). Freeze-induced changes were monitored by putting $5 \mu \mathrm{l}$ elastin solution $(2.0 \%$ in $0.25 \mathrm{M}$ tetradeuteroacetic acid in $\mathrm{D}_{2} \mathrm{O}$ ) between two $\mathrm{AgCl}$ windows and rapidly inserting this into a precooled ($70^{\circ} \mathrm{C}$ ) variable temperature cell (Specac, Orpington, UK). This gave a temperature rise of about $25^{\circ} \mathrm{C}$ that was restored within $10 \mathrm{~min}$. After $30 \mathrm{~min}$, infrared spectra were acquired in a continuous upward temperature gradient of $2.5^{\circ} \mathrm{C} / \mathrm{min}$. Fourier self-deconvolution was applied, using a bandwidth of $18 \mathrm{~cm}^{-1}$ and a K-factor of up to $\mathrm{K}=2.3$, to resolve overlapping bands while keeping overdeconvolution and noise to a minimum [12]. Curve fitting of absorbance spectra was performed as described before [13] using the OPUS NT 5.0 software.

\section{Microscopical techniques}

Transmission electron microscopy (TEM): Vapour and subsequently wet fixed samples were post fixed with $1 \%(\mathrm{w} / \mathrm{v})$ osmium tetroxide in $0.1 \mathrm{M} \mathrm{PB}$ for $1 \mathrm{~h}$. After a rinsing period of $3 \mathrm{~h}$ with $0.1 \mathrm{M} \mathrm{PB}$, samples were dehydrated in an ascending series of ethanol in water solutions, embedded in epoxy resin (Epon 812), and microtomed. Ultrathin sections $(60 \mathrm{~nm})$ were picked up on formvar-coated grids, post stained with lead citrate and uranyl acetate, and examined in a JEOL 1010 electron microscope. 
Frozen elastin specimens were freeze substituted at $-90^{\circ} \mathrm{C}$ in acetone and embedded in lowicryl at $-50^{\circ} \mathrm{C}[14,15]$.

Scanning electron microscopy (SEM): Lyophilised samples were sputtered with gold and studied with a JEOL JSM-6310 SEM apparatus with an accelerating voltage of 15 $\mathrm{kV}$. Wet samples first were critical point dried using $\mathrm{CO}_{2}(\mathrm{l})$.

Fluorescence-activated cell sorting (FACS): The average size of the stabilised vesicles was analysed by flow cytometry (Epics Elite flow cytometer, Coulter, Luton, UK). Vesicles were gated according to their forward and side scattering patterns. Fractions were collected on poly-D-lysine coated cover slips and left to attach for $60 \mathrm{~min}$. Cover slips were critical point dried, sputtered with gold, and studied by SEM.

Freeze microscope: A preparation of $2.0 \%(\mathrm{w} / \mathrm{v})$ elastin in $0.25 \mathrm{M}$ acetic acid was frozen at $-20^{\circ} \mathrm{C} / \mathrm{min}$ until $-70^{\circ} \mathrm{C}$ and analysed in the frozen state with a Lyostat 2 microscope (Biopharma Technology Limited, Winchester, UK).

Confocal microscopy: Elastin vesicles with incorporated fluorescent probes were deposited on poly-D-lysine coated cover slips. Confocal images were made at $488 \mathrm{~nm}$ and $594 \mathrm{~nm}$ with a BioRad MRC1024 confocal laser scanning microscope, equipped with an argon/krypton laser, using a 60x 1.4 NA oil objective and LaserSharp2000 acquisition software.

\section{RESULTS}

\section{Vesicle formation}

By quench-freezing at $-196^{\circ} \mathrm{C}$ (liquid nitrogen), annealing and lyophilising of a $2.0 \%$ $(\mathrm{w} / \mathrm{v})$ solution of elastin in $0.25 \mathrm{M}$ acetic acid, globular structures were formed ranging from $0.25-10 \mu \mathrm{m}$ in diameter as revealed by scanning electron microscopy (SEM) (Fig. 2A). Further analysis using transmission electron microscopy (TEM) showed the vesicular nature of these spheres. Elastin vesicles with a perfect smooth and round morphology were obtained with elastin equally distributed throughout the vesicle wall. Images suggest that vesicles displayed some plasticity when in contact with each other (Fig. 2B). After preparation of the elastin vesicles, they were stabilised by treatment with a $25 \%$ glutaraldehyde / $38 \%$ formaldehyde 1:1 vapour for 48 h ('vapour-fixation'). For further stabilisation, they were crosslinked in a solution of $0.5 \%$ glutaraldehyde in phosphate buffer of pH 7.4 for 4 h ('wet fixation'). Diameters of stabilised vesicles up to $10 \mu \mathrm{m}$ were found as analysed by fluorescence-activated cell sorting (FACS). Using FACS, it was possible to sort vesicles according to size (Fig. 2C). 
A

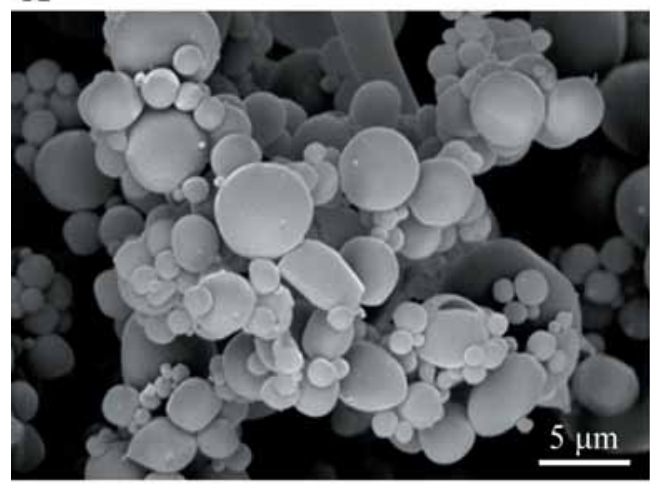

B

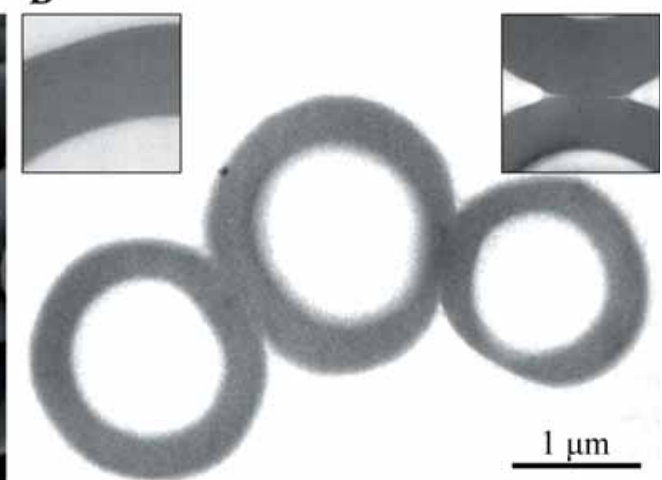

C

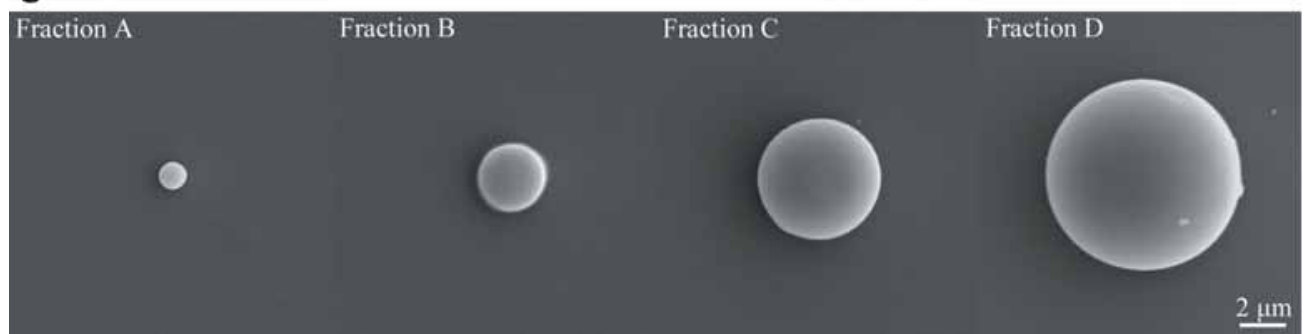

Figure 2. Elastin vesicles obtained by quench freezing at $-196^{\circ} \mathrm{C}$ of $2.0 \%$ solubilised elastin in $0.25 \mathrm{M}$ acetic acid followed by lyophilisation using the standard procedure (see M\&M). (A) Scanning electron micrograph (SEM) shows that globular structures are formed upon freezing and lyophilisation. Bar is $5 \mu m$. (B) Transmission electron micrograph (TEM) establishes vesicular nature of the globules in A. Inserts show that elastin is homogeneously distributed throughout the vesicle wall (left) and that vesicles may have some plasticity when in contact with each other (right). Bar is 1 $\mathrm{m}$. (C) SEM micrographs of stabilised vesicles that were sorted into four groups (A-D) based on their size using fluorescence-activated cell sorting (FACS). Bar is $2 \mu \mathrm{m}$.

\section{Parameters influencing vesicle formation}

The standard methodology involved a $2.0 \%$ elastin in $0.25 \mathrm{M}$ acetic acid solution which was quench frozen in liquid nitrogen $\left(-196^{\circ} \mathrm{C}\right)$. The sample was subsequently placed in the lyophiliser with a plate temperature of $-10^{\circ} \mathrm{C}$ that gradually decreased to $-20^{\circ} \mathrm{C}$ within $3 \mathrm{~h}$. When the plate temperature reached $-20^{\circ} \mathrm{C}$, pressure was reduced $(80$ $\mathrm{Pa}$ ) and these settings were kept constant for $8 \mathrm{~h}$. Plate temperature was then increased to $0^{\circ} \mathrm{C}$ over a $5 \mathrm{~h}$ period. Next, plate temperature was increased to $20^{\circ} \mathrm{C}$ and pressure decreased to $30 \mathrm{~Pa}$ and kept for $1 \mathrm{~h}$. Finally, the lyophiliser was slowly aerated and the samples were taken out of the lyophiliser (Fig. 1). Vesicle formation was dependent on many parameters, including elastin concentration, solvent composition, freezing temperature, annealing regime, pressure conditions during lyophilisation and type of biological macromolecule. Parameter modifications resulted in an altered morphology of the structures obtained.

Elastin concentration: Elastin content influenced the type of structures that were formed after freezing and lyophilisation (Fig. 3A). An optimum elastin concentration $(2.0 \%)$ existed to obtain vesicles. At lower concentrations $(0.2 \%)$ other self-assembled 
structures were found, including tyroid-like structures and open vesicles, whereas at higher concentration (5.0\%) sheets were predominantly found. At a concentration of $2.0 \%$, the majority of the structures in the preparation were vesicles.
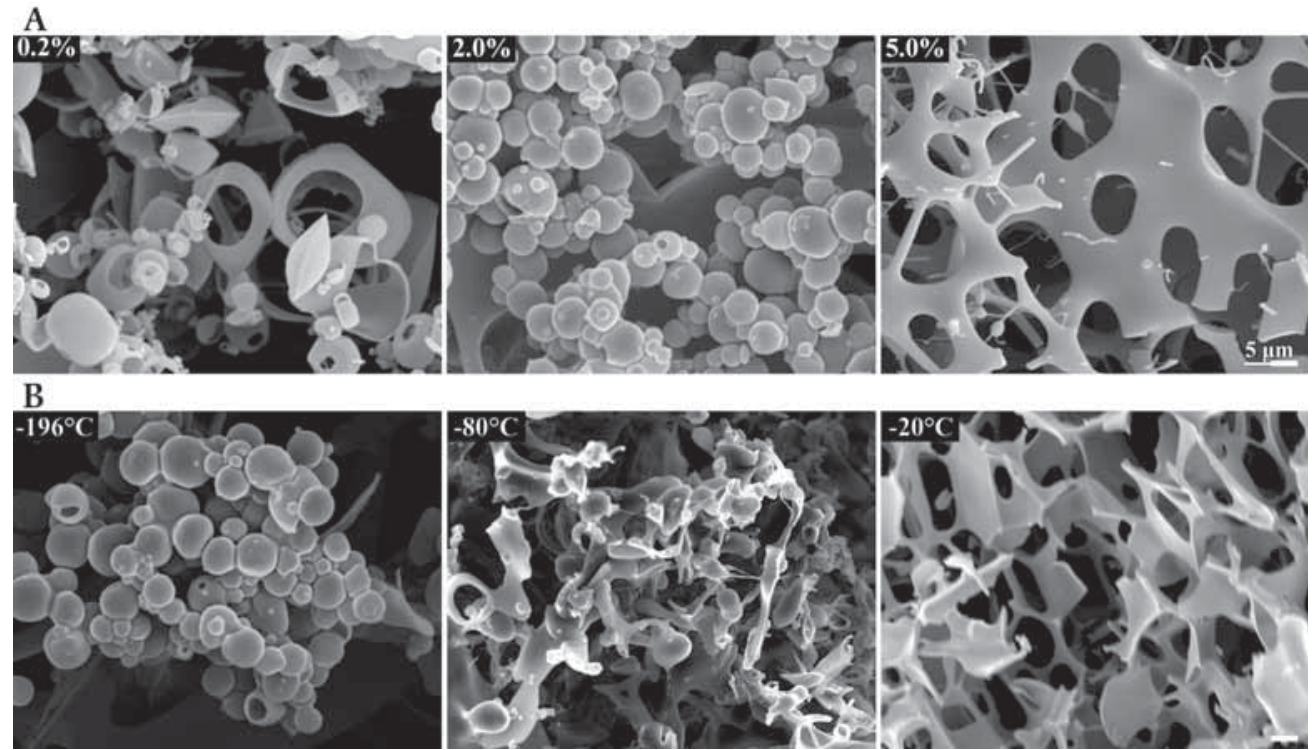

Figure 3. The effect of different parameters on the morphology of structures formed after freezing and lyophilisation, as analysed by scanning electron microscopy. (A) Morphology as a function of elastin concentration. The optimum concentration of elastin for vesicle formation is $2.0 \%(w / v)$. (B) Morphology as a function of freezing regime. The optimum freezing medium to obtain vesicles is liquid nitrogen $\left(-196^{\circ} \mathrm{C}\right)$. Bars are $5 \mu \mathrm{m}$.

Solvent composition: The solvent also influenced the structure that was formed. In an acidic environment (0.25 $\mathrm{M}$ formic acid, acetic acid, propionic acid or butyric acid), globules were formed. Globule size was smaller with increasing alkyl chain of the acid solvent. Globules turned out to be vesicles when analysed with TEM (results not shown). No vesicles were formed from $0.25 \mathrm{M} \mathrm{HCl}, 0.25 \mathrm{M}$ oxalic acid and 0.25 $\mathrm{M}$ sodium acetate. Instead, fibres of several $\mu \mathrm{m}$ wide were formed in $0.25 \mathrm{M}$ sodium acetate, resembling elastic fibre structures commonly found in vivo (results not shown).

Freezing temperature: Freezing temperature (freezing rate) was another important variable in vesicle formation. Freezing $2.0 \%$ elastin in $0.25 \mathrm{M}$ acetic acid in liquid $\mathrm{N}_{2}(-$ $196^{\circ} \mathrm{C}$ ) and subsequent lyophilisation yielded vesicles. When the freezing process was slowed down by using a solid $\mathrm{CO}_{2}$ /ethanol mixture $\left(-80^{\circ} \mathrm{C}\right)$ or by placing the sample in a $-20^{\circ} \mathrm{C}$ freezer, more sheet-like structures were found (Fig. $\mathbf{3 B}$ ).

Annealing regime: With the standard procedure for the preparation of vesicles, frozen specimens were left in a -10 to $-20^{\circ} \mathrm{C}$ environment for about $3 \mathrm{~h}$ (annealing). When this time period was prolonged, more sheet-like structures (instead of vesicles) were found after lyophilisation, indicating that macromolecular motion occurred. At a lower annealing temperature (e.g. $-80^{\circ} \mathrm{C}$ ), the vesicles obtained after lyophilisation 
were smaller, indicating that some macromolecular motion occurred with the standard procedure as well (results not shown).

Annealing was required to obtain globules as shown by microscopical analysis of frozen elastin preparations. After freezing and annealing, but before lyophilisation, globular structures were found that could be attributed to elastin (Fig. 4) Using TEM, thread-like structures with globular extensions were found when the elastin solution was frozen in liquid $\mathrm{N}_{2}$ and freeze-substituted in acetone at $-90^{\circ} \mathrm{C}$. Using light microscopy, elastin globules $(1-2 \mu \mathrm{m})$ were found when the elastin solution was frozen at $-20^{\circ} \mathrm{C} / \mathrm{min}$ until $-70^{\circ} \mathrm{C}$. Some of these globules were attached to a thread-like network. Globules formed out of the thread-like structures when the temperature was increased, as was shown by fluorescence microscopy of liquid nitrogen frozen samples that were left to thaw.

When the elastin preparation was completely melted, no rounded structures could be observed.
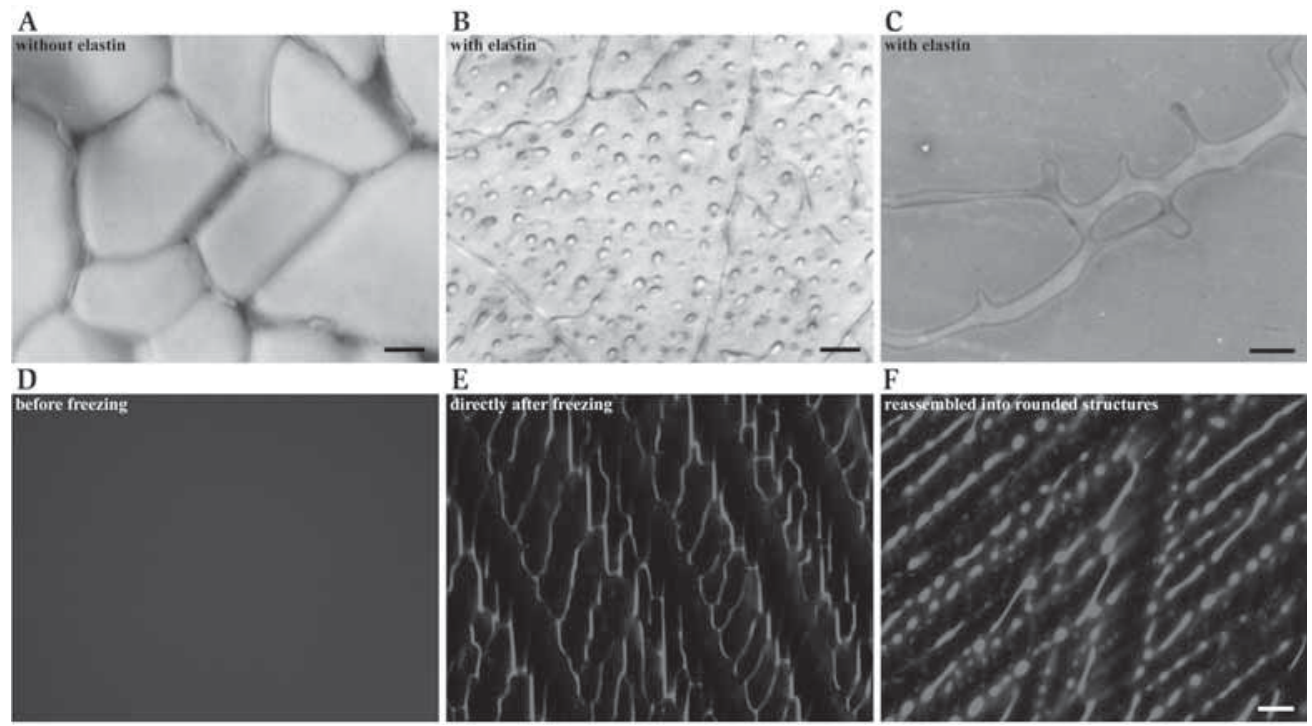

Figure 4. Morphology of frozen $2.0 \%$ elastin in $0.25 \mathrm{M}$ acetic acid. A, B Frozen at $-20^{\circ} \mathrm{C} / \mathrm{min}$ until $-70^{\circ} \mathrm{C}$ and analysed by light microscopy without (A) and with elastin (B). Rounded structures only appeared when elastin was present. C Frozen in liquid nitrogen, freeze-substituted at $-90^{\circ} \mathrm{C}$ in acetone, embedded in lowicryl and analysed by TEM. Thread-like structures showed globular extensions. D-F Elastin preparation containing Alexa Fluor594-labelled dextran before (D) and after (E-F) quench-freezing in liquid nitrogen, and analysed directly after freezing (E) and at a later time point $(F)$ by fluorescence microscopy. Rounded structures formed out of sheets when the temperature increased. Bar is $10 \mu \mathrm{m}$ in $A$ and B, $1 \mu \mathrm{m}$ in C, and $20 \mu \mathrm{m}$ for D-F.

Pressure conditions during lyophilisation: The pressure settings during lyophilisation also influenced vesicle formation. With the standard lyophilisation pressure (80 Pa), many vesicles were formed. At a lower pressure (20 Pa) more open vesicles were found, whereas at a higher pressure (400 Pa) more sheet-like structures were observed (results not shown).

Type of biological macromolecule : Applying the same freezing-annealing-lyophilisation technique as for elastin, vesicles could be prepared using macromolecules including serum albumin as an example of a spherical protein, type I atelocollagen, as an 
example of a rod-like protein, and heparin as an example of a glycosaminoglycan (a polysaccharide) (Fig. 5).
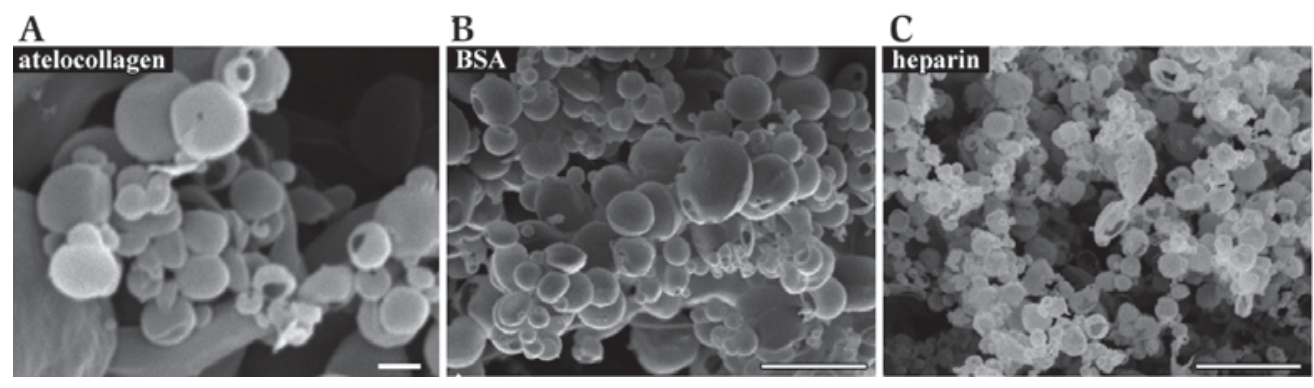

Figure 5. Vesicle-like structures can be formed from other macromolecules than elastin in $0.25 \mathrm{M}$ acetic acid. (A) $0.25 \%$ type I atelocollagen. (B) $0.25 \%$ bovine serum albumin (BSA). (C) $1.0 \%$ heparin. Heparin yielded the smallest structures. Bar is $10 \mu \mathrm{m}$.

\section{Structural analysis by infrared spectroscopy}

FT-IR spectra of quench-frozen $0.25 \mathrm{M}$ tetradeuteroacetic acid in $\mathrm{D}_{2} \mathrm{O}$ without and with $2.0 \%$ elastin were determined to give an indication of interactions in the frozen state. Without elastin (Fig. 6A), spectra were taken from -71 up to $-5^{\circ} \mathrm{C}$, and acetic acid displayed a temperature-dependent equilibrium between acetic acid monomeric and dimeric or polymeric structures. From -71 to $-15^{\circ} \mathrm{C}$, the carboxylic acid was present both in a dimer/polymer structure interacting with itself and as free, non-hydrogen bonded acetic acid monomers ( $\mathrm{C}=\mathrm{O}$ stretching band at $1648 \mathrm{~cm}^{-1}$ and $1733 \mathrm{~cm}^{-1}$, respectively) [16]. At $-15^{\circ} \mathrm{C}$, both bands collapsed and acetic acid acted only as a hydrogen bond acceptor, probably interacting with $\mathrm{D}_{2} \mathrm{O}\left(1704 \mathrm{~cm}^{-1}\right.$ band). With elastin present (Fig. 6B), spectra were taken from -68 up to $3^{\circ} \mathrm{C}$. Acetic acid solely acted as a hydrogen bond acceptor at first, as observed from the relatively strong $1704 \mathrm{~cm}^{-1}$ band. This band gradually decreased at higher temperature (until approximately $-22^{\circ} \mathrm{C}$ ) when more acetic acid interacted with itself and free acetic acid monomers appeared as shown by the $1648 \mathrm{~cm}^{-1}$ band superimposed upon the amide I protein band $\left(1645 \mathrm{~cm}^{-1}\right)$ and the $1726 \mathrm{~cm}^{-1}$ band, respectively. At $-20^{\circ} \mathrm{C}$ and higher, acetic acid behaved only as a hydrogen bond acceptor again (collapse of bands at 1648 and $1726 \mathrm{~cm}^{-1}$ and reappearance of $1704 \mathrm{~cm}^{-1}$ band). Finally, at $-68^{\circ} \mathrm{C}$ the amide I band was found at a lower frequency than at $-22^{\circ} \mathrm{C}\left(1629\right.$ vs. $\left.1645 \mathrm{~cm}^{-1}\right)$, suggesting enhanced hydrogen bonding between elastin molecules. No evidence was found for changes in apolar VanderWaals interactions, since a bandshift around $1450 \mathrm{~cm}^{-1}$ was absent in the temperature range studied (data not shown). 

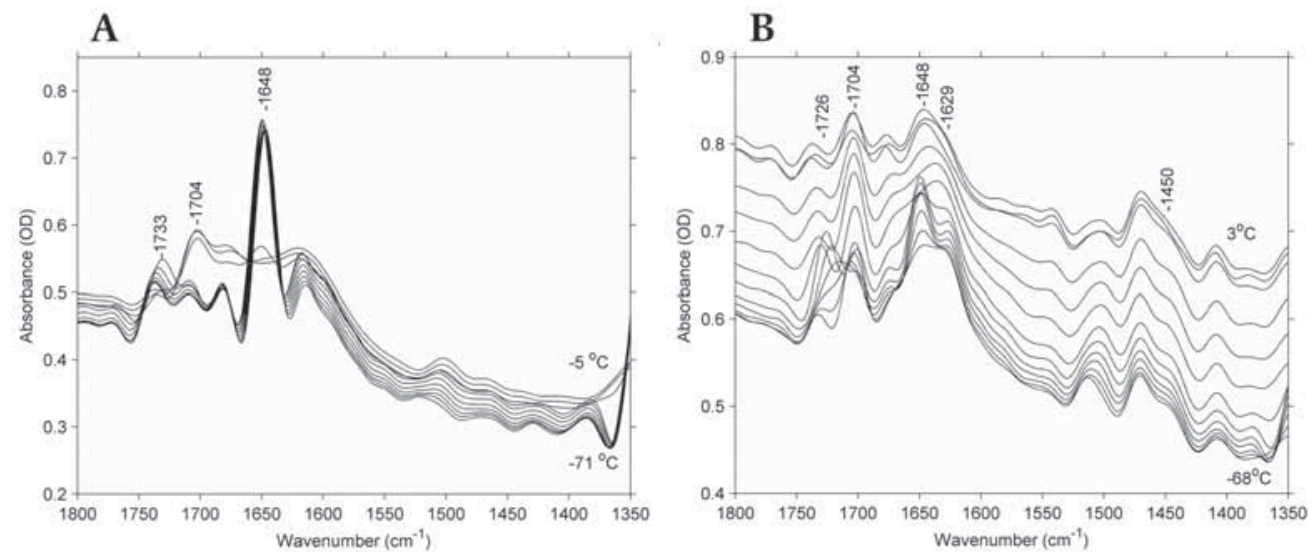

Figure 6. Expanded region of IR spectra of $0.25 \mathrm{M}$ tetradeuteroacetic acid in $\mathrm{D}_{2} \mathrm{O}$ without (A) and with $2.0 \%$ $(w / v)$ elastin $(B)$, acquired in a temperature gradient from about $-70^{\circ} \mathrm{C}$ (bottom) to $3^{\circ} \mathrm{C}$ (topmost spectrum). (A) The carboxylic acid vibrations were observed at $1648 \mathrm{~cm}^{-1}$ ( $C=O$ vibration in dimer or polymer), 1738 $\mathrm{cm}^{-1}$ (non-hydrogen bonded or free carboxylic acid $C=O$ group) and $1704 \mathrm{~cm}^{-1}$ (single hydrogen bond to carboxylic acid $C=O$ group). (B) Superimposed upon the amide I protein band (1645 $\left.\mathrm{cm}^{-1}\right)$, the carboxylic acid vibrations were observed at the same frequencies as for A, with a distinct temperature dependency.

\section{Incorporation of molecules into elastin vesicles}

Fluorescent probes were encapsulated in the vesicles to study the potential of elastin vesicles as a molecular carrier. Fluorescent-labelled macromolecular molecules could be incorporated either in the vesicle wall and/or in the vesicle lumen based on the applied technique. Incorporation into the vesicle wall occurred when the probe was added to the elastin solution prior to the freezing step, similar to entrapment in a polymeric chitosan-based hydrogel [17]. Inclusion of the probe in the vesicle lumen occurred upon incubation of vapour-fixed vesicles in a probe solution, followed by wet fixation and washing of the vesicles to remove non-incorporated probe. In this fashion, it was possible to differentially incorporate similar substances in vesicle wall and/ or lumen (e.g. Fig. 7A, fluorescent-labelled dextrans) or to incorporate two distinct substances in vesicle wall and/or lumen, e.g. fluorescent-labelled antibodies in vesicle wall and fluorescent-labelled dextran in vesicle lumen, or a hydrophilic fluorescent labelled dextran probe in the vesicle wall, and a lipophilic DiOC $_{18}$ probe in the vesicle lumen (results not shown).

Elastin vesicles with incorporated fluorescent probes were degraded by digestion with elastase as was shown by SEM at different time points. Elastin vesicle degradation resulted in the formation of elastin nanospheres (Fig. 7B). Elastase digestion also released the incorporated fluorescent macromolecules from the vesicles as was shown by confocal laser scanning microscopy (Fig. 7C). 

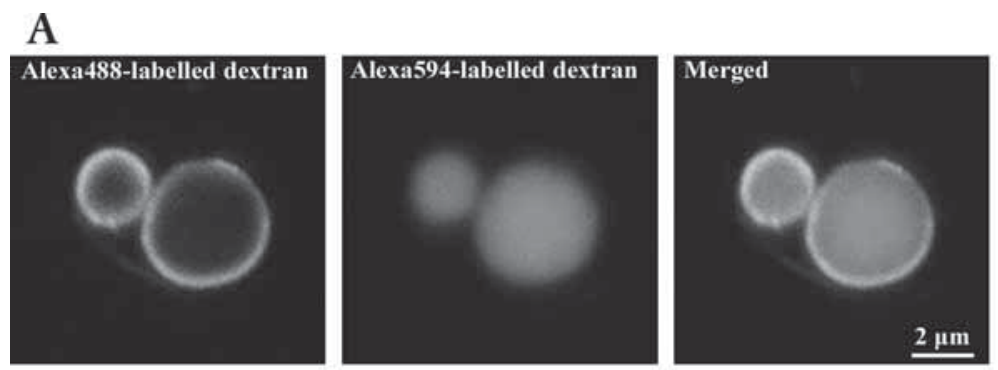

\section{B}
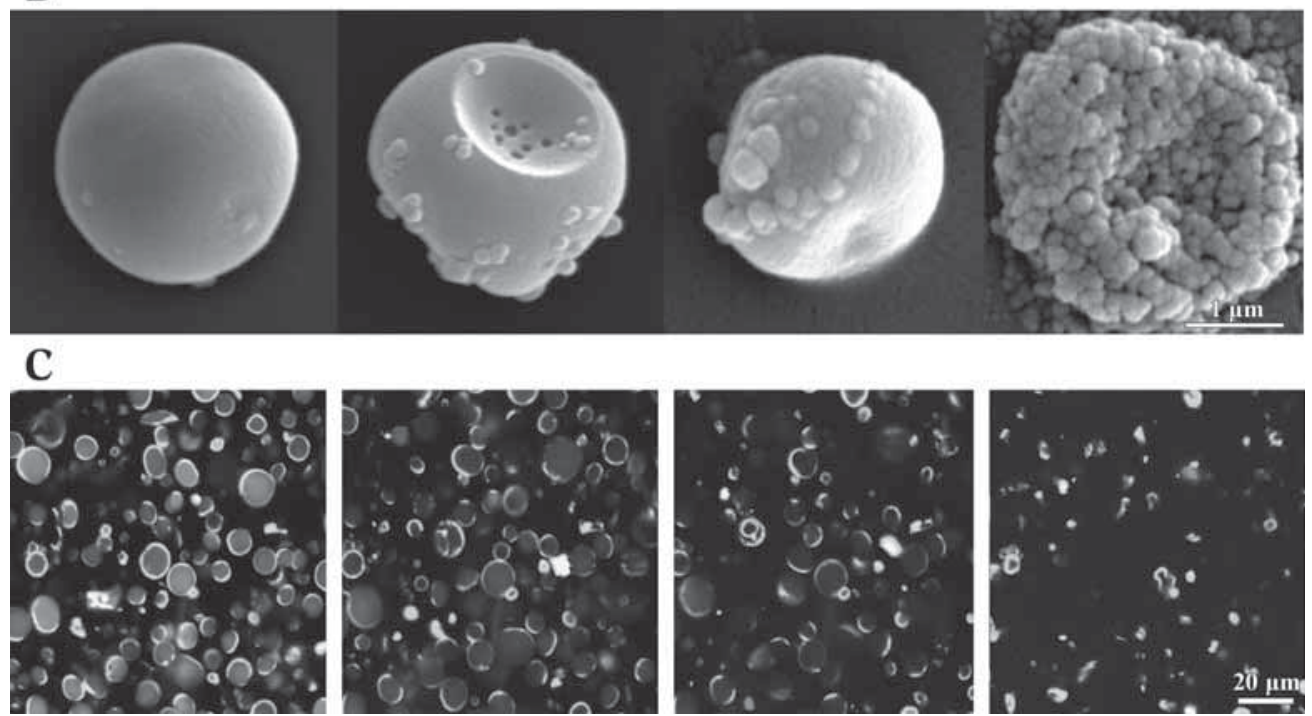

Figure 7. Fluorescent probes were differentially incorporated into the vesicle wall and the vesicle lumen as is shown in (A) for 10,000 Da dextran-conjugates labelled with Alexa Fluor488 (vesicle wall) or Alexa Fluor594 (vesicle lumen). Upon degradation by elastase, elastin vesicles reassembled into nanoglobules and fluorescent probes were released in the process as evaluated at various time points by SEM (B) and confocal microscopy (C). Fluorescent molecules from the vesicle lumen released more rapidly than from the vesicle wall. Bar is 2 $\mu \mathrm{m}$ in $\mathrm{A}, 1 \mathrm{\mu m}$ in $\mathrm{B}, 20 \mu \mathrm{m}$ in $C$. Colour figure on page 153.

\section{DISCUSSION}

\section{Plausible mechanisms for the formation of vesicles}

Upon freezing a solution of $0.25 \mathrm{M}$ acetic acid in water, pure ice crystals are formed initially, thereby increasing the concentration of acetic acid in the non-ice fraction [18]. In the presence of elastin, both acetic acid and elastin are concentrated in the nonice fraction as shown by microscopical analysis of frozen elastin preparations. Using quench-freezing at $-196^{\circ} \mathrm{C}$ alone, a network of thread-like structures was obtained. Globular structures were principally formed when the temperature was increased after freezing (annealing). Globular structures are commonly found as a highly-concentrated liquid protein phase [19]. The rapid freezing procedure may fix a metastable phase rather than following thermodynamical equilibrium rules. Both freezing and annealing induce the phase separation process between water and elastin/acetic acid into 
rounded structures.

Once globular structures are present in a frozen elastin suspension, two mechanisms may explain the formation of the lumen in elastin globules using the freezingannealing-lyophilisation methodology, i.e. double phase separation and the coffeestain mechanism (Fig. 8).

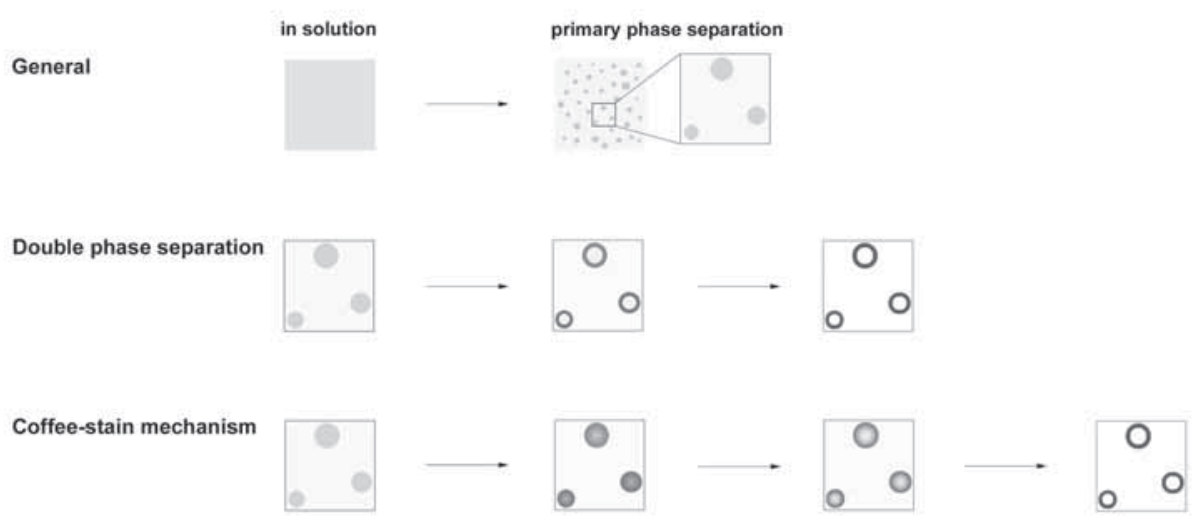

Figure 8. Plausible mechanisms for the formation of vesicles by the freezing, annealing and lyophilisation methodology. Elastin is in solution at $4^{\circ} \mathrm{C}$, but after freezing and annealing a primary phase separation into globular structures between ice and elastin/acetic acid was found. The mechanism of double phase separation explains the formation of the lumen in vesicles by a second phase separation between elastin and acetic acid, which probably also takes place during the freezing and annealing step. In the coffee-stain mechanism, the lumen is formed during lyophilisation because the globular fraction composed of concentrated elastin/acetic acid is not completely frozen and sublimation drives elastin molecules to the outer edge of the globule. For further details, see text.

Double phase separation explains the formation of the lumen by a second phase separation phenomenon prior to lyophilisation. As mentioned, the first phase separation results in globular structures after freezing and annealing. Concentrations due to freezing can rise up to 20-50 times the initial concentration and thus markedly increase molecular interactions that are negligible in the dilute solution and, concomitantly, add to the propensity for phase separation [20]. The second phase separation will then take place within the globular structures between concentrated elastin and concentrated acetic acid in such a way that elastin ends up at the ice interface. FT-IR results suggest that this phenomenon may be driven by the gradual increase of polymerised carboxylic groups in acetic acid when increasing the temperature of the frozen sample (and this may be applicable to other carboxylic acids and water, too). Finally, ice and acetic acid are removed by sublimation in the lyophilisation process resulting in elastin vesicles.

The second mechanism is a 3-dimensional analogue of the 'coffee-stain mechanism' [21] and can only occur when the contents of the highly concentrated globular structures remain liquid during the lyophilisation process (at $-20^{\circ} \mathrm{C}$ ). The original coffee-stain mechanism explains the formation of ring-like stains from solution droplets. During evaporation of the solvent the solute is concentrated at the edge of the droplet provided that the contact line of the solution with the solid substrate is pinned. To compensate for the evaporation losses, a capillary fluid flow carries the 
dispersed material from the interior out to the boundary of the drop and deposits as a solid ring $[21,22]$. In the $3-\mathrm{D}$ analogue, the elastin molecules are driven to the outer edge of the globule by sublimation of acetic acid. The droplet may be 'pinned' because sublimation of ice subtracts heat from the outer part of the globule, allowing the acetic acid at the boundary of the globule to freeze which is necessary for sublimation during lyophilisation.

We are not able to discriminate between these two mechanisms as some uncertainties exist. For example, the ternary phase diagram of the water/acetic acid/elastin system is not known as are the concentrations of elastin and acetic acid in globular structures in the frozen samples, and the melting point of this concentrated fraction at low pressure.

Conditions that were varied in the methodology, e.g. elastin concentration, solvent composition, freezing rate and annealing regime, generally influenced the initial phase separation and restructuring phase. The elastin starting concentration influences the freeze-induced elastin concentration in the non-ice fraction. With a low freeze-induced elastin concentration, tyroid structures are formed. With a high freeze-induced elastin concentration, sheet-like structures are formed, because separate globules cannot be created. With a more hydrophobic carboxylic acid solvent, globule size is smaller, probably due to a higher propensity to phase separate from water. With a slower freezing rate, more sheets are present. Fast freezing may lead to a physical fixation of a metastable phase separation state, whereas slower freezing may favour thermodynamical equilibrium conditions. Annealing induced the formation of globular structures as was found for frozen preparations by others [23]. However, a longer annealing time or a higher annealing temperature resulted in larger vesicles and ultimately sheet-like structures. That different circumstances influence vesicle formation offers a means to control vesicle parameters such as diameter. Larger vesicles may be prepared with a less hydrophobic carboxylic acid, a slower freezing rate, a longer annealing period or a higher annealing temperature.

Elastin displays self-assembling characteristics, but these do not seem to be of importance in the preparation of vesicles. During coacervation, which is a reversible self-assembly process of enhanced folding of protein molecules with increasing temperature, the disruption of protein-solvent hydrogen bonds allows apolar VanderWaals elastin-elastin interactions, thus leading towards more protein folding [24]. However, no changes in hydrophobic interactions were found with FT-IR. Furthermore, the ability of other biological macromolecules to form vesicles with the applied methodology indicates that it is a more common principle, unrelated to self-assembling behaviour elastin. Molecules that do not exhibit self-assembling behaviour can also yield vesicles. 


\section{Potential of (elastin) biovesicles}

Like certain polymersomes [25], elastin vesicles are able to encapsulate both aqueous solutions of proteins/drugs and lipophilic substances. In a pharmacological context, the simultaneous release of different materials is not easy and the preparation of multicomponent vesicles in a single delivery vehicle is beneficial in this respect [8]. With the possibility to incorporate different substances into the vesicle wall and the vesicle lumen, such a two-way system may be prepared with elastin vesicles. Furthermore, release of substances may be tailored by the extent of vesicle fixation and by the concentration of the substances to be incorporated.

Vesicles from biological proteins are especially interesting because they are biodegradable and biocompatible. They may form slow-release depots for therapeutics, may be directed to specific locations in the body (e.g. by incorporating specific antibodies into the vessel wall), and may release their content at specific sites (e.g. in case of elastin vesicles at sites of high elastase concentrations). Since vesicles can be prepared in large quantities application in tissue engineering is also possible.

\section{CONCLUSION}

We have shown that vesicles from natural macromolecules can be prepared by a freezing-annealing-lyophilisation methodology, as exemplified by solubilised elastin. Vesicles could be differentially charged with various molecules either in the vesicle wall and/or the vesicle lumen depending on the moment of addition. The guest molecules were released upon elastase digestion. These vesicles may have great potential as a (binary) delivery and release system.

\section{REFERENCES}

1. Liu F, Huang L. Development of non-viral vectors for systemic gene delivery. J Control Release 2002;78:259-266.

2. Antonietti M, Förster S. Vesicles and liposomes: A self-assembly principle beyond lipids. Adv Mater 2003;15:1323-1333.

3. Yang L, Liang H, Angelini TE, Butler J, Coridan R, Tang JX, Wong GC. Self-assembled virus-membrane complexes. Nat Mater 2004;3:615-619.

4. Shen H, Eisenberg A. Morphological Phase Diagram for a Ternary System of Block Copolymer PS310b-PAA52/Dioxane/H $\mathrm{H}_{20}$. J Phys Chem B 1999;103:9473-9487.

5. Bellomo EG, Wyrsta MD, Pakstis L, Pochan DJ, Deming TJ. Stimuli-responsive polypeptide vesicles by conformation-specific assembly. Nat Mater 2004;3:244-248.

6. Opsteen JA, Cornelissen JJLM, Van Hest JCM. Block copolymer vesicles. Pure Applied Chem 2004;76:1309-1319.

7. Choucair A, Eisenberg A. Control of amphiphilic block copolymer morphologies using solution conditions. Eur Phys J E Soft Matter 2003;10:37-44.

8. Discher DE, Eisenberg A. Polymer vesicles. Science 2002;297:967-973.

9. Daamen WF, Hafmans T, Veerkamp JH, Van Kuppevelt TH. Isolation of intact elastin fibers devoid of microfibrils. Tissue Eng 2005;11:1168-1176.

10. Partridge SM, Davis HF, Adair GS. The chemistry of connective tissues. 2 - Soluble proteins derived from partial hydrolysis of elastin. Biochem J 1955;61:11-21.

11. Daamen WF, Nillesen STM, Wismans R, Reinhardt DP, Hafmans T, Veerkamp JH, Van Kuppevelt TH. A biomaterial composed of collagen and solubilised elastin enhances angiogenesis and elastic fibre formation without calcification. This thesis 2005; Chapter 6. 
12. Kauppinen JK, Moffat DJ, Mantsch HH, Cameron DG. Fourier self-deconvolution - A method for resolving intrinsically overlapped bands. Appl Spectroph 1981;35:271-276.

13. Pistorius AM, de Grip WJ. Rhodopsin's secondary structure revisited: assignment of structural elements. Biochem Biophys Res Commun 1994;198:1040-1045.

14. van Lookeren-Campagne M., Oestreicher AB, van der Krift TP, Gispen WH, Verkleij AJ. Freezesubstitution and Lowicryl HM20 embedding of fixed rat brain: suitability for immunogold ultrastructural localization of neural antigens. J Histochem Cytochem 1991;39:1267-1279.

15. Lensen JF, Rops AL, Wijnhoven TJ, Hafmans T, Feitz WF, Oosterwijk E, Banas B, Bindels RJ, van den Heuvel LP, van d, V, Berden JH, Van Kuppevelt TH. Localization and functional characterization of glycosaminoglycan domains in the normal human kidney as revealed by phage display-derived single chain antibodies. J Am Soc Nephrol 2005;16:1279-1288.

16. Colthrup NB, Daly LH, Wiberley SE. Introduction to Infrared and Raman Spectroscopy. New York: Academic Press, 1964.

17. Noble L, Gray AI, Sadiq L, Uchegbu IF. A non-covalently cross-linked chitosan based hydrogel. Int J Pharm 1999;192:173-182.

18. Bartels J, Borchers H, Hausen H, Hellwege KH, Schäfer Kl, Schmidt E. Landolt-Börnstein Zahlenwerte und Funktionen aus Physik, Chemie, Astronomie, Geophysik und Technik - II Eigenschaften der Materie in irhren Aggregatzuständen. 6 ed. Berlin: Springer Verlag, 1962.

19. Kuznetsov YG, Malkin AJ, McPherson A. The liquid protein phase in crystallization: a case study - intact immunoglobulins. J Crystal Growth 2001;232:30-39.

20. Hatley RH, Mant A. Determination of the unfrozen water content of maximally freeze-concentrated carbohydrate solutions. Int J Biol Macromol 1993;15:227-232.

21. Deegan RD, Bakajin O, Dupont TF, Huber G, Nagel SR, Witten TA. Capillary flow as the cause of ring stains from dried liquid drops. Nature 1997;389:827-829.

22. Lensen MC, Takazawa K, Elemans JA, Jeukens CR, Christianen PC, Maan JC, Rowan AE, Nolte RJ. Aided self-assembly of porphyrin nanoaggregates into ring-shaped architectures. Chemistry 2004;10:831-839.

23. Heller MC, Carpenter JF, Randolph TW. Manipulation of lyophilization-induced phase separation: implications for pharmaceutical proteins. Biotechnol Prog 1997;13:590-596.

24. Vrhovski B, Jensen S, Weiss AS. Coacervation characteristics of recombinant human tropoelastin. Eur J Biochem 1997;250:92-98.

25. Photos PJ, Discher DE. PEG brush inhibition kinetics in opsonization-clearance: MW-scaling from self-assembled polymer vesicles in vivo. Summer Bioengineering Conference, Sonesta Beach Resort Key Biscayne, Florida 2003;2003 June 25-29:743-744. 


\section{chapter 8}

Summary, general conclusions and future directions

Samenvatting, algemene conclusies en toekomstvisie 


\section{SUMMARY}

\section{Elastin in biomaterials}

Extracellular matrix components are valuable building blocks for the preparation of biomaterials, especially if their biological, chemical and physical characteristics can be controlled. Elastin is present in elastic fibres as an insoluble, highly cross-linked protein, providing elasticity to organs like lung, aorta, and ligaments. Soluble elastin can be derived from elastin fibres by hydrolysis, and displays various biological effects, like enhancement of cell proliferation and induction of elastin synthesis. Despite its remarkable properties, elastin has found little use as a biomaterial. This thesis describes the preparation of purified insoluble elastin fibres and solubilised elastin, and their application as a biomaterial for tissue engineering purposes. The construction of tailormade (composite) scaffolds and the evaluation of their biocompatibility in vitro and in vivo, as well as the preparation of elastin biovesicles are assessed. In Chapter 1 an overview is given on the preparation and application of elastin-based biomaterials. Special attention is given to the different forms of elastin-based biomaterials that exist and some tissue engineering applications are highlighted.

\section{Preparation of elastin fibres and solubilised elastin}

Purity is of major importance when using extracellular matrix components as a biomaterial in order to be able to study the (cell-biological) effect of individual components. Purification of intact elastin from elastic fibres presents a major challenge, among others for the intimate interwoveness of elastin and microfibrils. Insoluble elastin -free of microfibrils- was isolated from equine ligamentum nuchae as described in Chapter 2. A modified procedure resulting in both intact and pure fibres is given in Chapter 3. The term 'elastin fibre' was introduced to indicate an elastic fibre in which the only component is elastin. Elastin fibres were used in the preparation of solubilised elastin by oxalic acid hydrolysis (Chapter 6) .

\section{Preparation and characterisation of collagen-elastin scaffolds}

Tailor-made biomaterials for tissue engineering are designed to mimic the extracellular matrix composition of a specific tissue. This is only possible when the characteristics of the biomaterials can be fully controlled. The development of molecularly-defined scaffolds from purified type I collagen fibrils, elastin fibres and chondroitin sulfate is described in Chapter 4. Collagen and elastin fibres physically interacted with each other in the scaffolds. Some collagen was necessary to obtain coherent scaffolds. The preparation of scaffolds containing crosslinked type I collagen fibrils and solubilised elastin is described in Chapter 6. Solubilised elastin formed globular structures 
that were incorporated in the collagenous part of the scaffolds. Many parameters determining the biochemical and mechanical properties of these scaffolds can be controlled, e.g. the composition (by the ECM components used and their ratio), the type and extent of chemical crosslinking, the pore size of the scaffold (by the freezing rate during the manufacturing process), the scaffold shape (by the mould), and the water-binding capacity (by the attachment of glycosaminoglycans). Scaffolds proved to be cytocompatible.

\section{Tissue response to collagen-elastin scaffolds}

Tissue response to porous scaffolds composed of crosslinked collagen-elastin fibres and collagen-solubilised elastin were studied after subcutaneous implantation in rats (Chapter 5 and 6, respectively). Collagen-elastin fibres scaffolds did not calcify in adult rats, but showed calcification in young Sprague Dawley rats (a sensitive calcification model). Collagen-solubilised elastin scaffolds, however, did not calcify. In scaffolds containing impure elastin (e.g. scaffolds containing pulverised ligament), calcification was more severe. None of the implanted scaffolds calcified in adult rats. Degradation of scaffolds and new matrix formation were related to cellular influx and degree of vascularisation. Scaffolds containing solubilised elastin increased elastic fibre production and induced angiogenesis.

\section{Preparation and characterisation of vesicles from solubilised elastin}

The preparation of vesicles from biological macromolecules offers a major challenge in material science. Vesicles (250 nm - $10 \mu \mathrm{m}$ in diameter) could be obtained from solubilised purified elastin using a novel approach combining freezing and lyophilisation procedures (Chapter 7). Vesicle formation was critically dependent on elastin concentration, solvent, freezing mode and pressure conditions during lyophilisation. The elastin vesicles could be fractionated based on their size. Fluorescent-labelled (macro)molecules were differentially incorporated into the vesicle wall and/or vesicle lumen and were released by elastase digestion. Vesicles can thus create a potential two-phase delivery system.

\section{GENERAL CONCLUSIONS}

Highly purified and intact elastin fibres were prepared which were devoid of microfibrils and could be solubilised by oxalic acid hydrolysis. Various elastin biomaterials were developed from these elastin preparations. At first, scaffolds were designed to mimic the extracellular matrix constitution and were composed of type I collagen, elastin fibres and glycosaminoglycans, or type I collagen and solubilised elastin. Particularly, scaffolds composed of collagen and solubilised elastin showed improved tissue 
regeneration after subcutaneous implantation, i.e. increased elastic fibre production and induced angiogenesis without calcification. In addition, new features could be given to elastin biomaterials as in the case of elastin biovesicles that were able to incorporate and release fluorescent macromolecules. It was thus shown that elastin is a valuable component of biomaterials for tissue engineering.

\section{FUTURE DIRECTIONS}

Elastin-based materials are promising in the field of biomaterials, tissue engineering and controlled release, especially because they exhibit interesting biological, biomechanical, biochemical and biophysical properties, and may comprise novel approaches for improving tissue regeneration. Extracellular matrix mimicking scaffolds are especially interesting when variables like chemical composition and architecture can be controlled, as shown in this thesis. Self-assembling elastin-based materials are an emerging and promising theme within the biomaterials field. A bottom-up approach may lead to well-defined biomaterials when proteins are used as building blocks for the fabrication of higher order structures via (self-)assembly [1].

From the preparation of biomaterials and the evaluation of their biocompatibility the next step can now be taken towards defined in vivo applications. Scaffolds can be designed to specifically mimic or regenerate a specific organ. One example is to make a bilayered skin construct that may not need the incorporation of cells outside the body, but attracts and controls the desired cells in vivo. The dermal element can be composed of a porous collagen-elastin scaffold with attached glycosaminoglycans that allow binding of growth factors that specifically promote angiogenesis and fibroblast proliferation. It can be covered by a collagen film containing heparan sulfate and a growth factor that stimulates keratinocyte proliferation (Fig. 1).

Elastin may also be valuable in vascular grafts, providing both desired mechanical properties (e.g. elasticity) and biological effects on specific cell types. Another application may be elastic cartilage present in e.g. auricle (external ear) and epiglottis. By combining different extracellular matrix components (including growth factors and morphogens), even the embryonic microenvironment may be mimicked. Embryonic scaffolds may provide the correct signals to the body to start the formation of new tissues. Elastin-based biomaterials thus have great potential for tissue engineering applications.

\section{REFERENCE}

1. Tu RS, Tirrell M. Bottom-up design of biomimetic assemblies. Adv Drug Deliv Rev 2004;56:153763. 


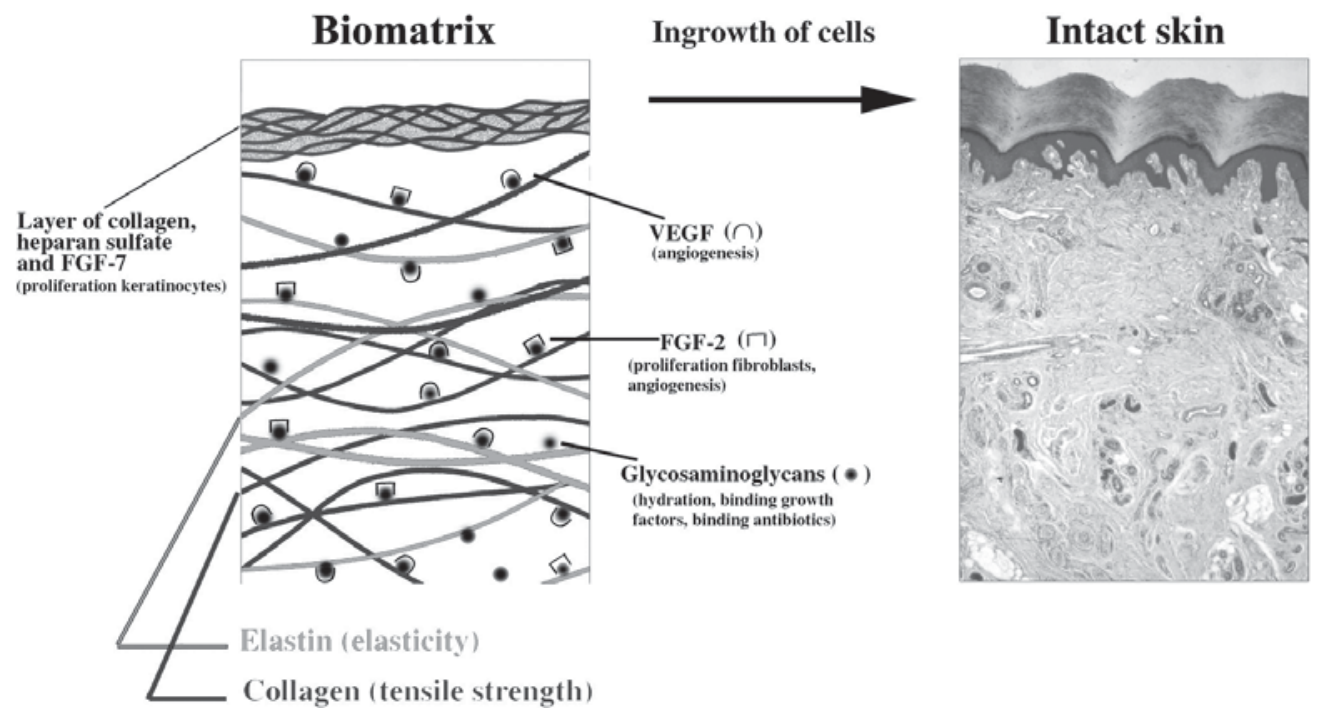

Figure 1. Design of a bilayered scaffold as a full-thickness skin graft. The scaffold contains elements for the influx and differentiation of cells. Population of the matrix by cells of the body should lead to the formation of intact skin.

Figuur 1. Ontwerp van een dubbellaags matrix voor een huidsubstituut dat zowel de dermale als de epidermale component bevat. De matrix bevat bouwstenen voor de instroom en differentiatie van cellen. Ingroei door lichaamseigen cellen in de matrix moet aanleiding geven tot de vorming van intacte huid.

\section{SAMENVATTING}

\section{Elastine in biomaterialen}

Extracellulaire matrix componenten zijn waardevolle bouwstenen om biomaterialen mee te bereiden, in het bijzonder als de biologische, chemische en fysische eigenschappen van deze materialen beheersbaar zijn. Elastine is aanwezig in elastische vezels als een onoplosbaar, verknoopt eiwit en het geeft elasticiteit aan organen zoals long, aorta en ligamenten. Oplosbaar elastine kan bereid worden uit elastinevezels door middel van hydrolyse. Het vertoont verscheidene biologische effecten zoals een verbeterde celproliferatie en verhoogde elastineproductie. Ondanks de bijzondere eigenschappen van elastine, kent het nog weinig toepassing als biomateriaal. Dit proefschrift beschrijft de zuivering van onoplosbare elastinevezels, de bereiding van oplosbaar elastine en de toepassing als biomateriaal voor weefseltechnologie (tissue engineering). De bereiding van op maat gemaakte matrices, de evaluatie van hun biocompatibiliteit en de bereiding van biovesicles worden hier beschreven. In Hoofdstuk 1 wordt een overzicht gegeven van de bereiding en toepassing van op elastine gebaseerde biomaterialen. Speciale aandacht wordt hierbij geschonken aan de verschillende vormen van elastine als biomateriaal en er wordt nader ingegaan op enkele toepassingen in de weefseltechnologie. 


\section{Bereiding van elastinevezels en oplosbaar elastine}

Bij het gebruik van extracellulaire matrixcomponenten als biomateriaal is zuiverheid van groot belang om in staat te zijn het (celbiologische) effect van de afzonderlijke componenten te bestuderen. Isolatie van intact elastine uit elastische vezels biedt een grote uitdaging, mede doordat elastine en microfibrillen hierin sterk verweven zijn. Onoplosbaar elastine werd gezuiverd uit paardennekligamenten zoals beschreven in Hoofdstuk 2. Een aangepaste methode (Hoofdstuk 3) resulteerde in zowel intacte als zuivere vezels. De term 'elastinevezel' werd geïntroduceerd om een elastische vezel aan te duiden met als enige bestanddeel elastine. Deze elastinevezels werden gebruikt om oplosbaar elastine te maken door middel van oxaalzuurhydrolyse (Hoofdstuk 6).

\section{Bereiding en karakterisering van collageen-elastine matrices}

Op maat gemaakte biomaterialen voor tissue engineering werden zodanig ontwikkeld dat zij de extracellulaire matrixcompositie van specifieke weefsels nabootsten. Dit is alleen mogelijk als de eigenschappen van deze biomaterialen beheerst kunnen worden. De ontwikkeling van moleculair-gedefinieerde matrices uit collageen type I fibrillen, elastinevezels en chondrö̈tinesulfaat staat beschreven in Hoofdstuk 4. Collageen en elastinevezels gingen een fysieke interactie met elkaar aan in deze matrices. Een kleine hoeveelheid collageen was nodig om stabiele matrices te maken. De bereiding van matrices met collageen type I fibrillen en oplosbaar elastine wordt beschreven in Hoofdstuk 6. Oplosbaar elastine vormde bolvormige structuren die deel uitmaakten van het collagene deel van de matrices. Diverse parameters die de biochemische en mechanische eigenschappen van deze matrices bepalen, kunnen beheerst worden, zoals de samenstelling (door de gebruikte extracellulaire matrixcomponenten en hun ratio), het type en de mate van chemische crosslinking, de poriegrootte van de matrix (door de invriessnelheid tijdens het bereidingsproces), de vorm van de matrix (door de mal) en de waterbindende eigenschappen (door koppeling van glycosaminoglycanen). Cellen konden op de gevormde matrices groeien en zich ontwikkelen.

\section{Weefselreactie op collageen-elastine matrices}

De weefselreactie op poreuze matrices, bestaande uit collageen met elastinevezels en collageen met oplosbaar elastine, is bestudeerd na onderhuidse implantatie in ratten (Hoofdstuk 5, respectievelijk 6). Collageen-elastinevezels matrices calcificeerden niet in volwassen ratten, maar wel in jonge Sprague Dawley ratten (een gevoelig model voor de bestudering van calcificatie). Matrices opgebouwd uit onzuivere componenten (bijvoorbeeld matrices met verpulverd ligament) vertoonden meer calcificatie, terwijl collageen-oplosbaar elastine matrices helemaal niet calcificeerden. De afbraak van de matrices en de vorming van nieuwe extracellulaire matrixcomponenten konden 
worden gerelateerd aan de mate van cellulaire instroming en bloedvatvorming. Vooral in matrices die oplosbaar elastine bevatten, werden nieuwe elastische vezels en bloedvaten waargenomen.

\section{Bereiding en karakterisering van vesicles uit oplosbaar elastine}

De bereiding van vesicles uit biologische macromoleculen biedt een grote uitdaging binnen de materiaalwetenschappen. Vesicles $(250 \mathrm{~nm}-10 \mu \mathrm{m}$ in diameter) konden vervaardigd worden uit oplosbaar elastine door middel van een nieuwe aanpak die invriezen en vriesdrogen combineert (Hoofdstuk 7). De vorming van vesicles was afhankelijk van elastineconcentratie, oplosmiddel, vriesprocedure en vacuümcondities. De vesicles konden gesorteerd worden op basis van hun grootte. Fluorescent-gelabelde (macro)moleculen werden opgesloten in de vesicle wand en/of de vesicleholte en kwamen vrij door digestie met het enzym elastase. Deze vesicles kunnen mogelijk als twee-fasen afgiftesysteem toegepast worden.

\section{ALGEMENE CONCLUSIES}

Hoog-gezuiverde intacte elastinevezels, die geen microfibrillen meer bevatten, zijn bereid. Deze elastinevezels konden oplosbaar worden gemaakt door middel van oxaalzuurhydrolyse. Verschillende elastinebiomaterialen werden ontwikkeld met zowel elastinevezels als oplosbaar elastine. Matrices bootsten de extracellulaire matrix na en waren opgebouwd uit collageen type I, elastinevezels en glycosaminoglycanen of uit collageen type I en opgelost elastine. Met name de laatstgenoemde matrices lieten een verbeterde weefselregeneratie zien na onderhuidse implantatie, dat wil zeggen dat deze een verhoogde elastinevezelproductie en bloedvatvorming gaven en geen calcificatie. Daarnaast werden nieuwe eigenschappen gevonden voor elastinebiomaterialen zoals de vorming van elastinevesicles waarmee het mogelijk was om fluorescente moleculen op te sluiten en te laten vrijkomen. Er is dus aangetoond dat elastine een waardevolle bouwsteen is van biomaterialen voor tissue engineering.

\section{TOEKOMSTVISIE}

Materialen gebaseerd op elastine zijn veelbelovend in het veld van biomaterialen weefseltechnologie en gedoseerde afgifte, vooral omdat deze materialen interessante biologische, biomechanische, biochemische en biofysische eigenschappen bezitten en nieuwe mogelijkheden bieden om weefselherstel te verbeteren. Matrices die op de werkelijke extracellulaire matrix gebaseerd zijn, worden vooral interessant indien variabelen, zoals chemische samenstelling en vorm, beheerst kunnen worden, 
hetgeen in dit proefschrift is aangetoond. Elastine-achtige materialen die gebaseerd zijn op het zelf-aggregerende gedrag van elastine zijn een opkomend en veelbelovend thema binnen het biomaterialenveld. Een 'bottom-up approach' kan leiden tot goed gedefinieerde biomaterialen indien eiwitmoleculen worden gebruikt als bouwstenen om tot grotere structuren te komen door middel van (zelf-)aggregatie [1].

$\mathrm{Na}$ de bereiding van biomaterialen en de evaluatie van hun biocompatibiliteit kan $\mathrm{nu}$ de volgende stap gezet worden in de richting van in vivo toepassingen. Matrices kunnen dusdanig ontworpen worden dat ze een bepaald orgaan nabootsen of kunnen regenereren. Een voorbeeld hiervan is een dubbellaags huidvervanging dat in het lichaam de gewenste cellen aantrekt en laat ontwikkelen in plaats van dit buiten het lichaam te bewerkstelligen. De dermale component kan bestaan uit een poreuze collageen-elastine matrix met glycosaminoglycanen die binding van groeifactoren mogelijk maakt die specifiek de bloedvatvorming of fibroblastengroei bevorderen. Deze laag wordt bedekt met een collageenvlies dat heparansulfaat bevat en een groeifactor die de groei van keratinocyten stimuleert (Fig. 1).

Elastine kan ook een waardevolle component zijn in bloedvatconstructen, en hierbij zowel de gewenste mechanische eigenschappen (elasticiteit) als celbiologische effecten geven. Een andere toepassing ligt mogelijk in de regeneratie van elastisch kraakbeen zoals dat aanwezig is in bijvoorbeeld de oorschelp en het strotklepje. Door verschillende extracellulaire matrixcomponenten (in combinatie met groeifactoren en morfogenen) te combineren, zou mogelijk zelfs de embryonale micro-omgeving nagebootst kunnen worden. Embryonale matrices zouden op deze manier de juiste signalen aan het lichaam kunnen geven om een aanzet te geven tot de vorming van nieuwe weefsels. Biomaterialen gebaseerd op elastine bieden dus grote mogelijkheden voor toepassing in de weefseltechnologie.

\section{REFERENTIE}

1. Tu RS, Tirrell M. Bottom-up design of biomimetic assemblies. Adv Drug Deliv Rev 2004;56:1537-63. 


\section{DANKWOORD}

Een promotie-onderzoek en een proefschrift schrijven doe je niet alleen. Daarom wil ik nu 'het boekie' af is iedereen bedanken die direct of indirect heeft bijgedragen aan de totstandkoming ervan.

Allereerst mijn promotor Prof.dr. Jacques Veerkamp en co-promotor Dr. Toin van Kuppevelt. Prof. Veerkamp, bedankt dat u altijd tijd hebt gevonden om over dit onderzoek mee te denken en mijn manuscripten te corrigeren, ook na uw emeritaat. Toin, je bent altijd erg enthousiast geweest over de mogelijkheden van tissue engineering. Mede door jouw innoverende ideeën konden we tot verrassende bevindingen komen. Bedankt ook dat je me vrijheid gaf in de uitvoering van het onderzoek. Dit heb ik zeer gewaardeerd.

Mijn paranimfen: Theo Hafmans en Herman van Moerkerk. Jullie hebben veel bijgedragen aan dit proefschrift. Theo, bedankt voor alles op het gebied van de TEM, voor het lay-outen en je aanstekelijke enthousiasme. Herman, bedankt voor de grote hoeveelheden collageen, voor je enorme kennis van 'ouderwetse' analysemethoden, maar ook voor het regelmatig redden van mijn laptop. Ik vind het fijn dat jullie straks naast me staan bij mijn verdediging.

De andere (ex)collega's van de afdeling Matrix Biochemie wil ik bedanken voor de plezierige samenwerking en de gezelligheid zowel binnen als buiten het lab. Vanzelfsprekend de andere tissue engineers: Suzan, Paul, Ronnie, Kaeuis en recentelijk Martin, Gerwen en Peter. Jeroen, bedankt voor je pioniersrol op het gebied van tissue engineering binnen onze afdeling: jouw proefschrift blijft een naslagwerk. Uiteraard hebben ook alle andere labbewoners een steentje bijgedragen aan dit proefschrift. Jullie waren altijd bereid mij ergens mee te helpen: Arie, Aukje, Elly, Els, Gerdy, Guido, Joost, Martijn, Mieke, Nicole, Tessa en Toon. Paul Jap, bedankt voor het delen van je onuitputtelijke histologische kennis.

De leden van de IOP-begeleidingscommissie ben ik zeer erkentelijk voor hun input tijdens de halfjaarlijkse besprekingen. Het was erg nuttig om mijn onderzoek eens vanuit een andere optiek belicht te zien.

Ook studenten die hebben bijgedragen aan dit onderzoek wil ik noemen: Suzanne, Walter, Gerwin, Suzan, Jeroen, Joost, Paul en Bas. Ook al levert niet ieder experiment meteen het gewenste resultaat op, jullie werk was zeker van betekenis voor de voortgang van het onderzoek. Leuk dat een aantal van jullie in het onderzoek zijn verder gegaan, en Suzan en Paul, fijn dat jullie daarbij zelfs voor Biochemie hebben gekozen. 
Met vele anderen heb ik plezierig samengewerkt, in het bijzonder Marja van Luyn, Laura Buttafoco, André Poot, Jan van Hest, Esther Middelkoop en Arthur Pistorius. Geert Poelen en Debby Smits bedank ik voor de vakkundige dierexperimentele assistentie. Natuurlijk wil ik ook alle anderen die hier niet met name genoemd worden bij deze bedanken.

Ook mijn familie en vrienden wil ik dank zeggen voor hun belangstelling. In het bijzonder wil ik alle leden en aanhang van de Free Style Herriekapel bedanken voor de broodnodige ontspanning.

Pa en ma, ik heb het zeer gewaardeerd dat jullie een onvoorwaardelijk vertrouwen in mij hebben, mij op allerlei manieren steunen en dat jullie tot op de dag van vandaag voor me klaar staan.

Lieke, bedankt dat je zo'n lieve baby bent en me de tijd gaf dit proefschrift af te maken. Serge, mijn lief, jou wil ik bedanken voor al je morele en praktische support, maar zeker ook voor je enorme relativerend vermogen dat ik zo nu en dan hard nodig heb.

Dank je wel allemaal!

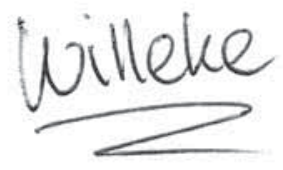

november 2005 


\section{CURRICULUM VITAE}

Willeke Janssen-Daamen werd geboren op 19 september 1975 te Druten, en behaalde in 1993 haar VWO-diploma aan het Pax Christi College te Druten. In datzelfde jaar begon zij met de studie Levensmiddelentechnologie aan de Landbouwuniversiteit te Wageningen. In september 1998 behaalde ze haar ingenieursdiploma met afstudeervakken bij de Afdeling Zuiveltechnologie \& Geïntegreerde Levensmiddelentechnologie van de Landbouwuniversiteit te Wageningen en het Nederlands Instituut voor Zuivelonderzoek (NIZO) te Ede. Daarnaast liep ze stage bij het Hannah Research Institute te Ayr, Schotland.

Van november 1998 tot juni 2004 werkte zij als assistent in opleiding bij de afdeling Biochemie van het Universitair Medisch Centrum 'St Radboud' te Nijmegen. De resultaten van dat promotieonderzoek zijn in dit proefschrift beschreven. Tijdens haar promotie was zij betrokken bij diverse onderwijstaken en het begeleiden van studenten en stagiaires. Tevens verzorgde ze verscheidene voordrachten en posterpresentaties op binnenlandse en buitenlandse congressen.

Sinds oktober 2004 is zij werkzaam als postdoc bij de afdeling Biochemie van het Universitair Medisch Centrum 'St Radboud' te Nijmegen. 


\section{PUBLICATIONS ON THIS SUBJECT}

Daamen WF, Hafmans T, Veerkamp JH, Van Kuppevelt TH. Comparison of five procedures for the purification of insoluble elastin. Biomaterials 2001;22:1997-2005.

Daamen WF, Hafmans T, Veerkamp JH, Van Kuppevelt TH. Purification of elastin and preparation of matrices for tissue engineering. Industrial Proteins 2001;9:15-17.

Daamen WF, Van Moerkerk HThB, Hafmans T, Buttafoco L, Poot AA, Veerkamp JH, Van Kuppevelt TH. Preparation and evaluation of molecularly-defined collagenelastin-glycosaminoglycan scaffolds for tissue engineering. Biomaterials 2003;24:4001-4009.

Buijtenhuijs P, Buttafoco L, Poot AA, Daamen WF, Van Kuppevelt TH, Dijkstra PJ, De Vos RA, Sterk LM, Geelkerken BR, Feijen J, Vermes I. Tissue engineering of blood vessels: Characterisation of smooth muscle cells for culturing on collagen and elastin based scaffolds. Biotechnology and Applied Biochemistry 2004;39:141-149.

Daamen WF, Nillesen STM, Hafmans T, Veerkamp JH, Van Luyn MJA, Van Kuppevelt TH. Tissue response of defined collagen-elastin scaffolds in young and adult rats with special attention to calcification. Biomaterials 2005;26:81-92.

Daamen WF, Hafmans T, Veerkamp JH, Van Kuppevelt TH. Isolation of intact elastin fibres devoid of microfibrils. Tissue Engineering 2005;11:1168-1176.

Daamen WF, Geutjes PJ, Van Kuppevelt TH. Method for obtaining a hollow particle. 2005; Patent pending, PCT/NL2005/000828.

Geutjes PJ, Daamen WF, Buma P, Feitz WF, Faraj KA, Van Kuppevelt TH. From molecules to matrix: construction and evaluation of molecularly-defined bioscaffolds. Advances in Experimental Biology and Medicine 2006;585:279-295.

Buttafoco L, Engbers-Buijtenhuijs P, Poot AA, Dijkstra PJ, Daamen WF, Van Kuppevelt TH, Vermes I, Feijen J. First steps towards tissue engineering of smalldiameter blood vessels: preparation of flat scaffolds of collagen and elastin by means of freeze-drying. Journal of Biomedical Materials Research B Applied Biomaterials 2006;77:357-68.

Daamen WF, Geutjes PJ, Nillesen STM, Van Moerkerk HThB, Wismans R, Hafmans T, Van Den Heuvel LPWJ, Pistorius AMA, Veerkamp JH, Van Hest JCM, Van Kuppevelt TH. Lyophilisomes: A new type of (bio)capsules. Advanced Materials 2007;19:673-677. 


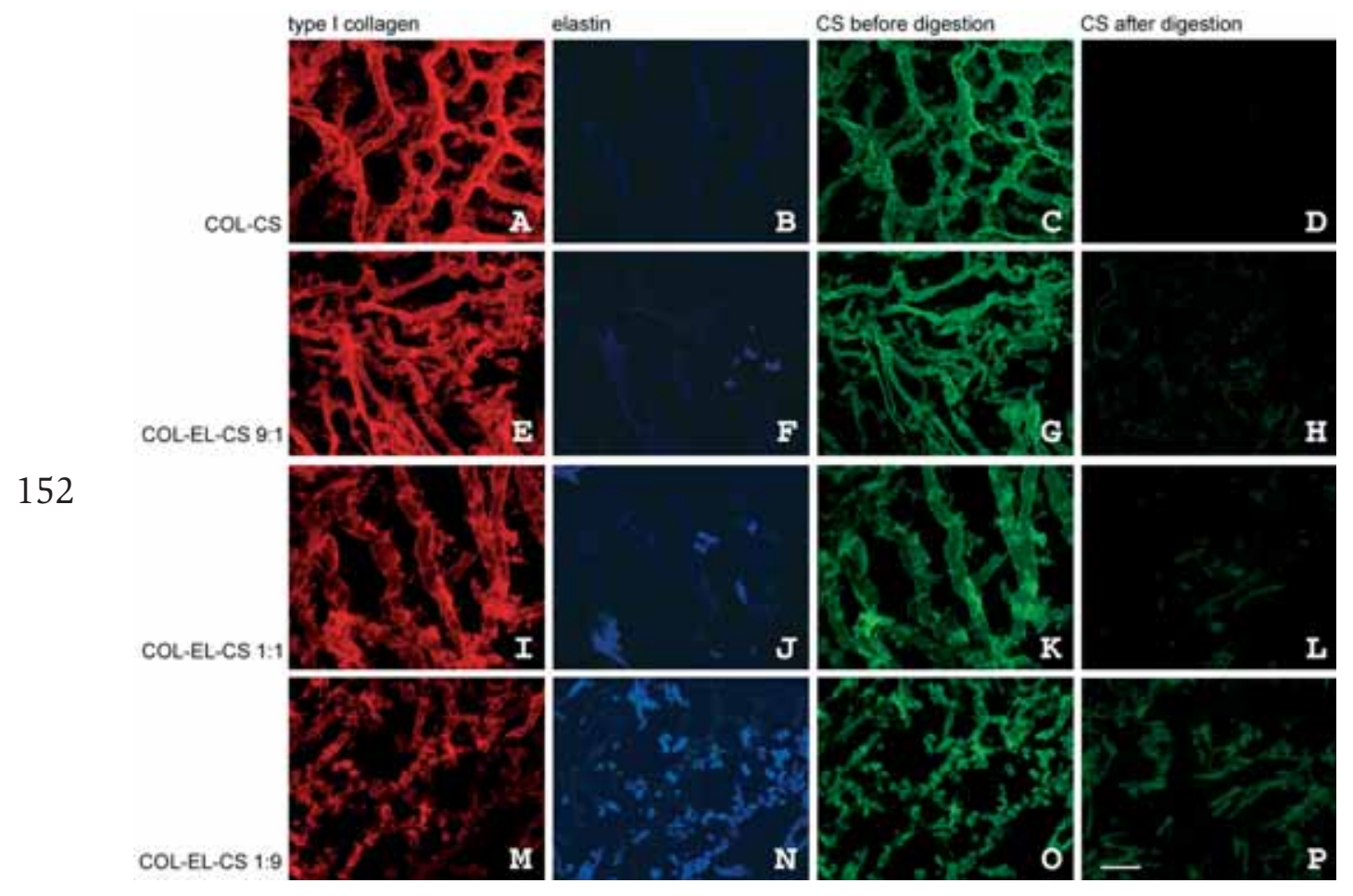

Chapter 4, Figure 4
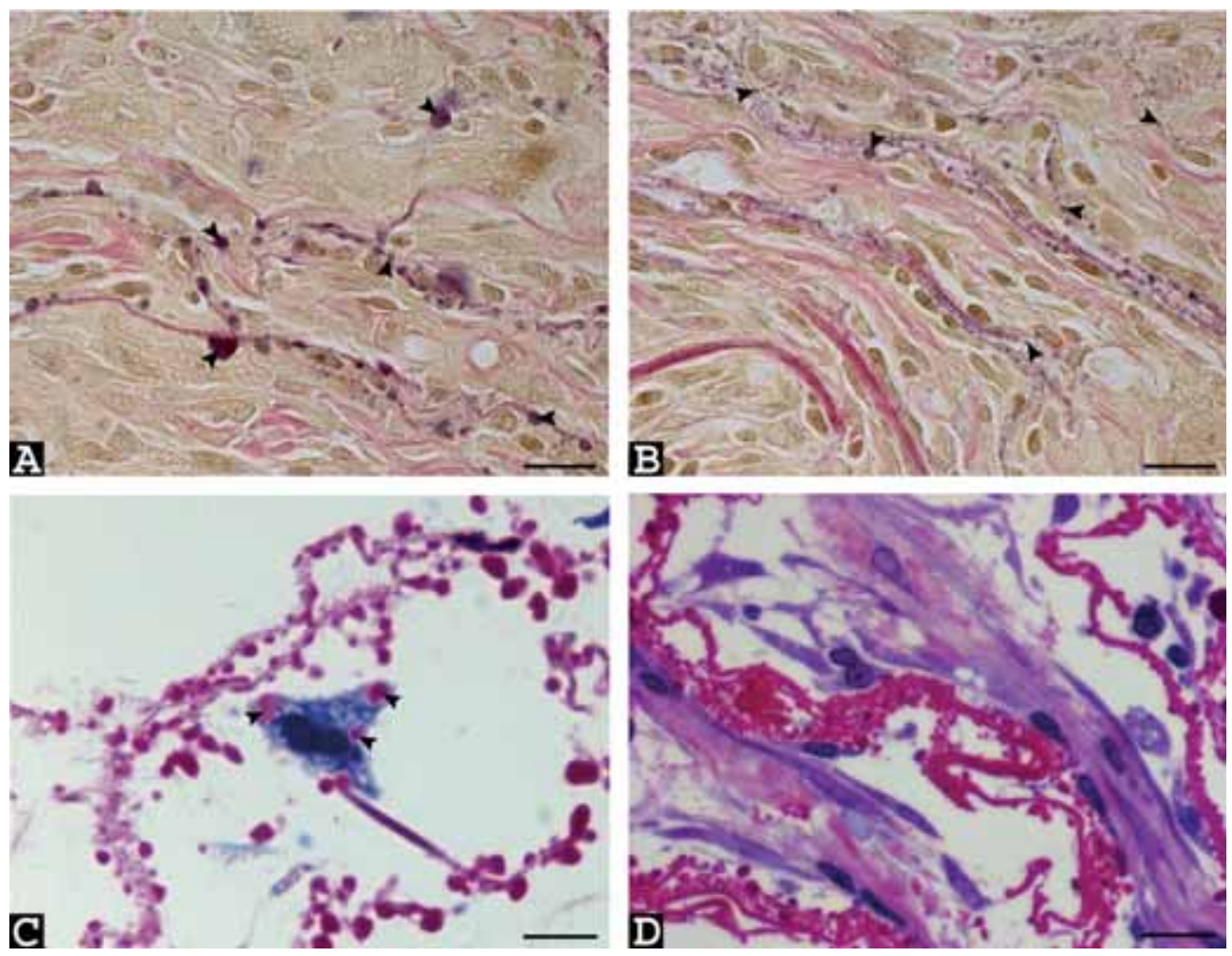

Chapter 6, Figure 5 


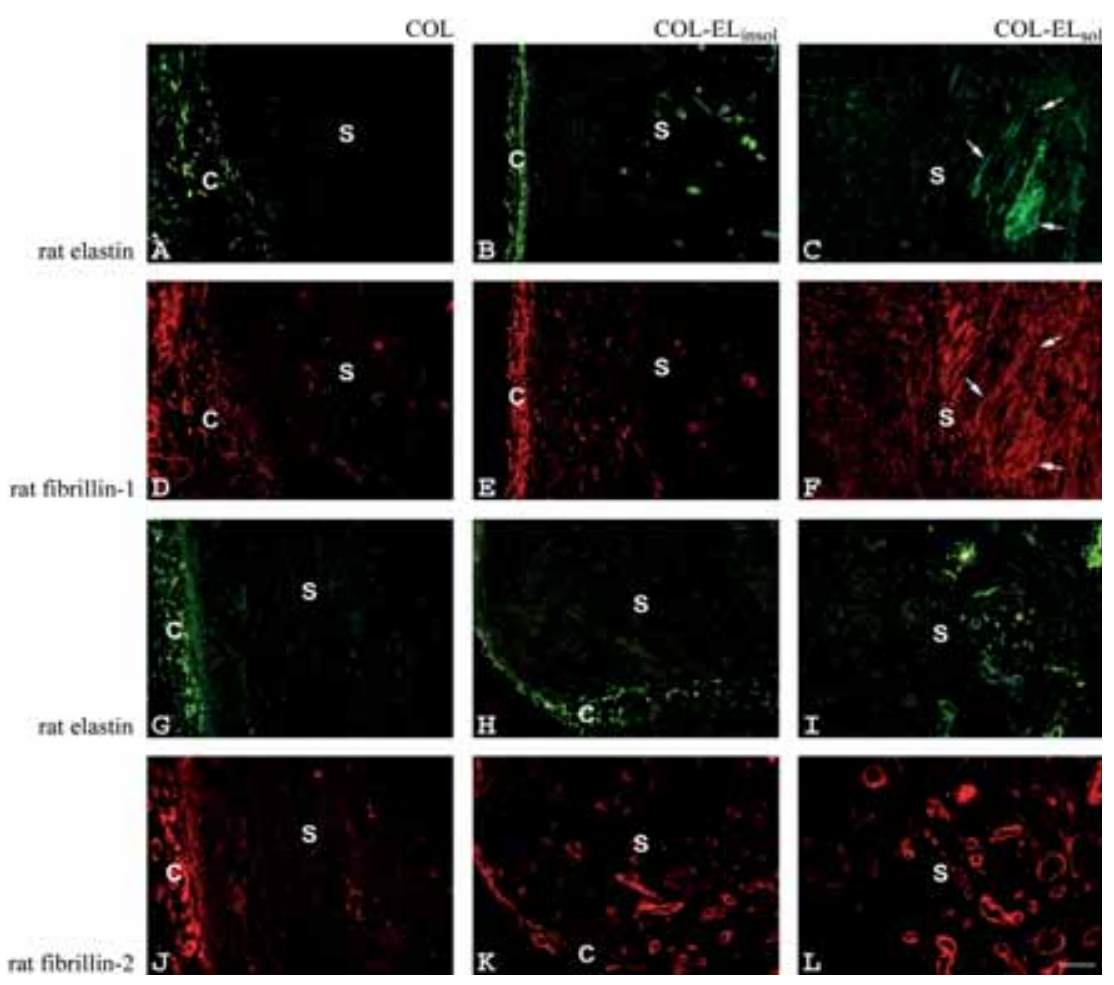

Chapter 6, Figure 6

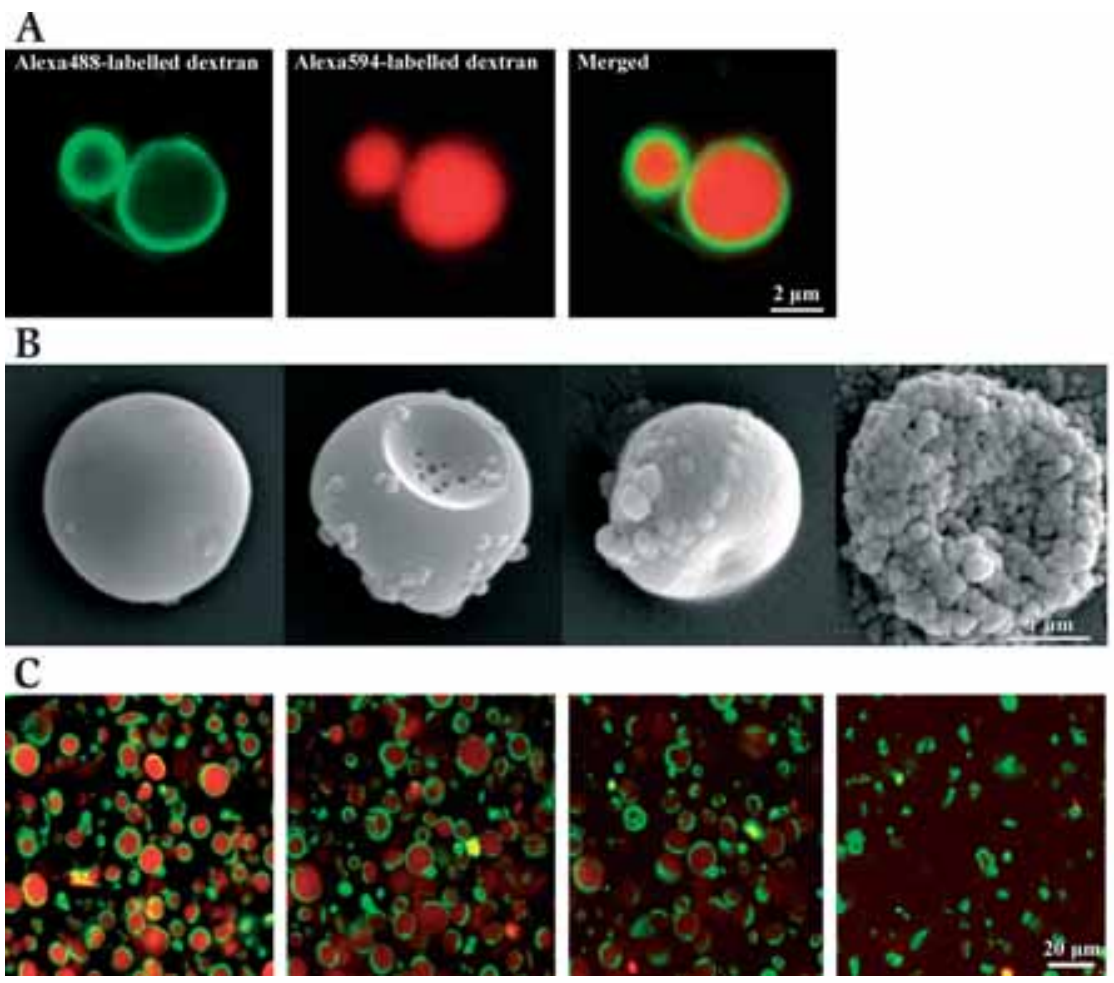

Chapter 7, Figure 7 
